Civil Society and the State

in Democratic East Asia 


\section{Protest and Social Movements}

Recent years have seen an explosion of protest movements around the world, and academic theories are racing to catch up with them. This series aims to further our understanding of the origins, dealings, decisions, and outcomes of social movements by fostering dialogue among many traditions of thought, across European nations and across continents. All theoretical perspectives are welcome. Books in the series typically combine theory with empirical research, dealing with various types of mobilization, from neighborhood groups to revolutions. We especially welcome work that synthesizes or compares different approaches to social movements, such as cultural and structural traditions, micro- and macro-social, economic and ideal, or qualitative and quantitative.

Books in the series will be published in English. One goal is to encourage nonnative speakers to introduce their work to Anglophone audiences. Another is to maximize accessibility: all books will be available in open access within a year after printed publication.

\section{Series Editors}

Jan Willem Duyvendak is professor of Sociology at the University of Amsterdam. James M. Jasper teaches at the Graduate Center of the City University of New York. 


\title{
Civil Society and the State in Democratic East Asia
}

\author{
Between Entanglement and Contention \\ in Post High Growth
}

\author{
Edited by \\ David Chiavacci, \\ Simona Grano, \\ and Julia Obinger
}




\section{FNSNF}

\section{SWiss National SCiEnCE Foundation}

Published with the support of the Swiss National Science Foundation.

Cover illustration: Simone Cossu

Cover design: Coördesign, Leiden

Lay-out: Crius Group, Hulshout

$$
\begin{array}{ll}
\text { ISBN } & 978 \text { 94 6372 } 3930 \\
\text { e-ISBN } & 9789048551613 \text { (pdf) } \\
\text { DOI } & 10.5117 / 9789463723930 \\
\text { NUR } & 903
\end{array}
$$

\section{(c) (1) $\Theta \Theta$}

Creative Commons License CC BY NC ND (http://creativecommons.org/licenses/by-nc-nd/3.o)

@ All authors / Amsterdam University Press B.V., Amsterdam 2020

Some rights reserved. Without limiting the rights under copyright reserved above, any part of this book may be reproduced, stored in or introduced into a retrieval system, or transmitted, in any form or by any means (electronic, mechanical, photocopying, recording or otherwise). 


\section{Table of Contents}

1 A New Era of Civil Society and State in East Asian Democracies

David Chiavacci and Simona A. Grano

\section{Part I Environmental Issues}

2 Interactions between Environmental Civil Society and the State during the Ma Ying-jeou and Tsai Ing-wen Administrations in Taiwan

Simona A. Grano

3 Working with and around Strong States

Environmental Networks in East Asia

Mary Alice Haddad

4 The Campaign for Nuclear Power in Japan before and after 2011 Between State, Market and Civil Society

Tobias Weiss

\section{Part II Identity Politics}

5 The 'Pro-Establishment' Radical Right Japan's Nativist Movement Reconsidered Naoto Higuchi

6 The Religion-Based Conservative Countermovement in Taiwan Origin, Tactics and Impacts

Ming-sho Ho

7 The Relationship between Mainstream and Movement Parties in Taiwan

Case Studies of the New Power Party (NPP) and the Green Party Taiwan-Social Democratic Party Alliance (GPT/SDP)

Tommy Chung Yin Kwan and Dafydd Fell 
8 New Immigration, Civic Activism and Identity in Japan

Influencing the 'Strong' State

David Chiavacci

\section{Part III Neoliberalism and Social Inclusion}

9 Japanese NPOs and the State Re-examined

Reflections Eighteen Years On

Akihiro Ogawa

10 Changing Patterns of South Korean Social Movements, 1960s-2010s

Testimony, Firebombs, Lawsuit and Candlelight

Jin-Wook Shin

11 Opening up the Welfare State to 'Outsiders'

Pro-Homeless Activism and Neoliberal Backlashes in Japan

Mahito Hayashi

12 Legal Mobilization and the Transformation of State-Society

Relations in South Korea in the Realm of Disability Policy

297

Celeste L. Arrington

Index

325

\section{List of Illustrations and Tables}

Illustrations

Figure 1.1 Proportion of elderly people (aged 65 years and older) in the population, $1965^{-2050} \quad 16$

$\begin{array}{lll}\text { Figure 5.1 Changes in Zaitokukai membership } & 118\end{array}$

Figure 5.2 Frequencies of appearance of countries in right-wing journal articles, 1982-2015 124

Figure 5.3 The rise of history as an issue for the radical right 125

Figure 5.4 Issues in events related to Zaitokukai, 2007-2012 $\quad 126$

$\begin{array}{lll}\text { Figure 5.5 Topics of right-wing journals, 2007-2012 } & 126\end{array}$

$\begin{array}{lll}\text { Figure 5.6 Scores of feeling thermometer } & 133\end{array}$ 
Figure 5.7 Scores of feeling thermometers towards the nativist movement and South Korea

Figure 8.1 Registered foreign residents in Japan, 1955-2015 (projection until 2020) 188

Figure 8.2 Three public debates on immigration, 1985-2017 189

Figure 8.3 Foreigners' crime and human rights frames, 1985-2017 197

Figure 8.4 Granted special permits of residence, 1996-2017 201

Figure 8.5 Foreign nationals entering Japan with a working visa, 1976-2017 204

Figure 11.1 Yokohama's local relief in the 1990s 277

Figure 11.2 A meeting between Hiratsuka's activists and the then Mayor Ritsuko Ōkura (seen at the back) 281

Figure 11.3 Households of Public Assistance, 1975-2014 287

Tables

Table 1.1 Change in power between conservative and progressive governments in democratic East Asia, 1988-2018 17

Table 5.1 Events leading to nativist movement membership $\quad 128$

Table 5.2 Number of articles on foreign residents in right-wing journals 130

$\begin{array}{lll}\text { Table 5.3 Result of exploratory factor analysis } & 134\end{array}$

Table 6.1 Three conservative campaigns in Taiwan 152

Table 8.1 Substantial reform proposals in immigration policy, 1984-2018

190 



\title{
1 A New Era of Civil Society and State in East Asian Democracies*
}

\author{
David Chiavacci and Simona A. Grano
}

Contemporary East Asia is marked by new and diversifying interactions between civil society and the state, which merit renewed scholarly attention (Cliff et al. 2018; Morris-Suzuki and Soh 2017; Ogawa 2018). In particular, the present volume focuses on various forms of entanglement and contention in Japan, South Korea and Taiwan, as these three countries represent the fully consolidated democracies of the region (Cheng and Chu 2018). The impacts of globalization and the 2008 financial crisis have, in recent years, led to protest movements and political backlashes across the globe (Della Porta 2017; Rodrik 2018). East Asia's 'mature' democracies have witnessed their own share of protests and conflicts. In spring 2014, the Sunflower Movement occupied the parliament in Taiwan for weeks and organized mass demonstrations that forced the ruling Kuomintang (KMT) government to make concessions regarding the Cross-Strait Service Trade Agreement with the People's Republic of China (PRC) (Ho 2015; Rowen 2015). In South Korea, a mass protest movement and nationwide demonstrations with millions of participants sustained over several months during the period 2016-2017 led to the enforced resignation and impeachment of President Park Geun-Hye (Shin and Moon 2017; Turner et al. 2018). Even in relatively 'quiet' Japan, the Fukushima nuclear disaster and security policy initiatives of the current Liberal Democratic Party (LDP) administration have resulted in the emergence of new social movements and mass demonstrations of a magnitude not witnessed in decades (Chiavacci and Obinger 2018b; Machimura and Satō 2016; Oguma 2013).

\footnotetext{
* The editors thank the Swiss Academy of Humanities and Social Sciences, the Swiss National Science Foundation, the Taiwanese Ministry of Education, and University of Zurich for their generous support, which made the publication of this volume possible.
}

Chiavacci, David, Simona Grano, and Julia Obinger (eds), Civil Society and the State in Democratic East Asia: Between Entanglement and Contention in Post High Growth. Amsterdam, Amsterdam University Press 2020 DOI: 10.5117/ 9789463723930_CHO1 
Such large, progressive protests against conservative establishments that featured on the front pages of Western mass media are only the tip of the iceberg in the changing relationship between civil society and state in democratic East Asia, however. All three societies studied in this book have in fact reached a novel era of post high growth and are now established democracies, which has led to new social anxieties and increasing normative diversity. These, in turn, have repercussions on the relationship and interactions between civil society and the state marked by surprising new avenues of cooperation and complex areas of contention. Moreover, the present book does not merely focus on progressive protest movements but attempts to reach beyond the classic dichotomy of state vs progressive civil society by including novel cases of so-called conservative countermovements.

Nevertheless, these developments are embedded in specific East Asian institutions and path dependencies. To gain a better understanding of the East Asian context, we will start with a short overview of the developmental state and its implications for the path of the three East Asian countries and their economic success story.

\section{Developmental State as Success Model of High Growth and Global Rise}

While not completely concurrent in their development, the three cases studied in the book are united by their strong state settings. Japan, South Korea and Taiwan represent three prime examples of developmental states in which fast-paced economic development was realized through state-led macroeconomic planning and intervention. In fact, the whole theoretical model of the developmental state and its building blocks (such as industrial policy or developmentalism as the dominant national ideology) are based on studies and theoretical considerations about the political economy in these three East Asian economies (Amsden 1989; Cumings 1984; Johnson 1982; Wade 1990; Woo-Cumings 1999). Despite relinquishing their ties as colonies of Japan after World War II, South Korea and Taiwan share with their former colonial master an institutional path dependency from the total war (later 1930s up to 1945), in which the Japanese empire mobilized all the resources of its economy and society. During this period, the economy came under strict state control and was fully geared to support the aggressive expansion wars of the Japanese empire. The formerly liberal political economy of laissez-faire capitalism was transformed into a system of total war, which constituted the foundation of the strong planning states after 
the war when economic growth became the main national goal in all three countries. Moreover, all three became United States (US) protectorates in the post-war era, and they were part of a region that was traumatized by several large-scale conflicts during the Cold War era. Consequently, regional insecurity forced their conservative establishment to succeed in their plans for economic development, and their bilateral security alliances with the US provided these three countries with crucial technological and economic support as well as preferential access to its markets.

High economic growth and rapid industrialization were the two top national priorities of the bureaucratic, economic and political elites in all three countries. The respective conservative establishments proved to be extremely successful in achieving these goals and in leading their respective countries to join the ranks of advanced industrial economies. By the late 1990s, these three East Asian economies had succeeded in becoming clear winners in globalization, modelling themselves as export champions and breaking the financial, economic and technological predominance of the West. Japan, South Korea and Taiwan embodied the core of those high-performance economies, which constituted the 'East Asian miracle of economic growth and public policy,' as it was called by the World Bank (1993) in its highly influential and controversial study sponsored by the Japanese government (for a retrospective view, see Page 2016).

Most importantly, the East Asian model did not merely propagate growth per se but 'shared growth' (Campos and Root 1996). On the one hand, state elites spurred private interests and encouraged business leaders to contribute to high growth. On the other hand, conservative establishments successfully mobilized workers and citizens for the national project of developmentalism by promising that the whole population would get its fair share of the growing pie, bringing increased purchasing power and prosperity. Economic development and shared growth introduced mass consumerism but also guaranteed stable life courses and general upward mobility, which lasted for decades and created new, large middle classes. The East Asian model of development also included a productivist welfare regime (Choi 2013; Holliday 2000), in which the welfare state was minimized and subordinated to economic progress. Social inclusion was achieved through shared growth rather than through comprehensive welfare states and social redistribution between social classes. Thus, developmentalism created a 'developmental citizenship' (Chang 2012) or a system of 'welfare through work' (Miura 2012), in which social inclusion was based on individual contribution to and shared benefits from the realization of high national growth. 
However, in all three countries, national development was not only a success story of harmonious economic growth and rising wealth. This path was also marked by intensive social and political conflicts. In Japan, the social contract of shared growth was only established in the 1960s after severe and violent disputes concerning the pillars and ideological orientation of Japan after the collapse of the expansionist politics implemented up to 1945 (Chiavacci 2007). In fact, the post-war conflict cycle came to an end as late as the mid-1970s when the idea of shared growth finally gained undisputed hegemony and became common consensus (Chiavacci and Obinger 2018a). In South Korea and Taiwan, economic development under authoritarian regimes led to increasingly self-confident and politically active middle classes that demanded greater political participation. It was in the 1980s, with the emergence of a more urban-based and cosmopolitan middle class, that both countries witnessed their first collective organized movements for political liberalization and then democracy. This increasing pressure and political uprising of citizens eventually led, in the second half of the 1980s, to the repealing of martial law and political democratization (Hsiao 2019: 27; Kim 2000). In both countries, however, developmentalism and shared growth remained the basic social contract after democratization for years to come.

In recent years, however, the three countries reached a fundamental turning point after their rapid economic development and compressed modernization came to a rather sudden end. A number of shocks ushered all three democracies into a new phase of post high growth.

\section{The Era of Post High Growth}

The most fundamental shock in Japan, South Korea and Taiwan has been the abrupt change from a path of rapid economic growth to sluggish economic development. In democratic East Asia, Japan was the first to undergo such a transformation. The bursting of the speculation bubble in the stock and property markets of the early 1990 s marked the beginning of a stop-and-go period in Japan's economic trajectory that resulted in economic stagnation in the past decades, as well as in heated public debates and political discussions about the so-called lost decades and the urgent need for structural reforms (e.g. Funabashi 2015). Growth figures for South Korea and Taiwan over the same period are significantly higher; nonetheless, they have also been experiencing slower growth, de-industrialization and restructuring since the Asian financial crisis of 1997, which marked a turning point in 
their development and led - in particular, in South Korea - to deregulation (London 2018: 230-233). This trend was further reinforced after the 2008 financial crisis, which had a curbing impact on all three economies, with especially harsh influences on their respective export industry. The global financial crisis resulted in decreasing growth rates in South Korea and Taiwan, which began their downward descent towards Japan's low levels of economic growth (Ito 2017: 9). However, compared to what was happening in numerous advanced economies of the West, in which growth was even lower and unemployment figures were much higher, democratic East Asia was not faring too badly after the 2008 financial crisis. Even Japan's economic expansion, when measured in terms of GDP per capita growth, compared to that of most other advanced industrialized economies has not fared so poorly. However, such phases of economic stagnation in democratic East Asia in all three countries led to a breakdown of the former model of shared growth acquired by a strong state.

What undermined the previous social contract was not slower economic growth per se, but the fact that this was accompanied by social diversification processes and new social insecurities. In recent years, income inequality has been increasing in all three economies (Solt 2019). In addition, especially in Japan and Taiwan, real wages are stagnating (ILO 2018: 123). In Japan and South Korea, labour market deregulation and neoliberal reforms have resulted in a significant increase in flexible non-standard employment with no career opportunities and low salaries (Chiavacci and Hommerich 2017; Kim 2018; Shin 2018; Shin 2019). The dominant self-view in Japan changed in the first half of the 2000 s from the former narrative of a general middle-class society marked by fairness and equality of opportunities and of outcomes into one of a gap society featuring growing social division, inequality and poverty (Chiavacci 2008). Similarly, debates in South Korea revolve around questions regarding the ongoing contraction and fundamental fragmentation of the middle classes into winner and losers, which are undermining social cohesion and leading to new anxieties (Koo 2019; Yang 2018). Likewise, Taiwan was able to achieve both growth and equality in the process of national development until the 1980 s but has, in recent years, been facing an increasing imbalance and rising low-income employment that are undermining citizens' trust in the government and its capacity to achieve a fair society (Chang 2017; Ku and Hsueh 2016: 354-355). Consequently, all three East Asian democracies are prime examples of the current challenges to shared or inclusive growth in East Asia, as highlighted in a recent report by the World Bank (2018). 
Moreover, existing problems gained new momentum. The earlier prioritization of economic growth as well as fast industrialization had triggered the creation of environmental protection movements in all three countries because of the rampant pollution and environmental degradation caused by rapid economic development (Broadbent 1998; Eder 1996; Grano 2015; Hsiao 1999; Lee and So 1999; Nakazawa 2001). In Japan, anti-pollution movements had started in the 1960 s and forced the conservative establishment in the early 1970 s to implement far-reaching adaptations in its policies. Environmental civil society actors and organizations in South Korea started primarily as anti-pollution movements and gained influence from the $1980 \mathrm{~s}$ onwards. In Taiwan, the environmental movement became a key player in the island's political transition, starting from the mid-1980s, as the emergence of anti-pollution protests accelerated the loosening of political control (Grano 2015: 42-48; Ho 2006: 27-85; Hsiao 1999: 31-54). Once established, environmental awareness never completely disappeared from the public and political agenda in all three countries. Furthermore, as will be further discussed below, global warming and the Fukushima nuclear disaster of 2011 breathed new life into environmental civil society organizations and movements across East Asia.

At the international level, the rise of the PRC has been rapidly tilting the regional power balance, contributing to rising economic and political insecurities in Japan, South Korea, and Taiwan. For instance, all three economies have benefited greatly from China's economic high growth and transformation. Investment and companies from all three countries played a central role in China's industrialization and ascendance. At the same time, however, the rise of the PRC presents numerous challenges to the regional advantage and economic leadership of Japan, South Korea, and Taiwan. Even though China's ascendance has likewise presented Western states - especially the US, as the dominant world hegemon - with novel insecurities resulting in a political backlash and increasing international tensions, the geopolitical vicinity in the case of East Asian democracies renders the PRC a factor for more serious consideration by the three countries under study. In view of the PRC's global might as well as its increasingly bold policies and claim to regional leadership that represent far more than mere economic challenges embodying de facto national security concerns (especially in the case of Taiwan and its uncertain political future), the political authorities and populations in all three countries have several reasons to be concerned.

Moreover, it is not only the growth gap difference with the PRC that is a source of anxiety, but also the fact that demographic development is at 
a fundamental turning point in all three countries, reinforcing the view that national development has reached its peak and has now started its downward spiral. All three East Asian democracies are faced with rapid aging due to their late and compressed first demographic transition, which presents a huge challenge (Obe 2019). Regarding this transformation, Japan is again the precursor. Until 1990, its proportion of elderly people (aged 65 and older) was still low compared to Western advanced industrial economies but increased rapidly in the subsequent years and turned Japan into the oldest society worldwide by the mid-20oos (see Figure 1.1). Demographic models, which are very accurate compared to economic or political prognosis, show that South Korea and Taiwan will follow this path of drastic demographic transformation in the coming years (Suehiro and Ōizumi 2017). In South Korea and Taiwan, the inescapable process of fast aging has started in the 2010s. Their demographic transformation will be even faster than that of Japan and will convert both countries into super-aged societies with over a fifth of their total population aged 65 or older in the mid-2020s (see Figure 1.1).

In fact, previous high growth rates in democratic East Asia were connected to the first demographic dividend of a fast-growing population and an increasing proportion of working-age people. Some authors identify an opportunity for a second demographic dividend with aging that may lead to rapid capital accumulation in East Asia (Mason and Kinugasa 2008). Nevertheless, debates about future development, in all three countries, are dominated by rapidly increasing proportions of aged and dependent people linked to questions regarding the future financing of the welfare systems. The economic slowdown of democratic East Asia compared to the still dynamic PRC almost represents a type of natural law and structural inevitability. For nations that have, for decades, defined their identity and pride primarily through the prism of their economic success stories and relevance, such outcomes are very bleak indeed. Moreover, rapid demographic change has already resulted in the transformation of Japan, South Korea and Taiwan into new immigration countries (Bayok et al. 2020; Fielding 2016). While all three East Asian democracies were non-immigration countries par excellence with no significant inflows up to the late 1980s, they have become new and important immigration countries with a significant net inflow that is starting to change the population's composition and is another challenge for national identity.

Finally, it has to be noted that all three countries have become fully consolidated democracies that have already experienced several changes of ruling parties. In all three, the formerly tight-knit conservative establishment 
Figure 1.1 Proportion of elderly people (aged 65 years and older) in the population, 1965-2050

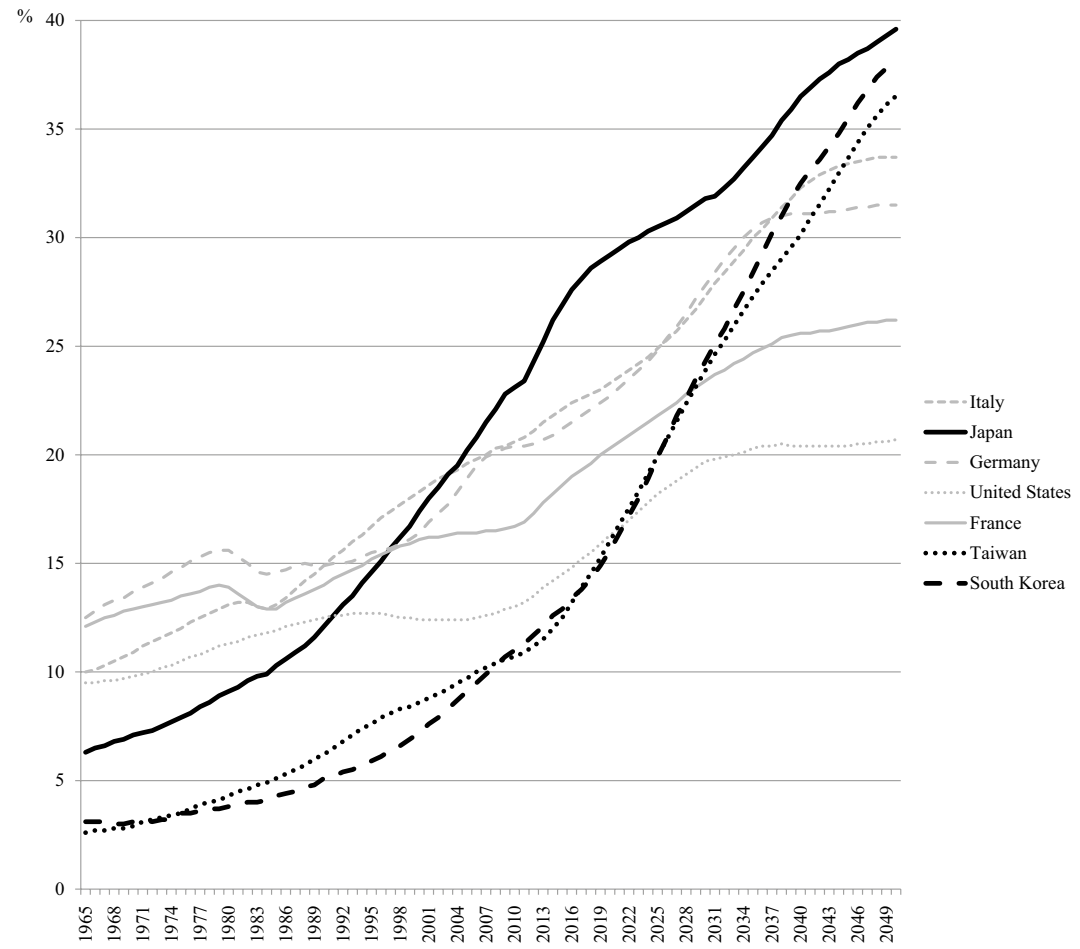

Source: OECD data (France, Germany, Italy, Japan, South Korea, and US); Department of Statistics, Ministry of Interior, Population Projection, National Development Council (Taiwan)

has lost elections to more progressive opponents, which has led to a significant change in power structures (for an overview, see Table 1.1).

It is not only the progressive side of civil society that has become better organized and more diverse, however. Conservative countermovements, which have risen as a backlash to more progressive governments and influences, have likewise gained momentum in the past decade and are now well established in all three countries. These conservative civil organizations and networks testify to the increasing normative diversity, which has arisen as a reaction to the advancement of progressive social ideas such as, to name but one example, same-sex marriage in Taiwan. Taiwan's conservative movement to defend the threatened traditional morality regarding the issues of abortion, same-sex marriage and gender equity in education is an intellectually fascinating case of a countermovement that is often neglected by scholars of Taiwan's civil society. Likewise, attempts 
Table 1.1 Change in power between conservative and progressive governments in democratic East Asia, 1988-2018

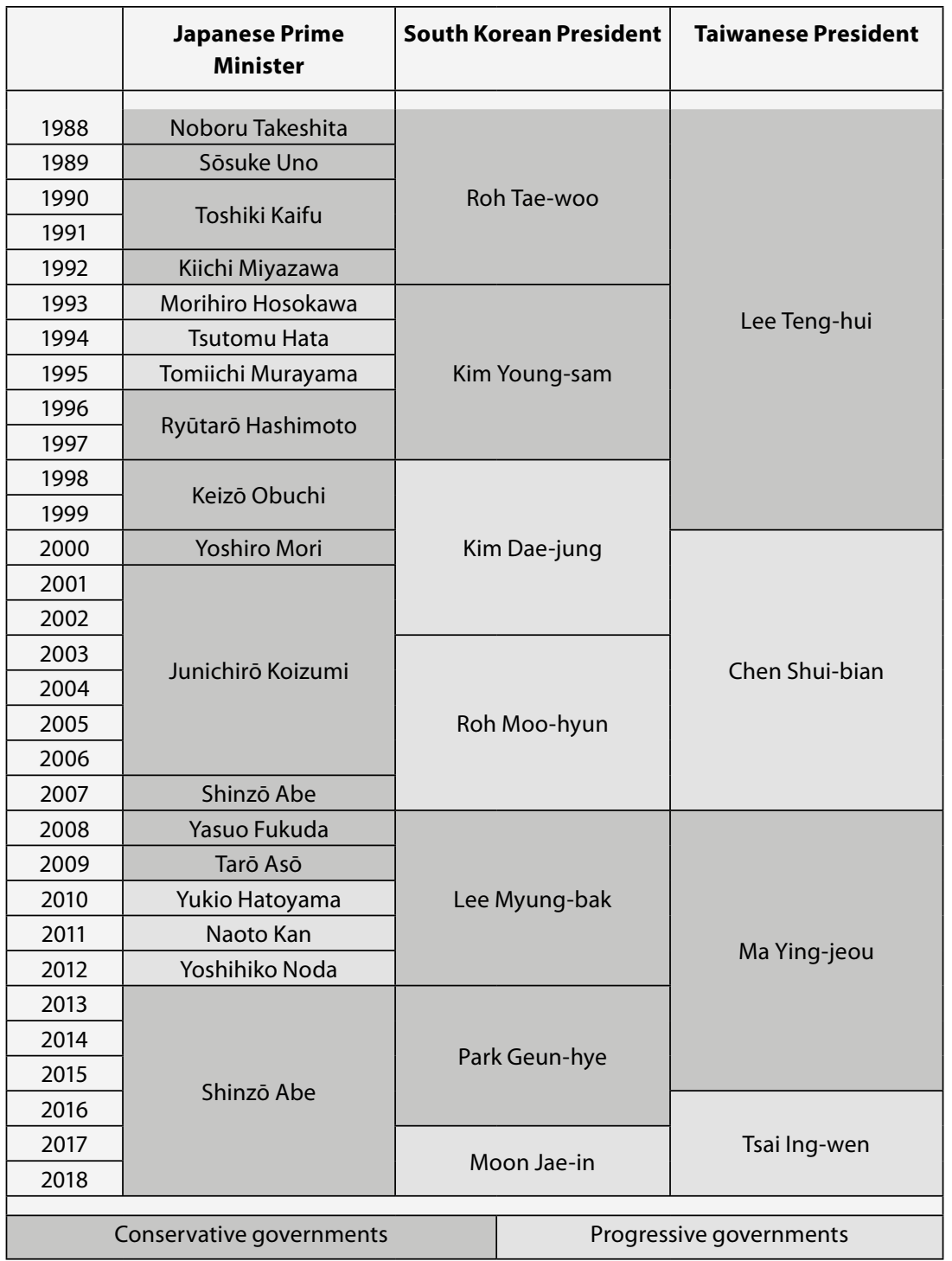

Source: Own compilation.

to legalize same-sex partnerships in Japan and South Korea have led to conservative backlashes.

Overall, these fundamental transformations have led to a reconfiguration of the playing field between the state and civil society that is marked by new 
forms of entanglement and contention as well as a new salience of social movements and political protests. Moreover, the former social contract of shared growth is under extreme pressure and the developmental state now appears to be an increasingly outdated model that is no longer able to successfully steer national development. In fact, it has been sidelined by a wave of neoliberal policies introduced by conservative establishments themselves that have weakened the previously successful social contract of shared growth.

\section{New Relation State vs Civil Society}

The present volume introduces a comparative perspective in identifying and discussing similarities and differences in East Asian democracies based on in-depth case studies. The contributions in our volume focus on three areas of entanglement and contention between civic agency and state control: (1) environmental issues, (2) identity politics, and (3) neoliberalism and social inclusion. These are highly topical issues that allow us to gain a fuller understanding of the most recent sociopolitical and regional developments.

\section{Environmental Issues}

The three papers in the first section focus on the issue of how civil society tackles environmental issues. As mentioned above, developmentalism, high economic growth, and rapid industrialization have led to high levels of pollution, which has sparked outrage and created important citizen movements in all three countries, resulting in the amendment of state policies in some areas. As an important issue that can no longer be overlooked globally, climate change has likewise reinvigorated civic activism against global warming in all three East Asian democracies. Moreover, the Fukushima nuclear disaster reinforced anti-nuclear movements, intensifying the level of contention (Chiavacci and Obinger 2018b; Grano 2014, 2016, 2017; Kim and Chung 2018; Machimura and Satō 2016).

Simona Grano's chapter deals with the political repercussions of the widespread discontent regarding the previous KMT administration in Taiwan and the ensuing change in ruling party in 2016. Popular discontent regarding several 'secondary' issues once again prompted the progressive Democratic Progressive Party (DPP) to revert to its early pro-environmental and social justice rhetoric to attract more voters. In the 2016 national elections, the DPP once again included in its ranks several former civil society 
leaders, activists and academics with strong environmental and social engagement that trace their origins to the galaxy of progressive social movements. This chapter explores whether more than three years after the start of the new administration, concrete results have been achieved by these activists or whether they have become, once again, quieter after having been re-integrated into the ranks of the ruling party. The chapter consolidates research on recent interactions and conflicts between the state trying to exert more influence across several fields - in this case the environmental one - and newly emerging or well-established social movements under two different political administrations (the Ma Ying-jeou and Tsai Ing-wen administrations) to pinpoint key differences.

The second chapter by Mary Alice Haddad addresses a fundamental puzzle: East Asia is a region still dominated by developmental states that favour business and constrain advocacy organizations, and yet Japan has been leading the world in high emissions standards for decades, and South Korea and Taiwan have both embarked on major green initiatives that involve not only green business development, but also new national parks, widespread energy conservation, and comprehensive recycling efforts. This chapter discusses how environmental organizations are networking with one another to make and empower allies within the government and business to effect pro-environmental changes. Focusing on the issue of the environment, it argues that non-profit organizations (NPOs) play important roles in developing the coordinating networks that facilitate policymaking in challenging and diverse political contexts. Haddad's chapter begins by discussing three specific types of networks commonly created by NPOs in East Asia to improve environmental policy: hub-and-spoke, horizontal, and vertical. It then discusses three ways that these networks influence policy: (1) facilitating peer-to-peer information sharing; (2) piloting new projects and disseminating best practices; and (3) empowering allies within the government. The chapter concludes by arguing that East Asia is a particularly good region to study how advocates and the networks they form are able to influence policy because of the challenging and diverse political contexts they face.

Finally, in the last chapter in this section, Tobias Weiss analyses the emergence of a countermovement in reaction to the rise of the movement against nuclear power in Japan since the 1970s. He traces the emergence of the conservative countermovement in the historical perspective and analyses the organizational and social basis, mobilization processes, and framing and political influence of the groups involved. Weiss then attempts to pinpoint the political impact of the Fukushima 2011 nuclear disaster on 
the movement. His chapter shows how the countermovement was able to survive a period of intense contestation, preserving its resource basis and retaining significant influence on the policymaking process due to support from large parts of the conservative establishment.

\section{Identity Politics}

National identities are the key issues addressed in the second section of our volume. National identities in Japan, South Korea and Taiwan have been interwoven with economic success stories and the ensuing increase in affluence and wide-ranging social inclusion. In recent years, however, these societies have been confronted with sluggish economic growth while at the same time facing the impending threat epitomized by the rise of the PRC. Both developments are fundamentally changing regional dynamics and have led to growing social anxieties in all three countries. Moreover, the growing influx of immigrants further impacts the question of national identity. Against this background, the first two contributions in section two analyse the recent upsurge in ultra-conservative and ultra-nationalistic movements.

Naoto Higuchi discusses in his chapter how Japan perceived the rise of nativist demonstrations and hate crimes from the late 200os, which led the parliament to enact the country's first anti-racism law in 2016. The aim of his chapter is to examine the pro-establishment nature of Japan's nativist movement. Although the movement often criticizes the ruling conservative establishment, it should be regarded as indirectly linked to the establishment in two ways. First, Japanese nativism is a variant of historical revisionism and the emergence of nativist violence is a 'by-product' of the rise of historical revisionism among the conservative establishment in post-Cold War Japan. Although the nativist movement and the conservative establishment are not directly associated with each other, the former took full advantage of the discursive opportunity that the latter offered. Second, the general public favour the nativist movement as part of the conservative establishment. The movement bridges sympathy with conservatism and antipathy towards neighbouring countries.

In his chapter, Ming-sho Ho analyses the rise of conservative religious movements in Taiwan, which are becoming increasingly active in the country's political arena, as a backlash to recent progressive activism in a variety of fields. Taiwan's conservative movement to defend the threatened traditional morality and sexualities is an intellectually fascinating case of countermovement yet an oft-neglected aspect of Taiwan's civil society. This chapter locates its origins in the preceding change of Taiwan's Christian 
community. Protestant and Catholic leaders pioneered the opposition to gender equity and pluralism, and over the years, they gained support from other religions. Ho analyses the contestation over the issues of abortion, same-sex marriage, and gender equity in education. On the whole, the conservative movement has largely failed to turn back the clock. However, its presence was powerfully felt and had the potential to usher in a new political alignment that moved beyond the pre-existing cleavage.

Taking a similar perspective, Dafydd Fell and Tommy Kwan analyse the relationship between the mainstream and the 'new movement' parties in Taiwan in recent years. Since democratization began in the mid-198os, Taiwan's party system has been dominated by two parties, the KMT and the DPP. Smaller parties have at times played an important role, however, bringing diversity into the system, emphasizing different marginalized issues, and representing neglected communities. These small parties tended to be those that split off from the mainstream parties, while alternative social movement parties struggled to be electorally relevant. The picture changed only recently with the rise of two different types of movement party, the New Power Party as well as the Green Party and Taiwan Social Democratic Party Alliance. In their chapter, Kwan and Fell examine the relationship of these new players with a mainstream party, the DPP. Were these parties better off working in alliance with the main parties or preserving their autonomy? The authors also offer some thoughts on why these parties adopted such strategies and how the relationship affected the development of these alternative parties.

In the final chapter of this section, David Chiavacci discusses immigrant advocacy groups' influence in Japan's immigration policy. Japan has been a new immigration country for three decades. However, its immigration policy has been marked by ideational and institutional fragmentation. This resulted in a deadlock without bold reforms and immunized state actors to external pressure. Even powerful business association, despite being core members of the conservative establishment, have struggled to impact immigration policy. Against this backdrop, civil advocacy has been surprisingly influential. While civic groups have generally not been included in decision-making bodies, they have altered the perception of immigration. Moreover, civic activists have cooperated closely with international organizations and foreign states, which gave them a voice indirectly through third parties. By analysing reforms combating human trafficking, this chapter identifies factors that resulted in decisive indirect influence of civic advocacy in this exceptional case. This allows us to gain a differentiated understanding of the limited, yet still sometimes significant, influence of civic activism on Japan's ‘strong' state in immigration policy. 


\section{Neoliberalism and Social Inclusion}

The third section of our volume grapples with questions concerning neoliberal reforms and social inclusion in East Asia. The guiding principle of developmentalism involves a significant amount of state intervention in markets through industrial policies and bureaucratic leadership rather than a comprehensive welfare state. However, in recent decades, neoliberalism, as it has been shaped in the United Kingdom or the US, appeared to be more successful in generating economic growth and thus rose to prominence in East Asia. Even though neoliberal policies include the state's activation and co-optation of civil society (Hundt 2015; Maeda 2012), they continue to undermine social inclusion, resulting in a backlash and new antagonistic civic activism against state policies.

Against this background, Akihiro Ogawa's argument in his chapter builds on long-term research at SLG, an NPO in eastern Tokyo, which was established under the 1998 NPO Law. Incorporated as an NPO in 2000, SLG is one of the largest civic society organizations promoting lifelong learning in Japan. Over nearly two decades, SLG successfully offered more than a hundred innovative courses to the local community. However, SLG faced a state of crisis and risked dissolution in 2018 due to the municipal government's decision to cut its funding. In his chapter, Ogawa argues that SLG was a successful case of neoliberalism-oriented public administration, pursuing decentralization and reduced costs. He claims, however, that SLG was not conducive to encouraging independent, citizen-oriented activities. His chapter documents current discussions at SLG, which reflect the reality of the Japanese civil society landscape, in which NPOs are central.

In his contribution, Jin-Wook Shin turns to South Korea. His chapter examines the changing patterns of South Korean social movements from the 1960 s to the 2010 in terms of their constituents, their communication and mobilization structure, and the way in which they influenced institutional politics. Some long-term trends that require particular attention include the extension of participants from cultural elites and organized activists to a huge number of ordinary citizens; a shift of the structure of the field of social movements from the inter-organizational ties of committed activists to highly decentralized networks of organizations, communities, and individuals; and a change in the way social movements affect institutional politics from the moralized acts of cultural elites through the disruption as well as negotiation by movement organizations to large-scale protest actions of individual citizens influencing public opinion and party politics. In response to such changes, the South Korean state and civil society now have the task of innovating their ideas, action repertoires, and mutual relationships. 
The examination of local/national trajectories of social movements for homeless people in Japan is the topic in Mahito Hayashi's contribution, the third chapter in this section. Hayashi argues that such 'pro-homeless' activism has fundamentally improved the Japanese welfare state. Japan's welfare-providing programmes are prone to exclusion. State-led high growth historically allocated resources for capitalist expansion, not for people's welfare. This persistent tendency hit the homeless the most. In turn, this has given pro-homeless activism significant potential and capacities. First, pro-homeless activism has predominantly taken local forms, improving welfare provision at welfare offices. Second, in the late 200os, activism won improvements at the national level as it reframed homelessness as a national problem of not only the 'outsiders,' but also the 'insiders' of society. Third, the wholesale inclusion of the homeless/poor has evoked their remarginalization. Today, neoliberal/neoconservative forces are advancing undeserving-poor discourses and anti-poor politics to cancel out movements' prior successes, which paradoxically testifies the power of pro-homeless activism to open up the welfare state.

Finally, Celeste Arrington discusses legal mobilization in the field of disability policy in South Korea. Since the 1990s, South Koreans have gained better access to the courts as a channel for pursuing social and policy change. In particular, Koreans with disabilities began using the courts to challenge discrimination, enforce their rights, augment other tactics and influence policymaking. Through qualitative comparative analysis of recent legal mobilization by Koreans with disabilities, Arrington investigates factors that influence when and why people mobilize the law. Drawing on sociolegal and social movement theories, her chapter shows that explanations focused on evolving legal opportunity structures - encompassing procedural rules, statutes, and legal interpretations - can only partly explain the changing patterns in legal mobilization. Explanations should also consider the 'support structures' for legal mobilization: lawyers, advocacy organizations, and funding. This research demonstrates the importance of considering the interaction between institutional and extra-institutional activism and reveals how legal mobilization has contributed to changes in how disabled people's organizations interact with the state in Korea.

\section{Concluding Remarks: Three Key Findings}

This book investigates the novel dynamics at play in Japan, South Korea and Taiwan by analysing the role (and respective interests) of the most important 
actors after the recent reconfiguration of state-civil society relations and the interplay of various stakeholders, social organizations and agencies at the local and national levels. Overall, we think that the different chapters of this book crystallize three key findings that testify to the increasing complexity of state-civil society relationships in East Asian democracies.

First, civil activism and movements have become better organized and more influential in East Asian democracies. Although their organizational base and resources are generally still quite limited, civil society actors have consciously worked to increase their influence in the policymaking process. They have built large, proactive policy networks and utilized them strategically to impact policymaking practices. These networks include relational webs among themselves as well as links to national policymakers and political parties (see chapters in this volume by Grano, Haddad, Kwan and Fell, and Hayashi). In this context, more progressive administrations that did not belong to more traditional conservative establishments that were heavily present in the past in all three countries have in recent decades presented activists with opportunities to become more vocal and effective in attaining their goals. Civil society actors, however, have not been able to achieve all their goals during these windows of opportunity. Cooperation with progressive administrations and parties has in fact sometimes been marked by friction (Grano, in this volume). Nevertheless, civil society actors have started to gain important experience in policymaking. Moreover, these networks include links to academic and juristic specialists and international actors, which are of crucial importance to gain expertise for policymaking despite having limited resources and to build stronger leverage on the conservative establishment (see chapters in this volume by Arrington as well as Chiavacci). Beneath the large protest events that received worldwide attention, a 'quiet revolution' is reshaping and strengthening the influence of civil society actors in East Asian democracies.

Second, even though the central state remains strong in East Asian democracies, the developmental state model as the dominant social contract has weakened significantly. All three polities still feature the centralization of power in which national governments and state bureaucracies issue policies and directives that are then applied in the localities. Conservative establishments face a period of transition with an uncertain outcome, however, and have to adapt to novel challenges such as rising social inequality, a sharp increase in elderly population rates, and a rising hegemon - the PRC - in the East Asian neighbourhood (see also Yun 2019). In this context, neoliberal reforms seem to offer the opportunity to generate renewed growth yet often turn out to be a de facto double-edged sword (see Ogawa, in this volume). 
Governments have outsourced certain duties to cut costs and rejuvenate the economy by enforcing freer market competition. This often results in the direct weakening of central states, however, which, in turn, become increasingly dependent on civil society. Moreover, neoliberalism has been identified in public discourse as a central factor in rising inequality and social exclusion. Therefore, conservative establishments in all three democracies have to find new arrangements and show renewed consideration for the population (see Mahito, in this volume). To remain strong, the state and its conservative establishment can no longer rely on quasi-absolute political dominance but have to develop abilities and techniques to absorb and integrate civil society as a driving force of innovation (see Weiss, in this volume).

Third, all three countries have witnessed the rise of new conservative movements (or countermovements) as a reaction to recent progressive shifts in society and politics. Furthermore, in contrast to the new right-wing populism in many Western democracies (Blee and Creasap 2010; Gross et al. 2011), almost none - or very few - of these new movements and actors are directed against the conservative establishment and/or adopt a clear anti-elitist stance (see also Hellmann 2017; Lie 2019; Wang 2019). Conversely, such conservative countermovements are usually somehow connected and nurtured by previously dominant conservative establishments (see chapters in this volume by Ho as well as Weiss). As a case in point, the new radical right movement in Japan featured in Higuchi's chapter, which is the most radical countermovement discussed in the book, still sports a pro-establishment nature (see also Higuchi 2018). In this context, it has to be noted that the largest conservative countermovement rallies of East Asia in recent years were probably the pro-Park demonstrations in South Korea, which attempted to impede the enforced resignation and impeachment of President Park Geun-Hye (Lee and Brown 2018). This is another strong indicator of the increasing maturity and diversity of East Asian democracies as the pressed conservative establishments have started to embrace 'street politics' and social movements' strategies from progressive civil society.

\section{References}

Amsden, Alice H. 1989. Asia's Next Giant: South Korea and Late Industrialization. New York: Oxford University Press

Bayok, Anastasiy; Franziska Plümmer; Gunter Schubert (eds). 2020. East Asian Migration Governance in Comparative Perspective: Norm Diffusion, Politics of Identity, Citizenship. London: Routledge. Forthcoming. 
Blee, Kathleen M.; Kimberly A. Creasap. 2010. 'Conservative and Right-wing Movements.' Annual Review of Sociology, 36: 269-286.

Broadbent, Jeffrey. 1998. Environmental Politics in Japan: Networks of Power and Protest. Cambridge: Cambridge University Press.

Campos, Jose Edgardo; Hilton L. Root. 1996. The Key to the Asian Miracle: Making Shared Growth Credible. Washington, DC: Brookings Institution.

Chang, Chin-fen. 2017. 'Economic Inequality and Determinants of Earnings in Taiwan in the 2008 Recession.' Development and Society, 46 (1): 55-82.

Chang, Kyongsop. 2012. 'Developmental Citizenship in Perspective: The South Korean Case and Beyond.' Contested Citizenship in East Asia: Developmental Politics, National Unity, and Globalisation. Kyongsop Chang; Bryan S. Turner (eds). London: Routledge, pp. 182-202.

Cheng, Tun-jen; Yun-han Chu (eds). 2018. Routledge Handbook of Democratization in East Asia. London: Routledge.

Chiavacci, David. 2007. 'The Social Basis of Developmental Capitalism in Japan: From Postwar Mobilization to Current Stress Symptoms and Future Disintegration.' Asian Business and Management, 6 (1): 35-55.

Chiavacci, David. 2008. 'From Class Struggle to General Middle-Class Society to Divided Society: Societal Models of Inequality in Postwar Japan.' Social Science Japan Journal, 11 (1): 5-27.

Chiavacci, David; Carola Hommerich (eds). 2017. Social Inequality in Post-Growth Japan: Transformation during Economic and Demographic Stagnation. London: Routledge.

Chiavacci, David; Julia Obinger. 2018a. 'Towards a New Protest Cycle in Contemporary Japan? The Resurgence of Social Movements and Confrontational Political Activism in Historical Perspective.' Social Movements and Political Activism in Contemporary Japan: Re-emerging from Invisibility. David Chiavacci; Julia Obinger (eds). London: Routledge, pp. 1-23.

Chiavacci, David; Julia Obinger (eds). 2018b. Re-emerging from Invisibility: Social Movements and Political Activism in Contemporary Japan. London: Routledge. Choi, Young Jun. 2013. 'Developmentalism and Productivism in East Asian Welfare Regimes.' Handbook on East Asian Social Policy. Misa Izuhara (ed.). Cheltenham: Edward Elgar, pp. 207-225.

Cliff, Tom; Tessa Morris-Suzuki; Shuge Wei (eds). 2018. The Living Politics of Self-Help Movements in East Asia. Singapore: Palgrave Macmillan.

Cumings, Bruce. 1984. 'The Origins and Development of the Northeast Asian Political Economy: Industrial Sectors, Product Cycles, and Political Consequences.' International Organization, 38 (1): 1-40.

Della Porta, Donatella (ed.). 2017. Global Diffusion of Protest: Riding the Protest Wave in the Neoliberal Crisis. Amsterdam: Amsterdam University Press. 
Eder, Norman. 1996. Poisoned Prosperity: Development, Modernization, and the Environment in South Korea. Armonk: M.E. Sharpe.

Fielding, Tony. 2016. Asian Migrations: Social and Geographical Mobilities in Southeast, East and Northeast Asia. London: Routledge.

Funabashi, Yōichi. 2015. Kenshō Nihon no 'Ushinawareta 20-nen': Nihon ha naze Teitai kara Nukedasenakatta no ka [Examining Japan's 'lost 20 years': Why couldn't Japan overcome stagnation?]. Tōkyō: Tōyō Keizai Shinpōsha.

Grano, Simona A. 2014. 'Perception of Risk towards Nuclear Energy in Taiwan and Hong Kong.' Taiwan in Comparative Perspective, 5: 60-78.

Grano, Simona A. 2015. Environmental Governance in Taiwan: A New Generation of Activists and Stakeholders. London: Routledge.

Grano, Simona A. 2016. 'The Anti-nuclear Power Movement.' Routledge Handbook of Contemporary Taiwan. Gunter Schubert (ed.). London: Routledge, pp. 297-312. Grano, Simona A. 2017. 'The Evolution of the Anti-nuclear Movement in Taiwan since 2008.' Taiwan's Social Movements under Ma Ying-jeou. Dafydd Fell (ed.). London: Routledge, pp. 154-176.

Gross, Neil; Thomas Medvetz; Rupert Russell. 2011. 'The Contemporary American Conservative Movement.' Annual Review of Sociology, 37: 325-354.

Hellmann, Olli. 2017. 'Populism in East Asia.' The Oxford Handbook of Populism. Cristóbal Rovira Kaltwasser; Paul Taggart; Paulina Ochoa Espejo; Pierr Ostiguy (eds). Oxford: Oxford University Press, pp. 161-178.

Higuchi, Naoto. 2018. 'The Radical Right in Japan.' The Oxford Handbook of the Radical Right. Jens Rydgren (ed.). Oxford: Oxford University Press, pp. 681-697. Ho, Ming-sho. 2006. Lǜsè Mínzhǔ: Táiwān Huánjìng Yùndòng de Yánjiū [Green democracy: A study of Taiwan's environmental movement]. Taipei: Socio Publishing.

Ho, Ming-sho. 2015. 'Occupy Congress in Taiwan: Political Opportunity, Threat, and the Sunflower Movement.' Journal of East Asian Studies, 15 (1): 69-97.

Holliday, Ian. 200o. 'Productivist Welfare Capitalism: Social Policy in East Asia.' Political Studies, 48 (4): 706-723.

Hsiao, Hsin-huang Michael. 1999. 'Environmental Movements in Taiwan.' Asia's Environmental Movements: Comparative Perspectives. Yok-shiu F. Lee; Alvin Y. So (eds). Armonk: M.E. Sharpe, pp. 31-54.

Hsiao, Hsin-huang Michael. 2019. 'The Tripartite Links of Middle Class, Civil Society and Democracy in Taiwan: 1980-2016.' Middle Class, Civil Society and Democracy in Asia. Hsin-Huang Michael Hsiao (ed.). London: Routledge, pp. 23-38.

Hundt, David. 2015. 'Neoliberalism, the Developmental State and Civil Society in Korea.' Asian Studies Review, 39 (3): 466-482.

ILO. 2018. Global Wage Report 2018/19: What Lies behind Gender Pay Gaps. Genva: International Labour Office. 
Ito, Takatoshi. 2017. 'Growth Convergence and the Middle-Income Trap.' Asian Development Review, 34 (1): 1-27.

Johnson, Chalmers. 1982. MITI and the Japanese Miracle: The Growth of Industrial Policy, 1925-1975. Stanford: Stanford University Press.

Kim, Sung Chull; Yousun Chung. 2018. 'Dynamics of Nuclear Power Policy in the Post-Fukushima Era: Interest Structure and Politicisation in Japan, Taiwan and Korea.' Asian Studies Review, 42 (1): 107-124.

Kim, Sunhyuk. 2000. The Politics of Democratization in Korea: The Role of Civil Society. Pittsburgh: University of Pittsburgh Press.

Kim, Youngmi (ed.). 2018. Korea's Quest for Economic Democratization: Globalization, Polarization and Contention. Cham: Palgrave Macmillan.

Koo, Hagen. 2019. 'Rising Inequality and Shifting Class Boundaries in South Korea in the Neo-Liberal Era.' Journal of Contemporary Asia, DOI: 10.1080/00472336.2019.1663242.

$\mathrm{Ku}$, Yeun-Wen; James Cherng-Tay Hsueh. 2016. 'Social Welfare.' Routledge Handbook of Contemporary Taiwan. Gunter Schubert (ed.). London: Routledge, pp. 342-358.

Lee, Joonseong; Katherine E Brown. 2018. "Make Korea with America Great Again”: An Articulation and Assemblage of South Korean Extreme Right Practices.' Communication, Culture and Critique, 11 (1): 53-66.

Lee, Yok-shiu F.; Alvin Y. So (eds). 1999. Asia's Environmental Movements: Comparative Perspectives. Armonk: M.E. Sharpe.

Lie, John. 2019. 'East Asian Exceptionalism to Western Populism and Migration Crisis.' The Oxford Handbook of Migration Crises. Cecilia Menjívar; Marie Ruiz; Immanuel Ness (eds). Oxford: Oxford University Press, pp. 197-209.

London, Jonathan D. 2018. Welfare and Inequality in Marketizing East Asia. London: Palgrave Macmillan.

Machimura, Takashi; Kei'ichi Satō (eds). 2016. Datsugenpatsu o mezasu Shimin Undō: San Ichi'ichi Shakai Undō no Shakaigaku. Tōkyō: Shinyōsha.

Maeda, Yosuke. 2012. 'Creating a Diversified Community: Community Safety Activity in Musashino City, Japan.' Geoforum, 43 (2): 342-352.

Mason, Andrew; Tomoko Kinugasa. 2008. 'East Asian Economic Development: Two Demographic Dividends.' Journal of Asian Economics, 19 (5-6): 389-399.

Miura, Mari. 2012. Welfare through Work: Conservative Ideas, Partisan Dynamics, and Social Protection in Japan. Ithaca: Cornell University Press.

Morris-Suzuki, Tessa; Eun Jeong Soh (eds). 2017. New Worlds from Below: Informal Life Politics and Grassroots Action in Twenty-first-Century Northeast Asia. Canberra: ANU Press

Nakazawa, Hideo. 2001. 'Kankyō Undō to Kankyō Seisaku no 35-nen: "Kankyō” o Teigi suru Kōkyōsei no Kōzoku Tenkan’ [35 Years of environmental movement 
and environmental policy: Structural transformation of the public sphere defining 'environment']. Kankyō Shakaigaku Kenkyū, 7: 85-98.

Obe, Mitsuru. 2019. 'Signs of Decline.' The Asian Nikkei Review, 15-21 April, pp. 32-35. Ogawa, Akihiro (ed.). 2018. Routledge Handbook of Civil Society in Asia. London: Routledge.

Oguma, Eiji. 2013. Genpatsu o tomeru Hitobito: 3.11 kara Kanteimae made [People stopping nuclear energy: From 3.11 to demonstrations]. Tōkyō: Bungei Shunjū.

Page, John. 2016. 'The East Asian Miracle and Development Policy: A Twenty-year Retrospective.' Japan's Development Assistance: Foreign Aid and the Post-2015 Agenda. Hiroshi Kato; John Page; Yasutami Shimomura (eds). Houndmills: Palgrave Macmillan, pp. 105-119.

Rodrik, Dani. 2018. 'Populism and the Economics of Globalization.' Journal of International Business Policy, 1 (1-2): 12-33.

Rowen, Ian. 2015. 'Inside Taiwan's Sunflower Movement: Twenty-Four Days in a Student-Occupied Parliament, and the Future of the Region.' Journal of Asian Studies, 74 (1): 5-21.

Shin, Gi-Wook; Rennie J. Moon. 2017. 'South Korea after Impeachment.' Journal of Democracy, 28 (4): 117-131.

Shin, Jin-Wook. 2018. 'Inequality and the Quality of Democracy in South Korea: Public Opinion and Electoral Politics, 1997-2012.' The Quality of Democracy in Korea: Three Decades after Democratization. Hannes B. Mosler; Eun-Jeung Lee; Hak-Jae Kim (eds). Cham: Palgrave Macmillan, pp. 147-173.

Shin, Kwang-Yeong. 2019. 'Neo-Liberal Economic Reform, Social Change, and Inequality in Post-Crisis Period in South Korea.' Asiatische Studien/Études Asiatiques, 73 (1): 89-109.

Solt, Frederick. 2019. 'Measuring Income Inequality across Countries and Over Time: The Standardized World Income Inequality Database.' SWIID (Standardized World Income Inequality Database), Version 8.o, February. https://fsolt.org/ swiid/ (26 April 2019).

Suehiro, Akira; Keiichirō Ōizumi (eds). 2017. Higashi Ajia no Shakai Daihendō: Jinkō Sensasu ga kataru Seikai [Drastic demographic and social change in East Asia: Analysis of the population censuses]. Tōkyō: Nagoya Daigaku Shuppankai.

Turner, Mark; Seung-Ho Kwon; Michael O’Donnell. 2018. 'Making Integrity Institutions Work in South Korea: The Role of People Power in the Impeachment of President Park in 2016.' Asian Survey, $5^{8}$ (5): 898-919.

Wade, Robert. 1990. Governing the Market: Economic Theory and the Role of Government in East Asian Industrialization. Princeton: Princeton University Press.

Wang, Joseph. 2019. 'Democratic Resilience in South Korea and Taiwan.' Democracy under Threat: A Crisis of Legitimacy? Ursula van Beek (ed.). Cham: Palgrave Macmillan, pp. 199-220. 
Woo-Cumings, Meredith (ed.). 1999. The Developmental State. Ithaca: Cornell University Press.

World Bank. 1993. The East Asian Miracle: Economic Growth and Public Policy. Washington, DC: World Bank.

World Bank. 2018. Riding the Wave: An East Asian Miracle for the $27^{\text {st }}$ Century. Washington, DC: World Bank.

Yang, Myungji. 2018. From Miracle to Mirage: The Making and Unmaking of the Korean Middle Class, 196o-2015. Ithaca: Cornell University Press.

Yun, Ji-Whan. 2019. 'Conservative Politics and Compassionate Paternalism in Korea and Japan: No Way Out?' Asian Survey, 59 (5): 911-936.

\section{About the Authors}

David Chiavacci is Professor in Social Science of Japan at the University of Zurich, Switzerland. His research covers political and economic sociology of contemporary Japan in a comparative perspective. He is known for his publications on social movements, social inequality as well as Japan's new immigration and immigration policy. His recent publications include Re-emerging from Invisibility: Social Movements and Political Activism in Contemporary Japan (Routledge, 2018, co-edited with Julia Obinger) and Japanese Political Economy Revisited: Abenomics and Institutional Change (Routledge, 2019, co-edited with Sébastien Lechevalier).

Simona Alba Grano is Senior Lecturer at the Institute of Asian and Oriental Studies at the University of Zürich, Switzerland. She is also a research fellow of the European Research Center on Contemporary Taiwan (ERCCT), at Tübingen, Germany. She has authored several book chapters and articles dealing with environmental and anti-nuclear concerns in East Asia over the past few years. In 2016 she guest edited a special number of China Information on the topic of 'environmental governance in China,' which includes articles on environmental rules and regulations by renowned China specialists. Her latest book as a single author is Environmental Governance in Taiwan: A New Generation of Activists and Stakeholders (Routledge, 2015), which analyses environmental governance mechanisms and actors in Taiwan through a multidisciplinary research approach. 


\section{Part I}

Environmental Issues 



\title{
2 Interactions between Environmental Civil Society and the State during the Ma Ying-jeou and Tsai Ing-wen Administrations in Taiwan*
}

\author{
Simona A. Grano
}

\begin{abstract}
This chapter deals with the political repercussions of popular discontent towards several secondary issues in Taiwan prompting a mainstream political formation like the DPP to revert to its early pro-environmental and social justice rhetoric to attract voters for the 2016 electoral tournament; several activists and academics that trace their origins to the social movements' galaxy were drafted by the DPP upon winning the elections. The aim of this chapter is to verify whether four years later concrete results have been achieved or whether the activists have become quieter after joining the ruling party. This chapter consolidates research on interactions and conflicts between the state trying to exert more influence across several fields and newly emerging/wellestablished social movements under the Ma Ying-jeou and Tsai Ing-wen administrations.
\end{abstract}

Keywords: strong states, civil society, environmental governance, EIA, legislative channels for popular participation, political opportunity structures

* The author gratefully acknowledges the generous intellectual contribution of Professor Ho Ming-sho. Part of this article was researched while the author was based in Taipei in 2016, for a two weeks research grant sponsored from the Swiss National Science Foundation (SNSF), at National Taiwan University as a visiting fellow under Professor Ho's mentorship.

Chiavacci, David, Simona Grano, and Julia Obinger (eds), Civil Society and the State in Democratic East Asia: Between Entanglement and Contention in Post High Growth. Amsterdam, Amsterdam University Press 2020 DOI: 10.5117/ 9789463723930_CHO2 
In Taiwan, as in other Asian nations, economic growth and transformation has been guided by a strong state that successfully activated and integrated private interests and citizens into national projects of 'developmentalism' and shared growth. As a consequence of this rapid economic development, a middle class has emerged, marked by greater claims for political participation, social equality as well as greater attention for quality-of-life concerns, such as better environmental protection and sustainability.

While many formerly strong states have seen a decline in their respective ability to successfully steer economic development and guarantee stable growth, several countries in East Asia have matured into fully modern societies with highly educated populations and stable work prospects. As a result, across Asia the well-established modernization model in which a strong developmental state single-handedly managed economic growth and then shared the fruits of its hard work with the population is increasingly being questioned by citizens; these, owing to new social and economic conflicts and rising social inequality, demand more political participation. In accordance with other parts of the world, these developments have created a new middle-class identity with citizens increasingly prone to voice their demands in politics by forming civil society organizations and actively participating in their countries' political life. Likewise, more people focus on issues such as environmental protection and other quality-of-life 'postmodern concerns,' which shatter the previously unquestioned attempt to achieve economic growth at all costs.

Since 1987 , when the KMT regime lifted martial law, Taiwan has undergone immense changes becoming a stable democracy where citizens' claims are increasingly vocal. In the past decade, and especially during the second Ma Ying-jeou administration (2012-2016), civic mobilizations related mostly to what Taiwanese perceived as a rapid increase of cross-strait relations and closeness with the Mainland.

On 16 January 2016 Taiwan held its second last round of national elections, which included both presidential and parliamentary contests, ${ }^{1}$ with the Democratic Progressive Party (DPP), winning back the presidency and also the majority of the legislature. Taiwan's third peaceful power turnover signified an important loss for the KMT, whose eight-year presidency (20082016) created widespread disappointment among citizens, particularly over the closer economic and political ties with the People's Republic of China (PRC). The latest elections have presented a golden opportunity for the

1 Voters were called to directly elect their president for the sixth time since 1996. Secondly, in a separate set of ballots, the 113 seats in the Legislative Yuan were elected. 
DPP to ride the wave of popular discontent and turn dissatisfaction in its favour, by championing several 'secondary' issues such as environmental protection $^{2}$ and social justice (especially popular among younger voters) that were previously advocated by smaller political formations like the Green Party of Taiwan (GPT) or by social movements.

This explains why in the 2016 electoral tournament the DPP enlisted several former NGOs' leaders, activists as well as academics with a strong environmental and social engagement that trace their origins to the social movements' galaxy3; to name but a few: previous Green Party chairperson Chen Man-Li, also former president of the Homemakers United Foundation; Prof. Wu Kuen-Yuh of National Taiwan University, a toxicologist often invited to give his professional opinion in regards to several EIAs ${ }^{4}$ involving polluting enterprises; Prof. Tsai Pei-hui, previous Secretary General of the organization Taiwan Rural Front, involved in several ecological campaigns of the past, such as fighting Taiwan's eighth petrochemical complex and advocating for land justice issues; Chen Chi-chung and Lawyer Chan Shun-kuei, who has lent his expertise and professional background to green activists on several occasions in the past. In the end, with the DPP's landslide victory these individuals have indeed been elected and Lawyer Chan has been nominated Vice-Minister for the Environment (he has meanwhile stepped down in December 2018), Chen Chi-chung has first become Deputy Minister

2 The DPP had vowed to put an end to environmental deterioration since at least the 1990s with several activists joining its ranks during those years, hoping to bring about positive results and more stringent regulations (Grano 2015: 49; Ho 2005a: 412). However, after the DPP began its ascent to 'institutionalization' scoring more than one-third of seats in the Legislative Yuan election of 1992 it gradually assumed a more cautious approach towards environmental movements, which came to be considered as an obstacle to economic development. This turnabout angered activists who established a new political organ in 1996, the Green Party of Taiwan (GPT), with the aim of capturing the sympathies of those who felt betrayed by the DPP change of position towards environmental problems (Ho 2003: 701-706).

3 As stated by Fell the problem of the DPP attracting social activists draining social movements of their human capital is not new. Even a political formation such as the Green Party faced this problem several times since many of its members believe that there is more that they can achieve for the environment if they are elected with a better-established party, as was the case with Edgar Lin in the 1990s (Fell 2016: 74).

4 Taiwan's EIA Act was formally enacted in 1994 modelled after the United States' own EIA Law (Ho 2004: 238). The introduction of such a system was a direct consequence of the sociopolitical situation of the country, with bureaucrats in need of a showcase to appease popular requests for increased participation. In principle the EIA stipulates how developmental projects of a certain size should be planned and reviewed, which requirements should be met and what are the fines and punishments for violators. In reality it does not always function as it should and there has long been talk of reforming it (Grano 2015: 174-175; Ho 2004; Lai 2017). 
and then, in January 2019, Minister of Council of Agriculture while Chen, Tsai and Wu have become members of the Legislative Yuan in charge of different sectors (e.g. food safety and public health [Wu], environmental protection, ecology and renewable energies [Chen]; land-related issues [Tsai]).

By following the shift of these civil society actors who have been elected with DPP, from individuals sympathetic to more visible acts of contention to legislators integrated in the ranks of the ruling party, this chapter shall pinpoint the effects of this incorporation of civil society actors into governmental echelons, for the country's environmental governance system and its efficacy.

With the increased institutionalization of social activists, formally enlisted in the DPP's ranks, environmental protesters seem to have shifted once again their modus operandi from more contentious acts, which had become quite common during the last four years of the Ma Ying-Jeou administration (2012-2016) - such as streets protests and occupation of public spaces ${ }^{5}$ - to more formal policy channels.

Barely one year after the new administration had taken over, optimism for the new government inside Taiwan had already been dampened by a series of factors ranging from a persistent economic recession, job insecurity, sluggish wages and a massive decrease of tourists from the Mainland (incidentally the first thing the taxi driver complained about, as I set foot in Taipei in September 2016). At the same time the Xi Jinping administration presents numerous challenges for Tsai, given her refusal to publicly acknowledge the 1992 Consensus, in the unequivocal way Beijing would want her to; in 2017 Taiwan suffered a series of blows on the international stage, such as not receiving an invitation - in its status as observer - to the WHA Assembly in May in Geneva (for the first time in nine years); China requiring airlines to replace 'Taiwan' with descriptions such as 'Taiwan, Province of China' in 2018; and inducing seven countries to sever relations with Taipei in less than four years. ${ }^{6}$

The present chapter shall concentrate on state-civil society relationship under both the KMT as well as the DPP administration with a focus on

5 For instance, the Sunflower Student Movement (Taiyanghua Xueyun) was a 24-day occupation (18 March-10 April) of Taiwan's legislature, to protest against the attempt on the part of the ruling Kuomintang (KMT) to pass the Cross-Strait Service Trade Agreement (CSSTA) with Mainland China for which protesters maintained a 'clause by clause' review was needed.

6 Since President Tsai Ing-wen came to office in 2016 seven countries have severed ties with the Republic of China, switching their diplomatic recognition to the PRC. The latest is Kiribati, following Solomon Islands, El Salvador, Burkina Faso, the Dominican Republic, Sao Tome and Principe and Panama. 
the latter tenure's implementation of green policies. It will likewise briefly analyse the recent rise of a 'pro-nuclear' countermovement, as a backlash against the DPP's current goal of phasing out nuclear energy by 2025. This last example moves beyond the classic dichotomy of state vs 'liberal' civil society showing that 'conservative' countermovements can also rise up in response to the latest wave of more progressive activism, which was responsible for bringing the DPP to the government.

Taking on Carter's (2007: 164-165) framework for assessing the different impacts environmental movements can have, the present chapter will define which effects these pressure groups wish to achieve and whether these coincide with what they have been able to accomplish in reality. Carter's four categories of analysis for assessing the types of impact of the environmental movement are: (1) sensitizing impacts, such as changing public agenda or public opinion; (2) procedural impacts, such as movement access to decision-making bodies; (3) structural impacts, such as changes in institutions and alliance structures; and (4) substantive impacts, such as closing a polluting plant or enacting new legislation.

I find Dafydd Fell's adding of a fifth category of external impact, the category of political impacts (5), such as the influence on election results (as quoted in Fell 2017:9) extremely useful and will also feature this category in my chapter.

\section{Theoretical Background and Methodology}

In the 1990s, when for the first time after the lifting of martial law activists became involved in politics, many held high hopes that, by working within the system and ranks of the ruling party they could actually be more effective in precipitating a positive change for the environment; such hopes became even stronger after the DPP was able to gain the presidency in 2000, concretely opening up several policy channels to social activists.

Specifically, many scholars of social movements in Taiwan believe that the emergence of various social groups that the state did not suppress, actively started to challenge the country's authoritarian rule in the $1980 \mathrm{~s}$ while at the same time creating a set of collective action repertoires and a so-called public sphere that dissidents and activists could use to facilitate the organization of political structures (Hsiao 1999; Wu 1990; Haddad 2015). ${ }^{7}$

7 Clearly, environmental protests at that time were closely linked with anti-authoritarian positioning and eroding one-party rule. 
This theory - the Theory of Political Opportunity Structures (POS) - focuses on the relationship between political environment and social movements (Kitschelt 1986; Kriesi 1991) or, in other words, on state capacity as a variable in explaining the policy impact of social movements (Ho 2005b: 345). It maintains that the most important incentives and possibilities for starting new phases of contention and activism are a direct consequence of changes in political opportunities related to the current system (Tarrow 1994: 87).

The Theory of POS can be defined as 'specific configurations of resources, institutional arrangements and historical precedents for social mobilization which facilitate the development of protest movements in some instances and constrains them in others' and it provides a suitable framework for understanding the transformative nature of the environmental movement in Taiwan. The nature of the political structure, authoritarian or democratic, comprises a set of incentives to either encourage or diminish social acts of resistance to political action and authority. Theory of POS maintains that open political systems diminish incentives to social mobilized protests through the opening of less risky avenues for political influence (as in the case of Taiwan during the 1990s, when activists were de facto incorporated into the government), whereas closed authoritarian regimes encourage, to a degree, challenging groups that manifest their discontent with active mobilization as the only viable mean of political persuasion.

In the case of Taiwan, when taking on a comparative perspective between the Ma Ying-jeou (2008-2016) and Tsai Ing-wen (2016- ) eras, we can devise several points, which seem to verify the hypothesis that during the more 'repressive' phase activists were more visible and active than they currently are (as of November 2019), during what is perceived by many as a more 'open' and 'friendlier' mode of administration towards civil society with wider availability of policy channels to express discontent. Examples will be provided throughout the chapter. Country-specific institutions and contexts do shape recent protests and conflicts and in the case of Taiwan it is a well-established fact that civil society actors are more vocal when the KMT is at the government, probably because of the stronger sense of kinship they historically share with the DPP and the perception and conviction that the latter is more willing to listen to the plight of the so-called third force (disan shili).

However, it will be worth remembering that to become 'institutionalized' (part of the government) does not automatically result in a higher rate of success; in fact, such hopes have been crushed once before during the first DPP national incumbency (2000-2008) when numerous activists were indeed included in the government's structure (Ho 2003: 694-695) and yet failed to 
create any long-lasting influence (Lyons 2009; Tang and Tang 1997), such as achieving the enactment of new legislation.

As far as the methodology is concerned, the present study uses data from newspapers, interviews and field observations to study environmental social activism-state relations under two different ruling parties in Taiwan, the KMT and the DPP, during the Ma Ying-jeou and the Tsai Ing-wen eras. ${ }^{8}$

The author carried out a series of interviews with several informants within a period of three weeks in September 2016 and then conducted followup research in the summer of 2017 (via an email questionnaire) to compare the DPP administration's planned policy goals and aims with their actual implementation one year later. In 2016 I carried out fifteen interviews with a total of ten informants within a period of two weeks. Further interviews on an individual basis were carried out with two informants in March and April 2018 via Skype.

The focus is on three main issues: nuclear power, EIA system reform, and air pollution.

\section{Social Movements and the State under the Ma Ying-jeou Administration}

The unprecedented social activism which Taiwan witnessed under the Ma administration, which culminated in the Sunflower Student Movement and the occupation of the Legislative Yuan in March 2014, did not come out of nowhere (Ho 2019; Lin and Wu 2016). After eight years of DPP rule (from 2000 to 2008) during which several activists were incorporated in governmental tasks, and social movements rather than standing in opposition to the state had become part of it, the relationship between the two became increasingly tense; the ruling party, confronted with the daunting task of managing the country, gradually became more lenient towards big businesses and less friendly towards its former allies (civic movements) and their plights (Ho 2003; Jobin 2010). By the end of the DPP mandate many social activists were deeply disappointed with their former political ally (Fell 2017:3). This sense of disillusionment towards what the DPP had accomplished, coupled with several scandals involving former President Chen Shui-bian's family

8 The present article will only analyse this clearly defined period of observation (2008-2019); this choice is dictated by the fact that it is difficult to predict what is going to happen in 2020, with the presidential elections and what impacts these shall have on the environmental sphere, especially on the phasing-out or continuation of nuclear energy. 
in corruption issues, led to the DPP's loss of the presidency for the next eight years.

In fact, as pointed out by Fell $(2017: 3)$ after the KMT won the national elections in 2008, having gained almost total control over many local administrations from 2005 onward, it felt sufficiently strong to ignore the various plights of protesters. For instance, the KMT administration opted for a highly 'developmentalist' approach to land disputes and energy issues, such as the controversy surrounding NPP- $4^{9}$ or the Huaguang Community and the Dapu cases (Chen 2017: 97). Furthermore, the privileged access to decision-making bodies that social movements' activists had reached under the DPP (category 2, procedural impacts) was completely shut off after 2008, pushing activists to seek for more radical ways to make their plights visible.

Dissatisfaction with the way social movements' requests were handled is what pushed activists to the streets and led to the occupation of the parliament in 2014 and to the subsequent loss of both local (Nine in One) as well as national elections (in 2016) on the part of the KMT as well as to the freezing of the country's fourth nuclear facility, due to popular pressure. However, social movements were also able to achieve some victories under the KMT administration such as in 2010, when Ma Ying-jeou himself issued a statement regarding the cancellation of a national project regarding the construction of a controversial petrochemical complex, the Kuokuang Petrochemical Plant, in Changhua County (Grano 2015: 92; Ho and Shieh 2011).

Many of the successes achieved by social movements, such as blocking controversial projects like NPP-4 and Kuokuang (category 4, substantive impacts) or getting public opinion enraged (category 1 , sensitizing impacts) over specific topics have not resulted in concrete legislation (Fell 2017: 13) though; the case studies illustrated in the next sections will attempt to pinpoint whether social movements have been able to pressure the DPP into passing important pieces of legislation on behalf of environmental protection from 2016 onward.

In the next few sections this chapter will present concrete examples of transformations and policies that in some cases have and in others have not been achieved, thereby helping to pinpoint whether this outward questioning of strong states more frequently occurs when conservative parties are ruling and less so, whenever a more 'progressive' party is.

9 NPP-4 stands to indicate the country's fourth nuclear power facility, eventually never completed but on which US $\$ 9$ billion were spent within a timeframe that lasted more than two decades. For more on NPP-4 controversial history see: Ho (2014) and Grano (2017). 


\section{Social Movements and the State under the Tsai Ing-wen Administration}

In September 2016, when I went to Taipei for three weeks, the Tsai administration was at the beginning of its tenure, which had effectively started in May of that same year. Several activists had been incorporated in the government and far-reaching policy goals and attempts to improve the regulation system in place for ecological safeguarding were on many legislators' agenda.

One of the first individuals I chose to interview was Tsui Su-hsin, Secretary General of Green Citizens Action Alliance (GCAA), ${ }^{10}$ whom I had interviewed several times in the past and who can be ascribed to the more 'independent' wing of environmentalists, at times wary of cooperation with bigger political formations, such as the DPP (Ho 2014; Grano 2017: 159).

When asked whether she thought that the DPP administration would be a good partner for social movements to cooperate, she told me that the DPP is very skilled at communication and was certainly going to open up several policy channels for activists as well as actively involve many of them in official positions.

Since the beginning of its tenure the DPP has in fact once more opened up several policy channels for activists (category 2, procedural impacts) that had been closed during the Ma administration.

On top of electing some environmental activists in key positions of responsibility, the Atomic Energy Council invited two of them to join their committee, one from Homemakers United Foundation and the other one from Taiwan Environmental Protection Union. Tsui's own organization has been invited to join the committee for the reduction of greenhouse gases, as well as the committee for energy and carbon use reduction. Many other organizations are participating to several official committees providing advice and counselling. GCAA currently also cooperates to amend the Electricity Act (Dianye Fa) with the Environmental Jurists Association (EJA) ${ }^{11}$ (Huanjing Falüren Xiehui). However, Tsui was also wary of the past and moderately cautious (Interview Tsui 2016):

10 GCAA of which Tsui is Secretary General has, since 2015, established a new association called The Alliance for the Transformation of Energy (Nengyuan Zhuanxing Tuidong Lianmeng), with membership from various environmental organizations, which seeks for methods to save energy by, for instance, upgrading all the generators of the country, among other things.

11 The EJA has two goals: it offers advice on administrative litigation in regard to environmental issues (huanjing xingzheng susong) to environmental groups and other concerned citizens, such as those who are touched by an eviction order resulting from land seizure for a developmental 
We are still not sure about the attitude of the new government, since they might invite us and then ignore our opinion as the former government did. We are still observing. So far, their attitude is acceptable for they involve us actively and try to maintain their electoral promises. But I think we will have to wait at least one year to start making a serious evaluation and establish trust.

\section{Original Policy Goals under the Tsai Ing-wen Administration}

Given the current administration's commitment to phasing out Taiwan's dependence on nuclear power (10\% of total power generation in 2018) by 2025 , the development of the 'Green energy plan,' one of the five key industries which Tsai pledged to rejuvenate and support, is an urgent task. In order to maintain Taiwan's competitiveness, providing affordable and reliable energy sources is a major concern of investors in several key industries. Therefore, the Tsai administration has already signed several contracts with foreign and domestic companies for wind farms and solar projects. In March 2016 the Executive Yuan announced an eight-year NT\$50 billion ( $\$ 1.65$ billion) infrastructure plan for green energy investment. The ambitious goal is to expand renewable energy from less than $5 \%$ of supply in 2016 to $20 \%$ by 2025 .

Among the most pressing concerns that all of my interviewees had pinpointed in September 2016 as urgent environmental matters for the current administration to solve, are: the reform of the Environmental Impact Assessment Law; the revision of the Electricity Law ${ }^{12}$; the improvement of soil, air and water pollution in the country's most contaminated areas of south and central Taiwan; solving the country's need for energy while meeting more stringent environmental standards and increasing renewable energies; the yet unresolved issue of nuclear waste; toxic waste and garbage abandoned all over the island; and the lack of a fully functioning safeguard system for rare and wild species of animals and plants.

More specifically, when directly asked, four of my interviewees, Chan Shun-kuei, Chen Man-li, Frida Tsai (Tsai Pei-hui) and Tsui Su-hsin have replied that the most pressing issue to be solved in terms of environmental

project. Their second goal is to help legislators and assist them in amending environmental laws or pressuring administrative agencies for adjustments after winning a lawsuit.

12 The revisions aim first of all at integrating small power providers of Photovoltaic panels in the national grid. Furthermore, the idea is to create different levels of tariffs: cheap (agriculture and fishing); medium (private household); high (industry); very high (commercial) (Interview Ho 2016). 
damage is the lethal air pollution in central and southern Taiwan, where residents are affected by the emissions of the heavy industry (Interview Chan 2016):

In the past the government paid less attention to concrete health risks and to epidemiological surveys. Preliminary results are now available and lead us to foresee such problems. A good case in point is the small village of Dalinpu, in the coastal areas surrounding Kaohsiung, where 20,00o residents, surrounded by thermal power stations, steel mills and petrochemical plants could be left with no choice but to emigrate as they undergo an immense risk of getting cancer; according to any international standard the pollution situation is unbearable.

Former Vice-Minister Chan Shun-kuei further believes that land-planning violations, among other things, also lead to air pollution. In fact, it is his opinion that Taiwan's most pressing problem is an out-of-control land-planning system whereby agricultural land is covered with industrial factories, which in turn create more pollution in areas that should strictly be devoted to agricultural use. ${ }^{13}$ Sorting out the many land-planning violations should also ensure that the industry would be confined to specific areas and not, as it is now, equally spread out (just like the pollution it produces) all over the island.

The second aim of this study, as mentioned above, is finding out whether such grand goals for a better environmental protection and sustainable Taiwan are currently anywhere nearer to being realized three years later or whether they remain unfulfilled promises now that state-civil society interactions seem to have once again become more 'cooperative' under a DPP incumbency. To this avail, one year after the first fieldwork, specifically in the summer of 2017, I sent out a questionnaire to the same legislators and social movement activists interviewed the previous year in 2016. I also used Skype to further interview two of my informants in 2018 in regard to the latest changes and transformations.

13 At the moment there is a situation by which residential, industrial and agricultural use land are completely mixed up, so that wastewater from industrial discharge as well as irrigation water for agriculture are also mixed together; containing air pollution, water pollution and soil contamination with heavy metals has thus become extremely difficult under the present system.

Additional problem is the surface area where it is permitted to construct residential housing in urban areas for which the reward is exorbitant for land developers and builders making land hugely expensive so that low income family are slowly but relentlessly pushed to the outskirts of cities, and making traffic congestion situation also more serious as public services are not able to keep up with the fast growth of residential community in certain areas, such as Neihu (Interview Chan 2017). 
During this follow-up phase I asked what was, so far, the biggest positive change achieved on behalf of the environment under the current administration. One of the interviewees pinpointed it in the different institutional positioning of the central government vis-à-vis the environmental protection sphere, as shown in the respect and support that Lin Chuan, the former premier, credited to the former Vice-Minister of the Environment Chan (Interview Zhang 2017). ${ }^{14} \mathrm{He}$ hinted that rather than looking for concrete achievement in what was still an early phase, the important change to be highlighted was the greater attention to the ecological environment paid by the current administration.

In fact, in these same interviews in 2017, two of my interviewees made positive assessment in terms of the actual will to improve the situation but lamented a lack of systematic ability in terms of achieving concrete actions. Both Lawyer Zhang Yu-yin as well as Tsui Su-hsin commented that, in spite of the 'No nuke homeland' (feihe jiayuan) slogan, the current administration had failed to provide concrete and structural solutions to diminishing the quota of electricity derived from nuclear and had also at times backtracked on its grand goals. In the words of Zhang Yu-Yin (Interview Zhang 2017):

Let us take recent events of the summer of 2017 as an example. Even the first unit of NPP-2, which had already been stopped, has quickly been reactivated in the midst of a so-called summer energy crisis [xiatian gongdian chijin]. Six months after it was shut down for annual maintenance, the No. 1 reactor at the second nuclear power plant located in New Taipei City resumed operation last Saturday with the approval of the Atomic Energy Council.

\section{Backlash from Pro-nuclear 'Conservatives'}

Under the 'nuclear-free homeland' policy launched by the DPP, Taiwan's six operable power reactors shall be decommissioned as their 40-year operating licenses expire. ${ }^{15}$ Shortly after taking office, the DPP government passed an amendment to the Electricity Act, passing its phase-out policy into law.

To phase out nuclear energy the government's plan is to increase its share of renewable energies from $4.7 \%$ to $20 \%$ by 2025 (Our Island 2017).

14 Environmental Protection Administration (EPA) Vice-Minister Chan Shun-kuei resigned in October 2018, in disagreement with the new Premier William Lai who was, according to Chan, trying to sway the EIA system.

15 Unit 1 of Taiwan's oldest plant, Chinshan, has been taken offline in 2018 and will be decommissioned, while the operating license of unit 2 is due to expire in July 2019. 
Several activists think that the plan is unrealistic in many of its goals. For instance, the increase of solar energy which should rise from the current $1 \mathrm{GW}$ to $20 \mathrm{GW}$ (equivalent to 7.4 times the current capacity of NPP-4) de facto would require an area of 30,000 hectares - bigger than the entire Taipei city area - to be covered with PV panels. Two of my interviewees proffered doubts (Interview Zhang 2017; Interview Tsui 2016).

The government furthermore suffered a setback in its anti-nuclear policy when in November 2018 the Taiwanese electorate was called to vote for local elections coupled with several referenda on various issues. One of these referenda saw a pro-nuclear alliance victorious with voters rejecting the government's plan to phase-out nuclear power with $59 \%$ of voters in favour of keeping nuclear energy in the mix and $41 \%$ against. Specifically, voters agreed to remove legal provisions set by the DPP mandating that Taiwan be nuclear-free by 2025 .

Despite the result of the referenda the Tsai government has stated that it shall proceed with its plan to phase out the use of nuclear energy. This has led to outrage from pro-nuclear advocates who are presently attempting to push for three more referenda. The first calls for the extension of the operating permits for these four nuclear reactors whose permits were originally set to expire between 2021 and 2025; these being the reactors at the Guosheng Nuclear Power Plant in New Taipei City and at the Ma-anshan Nuclear Power Plant in Pingtung. The second referendum calls for the resumption of work on Gongliao Nuclear Power Plant No. 4, controversial even among pro-nuclear supporters because of observations that its construction has been chaotic; and third pro-nuclear supporters call for a referendum on the current storage of nuclear waste materials on Orchid Island (Hioe 2019a).

\section{Substantive Impacts in the Making: Amending Taiwan's Air Pollution Control Act}

Like many governments the Tsai administration faces the two-pronged dilemma of fighting air pollution as well as wanting a nuclear free homeland and for these reasons it plans to increase its quota of electricity derived from natural gas and has therefore already built three stations in Taoyuan, which should serve to increase the production capacity of natural gas of the Ta Tan Power Plant (Datan Dianchang). In this specific case the geographical proximity to some precious coral reef on the nearby coast, once again make concerns such as ecological safeguarding and generating electricity, collide. 
Lawyer Zhang stressed that the Tsai administration so far has attempted to do many good things for energy generation and transformation but he fails to see any structural change. ${ }^{16}$ This in fact, is what he regards as the country most urgent need in the environmental sphere, namely energy transformation, especially given that the government is trying to substitute the $10 \%$ of electricity currently derived from nuclear energy with renewable energies, such as in the above mentioned case of the Ta Tan Power Plant), or PV panels or in the offshore wind turbines in Changhua (Interview Zhang 2017).

At the beginning of its tenure the DPP government charged former ViceMinister Chan with two fundamental tasks: modifying the Air Pollution Control Act (Kongqi Wuran Fangzhifa) and other air pollution control-related regulations; and putting the EIA system (the law and related rules and regulations) through a complete overhaul. If successful, these would be the first concrete substantive impacts and successes (category 4) achieved under the DPP national tenure on behalf of the environment.

The Taiwan Environmental Protection Administration (EPA) held three public hearings on draft amendments to the Air Pollution Control Act (in August 2017. On 21 December 2017, Taiwan's Executive Yuan publicly announced an action plan to cut air pollution and foster renewable energy. New 'hazardous air pollutant standards' to tax companies emitting stationary pollution have been launched at the end of 2017.

In total the EPA has identified 29 air pollutants to be taxed, including heavy metals emitted by coal-fired power plants and by petrochemical facilities. The new standards will regulate companies such as Taiwan Power Co., Formosa Plastic Group and CPC Corp., Taiwan. As of June 2018, legislators have in fact passed the third reading of draft amendments to several articles such as article 9 of the Air Pollution Control Act. ${ }^{17}$ Under the law emissions standards for cars over ten years in age have been raised, and if a driver's vehicle fails an emissions inspection or does not have their vehicle inspected, their license plate will be confiscated. Furthermore, the bill has set the target to create air quality control districts (kongqipinzhi weihuqu) in which older vehicles will be prohibited from being driven in and violators could face a

16 Original Chinese phrase: (muqian weizhi, Tsaizhengfuyou shitu zainengyuan zhuanxingshang zuo yixie shiqing, dan wo hai kanbuchu Tsai zhengfu zai chuli nengyuan gongdian de jiegou wentishang, you shenme juda de zhuanbian).

17 Article 9 allows emission allowances to be obtained for stationary sources of air pollution through trades and auctions or by reducing the emissions of mobile sources; it thus encourages companies to obtain emission allowances by buying used cars to speed up the replacement of older cars. 
fine of between NT\$500 to NT\$6o,000 (Lin 2018b). The amendments state that the total amount of air pollution shall be determined by the Taiwan EPA, which must consult with the Ministry of Economic Affairs (MOEA), a provision that sparked outrage among civic society echelons, before filing to the Executive Yuan on a stage-by-stage and zone-by-zone basis after the establishment of a checking system for pollution source emission quantities and an emissions trading system.

Vice-Minister Chan in 2017 told me that the biggest goal that the current DPP administration had reached in the two years since taking office, was securing the participation and involvement of chief executives and senior leaders in several press conference and happenings regarding the strategies to cap air pollution. In fact, he was of the opinion that the Environmental Administration alone cannot achieve much; in his view there needs to be cooperation between various involved actors such as the big industry, energy providers, the traffic bureau and others. The control of air pollution, in his opinion, represents the most pressing issue for Taiwan and for the DPP administration. Again, so far, a common observation among many of my informants deals with the positive orientation and commitment of DPP politicians towards the actual safeguard and protection of the environment. As Vice-Minister Chan resigned in 2018, he did so out of disagreement with former Premier William Lai (who has meanwhile also been replaced) whom he considered too close to the business sector.

Other legislators elect shared similar positive opinion in regard to the constructive interest shown among DPP politicians towards the environmental sphere and the party's cooperation with social movements. In the words of Chen Man-li (Interview Chen 2016):

We are now the ruling party, and if I criticize harshly without previously understanding the issue at stake, my attitude is nothing but showing off and will not lead to the solution of a problem. By the way even when I was in the Homemakers United Foundation, I was not so harsh. And now as politician, I am still not a radical. Some NGO experts, individuals, or governments come to me for help and my assistants will earmark their appeals into various categories: environment, social welfare, labour, renewal energy, and sustainable development. Now that I am a legislator whenever I encounter any case pertaining to one of these five categories, I will submit my questions, amend, or create the laws in the parliament, and establish a bridge between the NGO and the senior administrative department which is more influential in that case, in order to do something concrete. 
However, while legislators-elect are still very much positive in regard to the DPP's commitment towards environmental protection, activists from the more 'independent' fringe, who have not become part of the government, remain sceptical (Interview Tsui 2018) ${ }^{18}$ :

So far, the fulfilment of their (the DPP) electoral promises is not satisfactory. There are no concrete policies formulated and enacted yet. I can see that the environmental sphere is not their priority. As result, NGOs for environmental protection are not satisfied and continue holding a series of demonstrations.

After the 2016 national elections, which brought several new actors on the political scene, activists have begun to look around for more suitable allies. As Kwan and Fell (in this volume) state, even though Taiwan's political life since the country democratized has been dominated by the KMT and the DPP, smaller political formations have at times played a crucial role by bringing diversity into the system and by emphasizing neglected issues and communities.

Tsui, for instance, thinks that members of the New Power Party are a better and fresher option for NGOs to ally with, since they are more independent and objective than candidates elected with DPP such as Chen Man- $\mathrm{Li}^{19}$ but at the same time they too are interested and concerned about issues that pertain to ecological safeguarding, such as air pollution and the problem of coal-fired power stations (some members of NPP come from southern and central Taiwan) (Interview Tsui 2016). Furthermore, the above-mentioned cabinet reshuffles which brought Lin Chuan to resign and William Lai to temporarily assume office as premier (Lin 2017a) have reinforced prejudices among activists that other parties than the DPP might be better suited as partners, given that William Lai was more sympathetic towards economic development, obstructing space for environmental reforms (Lin 2018a).

However, on 9 April 2018, the country's legislature approved several amendments to Taiwan's Air Pollution Control Act, placing tighter emissions

18 I am grateful to Professor Ming-Sho Ho for the following comment: 'I think there's a complexity of ecology among Taiwan's environmentalists. Radical or moderate is just one way to understand the differences. It also involves difference of priorities, such as air pollution versus no nukes.'

19 A thing that instantly struck a chord with me as when I asked Chen for a mid-term assessment on the DPP's accomplishment so far, in June 2017, she declined to answer with the explanation that she is now: 'part of the DPP government' (wo shi minjindang, xianzai wufa zhendui Tsai Ing-Wen zhengfu zuo pinglun, hen baoqian) (Interview Chen 2017). 
restrictions on old cars, two-stroke scooters and diesel trucks (Everington 2018); in June 2018, when the contentious bill was finally passed such concrete achievements represent the first substantive impacts (category 4) in the realm of environmental protection reached under the Tsai administration.

\section{Substantive Impacts in the Making: Reforming the Environmental Impact Assessment Law}

In the past few years, due to an increase in the availability of legal channels, such as the Environmental Impact Assessment (EIA) Law (Huanjing Yingxiang Pinggu Fa), environmental groups have gained more influence to fight economic interests. At the same time the EIA Law has been often criticized for being either too lenient towards big corporations' interests or a mere obligatory channel for projects of a certain size without real effectiveness in the past (Ho 2004).

As the DPP was running its electoral campaign in 2014, Lin Chuan, the previous premier, organized a think tank where he invited several social activists, in order to share their views on urgent reforms needed. One of the invitees was lawyer Chan Shun-kuei, who shared his ideas on how to amend the EIA system. After Tsai won the election, lawyer Chan was invited to join the administration as Vice-Minister of the Environmental Protection Administration. As mentioned, he later resigned at the end of 2018 in disagreement with then premier, William Lai (meanwhile replaced by Su Tseng-chang).

During an interview with the author, Chan remarked how one of the main conflicts between industrialists and environmental activists revolves around the EIA Law, which he had hoped to solve during his tenure. Industrialists consider it as a stumbling block for development and particularly fear the final veto power to a project (Interview Chan 2016).

I asked industrialists what the main problem with the EIA was and discovered that what they feared most was the lengthy procedure of the environmental evaluation and its lack of efficiency, which increased risks and costs. On the other hand, activists and concerned residents often think of the EIA as tilted towards development and business interests. My concrete proposal is to increase the pace of the assessment while at the same time drawing new stringent standards to protect the environment, which will allow us to refuse cases in the early stages, thereby increasing the veto percentage from the current $5 \%$ to $10 \%$. 
Changes to the EIA have been in planning since the new administration came along but former Vice-Minister Chan has been working on a total overhaul of the system for many years now, in his previous capacity as a lawyer.

On 2 May 2017 the Environmental Protection Administration communicated that it planned to amend the Environmental Impact Assessment Enforcement Rules and the Standards for Determining Specific Items and Scope of Environmental Impact Assessments for Development Activities. Furthermore the EPA, under Chan's guidance, drafted a social impact assessment (SIA) standard by which to gauge the social impact of controversial projects of a certain size, which until this point had never been legally included in the EIA system. The legal community in Taiwan has long been vocal on the need for such an impact to be taken into consideration; specifically, such a system would be geared at quantifying the damage suffered by the people living in the place where the project is being planned. Primary goals of SIA implementation are to prevent forcible relocation and more respectful treatment when a development concerns the indigenous land.

A few university professors are also involved in helping to create such a standard for assessing the social impact of these projects, such as Chou Kuei-tian and Ho Ming-sho, who are contracted to formulate a technical guideline to be used in SIA.

Taiwan's legal scholars are divided on whether to implement a SIA in the current EIA framework, but the EJA was quite enthusiastic about it.

Environmental lawyers from the EJA among others convened a forum in June 2017 to call for higher fines and stricter criteria; the draft proposes increasing fines by a factor of ten, with the maximum fine reaching NT $\$ 15$ million (US\$497,892) (Lin 2017b).

Taiwan's environmental activists on the other hand are actually divided over the EPA's EIA reform promoted by Chan, considering allowing certain urban development projects to be exempt from an EIA evaluation a step back (Taipei Times 2017) ${ }^{20}$ The EPA position at the time was that the amendments to EIA legislation include tighter restrictions for certain items, while previously exempt projects would now require assessments. However, some

20 In the case of urban development, for instance, the EPA's draft exempts the development of communities, renewal of old communities, exhibitions, fairs, exhibition venues, underground shopping streets, high rises, hotels, nursing institutions, social welfare institutions, integrated industrial and commercial areas and shopping centres from undergoing an environmental assessment. The main reason adduced is that urban planning reviews already include environmental protection measures and requirements with regards to landscaping, traffic impact, sunlight and wind shear, which would overlap with EIAs. 
items would be exempted because these items are already regulated by other laws, such as the Urban Planning Act (Dushi Jihua Fa) (Taipei Times 2017).

As explained to me by former Vice-Minister Chan in 2017, the plan to reform the EIA foresaw the end of the first phase of the changes to the EIA system to be reached by the end of August 2017. In the unpublished draft, the EPA identified development projects that should undergo a strategic environmental assessment (SEA), which would need to be ratified by the Executive Yuan instead of being stalled in ministries (as it now the case); the second phase should be achieved within the next four years; for the third stage it would require another ten to fifteen years, allowing Taiwan's own EIA system to become like the US model (Interview Chan 2017). Developments that involve massive land exploitation would have to undergo an EIA and agencies that oversee developers are to be held accountable for EIA procedures under the amendment; the agencies would be required to account for the developers' reports, rather than just delivering the documents to the EPA (Interview Chan 2017). The draft amendment to the Environmental Impact Assessment Act was promulgated on 20 September 2017, but given that Vice-Minister Chan subsequently resigned the future of the process is unclear even though the first phase of the reform has been achieved (Interview Chan 2018).

In October 2018 the EPA announced revisions aimed to enhance the credibility of the EPA among several agencies, allowing it to filter development and reach a more efficient review process. The EPA is already trailing this process by reviewing the ecological impacts of the Taiwan government's ambitious plans to expand offshore wind power and solar power installations. The screening led the EIA Commission to approve only two of seven sets of offshore wind power projects off Changhua County on Taiwan's west coast. Further information has been requested for the remaining sites. According to Chan, the developer and the responsible government agency - the Ministry of Economic Affairs - had not provided sufficient data to support their proposals to alleviate potential impacts on marine ecology, notably the endangered Taiwan white dolphin.

To sum up, the legal framework for improving air pollution and environmental assessment procedures - Chan's key objectives - is in place and some concrete achievements have been reached in terms of implementing new sets of regulation for both air pollution as well as the transformation of the EIA system. Nuclear energy is a much more complicated matter which, traditionally, has epitomized an ideology-laden issue opposed by the DPP and supported by the KMT. Thus, who will win the elections next year will have important repercussions on the continuation of the usage of nuclear energy in the current energy mix and in the extension of the shelf life of soon-to-be expired reactors. 


\section{Conclusion}

With the help of first-hand interviews this chapter has tried to establish whether the blossoming of civic society questioning the state more frequently occurs when conservative parties are ruling and, less so, whenever a more 'progressive' party is; this has been done through the analysis of two concrete case studies: air pollution regulations and the EIA system.

The strong dirigisme of the previous KMT administration and at times illiberal behaviour have had an empowering effect on Taiwanese civil society throughout the last decade, with activists becoming stronger whenever the KMT was in power and weakening in visibility whenever the DPP has been ruling.

The latest administration, whose full effects and influences on both the environmental sphere as well as on civil society will be easier to gauge at the end of Tsai's tenure, has de facto incorporated several civil society actors who have been active in trying to change the system from the inside.

Even if civil society's visibility has diminished this does not automatically mean that activists are less effective or incapable of influencing the system. A less hostile relationship between such important groups, state and civil society, might actually represent a positive outcome, which would allow activists to achieve a transformation of the system from within. In fact, by appointing key technical figures in key positions of power of the environmental hierarchy, the DPP has shown good chances of achieving long-sought solutions to many environmental problems still affecting the country.

Those motivating factors, which brought people to vote for the DPP in the 2016 elections, such as transitional justice, fairness, inclusiveness, protection of disadvantaged groups and quality-of-life concerns, continue to be important issues among the general population. In the case of Taiwan, social inclusion and equality were not achieved through a redistribution of resources but rather an increase in purchasing power, new mass consumer lifestyles and a general intergenerational social upward mobility through the widening and proportional growth of the higher social classes. In the past few years due to saturation through mass consumerism and the limitations regarding upward mobility, the previously cohesive model of social inclusion and equality is beginning to crumble, while citizens demand for more justice and fairness in many areas.

Furthermore, in the case of Taiwan more than in other Asian states, the rise of a political and economic heavy weight such as Mainland China is increasingly disrupting and influencing Taiwan's internal dynamics, 
pushing its politicians to reposition themselves and their policies and raising questions of national identity and sovereignty. In practice these issues will make it more complicated for the current administration to be successful on all fronts.

However, at least on the environmental sphere, even though further and continuous monitoring is needed for a comprehensive evaluation when compared with the positive orientation and talk of goodwill by many legislators last year, in 2018 concrete plans for action were drafted and presented by the EPA (namely the revisions to the EIA) and achievements identified regarding the amendments to the Air Pollution Control Law.

Finally, when comparing what green activists have been able to achieve under the two different administrations studied in the present chapter, environmental movements during the second Ma tenure (2012-2016) managed to fulfil categories 3 and 4 (structural impacts, such as changes in institutions and alliance structures, and substantive impacts, such as closing a polluting plant or enacting new legislation) by changing and forming new political alliances (e.g. SDP-GPT) ${ }^{21}$ and by achieving the closure of polluting plants, most notably NPP-4 after the Sunflower Student Movement; and most notably categories 1 and 5 (sensitizing impacts, such as changing public agenda or public opinion, and political impacts on election results); these two categories are closely linked to each other as often by influencing public opinion one can consequently sway electoral results as happened during both the local (Nine in One) elections of 2014 as well as for the national (presidential) elections of 2016. In both cases the KMT suffered major losses with the DPP eventually gaining the country's presidency.

Two things radically changed thanks to the ability of impacting and changing public opinion on part of social movements: (1) popular opinion's stance towards both tighter relations with China and (2) public support of nuclear energy.

For both issues public support was quite high during the first Ma administration and became abruptly lower, thanks to social movements' campaigning efforts, during his second administration, leading to substantial policy changes (substantive impacts) and influencing elections (political impacts). However, regarding support for nuclear energy, the tide seems to have once again changed with the aforementioned referendum of 2018 .

The rise of anti-progressive movements and pro-nuclear activists in 2018, demanding to extend the operating limits and permits for several of the countries' reactors, originally planned to expire between 2019 and 2021 (Hioe 
2019b) has reinvigorated progressive civil society, with two demonstrations in April 2019 opposing nuclear energy.

Category 2 (procedural impacts), on the other hand, namely movement access to decision-making bodies, seems to have been taking place only when the DPP is in power with its opening of several privileged channels for social activists.

In fact, the DPP has consistently been open in inviting and including social activists in its ranks and in creating ad hoc committees for them to participate in; however, in the first two years of its administration the party had performed less than ideally in category 4 (substantive impacts), such as enacting new legislation and achieving more concrete actions. This has started to change with the aforementioned passing of the bill on air pollution and the revisions to the EIA during the first half of 2018 when the DPP achieved some concrete results.

Thus, so far, we can say that during the first two years of Tsai's term the relationship between DPP state and social activists was more cooperative and civil than with the previous administration but had remained nevertheless stuck at a more ideological level of theoretical commitment; however, precipitating concrete and real policy changes and other more substantive impacts, to be fair, needs time and while a few timid steps have been taken in this direction, a more balanced reading of the current achievements of the Tsai administration will be only possible after the end of her tenure.

\section{References}

Carter, Neil. 2007. The Politics of the Environment. Cambridge: Cambridge University Press.

Chen, Ketty W. 2017. 'This Is Your Land? This Is MY Land: Land Expropriation during the Ma Ying-jeou Administration and Implications for Social Movements.' Taiwan's Social Movements after Ma Ying-jeou. Dafydd Fell (ed.). London: Routledge, pp. 92-112.

Everington, Keoni. 2018. ‘Changes to Taiwan’s Air Pollution Law Aimed at 5 Million Two-stroke Scooters, “Old Cars.”' Taiwan News, 10 April. https://www.taiwannews. com.tw/en/news/3401915 (10 June 2019).

Fell, Dafydd. 2016. 'The Electoral Fortunes of Taiwan's Green Party: 1996-2012'. Japanese Journal of Political Science, 17 (1): 63-83.

Fell, Dafydd. 2017. 'Social Movements in Taiwan after 2008.' Taiwan's Social Movements after Ma Ying-jeou. Dafydd Fell (ed.). London: Routledge, pp. 1-17.

Grano, Simona A. 2015. Environmental Governance in Taiwan: A New Generation of Activists and Stakeholders. London: Routledge. 
Grano, Simona A. 2017. 'The Evolution of the Anti-nuclear Movement in Taiwan since 2008.' Taiwan's Social Movements under Ma Ying-jeou. Dafydd Fell (ed.). London: Routledge, pp. 154-176.

Haddad, Mary Alice. 2015. 'Paradoxes of Democratization: Environmental Politics in East Asia.' Routledge Handbook of East Asia and the Environment. Paul G. Harris; Graeme Lang (eds). New York: Routledge, pp. 86-104.

Hioe, Brian. 2019a. 'Nuclear Energy Likely to Reemerge as a Contested Issue Going into 2020 Elections.' New Bloom, 23 February. https://newbloommag. net/2019/02/23/nuclear-energy-2020/ (10 June 2019).

Hioe, Brian. 2019b. 'Ten Thousand Protest against Nuclear Power, Visits by Tsai and Lai at Demonstration.' New Bloom, 27 April. https://newbloommag.net/2019/04/27/ nuclear-demo-tsai-lai/ (10 June 2019).

Ho, Ming-sho. 2003. 'The Politics of Anti-nuclear Protest in Taiwan: A Case of Party-Dependent Movement (1980-200o).' Modern Asian Studies, 37 (3): 683-708.

Ho, Ming-sho. 2004. 'Contested Governance between Politics and Professionalism in Taiwan.' Journal of Contemporary Asia, 34 (2): 238-253.

Ho, Ming-sho. 2005a. 'Taiwan's State and Social Movements Under the DPP Government, 2000-2004.' Journal of East Asian Studies, 5: 401-425.

Ho, Ming-sho. 2005b. 'Weakened State and Social Movement: The Paradox of Taiwanese Environmental Politics After Power Transfer.' Journal of Contemporary China, 34(2): 339-352.

Ho, Ming-sho. 2014. 'The Fukushima Effect: Explaining the Resurgence of the Anti-nuclear Movement in Taiwan.' Environmental Politics, 23 (6): 965-983.

Ho, Ming-sho. 2019. Challenging Beijing's Mandate of Heaven: Taiwan's Sunflower Movement and Hong Kong's Umbrella Movement. Philadelphia: Temple University Press.

Ho, Ming-sho; Hsiu-hsin Lin (eds). 2011. Shehui Yundong de Shidai: Wanjin Ershinian lai de Taiwan Xingdong Zhuyi [The era of social movements: Taiwan's activism in the past two decades]. Taipei: Socio Publishing.

Ho, Ming-sho; Jyh-cherng Shieh. 2011. Baqing you Taiwan: Guoguang Shihua de Gushi [The eight naphtha crackers travels around Taiwan: Guoguang Shihua's story]. New Taipei City: Rive Gauche Publishing House.

Hsiao, Michael Hsin-Huang. 1999. 'Environmental movements in Taiwan' in Y. S. Lee and Y. So (eds.) Asia's Environmental Movements: Comparative Perspectives, Armonk, New York and London: M. E. Sharpe, pp. 31-54.

Jobin, Paul. 2010. 'Hazards and Protests in the "Green Silicon Island."' China Perspectives, 3: 47-62.

Kitschelt, Herbert P. 1986. 'Political Opportunity Structures and Political Protest: Anti-nuclear Movements in Four Democracies.' British Journal of Political Science, 16 (1): 57-85. 
Kriesi, Hanspeter. 1991. 'The Political Opportunity Structure of New Social Movements: Its Impact on Their Mobilization.' WZB Discussion Paper FS III 91-103. Berlin: WZB (Wissenschaftszentrum Berlin).

Lai, Pin-Yu. 2017. 'Huánpíng zǐ fă Gōng tīng 'Dūshì Tǔdì Miăn Huánpíng' Făntán dà Jiāng Cǎi Shāchē’ [The EIA sub-law public hearing 'Urban Land Exemption Assessment' rebounded]. Taiwan Environmental Information Center, 10 July. http://e-info.org.tw/node/206o83?utm_source=\%E7\%92\%Bo\%E5\%A2\%83 \%Е8\%B3\%87\%Е8\%A8\%8A\%Е9\%gB\%BB\%Е5\%AD\%go\%Е5\%Ao\%B1\&u tm_campaign=fe561ea141-EMAIL_CAMPAIGN\&utm_medium=email\&utm _ term=o_f99f939cdc-fe561ea141-84970577 (10 June 2019).

Lin, Chia-Nan. 2017a. 'Lai's Administration Could Restrict EPA's Reforms, Deputy Minister Says.' Taipei Times, 7 September. http://www.taipeitimes.com/News/ taiwan/archives/2017/09/07/2003677969 (10 June 2019).

Lin, Chia-Nan. 2017b. 'Lawyers Publish Draft EIA Rules.' Taipei Times, 5 June. http://www.taipeitimes.com/News/taiwan/archives/2017/06/05/2003671950 (10 June 2019).

Lin, Chia-Nan. 2018a. 'Lai Promised to Amend Law, EPA Deputy Head Says.' Taipei Times, 21 March. http://www.taipeitimes.com/News/taiwan/archives/ 2018/03/21/2003689726 (10 June 2019).

Lin, Hsiu-hsin; Rwei-ren Wu (eds). 2016. Zhaopo: Taiyanghua Yundong de Zhenfu, Congshen yu Jingyu [Shining through: The scope, depth and horizon of the Sunflower Movement]. Taipei: Rive Gauche Publishing.

Lin, Sean. 2018b. 'Lawmakers Pass Contentious Pollution Bill.' Taipei Times, 27 June. http://www.taipeitimes.com/News/taiwan/archives/2018/o6/27/2003695624 (10 June 2019).

Liu, Hwa-jen. 2015. Leverage of the Weak: Labor and Environmental Movements in Taiwan and South Korea. Minneapolis: University of Minnesota Press.

Lyons, David. 2009. 'The Two-headed Dragon: Environmental Policy and Progress Under Rising Democracy in Taiwan.' East Asia, 26 (1): 57-76

Our Island. 2017. Nengyuan Taiwan Qidong: Zhuanxing Zhi Lu [Renewable energies Taiwan: starting on the road of (energy) transformation]. Part A, 24 July.

Shu, Wei-der. 2011. 'Taiwan Shehui Yundong Yanjiu de Lishi Kaocha' [A historical investigation of Taiwan's social movement study]. Shehui Yundong de Shidai: Wanjin Ershinian lai de Taiwan Xingdong Zhuyi. Ming-sho Ho; Hsiu-hsin Lin (eds). Taipei: Socio Publishing, pp. 449-519.

Taipei Times. 2017. 'The Liberty Times Editorial: EIA Reform Needs Rational Debate.' 11 June. http://www.taipeitimes.com/News/editorials/archives/ 2017/06/11/2003672320 (11 June 2019).

Tang, Ching-Ping. 2001. 'Democratic Governance and Environmental Protection' (minzhu zhiliyu huanjing baohu). Taiwanese Political Science Periodical, 5: 178-217. 
Tang, Shui-yan and Tang Ching-Ping. 1997. 'Democratization and Environmental Politics in Taiwan.'Asian Survey, 37 (3): 281-294.

Tarrow, Sidney. 1994. Power in Movement: Social Movements, Collective Action and Politics. Cambridge: Cambridge University Press.

Wu, Je-Ming. 1990. Social Protests During the Period of Transformation of Taiwan's Political Regime. (In Chinese). Master Thesis, Graduate Institute of Political Science, National Taiwan University.

\section{Interviews}

Interview Chan 2016. Shun-kuei Chan, Vice-Minister of the Environmental Protection Administration, September 2016.

Interview Chan 2017. Shun-kuei Chan, Vice-Minister of the Environmental Protection Administration, follow-up communication via Facebook, 15 August 2017.

Interview Chan 2018. Shun-kuei Chan, Former Vice-Minister of the Environmental Protection Administration, follow-up communication via Facebook, December 2018.

Interview Chen 2016. Man-li Chen, Legislator in charge of environmental protection, ecology and renewable energies, 13 September 2016.

Interview Ho 2016. Ming-sho Ho, Professor at the Department of Sociology at National Taiwan University, 13 September 2016.

Interview Tsai 2016. Pei-Hui Frida Tsai, Legislator in charge of land-related issues, 14 September 2016.

Interview Tsui 2016. Su-Hsin Tsui, Secretary General of Green Citizens Action Alliance, 21 September 2016.

Interview Tsui 2018. Su-Hsin Tsui, Secretary General of Green Citizens Action Alliance, communication via Facebook, 21 March 2018.

Interview Wu 2016. Kuen-Yu Wu, Legislator in charge of Food Safety and Public Health, 11 September 2016.

Interview Zhang 2016. Yuyin Zhang, Lawyer at the Environmental Jurists' Association, 22 September 2016.

Interview Zhang 2017. Yuyin Zhang, Lawyer at the Environmental Jurists' Association, communication via email, 4 July 2017.

\section{About the Author}

Simona AlBA Grano is Senior Lecturer at the Institute of Asian and Oriental Studies at the University of Zürich, Switzerland. She is also a research fellow of the European Research Center on Contemporary Taiwan (ERCCT), at 
Tübingen, Germany. She has authored several book chapters and articles dealing with environmental and anti-nuclear concerns in East Asia over the past few years. In 2016 she guest edited a special number of China Information on the topic of 'environmental governance in China,' which includes articles on environmental rules and regulations by renowned China specialists. Her latest book as a single author is Environmental Governance in Taiwan: A New Generation of Activists and Stakeholders (Routledge, 2015), which analyses environmental governance mechanisms and actors in Taiwan through a multidisciplinary research approach. 


\title{
3 Working with and around Strong States
}

\author{
Environmental Networks in East Asia
}

Mary Alice Haddad

\begin{abstract}
East Asia is a region dominated by developmental states that favour business and constrain advocacy organizations, yet Japan has been leading the world in emissions standards for decades, China has recently become the world's largest producer of photovoltaic panels and a world leader in renewable energy, and Korea and Taiwan have both embarked on major green initiatives that involve green business development, the creation of national parks, widespread energy conservation and comprehensive recycling efforts. This chapter discusses environmental organizations' networking strategies to find allies within governmental and business echelons in order to affect pro-environmental changes. Focusing on the issue area of the environment, it argues that non-profit organizations play important roles in developing the coordinating networks that facilitate policymaking in challenging and diverse political contexts.
\end{abstract}

Keywords: China, Japan, East Asia, civil society, non-profit organizations, networks, environmental policy

East Asia is a region characterized by developmental states that have prioritized economic growth and worked closely with business interests in order to create the world's most vibrant economic region. The region's rapid economic growth has come at a terrible environmental and social cost as intense pollution spread in the wake of rapid industrialization. First in Japan, then in the 'Asian Tigers' of South Korea and Taiwan, and most recently in the much larger China, citizens in each place have organized and successfully demanded relief. In East Asia today, whether they are located

Chiavacci, David, Simona Grano, and Julia Obinger (eds), Civil Society and the State in Democratic East Asia: Between Entanglement and Contention in Post High Growth. Amsterdam, Amsterdam University Press 2020 DOI: $10.5117 / 9789463723930 \_C H 03$ 
in China, Japan, South Korea or Taiwan, environmental organizations have found creative ways to work with and around their governments. The result is a region containing a political paradox: strong, pro-business governments that promote extensive environmental policies.

This chapter aims to shed light on one explanation for this paradox organizational networks. As one of their most effective responses to working within a political context of strong states, environmental organizations in the region have created policy-relevant networks that simultaneously work with and around their states. Through these networks, both formal and informal, environmental activists in the region have found ways to leverage their scarce resources by sharing information and coordinating their advocacy efforts. They are able to pilot new projects and disseminate best practices. Finally, and perhaps most importantly, they are able to utilize these networks to cultivate and empower allies inside the government at both the local and national levels.

The patterns and behaviour of these networks and their members help us understand not only how citizens in East Asia have fundamentally transformed the growth-first politics of the earlier developmental state period, the focus of this volume, but also how citizens more broadly can be effective actors even in hostile and diverse political contexts. Environmental advocacy in East Asia is a 'hard case' for political advocacy. The political, legal, and social environment in which these advocates operate is especially hostile, so their ability to influence policy is particularly impressive. Thus, environmental advocates in East Asia can offer models of success that should be useful to activists everywhere.

\section{A Brief History of Environmental Politics in East Asia}

Across East Asia the environment was one of the first issue areas around which citizens in the region were able to organize politically and made successful demands of their states. Environmental activism across the region followed directly from pollution caused by rapid industrialization residents living near industrial facilities found their health and livelihoods threatened by polluting companies and demanded redress. In all cases this activism began in non-democratic political contexts, although it has matured, diversified and strengthened over time.

Environmental advocacy in the region began in Japan, which was the first country to industrialize. As in all countries, initial efforts took on the classic NIMBY (Not In My Back Yard) form, where local residents protested 
the pollution of a particular industrial plant that was polluting their community - these early advocates were not part of any national movement, they did not promote broader ideological goals, and they were not members of the elite. East Asia's first environmental advocates, in all cases, were farmers and fishermen who saw their children die, their wives get sick, and their crop and fishing yields collapse. Under Confucian political philosophy, a core political and social tenant shared by all the societies in the region, individuals are entitled to the right of subsistence, and governments lose their legitimacy if that right is threatened (Tu 1998, 1999). As a result, the states in the region have recognized that failing to deal with the environmental challenges constitutes an existential threat.

Japan's earliest environmental advocates were located in small, rural mining towns - the Ashio mine in Tochigi prefecture, Sumitomo's mine in Ehime and Hitachi's mine in Ibaraki. When industrial production exploded in the 1880 s, residents quickly found that the sulphur and other heavy metals emitted from the smokestacks was polluting the soil and nearby streams, decimating crop and fishing yields, and causing serious health problems for residents. Although culpability was initially denied, company and government officials found a technical solution to the problem (higher smokestacks) by the early 1900 s and compensated victims, so protests disappeared (McKean 1981). The next set of environmental protests erupted as pollution spread as a result of Japan's next surge - industrial expansion in the 1950s. In the 1960s, communities like Minamata rose up and demanded that the government force companies to halt their polluting practices. By then Japan had democratic institutions, so these victims were able to take perpetrators to court, and Liberal Democratic Party (LDP) leaders were pressured as citizens across the country voted opposition party candidates into city and prefectural government offices (McKean 1981; Upham 1987). By 1970 the LDP in Tokyo was feeling the pressure and worked closely with industry to get ahead of the rising citizen discontent, eventually passing such extensive environmental legislation that the 1970 Diet came to be known as the Pollution Diet. The ambitious emission goals set Japan on a course to become a global leader in environmental policy and Japanese firms on route to market leadership in green technology.

For South Korea and Taiwan, the period of industrial expansion occurred two decades later, so their environmental protests began in the 1980s. Unlike in Japan, which was able to resolve the disputes without significant political change, South Korea and Taiwan's environmental movement merged with the pro-democracy movements in both countries. Advocates had recognized that the core problem was related to governance - the close 
government-business relationship of their authoritarian governments was not prioritizing the needs of the people in their policies. Unlike in Japan, the ruling party and business in South Korea and Taiwan were not able to get ahead of the problem, and both countries saw their decades-old military rule overthrown by peaceful democratic/environmental populist movements by the end of the decade (Lee 2000; Ku 2011; Reardon-Anderson 1997).

In China, the story is just now unfolding. China's industrial expansion exploded with its admission into the World Trade Organization in 2001. By mid-decade China's environmental problems were starting to become a concern globally (Economy 2004), and by the end of the decade environmental protests were spreading across the country as citizens in small rural communities as well as giant cosmopolitan cities were demanding that the government address their pollution problems (Economy 2011). Now, China is actively seeking to follow the Japanese model whereby the single ruling party works with business to get ahead of the problem, rather than the Taiwanese and South Korean path in which they fail to do so and end up out of power (Haddad 2015).

In all four countries, and indeed in much of the world, there has been a dramatic expansion in environmental organizations and advocacy in the last two decades as a result of the expansion of the global environmental movement and the spread of information technology, which has significantly sped the rate of information transfer and facilitated the creation and maintenance of organizational networks. A few pivotal events helped spur this growth. The 1992 establishment of the UN Framework Convention on Climate Change during the Earth Summit in Rio raised the prominence of climate change, inspiring many countries and activists to push for the creation of national and local plans to adapt and mitigate its effects (Keck and Sikkink 1998).

These initial efforts were strengthened in the 1998 Kyoto Protocol, which established legally binding obligations for countries that ratified it. The East Asian location of that 1997 Conference of Parties ensured record-braking NGO participation, and the beginning of many national and regional environmental networks in East Asia (Reimann 2003; Cheng 2014; Lee 2013; Tiberghien and Schreurs 2007). The Olympic Games have also offered symbolic and commercial opportunities for the national governments of China (Beijing, 2008), South Korea (Pyeongchang, 2018), and Tokyo (2020) to compete for the 'greenest' Olympics.

Even more than crafted political opportunities, the planet itself has forced everyone in the region - businesses, governments, and citizens - to acknowledge the deadly effects of climate change. Typhoons (Mei and Xie 
2016), river and coastal flooding (Arnell and Gosling 2016), and droughts and dust storms (Zhang and Zhou 2015) have all increased their scope, frequency, and intensity in recent years. By far the single most politically influential disaster in the region was the Triple Disaster (earthquake, tsunami, and nuclear disaster) on 11 March 2011 in Tohoku, Japan (Samuels 2013). The nuclear meltdown in Fukushima focused global attention on the unsustainability of current energy consumption patterns as well as the political corruption that has supported those energy systems. The Fukushima disaster reinvigorated anti-nuclear movements around the region (Grano 2015; Aldrich 2012; Chiavacci and Obinger 2018; Harris and Lang 2015), some of which combined with other social and political movements targeting pro-business governments (Ho 2019; Harris and Lang 2015).

Whether spurred by industrial pollution, political opportunism, natural disasters or artistic inspiration, all of the chapters in this volume document East Asia's rising civic activism. In democratic and non-democratic states alike, we have seen a common pattern of pro-business developmental states engage in policies that rapidly expanded industrial development with horrific environmental consequences, generating widespread civic protests that result from the threats to life and livelihood caused by pollution, and governments are responding to citizen demands. However, although activism is rising, repression is rising, too. In China, advocates are frequently jailed when they become too outspoken (Radio Free Asia 2016). In South Korea, political lobbying is illegal, and Japan's free press is being repressed by a hostile administration (Fackler 2016, 2017).

Nevertheless, citizens across the region are working with and against their governments to promote a better environment for their communities and the world (Harris and Lang 2015). The remainder of this chapter will examine one way in which organizations are pursuing this goal - networking with other organizations to assist and pressure governments to develop and implement better policies.

\section{Methodology}

This chapter emerges from an inductive examination of advocacy in East Asia working in the environmental policy realm. As part of a broader project that investigates multiple advocacy strategies, this chapter examines the behaviour of environmental organizations and the networks that they create in order to generate insights into the patterns of network formation and the effects of those networks on policymaking and outcomes. It is 
particularly interested in broader insights that can be gained concerning civic activism across political regime types that might be applicable in other parts of the world.

The research presented here is based on two primary sources: five months of fieldwork in East Asia and an original database of environmental organizations in the region. I conducted research trips to Beijing, Seoul, and Taipei in 2010, with trips to Tokyo and Beijing in 2011 and 2015. The bulk of the research presented here was gathered from interviews conducted with nearly a hundred advocates, journalists, government officials, business people, grassroots volunteers and academics. In each city I reached out to environmental policymakers inside and outside of government as well as grassroots advocates and artists. I used a combination of cold contacts and snowball-type sampling to gather a diverse a range of advocates and policymakers.

The typology of networks was conceptualized by the author after analysing the processes through which advocates sought to influence policymakers as they worked to craft environmental policy in their own localities and countries. Through a close examination of the interactions of advocates and policymakers, the flow of financing to non-governmental organizations, policy tracing from problem definition through policy formation and execution, the author was able to identify patterns in the formal and informal networks among advocates and policymakers.

The examples given below are chosen because they offer good illustrations of the typologies conceptualized. Because all of these data were collected as part of an inductive research process, none of the evidence presented here is intended to test any particular hypothesis or theory. Rather, the cases here are introduced to begin to develop a better theory about how civic organizations in challenging and diverse settings can work with one another to collaborate and pressure governments to change policy.

\section{Typology of Environmental Networks in East Asia}

This section will describe three types of networks that environmental advocates create in order to promote pro-environmental policy and behaviour change: (1) hub-and-spoke networks, in which a non-profit creates a 'hub' that connects smaller organizations to one another around a policy area; (2) horizontal networks in which the non-profits facilitate the connection of a wide variety of actors - governmental, non-profit, and private - to one another; (3) vertical networks in which the non-profits connect local and 
central government officials in ways designed to enhance the political power of pro-environmental officials in their negotiations with other parts of their own government.

The key features of all three types of networks is that they bring diverse sets of people together in ways that help promote the development of long-term personal relationships that can facilitate formal and informal collaboration related to policymaking and implementation. All three types of networks can be found across all the places in East Asia and, I suspect, across the world. The examples are drawn from different countries rather than a single country in order to help the reader understand that the types of networks are found all over. The types of networks as conceptualized are neither country nor region specific.

\section{Hub-and-Spoke Network: Non-profit Organization as Funder/ Coordinator}

A hub-and-spoke network is one where a single organization forms the 'hub' though which other individual and organizational 'spokes' connect. The 'spokes' often have very little way to connect to the other 'spokes' except through the hub. A key characteristic of the hub-and-spoke networks in East Asia (and likely elsewhere) is that they hub organizations are often GONGOs (government-organized non-governmental organizations) (Hasmath et al. 2019). GONGOs are frequently established with government funds, receive most of their income from the government and are led by former government officials. This means that facilitating government-NGO coordination and collaboration is core to their mission, in contrast to advocacy NGOs, which have a mission that does not presume government collaboration. Thus, one of the most important roles of these 'hub' organizations is to help serve as a channel from the NGO community to governmental policymakers.

A hub-and-spoke network can be created in a number of different ways, and I will discuss two distinct variations here. The first is one is hub-asfunder, where the network is formally institutionalized with a funding organization located at the centre of the network and member/recipient organizations joining that network. The power of the groups is very hierarchical in this arrangement - the funder has the money and the recipient organizations are the ones implementing the environmental agendas, but they are dependent on the funding organization. In this model the hub organization is usually set up to be the primary means through which the member organizations can access policymakers. 
A second model is hub-as-organizer. In this model, the hub organization creates opportunities for members to come together and connect with relevant policymakers. Similar to the first type, there would often be little opportunity for members to connect without the assistance of the hub. However, in this model the hub organization rarely funds the members directly but merely introduces them to one another and may also introduce them to funders. Similarly, the member organizations are usually highly diverse in their power/resources, so the network is a highly heterogeneous and relatively un-hierarchical type of network, in contrast to the hub-asfunder model. In this model, governmental organizations and funders are often members themselves. Thus, the hub organization serves more a role of matchmaker to help the funders, policymakers and relevant governmental organizations/people meet each other rather than creating an arrangement where the NGO groups have to go through the 'hub' organization in order to access policymakers or funders. In some cases, once introduced, 'spoke' organizations are able to break off and form new networks of their own.

\section{Hub-as-Funder}

Perhaps the most archetypical hub-as-funder network that I found in my research was created by the China Association for NGO Cooperation (CANGO), which is a GONGO operating in Beijing whose main mission is to promote the development and support of NGOs in China. CANGO has a strong focus on environment and sustainable development. Like its counterparts elsewhere in the region, it seeks to build and sustain networks that will enhance the capacity for environmental organizations in China.

One of the main ways it promotes environmental agendas is by funnelling money that is collected from foreign organizations to local NGOs. Indeed, CANGO was originally the China International Technology and Cooperation Exchange Organization, which was the branch of the Chinese government that helped implement official development assistance (ODA) that was given to China by foreign governments. When the pattern of international aid shifted such that (a) aid was often given directly to organizations rather than going through the government, and (b) donations often came from international NGOs rather than foreign governments, CANGO broke off from the official implementing agency to form its own NGO in 1992, although it retains very strong ties to the government.

Most non-profit organizations in China (and most places in the world) tend to be very small, with few if any professional staff. As a result, their capacity to design and implement projects as well as to find funding for 
those projects is extremely limited. CANGO helps increase the capacity of these groups through a variety of capacity-building initiatives, including workshops on fundraising, budgeting, etc. It works with multiple organizations by helping them with project development, implementation, and assessment.

For example, the Green Commuting Network was formed in 2007 to connect Chinese NGOs that were working to develop more environmentally sustainable commuting behaviour, and by 2009 the network included 20 NGOs from across the country. Members of the network promote green commuting campaigns, participate in annual conferences and take part in volunteer management workshops. The Green Commuting Network also engaged in research, gathering commuting data in seven cities in 2011. Separate but concurrent with the Green Commuting Network, CANGO established a Green Commuting Fund in 2009. The fund helps support green commuting initiatives around the country and also enabled the first voluntary domestic carbon credit trading in China. ${ }^{1}$

It should be noted that international organizations can also form these types of hub-as-funder networks around a local branch office or a particular project. In these networks the international organization acts as the hub-as-funder, and the participating local NGOs participate in codevelopment and project implementation. Examples include the Yangtze Wetland Conservation Network (where the hub was WWF China and local NGOs form the spokes).

\section{Hub-as-Coordinator}

The organization that perhaps best exemplifies how to create networks where the hub organization performs a coordinator role is the Institute for Global Environmental Strategies (IGES), which is based in Kanagawa with branch/affiliated units in Tokyo, Kansai and Kitakyushu within Japan as well as in Beijing, Bangkok and New Delhi. It was formed in 1998 as part of an initiative of the Japanese government. Its mission is to conduct 'practical and innovative research for realizing sustainable development in the Asia-Pacific region.'2 To this end it has seven different research themes ranging from climate and energy to sustainable cities. Each of the

1 For more about these initiatives, see CANGO's annual reports, http://www.cango.org/ upload/files/Annual\%2oReport\%202013.pdf (24 February 2018).

2 See the 'About Us' page on the IGES website, http://www.iges.or.jp/en/outline/index.html (24 February 2018). 
focal themes has a team of in-house and external researchers working on particular projects, and they publish policy reports and working papers with titles such as 'Designing Adaptation Finance for the Green Climate Fund: Challenges and Opportunities Drawn from Existing Multilateral Funds for Adaptation.'3

In addition to their research and policy participation, IGES is very active in facilitating peer-to-peer learning and dissemination of best practices across the region. Through its regional centres it hosts events that bring together a wide range of different types of participants that are all concerned with particular issues. For example, the annual High Level Seminar on Environmentally Sustainable Cities brings together local municipal leaders with direct experience developing and implementing environmental policy at a local level (e.g. sanitation district heads, transportation office directors, and mayors), NGO activists working on these issues in the region, academics and also funding agencies (e.g. JICA, the organization that disburses most of Japan's development aid).

There are several important characteristics to notice about the networks that IGES helps to form and maintain:

- Members of the network come from all sectors of the economy: non-profit, for-profit, government, academic, etc.

- The connections formed with one another are generally informal. Some of the networks are membership based and have requirements for participation, but most do not.

- The power structure of the network is horizontal - despite the very different levels of power and resources among the participants in the network, each has relatively equal membership status and participates on an equal basis for the most part.

- The coordinating organization - IGES - is not a primary funder of the organizations in the network. For the most part, IGES finances the network itself, helps maintain communication, hosts conferences, etc., but it does not generally give funding to member organizations to carry on their missions.

This last point is a very important one. Funding organizations, for example, Japan International Cooperation Agency (JICA), frequently participate in the networks that involved international groups, and the events create the opportunity for organizations and governments seeking funding to solicit 
funds and pitch proposals. However, IGES does not itself offer members funding, so it is able to serve as an impartial coordinator and facilitator, significantly reducing the power asymmetry that would exist if it were serving as both coordinator and funder of its members.

\section{Horizontal Network: Fluid, Web-like Networks with No Centre}

Because environmental organizations are frequently all-volunteer or have very few professional staff, they form networks in order to increase their capacity to carry out projects and also to advocate for policy change. These types of networks are usually characterized by their high level of flexibility - it is easy to join and easy to leave. It is easy to remain connected but not active, or to shift from being not particularly active to highly active and then back to not very active again. Networks are a method to connect with like-minded individuals and organizations. Networks can also provide political cover for individual organizations that may be engaged in work that is controversial or challenges the status quo, since it is the network that is taking the action, not any particular organization.

Horizontal networks can be as informal as an email list set up after a conference or as formal as an organization with annual dues. They are highly diverse in form, but, as with the above, I will highlight two distinct types below: event-focused networks and issue-focused networks. The key characteristic of the first type is that they are short-term, focused on creating a network of individuals and organizations to ease coordination around a particular event. After the event, it may be that the network re-forms with a different purpose and continues to expand. More frequently, the network disbands after the event, although once it has formed, it is relatively easy to reactive or re-engage the participants in order to support other events in the future. The key characteristic of the second type of network is that the members are drawn together because of interest in a particular issue.

\section{Event-Focused Networks}

Perhaps one of the best-known environmental NGOs in Japan is the Kiko Network (Kiko Nettowaku - kikō is the Japanese word for 'climate'). It began as a horizontal event-focused network, the Kiko Forum, which grew and eventually institutionalized into an issue-focused network organization. Since 1995, the United Nations Framework Convention on Climate Change has held annual Conferences of the Parties (COP) meetings. The third of these $\left(\mathrm{COP}_{3}\right)$ was held in December 1997 and was the conference that first 
adopted the Kyoto Protocol. In the late 1990s, it was not yet standard practice to hold a 'shadow' conference that gathered the NGO community together at the same time as governmental leaders were also meeting. Kiko Forum's efforts to mobilize the NGO community prior to the $\mathrm{COP}_{3}$ meetings in Kyoto contributed to the creation of the 'meetings in conjunction' that has now become standard practice with all of the major intergovernmental conferences (e.g. COP, G8, WTO etc.).

Starting in early 1997, the Kiko Forum began mobilizing the NGO community both within Japan and around the world to connect the organizations working on environmental issues to share information, arrange meetings, and raise public awareness prior to and during the $\mathrm{COP}_{3}$ meetings in Kyoto. It was very successful, not only enabling the NGO community to participate actively in the $\mathrm{COP}_{3}$ meetings, but also by establishing a model that other groups could follow. Following the meeting, the Kiko Forum disbanded and formed a more permanent NGO, called Kiko Network, or Kiko-Net. ${ }^{4}$ Although it is now a registered non-profit, it remains very small by international standards. Although it has a membership of about 700 organizations, it has only about ten staff members - six in Kyoto and four in Tokyo (Reimann 2003).

More typical than event-based networks that institutionalize into their own organizations are networks that form around particular events and then disband when the event is over. One example from China is the group of NGOs that networked together to promote the 26 Degree campaign, which began in Beijing in 2004. This campaign aimed to get everyone, but particularly large hotels and businesses, to keep their air conditioners set to 26 (as opposed to 22 or 20 ) degrees in the summer. Partnering with a number of international NGOs with offices in Beijing (e.g. WWF), a group of local Chinese environmental groups (including Global Village of Beijing, Green Earth Volunteers and Friends of Nature) got together to run a very successful campaign that not only raised public awareness in Beijing, but also resulted in significant carbon emissions savings, and, ultimately, a shift in local and national public policy that required government offices to keep their air conditioners set at or above 26 degrees, and set that temperature as the standard for hotels, restaurants, and office buildings. The network that they formed was significantly based on the personal network already existing among the leaders of these groups, and it remained ad hoc, dissolving once the campaign finished.

4 Koko Network homepage (in Japanese, English page also available, http://www.kikonet. org/ (24 February 2018). 


\section{Issue-Focused Networks}

Issue-focused networks bring together lose associations of organizations which have similar interests. The issue might be air pollution, garbage, fisheries management, etc. Many of the most enduring of these networks are organized around rivers. Rivers are themselves network systems, so perhaps it is only natural that organizations located in different towns and cities along the same river, even if they are in different countries, frequently form networks among their organizations.

Sometimes these networks seek to join together multiple organizations and local governments to mobilize support for changes in national policy (see Waley 2005). More frequently, they are focused on local environmental issues, and use their network connections to gain support to fight their local NIMBY (Not In My Back Yard) battles (Litzinger 2007). Grano's chapter in this volume shows how these local NIMBY fights can grow to form national political movements, and Weiss's chapter demonstrates how networks of organizations with different issue foci (e.g. women's rights and environment) can combine to demand political change from the ruling party.

A successful example of an issue-focused network that transformed into a national non-profit organization is Wetlands Taiwan. The organization originated in the mid-1990s from a grassroots NIMBY battle against the expansion of the Tainan Industrial Park on Taiwan's south-eastern coast. As similar NIMBY battles were fought across the country against the expansion of industrial parks and the degradation of the surrounding environment, similar efforts in other localities joined together. Now Wetlands Taiwan is a network of regional associations which focus on protecting particular wetlands. While the Tainan association remains the strongest (the organization's headquarters is there), the other associations and the national network work closely with local residents, local organizations, local and national governments on conservation issues. They disseminate relevant local and international news pertaining to wetland conservation, host lectures, organize activities such as bird watching tours inside the protected areas, and work with local and national policymakers on issues related to wetlands conservation.

\section{Vertical Networks}

When NGOs form vertical networks, they are frequently acting as a matchmaker or policy broker, introducing lower-level bureaucrats to higherlevel bureaucrats, connecting local governments to corporate investors, or 
enabling civil servants to encounter international actors that the lower-level policymakers would otherwise have no way to meet. In some ways the relationship is somewhat similar to the hub-and-spoke model above, but in these models (a) the 'spokes' have very different status and power, and (b) the NGO/GONGO does not remain the hub, but rather uses its network to facilitate new relationships among actors that might not have been previously connected. Once the new links are made, the NGO will remain connected to all parties, but it will usually step back, enabling the 'spokes' to create the architecture and purpose of the new, policy-relevant network.

The largest environmental organization in East Asia is the Korea Federation for Environmental Movements (KFEM). It has 80,000 members and 52 regional organizations. It was intimately involved with Korea's democratization movement (Kim 2000; Ku 2011; Lee et al. 1999), and has been active in the global environmental movement since its inception. It is active in a wide range of environmental issues, and its federated organizational structure, combined with its five specialized institutions (including a research institute and a legal assistance centre) enable it to connect local concerns directly with allies in the national government and international environmental organizations. Sometimes this is done with a specific purpose in mind - such as blocking the Saemangeum project component of the Four Major River Project. In other cases, the organizations work to connect relevant actors together around issues of concern, such as food safety. The goal in these cases is not necessarily to influence policy directly, but rather to facilitate favourable change by connecting policy actors that might have difficulty finding one another together (Interview KFEM 2011; Ku 2011; Lee 2000).

\section{Modes of Network Advocacy}

The three types of networks described above - hub-and-spoke, horizontal, and vertical - are the formal and informal institutional structures that facilitate network advocacy. Each of the actors within the network engage in their own advocacy efforts independently - for example, lobbying legislators, engaging in public protests, legal advocacy, writing policy papers, grassroots education, cultivating connections with policymakers, etc.

However, the policy-relevant networks that the NGOs have created are not merely the sum of these individual actors' efforts. I am arguing here that the networks themselves exert a somewhat independent, or more precisely, interdependent effect on the policymaking process. In particular, these networks help interested policymakers work around institutional 
collective action problems. As a result, the networks can have a catalytic effect on other forms of advocacy. This section attempts to describe three effects that the networks exert on policy: information exchange, ally empowerment and citizen engagement. In all cases, the central feature of the network's effectiveness in influencing policy is the ways that it is able to reduce the institutional collective action problems found in environmental policymaking.

\section{Information Catalyst: Easing Coordination Problems and Lowering Transaction Costs}

The networks described above act as a catalyst for policy-relevant knowledge creation and dissemination. As mentioned above, the environmental organizations in East Asia are miniscule compared to their counterparts in North America and Europe. For example, in 2017 The Nature Conservancy (founded in 1915) reported total net assets of $\$ 6.2$ billion, gained $\$ 1.1$ billion in revenue, carried out 472,79o conservation activities and events, and had 46,650 members and 3,500 fulltime staff. The Nature Conservancy has permanent offices in 50 US states and 29 additional countries. In 2017 it was involved in projects located in 72 different countries around the world (The Nature Conservancy 2018).

In contrast, one of the oldest and largest environmental organizations in East Asia is the Wild Bird Society of Japan. While it is almost as old (founded in 1934) and has similar membership levels $(45,000)$ as The Nature Conservancy, it is a tiny fraction of its size and influence. The Wild Bird Society of Japan has only seven regional branches inside Japan with no international offices and just \$1o million in income (Wild Bird Society Japan 2018 ) - in other words, fewer than $10 \%$ of the offices and $1 \%$ of the income as compared to The Nature Conservancy. And, The Wild Bird Society is one of the biggest environmental groups in the region. The vast majority of environmental organizations in East Asia depend largely on volunteer labour and have fewer than ten staff members (Haddad 2017).

As a result of their comparatively small size and low level of professionalization, East Asia's environmental organizations do not have the resources individually to (a) figure out which knowledge is the most policy relevant, (b) generate that knowledge, and (c) disseminate the new knowledge to relevant policymakers. Additionally, bureaucratic structures often put up barriers between different ministries and between central government and local government officials. Finally, all actors - governmental, NGO and private - have limited resources. Without these networks, all of the policy 
actors are forced to work rather independently - trying to identify relevant problems, generating policy solutions, testing those solutions, and then disseminating best practices. Without the networks, these actors cannot be very efficient. Limited resources mean that no single actor can do much. Limited coordination results in both redundancies in efforts and gaps in coverage. Limited exchange slows the adoption of policies and practices that work, even once they have been developed and refined.

NGO-generated networks can help policy-relevant actors work around institutional barriers to be significantly more efficient in the way that they deploy resources to generate new policy-relevant knowledge and then disseminate that knowledge once it has been created. There are numerous areas of environmental policymaking where this can be seen, but perhaps the most obvious is the ability to find relevant sites to conduct local pilot projects and then enable the results of those pilot projects to be disseminated to others - national government policymakers within the same country, local governments in foreign countries or international NGOs that can spread the information to governments and environmental organizations around the world. These networks enable peerto-peer knowledge generation and sharing in ways that would be impossible, or at least significantly more difficult, without the networks.

The KitaQ System Composting 5 is an excellent example of how one environmental GONGO worked with a variety of actors governments to (a) identify a good pilot site, (b) carry out the pilot project, (c) facilitate peer-to-peer learning about the pilot, (d) replicate the pilot project elsewhere, and (e) disseminate information about the successful project for widespread adaptation - currently eleven cities in five countries.

The composting project began in Kitakyushu, Japan, as part of the city's efforts to reduce household solid waste. Working with experts from the local university and city residents, and funded by the local and national governments, activists and city officials developed an urban-friendly composting system that they thought was replicable. The Institute for Global Environmental Strategies, a Japanese GONGO with a branch office in Kitakyushu, with funding and assistance from the Japan International Cooperation Agency, facilitated a connection between the officials in Kitakyushu and Pusdakota, a local environmental NGO located in Surabaya, Indonesia. The project was piloted from 2005 to -2007. Over the course of the period, the city, with a population of three million, saw a reduction of 350 tons $(23 \%)$ in the solid waste collected annually. There was also a dramatic improvement in the hygiene and aesthetics of the city streets as abandoned lots were 
transformed from informal garbage dumps to public green spaces that utilized the compost generated for gardening. Through the activities of the city, IGES, local NGOs and additional corporate sponsors, the composting system has now spread to nineteen additional communities. ${ }^{6}$ IGES (in collaboration with others) continues to develop policy tools for easy implementation by other municipalities as well as hosting conferences that are specifically designed to bring together communities with experience in the system and those that are thinking about implementing it. ${ }^{7}$

It would be tempting to ascribe the success of the KitaQ System Composting to IGES exclusively. There are ways that the experience of developing, refining and disseminating the system could be seen as analogous to the process followed by most development programmes emerging from large development banks such as the World Bank or the Asian Development Bank. I would like to argue here, though, that while IGES and the Kitakyushu city government were important actors, utilizing the advocacy strategies commonly used for policy advocacy - for example, pilot projects, policy papers, public information sessions, press coverage, engagement with local leaders, etc. - the network created by IGES exerted a somewhat independent catalytic effect on the outcome. The network dramatically expanded the number of communities considering adopting this policy solution; communities that would never have been reached by IGES or Kitakyushu without the network that they had created.

Furthermore, the network created a comprehensive policy feedback loop that enabled the piloted composting system to be refined, tested in new areas, further refined, etc. by multiple communities at the same time. Finally, most of the people involved in the programme were ordinary citizens volunteering their time. They were supported by a small number of paid staff at the NGOs, local government offices and national development agencies, but most of the people who were engaged in developing, implementing, refining and disseminating the projects were volunteers.

The network acted as a catalyst for information exchange by increasing (a) the number of actors involved, (b) the quantity and quality of feedback about the system and policy implementation, and (c) the scope of further dissemination. The network was not just an add-on or a communication method; it took on a life of its own and acted in ways that was more than the sum of its component parts.

6 See the Surabaya case study, http://kitakyushu.iges.or.jp/publication/Takakura/Surabaya_Experience_Full.pdf (15 May 2017).

7 See the IGES composting page, http://www.iges.or.jp/en/archive/kuc/compost.html (15 May 2017). 
An important feature of the networks created by these NGOs is the way that they continue to grow in unexpected ways, which are often complementary to the original policy goal. In October 2015 the cities of Kitakyushu and Haiphong, Vietnam, became one of three pioneering twinning cities to collaborate in a City-to-City Cooperation $\left(\mathrm{C}_{3}\right)$ programme sponsored by the international NGO Clean Air Asia to reduce air pollution. ${ }^{8}$ Where did this seemingly odd partnership originate? Perhaps at the Networking Meeting for Local Governments: Creating Low-Carbon and Sustainable Cities sponsored by IGES and held in Siem Reap, Cambodia, in March 2012. At that meeting IGES staff presented information about the Surabaya composting pilot, where both the NGO Clean Air Asia and representatives from Haiphong were participants. In 2014 Nippon Steel, Sumikin Engineering, Amita, and NTT Data Institute Management Consulting presented a low-carbon development plan for Haiphong, which was modelled on the Surabayu example. ${ }^{9}$ That same year Kitakyushu and Haiphong formalized a sister city relationship. ${ }^{10}$ One year later the two cities were collaborating on clean air initiatives, branching out into and expanding an entirely different NGO-facilitated network. They went from composting to clean air in the space of three years. Allies expanded from a couple of NGOs and two local governments to additional international NGOs, several national funding agencies and numerous corporations from both countries.

\section{Empower Allies: Overcome Bureaucratic Barriers and Furnish Allies with Resources}

One of an advocate's most powerful strategies is to cultivate influential policymakers. One of the best ways that NGOs can do this is to form personal connections with early and mid-career bureaucrats and support those individuals as they gain experience and power. Connecting these officials to others in the NGO network can be one of the most important methods through which these sympathetic insiders can be empowered. The NGOcreated network enables these lower- and mid-level public servants to bypass the layers of bureaucracy that inhibit communication with central government officials. The networks also connect these policymakers to individuals

8 Clean Air Partnership page of Clean Air Asia, http://cleanairasia.org/cities-clean-airpartnership/ (15 May 2017).

9 See http://asiangreencamp.net/eng/pdf/68.pdf (15 May 2017).

10 Kitakyushu city information about sister city agreement, http://www.city.kitakyushu.lg.jp/ english/file_oo49.html (15 May 2017). 
and organizations they would never otherwise be able to encounter through their day-to-day operations. In the end, the new relationships that are formed through the network can significantly enhance the capacity of these policymakers to enact effective and far-reaching policies.

Here is a description of how the process worked in one case in China, as described by Barbara Finamore, Senior Attorney and Asia Director, China Program of the Natural Resource Defense Council (NRDC) (Interview Finamore 2015):

The first really big project that we did was energy efficiency in Jiangsu. We went to a conference in Chongqing hosted by the Demand-side Management Center set up by the Asian Development Bank. The head of the Jiangsu power company was the head of that collaborative project, and I kept up with him for years. First, we did the demand-side management project. For that project the utility companies pay customers to be more efficient. It was very successful and got the attention of the central government. It took ten years, but eventually the central government extended the rules nationwide.

So, we kept in touch. We brought people down to Jiangsu. We brought people from California. We brought California officials to China. We brought Jiangsu officials to California. We brought central government officials to California. We brought Governor Schwarzenegger to China because California was a leader in demand-side management because of their energy crisis. There can be a gap in the connection, but it is still there, and now he [my Chinese contact] is very important.

There are people who sat through all those meetings, who were very quiet, but who sat in all the meetings who move up the administrative ladder, and now those people are running the regulation companies. They're not quiet anymore.

[Interviewer: It seems like you're not just empowering allies by giving them information, but you're also empowering them by helping them to make political connections. Can you expand on that?]

We brokered a memorandum of understanding between the California public utility commission and the Jiangsu utility to cooperate on energy efficiency. We brought the California officials over to Jiangsu - they're sister provinces. The MOU (Memorandum of Understanding) had two parts - the first was government to government, and the second included the NRDC as implementers. I helped found the China-US Energy Efficiency Alliance ten years ago - that alliance is now helping other communities form these kinds of agreements. 
NGOs can serve a critically important role in improving and promoting policy development by building networks across bureaucratic divides that impede policymaking through purely governmental procedures. Governmental bureaucracies can often be rigid, making it difficult for like-minded policymakers to find each other and work together. NGO-generated networks can help connect these dots by bringing these officials together. Since officials (and sometimes NGO professionals) move around, these personal networks remain dynamic, sometimes being activated, sometimes going dormant, waiting for the time when the connection can be usefully employed. Sometimes, as was the case for the China-US Energy Efficiency Alliance, the network itself can become institutionalized enough to become an independent organization.

\section{Engage Citizens: Raise Awareness, Motivate Volunteers, Spur Engagement}

The final and most obvious way that NGO-created networks act as policy catalysts is the ways that they can engage citizens. When organizations are connected through a network, they can dramatically expand their reach. They can spread the word about particular issues. They can coordinate volunteer activities. They can motivate the public to become more politically engaged.

The 26 Degree Campaign is a highly successful example of how environmental organizations with few resources can network together for a huge policy impact. In 2004 Sheri Liao, founder of Global Village, floated the idea for the campaign to her NGO colleagues in the city. She described the origin of the idea to me during an interview in Beijing in 2015 (Interview Liao 2015):

I think I got the idea when I was in the US. I would go into a supermarket in the summer time, and I would have to wear a sweater. I'd think, 'This is ridiculous!' At the time I hoped that China would not do this kind of thing. But then I found that China was following the same path. So, I discussed it with some NGO people, and we came up with the idea of 26 [degrees] in summer and 20 [degrees] in winter.

The small group met several times to discuss their plan of action. They collaborated to put together a report that documented how much energy would be saved if people set their air conditioners higher. Hotels and large businesses, especially, were setting the thermostats very low - 17 or 19 degrees - because businessmen were expected to wear jackets, even in the summer, so the room temperature needed to be cool for them to be 
comfortable. The NGO leaders used their good relationships with the press to gain a lot of coverage of their findings. An energy shortage that summer helped fuel interest in the issue. Beijing factories experienced power rationing during peak hours, and Beijing was the last of the major cities to face power cuts, which had spread across most of the electricity markets in the country. ${ }^{11}$ Journalists began to spot-check hotels and publish what they found in their newspapers. Friends of Nature mobilized volunteers to go into public spaces such as shopping malls, hotels and businesses and record the temperature, and violators would be written up by the organization and also by the press (Interview He 2015; Interview Liao 2015; Interview Wang 2015; Interview Yang 2011).

In 2005, the campaign gained momentum - more organizations joined the campaign, it gained greater press coverage, and the Beijing mayor, always concerned about local pollution, also got involved. By this time the idea had caught the attention of the central government, and Premier Wen Jiabao announced that government offices and meeting rooms would not have temperatures set below 26 degrees, and in July the Beijing municipal government sent a directive to all corporations in Beijing urging them to save energy by adopting the 26 degree standard in all restaurants, hotels, offices, banks and other public areas. ${ }^{12}$

Although the excitement around the campaign has waned, the network has expanded. By 2015 Friends of Nature was coordinating more than 50 volunteers in Beijing and collaborating with NGOs in 30 other Chinese cities to crowdsource temperature readings on a variety of buildings and share the data on WeChat. Their efforts were not just a collaboration with other NGOs and the press but also businesses - for example, HSBC helped to fund their efforts (Interview Wang 2015). The campaign's success was a direct result of the event-based network created by the NGOs. That network enabled the organizers to coordinate their use of resources to develop high-quality research. They were able raise public awareness through their collaboration with the press.

Residents of Beijing knew that their air was bad, but most had not made the connection between the temperature of their homes and offices and the quality of the air they were breathing. The network created a framework whereby citizens could be motivated to action and then engage in a

11 Financial Times article about the power cuts, http://www.ft.com/cms/s/o/7d8318o6-d14411d8-99cf-oooooe2511c8.html?ft_site=falcon\&desktop=true\#axzz4hF54XH8E (16 May 2017).

12 See the Friends of Nature report about the campaign, http://www.fon.org.cn/uploads/ attachment/47111361524307.pdf (16 May 2017). 
productive way to help solve the problem. The network enabled profitable and productive collaborations with businesses to reduce emissions. It framed its grassroots activities in ways that were digestible for policymakers and convince high-level officials to change government policy. The network enabled all of these actions - it had an independent, catalytic effect on citizen engagement.

\section{Conclusion}

This chapter has described three types of networks that NGOs in East Asia commonly build as part of their advocacy strategies: hub-and-spoke networks, horizontal networks and vertical networks. These networks in turn enable policy actors within and outside of governments at local, regional and national levels to overcome institutional collective action problems. In particular, they enable diverse actors to work together for the creation and dissemination of policy-relevant knowledge. They create a mechanism whereby NGOs can empower allies in government by helping them to overcome bureaucratic barriers and by connecting them to new resources. The activists are not changing the interests of these elite actors; they are changing their ideas. Activists working through their networks are able to persuade policymakers that certain activities are problems and help them develop productive policy solutions to solve those problems (Teets 2018). Finally, networks dramatically expand citizen engagement related to the policy area - spreading awareness of issues that matter, inspiring individuals to volunteer their time and facilitating citizen engagement in politics. They have contributed to the transformation of East Asia's political landscape in the post-high growth period.

These examples, while they originate in East Asia, are likely found in other parts of the world. When we study citizen activism as well as the public policy related to that advocacy, we should also be examining the networks that advocates - located both inside and outside the government - have formed and the diverse ways that those networks are affecting both the policymaking process and policy outcomes. The networks that non-profits create can alter the fundamental structure of policymaking in the places where they exist. They can create new patterns that change the flow of policy ideas, experimentation, feedback and implementation not only between the governmental actors and the objects of the policy (e.g. citizens, corporations) but even among the governmental policymakers themselves. These externally created networks can fundamentally reshape policy subsystems - how they operate at any given point in time and how they evolve over time. 
East Asia is a particularly difficult political context for policy advocates because governments in the region tend to be conservative, pro-business, and the legal structures are often hostile to advocacy organizations. Examining how civic organizations are working with and against their governments in this challenging political context can offer insights that are relevant for advocates everywhere.

\section{References}

Aldrich, Daniel P. 2012. 'Post-Crisis Japanese Nuclear Policy: From Top-Down Directives to Bottom-Up Activism.' Asia Pacific Issues: Analysis from the East-West Center, 103: 1-12.

Arnell, Nigel W.; Simon N. Gosling. 2016. 'The Impacts of Climate Change on River Flood Risk at the Global Scale.' Climatic Change, 134 (3): 387-401.

Cheng, Fang-Ting. 2014. 'From Foot-Draggers to Strategic Counter-Partners: The Dynamics of US and Chinese Policies for Tackling Climate Change.' IDE-Discussion Paper, 476. Tokyo: IDE-JETRO.

Chiavacci, David; Julia Obinger (eds). 2018. Social Movements and Political Activism in Contemporary Japan: Re-emerging from Invisibility. London: Routledge.

Economy, Elizabeth. 2004. The River Runs Black: The Environmental Challenge to China's Future. Ithaca: Cornell University Press.

Economy, Elizabeth. 2011. Roots of Protest and the Party Response. US-China Economic and Security Review Commission, US Senate/US House of Representatives, First Session, $112^{\text {th }}$ Congress, 5 February, Washington, DC.

Fackler, Martin. 2016. 'The Silencing of Japan's Free Press.' Foreign Policy, 25 May. https://foreignpolicy.com/2016/05/27/the-silencing-of-japans-free-press-shinzoabe-media/ (11 December 2019).

Fackler, Martin. 2017. 'A Pooch after All? The Asahi Shinbun's Foray into Watchdog Journalism.' Press Freedom in Contemporary Japan. Jeff Kingston (ed.). New York: Routledge, pp. 41-55.

Grano, Simona A. 2015. Environmental Governance in Taiwan: A New Generation of Activists and Stakeholders. New York: Routledge.

Haddad, Mary Alice. 2015. 'Paradoxes of Democratization: Environmental Politics in East Asia.' Routledge Handbook of East Asia and the Environment. Paul G. Harris; Graeme Lang (eds). New York: Routledge, pp. 86-104.

Haddad, Mary Alice. 2017. 'Environmental Advocacy: Insights from East Asia.' Asian Journal of Political Science, 25 (3): 401-419.

Harris, Paul G.; Graeme Lang (eds). 2015. Routledge Handbook of Environment and Society in Asia. New York: Routledge. 
Hasmath, Reza; Timothy Hildebrandt; Jennifer Y.J. Hsu. 2019. 'Conceptualizing Government-Organized Non-Governmental Organizations.' Journal of Civil Society, 15 (3): 267-284.

Ho, Ming-sho. 2019. Challenging Beijing's Mandate of Heaven: Taiwan's Sunflower Movement and Hong Kong's Umbrella Movement. Philadelphia: Temple University Press. Keck, Margaret; Kathryn Sikkink. 1998. Activists beyond Borders: Advocacy Networks in International Politics. Ithaca: Cornell University Press.

Kim, Hyuk-Rae. 200o. 'The State and Civil Society in Transition: The Role of NonGovernmental Organizations in South Korea.' The Pacific Review, 13 (4): 595-613.

$\mathrm{Ku}$, Dowan. 2011. 'The Korean Environmental Movement: Green Politics through Social Movement.' East Asian Social Movements: Power, Protest, and Change in a Dynamic Region. Jeffrey Broadbent; Victoria Brockman (eds). New York: Springer, pp. 205-229.

Lee, See-Jae. 200o. 'The Environmental Movement and Its Political Empowerment.' Korea Journal, 43: 131-16o.

Lee, Su-Hoon; Hsin-Huang Michael Hsiao; Hwa-Jen Liu; On-Kwok Lai; Francisco A. Magno; Alvin Y. So. 1999. 'The Impact of Democratization on Environmental Movements.' Asia's Environmental Movements. Yok-shiu F. Lee; Alvin Y. So (eds). Armonk: M.E. Sharpe, pp. 252-268.

Lee, Taedong. 2013. 'Global Cities and Transnational Climate Change Networks.' Global Environmental Politics, 13 (1): 108-128.

Litzinger, Ralph 2007. 'In Search of the Grassroots: Hydroelectric Politics in Northwest Yunnan.' Grassroots Political Reform in Contemporary China. Elizabeth Perry; Merle Goldman (eds). Cambridge, MA: Harvard University Press, pp. 282-299.

McKean, Margaret. 1981. Environmental Protest and Citizen Politics in Japan. Berkeley: University of California Press.

Mei, Wei; Shang-Ping Xie. 2016. 'Intensification of Landfalling Typhoons over the Northwest Pacific since the Late 1970s.' Nature Geoscience, 9: 753-757.

The Nature Conservancy. 2018. The Nature Conservancy 2017 Annual Report. Richmond: Worth Higgins \& Associates.

Radio Free Asia. 2016. 'China Jails Environmental Activist for "Revealing State Secret."' Radio Free Asia, 11 October.

Reardon-Anderson, James. 1997. Pollution, Politics, and Foreign Investment in Taiwan: The Lukang Rebellion. New York: M.E. Sharpe.

Reimann, Kim. 2003. 'Building Global Civil Society from the Outside In? Japanese International Development NGOs, the State, and International Norms.' The State of Civil Society in Japan. Frank Schwartz; Susan Pharr (eds). New York: Cambridge University Press, pp. 298-315.

Samuels, Richard. 2013.3.11:Disaster and Change in Japan. Ithaca: Cornell University Press. 
Teets, Jessica. 2018. 'The Power of Policy Networks in Authoritarian Regimes: Changing Environmental Policy in China.' Governance, 31 (1): 125-141.

Tiberghien, Yves; Miranda Schreurs. 2007. 'High Noon in Japan: Embedded Symbolism and Post-2001 Kyoto Protocol Politics.' Global Environmental Politics, 7 (4): 70-91.

$\mathrm{Tu}$, Weiming. 1998. 'The Continuity of Being: Chinese Visions of Nature.' Confucianism and Ecology. May Evelyn Tucker; John Berthrong (eds). Cambridge, MA: Harvard University Press for the Harvard University Center for the Study of World Religions, pp. 105-122.

Tu, Weiming. 1999. Humanity and Self-Cultivation: Essays in Confucian Thought. Boston: Cheng \& Tsui.

Upham, Frank K. 1987. Law and Social Change in Postwar Japan. Cambridge, MA: Harvard University Press.

Waley, Paul. 2005. 'Ruining and Restoring Rivers: The State and Civil Society in Japan.' Pacific Affairs, 78 (2): 195-215.

Wild Bird Society Japan. 2018. Business Plan for Heisei 30 . Tokyo: Wild Bird Society Japan.

Zhang, Lixia; Tianjun Zhou. 2015. 'Drought over East Asia: A Review.' Journal of Climate, 28 (8): 3375-3399.

\section{Interviews}

Interview Finamore 2015. Barbara Finamore, Senior Attorney and Asia Director, China Program of the Natural Resource Defense Council, 2015.

Interview He 2015. Yong He of Green Earth Volunteers, 2015.

Interview KFEM 2011. Leader of Korea Federation for Environmental Movements

(KFEM), 2011.

Interview Liao 2015. Sheri Liao, Founder of Global Village, 2015.

Interview Wang 2015. Yuan Wang of Friends of Nature, 2015.

Interview Yang 2011. Fuqiang Yang of Natural Resource Defense Council, 2011.

\section{About the Author}

Mary Alice Haddad is Professor of Government, East Asian Studies, and Environmental Studies at Wesleyan University, United States. Her current work concerns environmental politics in East Asia, especially China, Japan, Korea, and Taiwan. Her earlier books focused on civic engagement, democracy, citizenship, volunteering and non-profit organizations. A Fulbright and Harvard Academy scholar, Haddad is the author of Building Democracy in Japan (Cambridge University Press, 2012) and Politics and 
Volunteering in Japan: A Global Perspective (Cambridge University Press, 2007) and co-editor with Carol Hager of NIMBY Is Beautiful: Cases of Local Activism and Environmental Innovation around the World (Berghahn, 2015). She has published in journals such as Comparative Political Studies, Democratization, Journal of Asian Studies, and Nonprofit and Voluntary Sector Quarterly. 


\title{
4 The Campaign for Nuclear Power in Japan before and after 2011
}

\author{
Between State, Market and Civil Society
}

Tobias Weiss

\begin{abstract}
In the chapter I analyse the emergence of a countermovement in reaction to the rise of the movement against nuclear power in Japan since the 1970 s. I trace the emergence of the countermovement in historical perspective, and analyse the organizational and social basis, the mobilization processes, the framing, and political influence of the groups involved. I then analyse the political impact of the Fukushima 2011 nuclear accident on the movement. I show how the countermovement was able survive a period of intense contestation preserving its resource basis and retaining significant influence on the policymaking process due to support from parts of the national bureaucracy and conservative politicians.
\end{abstract}

Keywords: social movements, Japan, countermovements, civil society, nuclear power

The recent wave of conservative movements poses a challenge to researchers of civil society. Can civil society be conservative or even reactionary? While Heinrich (2005) argues for discerning certain progressive values (for instance, adherence to human rights and gender equality) to empirically identify civil society actors and organizations, Way (2014) holds that civil society can be found in both progressive and conservative sectors of society as long as they are organized and distinct from the state and from the market. In this chapter I will adapt the latter approach focusing on organized groups seeking to preserve existing interests and policies in Japanese nuclear power

Chiavacci, David, Simona Grano, and Julia Obinger (eds), Civil Society and the State in Democratic East Asia: Between Entanglement and Contention in Post High Growth. Amsterdam, Amsterdam University Press 2020 DOI: 10.5117/ 9789463723930_CHO4 
politics. This approach contrasts prevailing tendencies to focus mainly on the progressive sectors of civil society (for similar assessments see Katz 2006; Fuchs 2018; Meyer and Staggenborg 1996; Ho, in this volume).

Observers have asked why a strong movement against nuclear weapons (in the 1950s) and an environmental movement (in the 1970s) developed in Japan, but the movement against the civil use of nuclear power remained much weaker (Avenell 2012). In this chapter I will analyse the campaign to promote the civil use of nuclear power as a countermovement (directed against the movement against nuclear power) taking place at the intersection between civil society, the market and the state. While it is hard to gauge its effects on the anti-nuclear movement, by scrutinizing the mobilizing structures, framing, and political influence of the movement, I aim to complement existing explanations of the relatively limited strength of the anti-nuclear movement before 2011 and shed light on future prospects for Japan's nuclear energy policy.

Developmental states have been associated with a strong state and a weak civil society (Hsu 2012). The category 'developmental state' is connected to the dynamics of late development analysed by Gerschenkron (1962). The state assumes an important role in political economies developing in an international environment where other countries have already set the path. Developmental state theorists like Johnson (1982) took up this argument and identified a strong and autonomous national bureaucracy, an economy managed through industrial policy and a relatively weak legislative branch as elements typical of the developmental state. In this model the state is the main driver for political and social change, marginalizing groups that defy its goals of economic growth and modernization. Civil society remains weak (Pekkanen 2004: 363).

While hardly anyone would deny the strength of the Japanese state during most of the Cold War period and its ability to accomplish developmental goals, scholars of Japanese civil society note the blurriness of the boundaries between civil society and the state. Garon (1997) argues that the penetration of the Japanese state into peoples' everyday life does not necessarily have to be interpreted as one-sided movement. A (social) movement in this view can originate within state agencies or outside of it. Movements originating within state agencies can be taken up and advanced by social forces outside of the state (or market). A campaign according to Garon (1997: 3-20) might be managed by state agencies, but it also involves the mobilization and collaboration of parts of civil society. Garon emphasizes that, in order to understand the emergence and dynamics of campaigns, the relation between state and civil society should be conceptualized not as exclusively oppositional, but as multilayered and multidirectional. 
Post-war Japan has seen multiple campaigns, for example, the New Life Movement (Shin Seikatsu Undō) aimed at 'modernizing' the household and defining certain gender roles (Gordon 1997) and the Productivity Movement (Seisansei Undō) aimed at increasing industrial productivity (Gordon 1998). These campaigns were initiated by government agencies or influential groups within the state or market sectors, but the agents of the campaigns were never limited to these sectors. While I would argue that at least some campaigns can be seen as countermovements, aiming to deflect or absorb challenges to the state or powerful elites, the most active promoters were not always bureaucrats or politicians. Even if a campaign might originate within the state, the spread of it and its success depended on the resonance it was able to produce within civil society. To analyse campaigns, I would argue that a focus on the links between state, market and (civil) society is important - for instance, on foundations or public policy companies often managed in cooperation between private industries and the bureaucracy. The success of campaigns might depend not only on the power of the state, but also on the dynamics between movements and countermovements in specific sectors of society.

My main interest here is how the countermovement emerged and how the Fukushima nuclear accident in 2011, which was perceived by many as a failure of the Japanese developmental state, affected the pro-nuclear campaign. ${ }^{1}$ I will start sketching the emergence of the pro-nuclear campaign, as reaction from state and nuclear industry to a rising anti-nuclear movement since the $1970 \mathrm{~s}$ using documents and statements from the actors involved. In the following section I will analyse the mobilizing structure, the framing and the political efficacy of the campaign prior to 2011. In the final section I will trace changes after the Fukushima nuclear accident. We can see that a 'developmental' alliance between companies, the bureaucracy and the conservative party built up a strong countermovement, especially in professional circles connected to the nuclear industry and local communities hosting facilities. I argue that this countermovement adopted a strategy used by company managers in the labour struggles from the 1950 s on. Before 2011 parts of the movement were transformed to non-profit organizations and held significant resources and influence on policymaking, deflecting also challenges from sectors of the bureaucracy pushing for liberalization of the energy market. Mainly due to its strong resource base and political networks the countermovement survived the 2011 accident and retained resources and some political influence, even though its power over policy making was weakened. 


\section{The Pro-nuclear Campaign}

\section{The Emergence of a Pro-nuclear Campaign}

The emergence of a pro-nuclear campaign in Japan was a reaction to the rise of environmental citizen movements in the early 1970s and increasing local resistance to the construction of nuclear power plants. The atomic bombings of Hiroshima and Nagasaki had led to the emergence a strong movement against nuclear weapons. In 1954 popular opposition to the development and use of nuclear weapons surfaced after a Japanese fishing boat was hit by radioactive fallout from a US nuclear weapon test (Utsumi 2012). A housewife initiated a petition against nuclear weapons, eventually gathering 30 million signatures, and a countrywide social movement against nuclear weapons emerged. While this movement must have triggered ambiguous feelings among conservative political circles (Arima 2008), the opposition to nuclear weapons did not naturally translate into opposition against the 'peaceful use' of nuclear power for electricity production. It was argued by progressive as well as conservative parties that Japan as the only victim of atomic bombs had to become a forerunner in the peaceful use of nuclear power (Weiss 2019a: 193-196, 243-246). In the 1950s, over 6oo Japanese companies joined the newly established Japan Atomic Industrial Forum (Yamaoka 2015: 235). The US embassy together with various Japanese newspapers conducted countrywide exhibitions promoting the peaceful use of nuclear power under the Atoms for Peace programme. The founding of the Japan Atomic Industrial Forum (JAIF), the federation of the nuclear industry, in 1956 was the precursor of the pro-nuclear campaign starting in the 1970s. The JAIF established local atomic forums (genshiryoku kondankai) in Kansai, Chūbu and Ibaraki. These forums not only included managers of companies aiming to build up a nuclear industry, but also journalists and influential regional power holders, for instance, leaders of fishing cooperatives and housewives' groups (see, for example, HGK 2002: 8). From the start this campaign might also have aimed to counter the success of the movement against nuclear weapons, but since there was not any substantial opposition against the civil use of nuclear power, it is not clear whether we can speak of a countermovement before the 1970s.

\section{The Environmental Crisis}

In the early 1970 s there was a sense of crisis in the long-term ruling party, the conservative Liberal Democratic Party (LDP) and the Japanese business 
community. Opposition parties had made gains in local elections and had taken hold of various local governments. Countrywide protests against cases of pollution were on the rise and had forced the conservative government to pass stricter legislation for environmental protection (McKean 1981). The PR manager of the utility company TEPCO (Tokyo Electric Power Company) in retrospect decried the 'anti-company mood' in Japan during this period (Suzuki 1983: 15). At the same time Japan was affected by the oil crisis. The oil shock in 1973 caused a strong recession, and policymakers worried about the safety of future energy supply. A group of conservative intellectuals, under the name Group 1984, published a manifest claiming (Group 1984 1975: 99):

The Japan of the 1970s did not make the stupid mistake to start an international war over raw materials. But it turned the war about raw materials into a civil war. This was an extremely unwise move. The safe long-term supply with raw materials can hardly be maintained anymore. If we don't take revolutionary measures here, the Japanese economy will face physical annihilation!

This statement is the expression of an at the time widespread belief among policy makers and industry managers that 'the energy question' would decide the future of Japan's industrial development and that intensive efforts would have to be made to aquiesce Japan's population to accept nuclear power plants.

\section{Organizations Connecting State, Market and Civil Society}

Three foundations played important roles organizing such 'revolutionary measures' in nuclear power policy, which included the expansion of nuclear power generation and a strategy to achieve public acceptance for it: the federation of the nuclear industry, JAIF; the Japan Atomic Energy Relations Organization (JAERO); and the Japan Productivity Center (JPC).

\section{Japan Atomic Energy Relations Organization (JAERO)}

JAERO's Japanese name means - when translated literally - 'Foundation for Fostering a Nuclear Culture' (Genshiryoku Bunka Shinkō Zaidan). It was founded originally in 1965 as the Center for Nuclear Power Dissemination in Ibaraki, where many facilities of nuclear power research and production had been built. JAERO's official history explains the purpose of its founding 
with 'special feelings' (genshiryoku ni taisuru tokushu kanjō) of the Japanese populace towards nuclear power (JAERO 1994: 232). The upgrading of its activities to a national scale in 1969 can be understood in the context of protests against American nuclear submarines and warships entering Japanese harbours, for example, during the 'struggle of Sasebō' in 1968. Prime Minister Eisaku Satō had bemoaned the 'nuclear allergy' of the Japanese people (Hook 1984). JAERO's activities include the targeting of important segments of the population with nuclear power PR: scientists, teachers, doctors, journalists and the local population near nuclear power plant sites (JAERO 1994). JAERO's official history mentions the 'need to bring together various segments of society to promote nuclear power' (JAERO 1994: 239).

\section{Japan Productivity Center (JPC)}

The JPC, the organizational hub of the Productivity Movement (Seisansei Undō), organized by a coalition of the conservative labour unions (Dōmei federation), the Ministry of International Trade and Industry (MITI; since 2002: Ministry of Economy Trade and Industry; METI) and business federations, which, from the 1970s, began to play a role in nuclear politics. In 1972 it convened the First Industry Conference on the Environmental Problem (Daiichi Kankyō Mondai Sangyō Kaigi), bringing together about 200 business managers, scholars and bureaucrats. Participants called for a 'neutral third-party movement' (NSH 1972: 63) to check the challenge of the environmental movement. The Japan Social Economic Conference (Shakai Keizai Kokumin Kaigi) was established as a sub-organization in the JPC focusing among other issues on establishing consensus on the nuclear power issue. A key person was Hidezō Inaba, an economist, member of the Atomic Energy Commission (JAEC) and former bureaucrat of the Cabinet Planning Board (Kikakuin), the prewar 'economic general staff' and centre of industrial planning, according to Johnson (1982). From the 1970s, Inaba worked to create a 'neutral third-party movement' for the public acceptance of nuclear power (Ebina 1992: 185). The 'neutral third-party movement' was essentially a countermovement against the anti-nuclear movement. This becomes clear when we look at the social groups targeted by the movement and the history of its organizational base, the JPC.

\section{0s: Countermovement in Labour Politics}

The JPC had been established in 1955 during a period of intense labour conflict. At that time public and private sector unions organized a large share 
of workers in the Sōhyō labour federation, mobilizing them for demonstrations, making political demands and supporting the oppositional Japan Socialist Party (JSP). The Productivity Movement was initiated by an alliance of conservative labour activists in the Dōmei unions (politically supporting the right wing of the JSP, which in 1960 split and formed the Democratic Socialist Party, DSP), company management and MITI bureaucrats. Inaba was among the first generation of JPC board members (NSH 2005). The JPC was part of a larger drive to curb the influence of Sōhyō and activist unions close to the Communist Party. It contributed to making Dōmei the largest labour federation in the private sector (as opposed to the public sector, where Sōhyō remained strong; see Gordon 1998). The countermovement utilized existing hierarchies in the workplace, mobilizing older foremen and workplace leaders in 'informal organizations' (Suzuki 2003) aiming to isolate 'leftist' elements. When the campaign succeeded in taking over control of many unions in the private sector, the Sōhyō and communist-affiliated unions began to create cultural circles in order to maintain their organizational bases. To counter this, companies built 'independent' leisure circles (Gordon 1997).

\section{0s: Countermovement in Nuclear Politics}

Inaba's 'neutral third-party movement' was essentially the organization of a countermovement modelled after 'informal organizations' and 'independent leisure circles' in nuclear politics. In the 1970 s the civil use of nuclear power became increasingly contested in Japan. Union members, consumer advocates, critical scientists, and lawyers cooperated with the opposition parties to mobilize protests against the siting of nuclear power plants. The time needed to build the reactors increased (Aldrich 2008). In 1974, the government's nuclear policy suffered a major defeat when Japan's first nuclear-powered ship was blocked re-entrance into its home port by angry fishermen after a radiation leak (JAERO 1994: 240).

To counter these trends the JPC started mobilizing Dōmei union members. The JPC held regular 'energy seminars' from 1976 to 1981, inviting union members, journalists and academics emphasizing the need for nuclear power. It also started organizing 'grassroots movements' based on local Dōmei and DSP organizations and local business groups, starting with a 'meeting of people in Shimane prefecture for the promotion of nuclear energy' (Suzuki 2016: 598). In the same year Japan's first 'pro-nuclear citizen group,' Energy and Life-Citizen Group, was founded by a nuclear engineer. The founder had worked as consultant for companies and think tanks in the nuclear industry and later founded two companies offering services 
related to the 'public acceptance' of nuclear power (Minakuchi 2016). In the group's newsletter he conceded that most of the 300 participants had been union members in companies in the nuclear industry (EKSKH 1998). In a newspaper article the group was introduced as 'founded by heavy machinery and utility union members and nuclear power researchers' (AS 1989b). It aimed to 'expand the discussion' concerning nuclear power and contribute to a 'healthy energy development' in Japan. While this pioneer group of the 'pro-nuclear civil society' did not survive until 2011, a multitude of similar groups appeared from the early 1990 on.

\section{The Regional Base of the 'Pro-nuclear Civil Society'}

Through a subsidy system installed in 1974, JAERO, JPC and other government-affiliated foundations in alliance with utility companies and JAIF became suppliers of capital to local and national subcontractor groups. Local sub-leaders play an important role in mobilizing members through relatively hierarchical, clientelist networks (for details on mechanisms of mobilization, see Weiss 2019b). This hierarchical element is also visible in the regional atomic forums of JAIF. Dense personal and institutional networks managed by local power holders (yūryokusha) allowed the regional nuclear forums to mobilize large parts of the local populations. Local atomic forums were in most regions built inside the local chambers of commerce (shōkō kaigisho), which were at the same time a support base of the LDP (Taguchi 1960). From the organizational structures of JAIF and the spatial concentration of other 'pro-nuclear groups' it appears that this is especially true for regions where nuclear power plants came to generate an important share of public and private income like the prefectures of Fukui, Fukushima, Aomori and Ibaraki, hosting multiple nuclear power facilities. ${ }^{2}$ For instance, the Hokuriku Nuclear Forum, established in the 1970s, mobilized a large number of private companies (including newspapers and TV stations) in the three prefectures of Hokuriku and included representatives of most universities, some schools, and the agricultural and fishing cooperatives as well as housewives' federations (fujinren) and young men's federations (seinendan) of the three Hokuriku prefectures (HGK 2002: 3). This encompassing mobilization can probably be attributed

2 The concentration of multiple facilities in a few locations is connected to the fact that it is easier to convince communities already hosting one reactor to accept a new one. Also, host communities come to rely on subsidies and tend to accept additional reactors providing resources to maintain public income at a high level. 
to top-down calls for mobilization via mid-level local leaders, the prevailing mode of organization of conservative associations at that time (compare Taguchi 1960). Progressive groups like the prefectural Sōhyō unions were not included, however, presumably because they were opposed to nuclear power or at least opposed to the conservative organizations at the time the forum was set up (HGK 2002: 3, 8). Local volunteers were recruited through a 'nuclear power monitor' system created in 1978 by the Science and Technology Agency. For this programme a number of local opinion leaders were handpicked by governments of prefectures where nuclear power plants were located to communicate the safety of nuclear power and gather people's opinions (Interview FNRAJG 2017). The system was put in place shortly before a reform that increased the frequency of public hearings on the building of nuclear power plants ( $A S$ 1979).

\section{0-1990s: Expansion of the Countermovement}

Honda (2005: 79-85) notes that with the victory of conservative unionism leading to the founding of the Rengō federation (the merger of Sōhyō and Dōmei union federations proceeded in the 1980s), the basis of the anti-nuclear movement in labour unions was significantly weakened. Since the early 1980 s, however, a 'new wave' of the anti-nuclear movement had risen. This 'new wave' emerged from a stratum of middle-aged housewives organized in consumer groups (JAERO 1994: 133). In alliance with youth groups and older activists from the 196os student movement, they staged protests against a test at the Ikata nuclear power plant in 1988 and the building of a nuclear fuel reprocessing plant in Aomori in the early 199os (Suga 2012). On the local level, residents' movements were aided by a series of scandals and accidents in the nuclear industry from the 1990s (Yoshioka 2011). They succeeded in stopping two construction projects as well as the use of plutonium-enriched fuel in one location (Honda 2005). Also, in the late 1980s and early 1990s, international environmental groups gained a foothold in Japan (Mason 1999). The international NGO Greenpeace, for instance, staged protests against the transport of reprocessed plutonium from Europe to Japan ( $A S$ 1992). Suga (2012) argues that this 'new wave' was the most substantial challenge to Japanese nuclear power policy in Japanese history. In this situation the countermovement sought to expand its influence to weaken the social basis of protest activity.

The local atomic forums had targeted women using existing networks, including parent-teacher associations and women's groups, to screen PR films and invite researchers and celebrities to deliver talks directed at 
female audiences. In Hokuriku the targeting of housewives started in 1979 (HGK 2002: 8). These groups expanded through the mobilization of female employees of the nuclear industry, related businesses and the use of family and local networks (Weiss 2019b). Most local JAIF groups organized women's groups under (at least nominally) separate organizations (see Weiss 2019b: 5-13). The prefectural groups were organized into subgroups on the local town and village level. In some towns where plants are located these groups claim impressive membership numbers. For instance, the Takahama Women's Net in the town of Takahama, a community with 10,000 residents hosting four nuclear reactors, claims to have 1,300 female members (Weiss 2019b). If we take the female population to be around $50 \%$, this would add up to one-quarter of the female population. While the 'pro-nuclear groups' might have an interest to inflate their membership, and thus the numbers cannot be taken at face value, encompassing mobilization is surely related to the strong reliance of host communities on subsidies and economic benefits accompanied by the building and operation of nuclear power plants.

The 1990s and early 200os saw the emergence of various 'pro-nuclear consumer and environmental groups.' From 1989, JAERO took responsibility over the nuclear power monitor system. The dispatch of speakers (kōshihaken) for various kinds of events was stepped up. Subcontractors of JAERO and other companies and organizations connected to the nuclear industry started to conduct regular education seminars for opinion leaders from various social strata to educate them about energy issues, radiation and related topics. These opinion leaders are then mobilized to spread their 'educated opinion' among followers and the general public on symposia and various kinds of events. In 1989 TEPCO alone was dispatching speakers to a hundred events per month ( $A S$ 1989a). Government agencies, other utilities and semi-private groups sponsor additional symposia, workshops etc. Together, the multiple events by various organizations make for a large-scale pro-nuclear education campaign.

After an accident in Japan's fast-breeding reactor in 1995, the monitor programme's scale was expanded (JAEC 1996). Another programme supplying speakers for nuclear power education events had been installed in 1979. METI cooperated with businesses to create a programme aimed at building up a corps of consumer advocates outside the framework of the pre-existing (relatively independent) consumer movement. These consumption life advisors (shōhi seikatsu advisor) were recruited mainly among housewives. They are trained to mediate between consumer interests and businesses. Consumption life advisors are hired by companies. They listen to consumers and represent their perspective within the companies, helping to develop 
better products $(A S 1980)$. A foundation was created by MITI to develop the curriculum, conduct professional examinations, and certify the education of graduates of this new programme. Today about 14,000 consumption life advisors are represented in a nationwide network of NPOs and federations (NSK 2012). TEPCO, for instance, became a major employer of consumption life advisors (Hōgaku Shoin Henshūbu 1999).

In the 199os, the Ministry of the Environment also created a programme to educate a corps of environmental counsellors (kankyō counselor). Similar to the consumption life advisors, environmental counsellors are hired by companies to mediate in cases of conflict over environmental issues, or to lecture about compliance and social responsibility; they also obtain employment from public agencies (Kozumi and Sasaki 2010). While only a part of all consumption life advisors and environmental counsellors deal with nuclear power, both often appear as pro-nuclear speakers in local and national advisory councils and as lecturers on events and hearings sponsored by the nuclear industry together with direct stakeholders like scientists and employees of the nuclear industry (Weiss 2019b).

Within the JPC, an umbrella organization named Energy Think Together (ETT) was created in 1990 aiming to 'think about energy, everybody together, and spread the information gained this way' (ETT 2017). In 1991, an informal advisory council financed by the Science and Technology Agency and run by JAERO was installed to come up with a 'strategy for public acceptance of nuclear power.' This document, whose main authors were not bureaucrats, but think tank employees, journalists and scholars, put housewives in the centre of attention of nuclear power PR: 'Women trust local consumer centres. They have a strong interest in the environment. If we can co-opt the leaders of such centres, they would make for strong allies' (GPAHI 1991). Various 'pro-nuclear citizen groups' emerged promoting 'environmental protection through nuclear power,' 'energy education,' 'energy from a consumer's perspective,' and 'radiation education' (for an overview of these groups, see Weiss 2019b).

\section{Before 2011: An NPO Boom?}

In 2000 the Science and Technology Agency's radiation monitor programme was terminated. Starting around the same time multiple non-profit organizations (NPOs) promoting nuclear power began to appear. There had been a change in legislation in 1998, creating this new type of association. This led to an 'NPO boom,' the rise of a non-profit sector of about 70,000 organizations (Ogawa, this volume). The nuclear industry apparently saw 
promise in using NPOs to promote nuclear power. On the national level, utilities like TEPCO and Kansai Electric Power sponsored women's groups focusing on consumer issues and environmental protection. An umbrella group named Asuka Energy Forum - active in the market areas of TEPCO and the utilities of Tōhoku, Hokkaidō, Chūbu, Hokuriku (except Fukui) and Chūgoku ${ }^{3}$ with local women's subgroups in various nuclear power plant locations and smaller cities - was created in 2001 and became an NPO in 2003. This group claims to have twelve local subgroups, some of them also registered as NPOs (Weiss 2019b: 5-13). Kansai Electric Power sponsored its own NPO in 2001. Another NPO was co-opted by Denjiren, the federation of utility companies. Its activities initially aimed at spreading ideas of recycling and waste management in Japan (see Weiss 2019b). From 2007 the group became a partner of the government's search for a nuclear waste disposal facility co-sponsoring several workshops. Asuka and the respective local groups started to conduct and promote various kinds of activities to attract new people to their activities. These activities are at times reflected in the names of the local subgroups. One of them, for example, is the Readers Circle Aomori, founded in 1995, and another local group is simply called Free Time, founded in 1993 (Weiss 2019b). The activities described in Asuka's newsletter range from regular 'energy cooking' with celebrities to local 'energy talks' for women and power plant and facility tours (AEF 2001-2012). Asuka and other groups also placed expensive advertisements in newspapers to attract new members (Sugimoto 2013a).

Nuclear scientists and technicians also began to found various NPOs in the 200os. A name appearing in multiple groups is that of Akito Arima. Arima is a nuclear physicist and became head of Tokyo University in the 1980s and LDP Diet member and Minister of Education in 1998. During the 1967-1968 student movement he had been appointed special assistant of the president of Tokyo University to handle the measures against revolting students. When he became president of Tokyo University in the 1980 , he started a drive to collect funds from the private sector to upgrade the university's facilities ( $A S 2015 \mathrm{a}, A S 2015$ b). Arima is in the board of six NPOs and other groups engaged in nuclear-power-related activities (Weiss 2019b: $5-13) \cdot{ }^{4}$ Other nuclear engineering professors founded similar groups and

3 Until 2011 the electricity market was split into ten regional utilities, each controlling electricity production, distribution and sale in its area.

4 These are the Radiation Education Forum (founded 1994, NPO in 2000), the Internet Journalist Association (2002), and the groups Thinking about the Earth Group (founded 2007, inactive), Japan Energy Conference (founded 2012), Japan Energy Policy Forum (founded 2012) and the National Nuclear Conference (founded 2014). 
NPOs. Like the NPOs targeting women, they conduct lectures and symposia about the effects of radiation and the need for nuclear power and its safety. While some of them concentrate mainly on research and academic activities, all of them are engaged in nuclear power PR to some extent (Weiss 2019b: 5-13). The researchers often team up with representatives of the women's NPOs to combine a 'consumer perspective' on nuclear power with scientific knowledge (for example, in the energy talks conducted by Asuka; AEF 2001-2012). Like the women's NPOs, they receive subcontracts for PR and workshops aiming to find a site for a nuclear waste disposal facility from the government and the nuclear industry (see below). There are also groups organizing journalists, media celebrities, business elites and policymakers (on the national level) as well as businessmen and teachers from communities with nuclear plants. Some of them have NPO status, some not. It appears that parts of the groups organized in JAIF forums were transferred to NPOs and groups with a more modern appearance.

The various pro-nuclear groups receive substantial amounts of money as subcontractors for the government and the nuclear industry, as well as donations. Two sources of financial support deserve special attention.

(1) Until 2011, utilities in Japan were endowed with regional monopolies. The energy prices were proposed based on cost projections by the utilities and are subject to permission by METI. In the projection of costs, public relations and public acceptance measures were included under the label 'development and diffusion costs' (fukyū kaihatsu kankeihi) of nuclear power plants. Informal meetings, advertisements, facility tours, the dispatch of speakers as well as costs of PR facilities can be financed through the electricity fees. Due to this way of budgeting the utilities have the financial means for various kinds of activities. There are extraordinary amounts of electricity money (denryoku money) available in public relations campaigns. A journalist traced the trend of development and diffusion costs over 40 years and concluded that they were elevated as a countermeasure to the loss of trust each time after a major nuclear accident. From 1990 to 2011 these costs exceeded $€ 65^{\circ}$ million 5 per year (Komori 2012a).

(2) In addition to the electricity fee, a rich subsidy system for communities hosting power plants was installed in 1974. A special budget for these subsidies was installed outside of the Diet - the special budget for electricity sources (Dengen Tokubetsu Kaikei). The subsidies are distributed by METI and the Ministry of Education (MEXT, before 2002 by the Science and Technology Agency). Since a change in the electricity law in 2002 (the basic 
energy policy law), NPOs and other groups can team up with foundations like JAERO or private companies receiving these subsidies as subcontractors (see below).

This financial environment guarantees a steady flow of money to the pro-nuclear campaign. Prior to 2011 'pro-nuclear civil society' groups were much better off financially than their anti-nuclear counterparts (for details on the funding, see Weiss 2019b: 5-13).

\section{Framing of Nuclear Power}

Since I have described the framing of nuclear power by the 'pro-nuclear civil society' in detail elsewhere (Weiss 2019a: 188-239, 279-291), I will only give a brief overview here. In general, nuclear power is framed positively by all of the groups. Recurring themes are Japan's reliance on nuclear power and its lack of natural energy sources, its dependence on foreign energy, the safety and high technological level of nuclear power, the need for a stable supply of energy (or a balanced energy mix), the economic benefits of nuclear power, for instance, low electricity prices and the economic gains from exports. The pro-nuclear groups underline that nuclear weapons and nuclear power are completely separate issues. A relatively prominent aspect of their framing is also the claim that nuclear power is a green technology, serving to limit carbon dioxide production. As described above, many of the pro-nuclear groups are based in peripheral regions of Japan, where power plants are located. They argue that the building of nuclear power plants contributes to regional development, and they underline the integration of power plants into the local community emphasizing their contribution to national prosperity through electricity production. Another common thread is the focus on 'educating' the population to overcome 'irrational sentiments' regarding nuclear power.

The groups run by scientists and political elites tend towards a technical and policy-oriented framing. In a newspaper advertisement by the Thinking about the Earth Group, which was organized as a 'national movement to establish love for the earth' before the Tokyo Summit in 2008 (Sankei Shinbun 2008) the founder Akito Arima describes the carbon dioxide output in tons by various countries and explains that in the future fossil fuels will run out. He goes on to explain that carbon dioxide emissions are increasing and that new energy sources won't be ready in time to inhibit global warming. Arima then shifts his focus to nuclear power, which he presents as the only chance to fight global warming and prepare for future scarcity of fossil fuels. 
Some groups employ more aggressive rhetoric. Members of a gathering called 'Making Statements about Nuclear Power Group,' consisting mainly of former nuclear power technicians and managers, for instance, label themselves as 'worried patriots' (ukoku no shi) and underline that 'whenever we meet and talk about nuclear power, we express our worries and criticism about Japan's energy policy, the media, and the present situation.' They aim to 'disseminate our right opinion [tadashii iken] and our right information [tadashiijōhō] based on the common understanding that nuclear power cannot be disregarded in Japanese energy policy.' They go on to explain that 'nowadays the enemies of nuclear power are actively making statements in an organized way, and the pro-nuclear group often remains silent' (GMHK 2006).

In contrast to this rather aggressive framing, women's groups focus on everyday life and employ a softer language. In the Asuka newsletter ( $A E F N$ 2001:1) the chairwoman introduces the group with the following statement:

We are a group of consumption life advisors interested in the energy problem. We conducted study groups and have taken part in [nuclear facility] tours and visits for a couple of years. [...] We realized how important it is to raise one's voice as a consumer. From our consumption life advisor standpoint, bringing together the three groups of companies, the administration and consumers, we want to participate widely and disseminate information!

After an 'energy talk salon' in Japan's largest power plant location, Kashiwazaki, one member sums up her conclusions (AEFN 2002: 2):

Talking with middle school students I felt that they don't have a sense for saving energy. It is natural for them to have plenty of energy. Even if we use as much of it as we want, there are no problems. [...] It is an adult's responsibility to learn about the problems of energy and environment, which are at the basis of everyday life.

Another member adds (AEFN 2002: 2):

If we think about energy and electricity it is common to think in patterns like pro-nuclear vs anti-nuclear or to assume that saving energy and promoting renewables is equal to saving the environment. But since already $42 \%$ of greater Tokyo's energy supply comes from nuclear power, we cannot let go of nuclear power and only increase energy saving and renewables. 
While the language is softer than in the more 'masculine' groups of scientists (presumably due to the mainly male audience), Asuka members make clear that they were surprised to learn that 'not everything in the news is true' and remind journalists to 'stick to the truth.' The newsletter also presents the tour report of a 'wind turbine, which did not move, due to lack of wind' (AEFN 2002: 3). Local people from Kashiwazaki are reported to have asked their counterparts from Tokyo, who were invited for this event, to 'be aware that their energy is produced in Kashiwazaki' and to 'become able to understand nuclear reactors and pluthermal' (Plutonium-Uranium mixed oxide fuel, a measure promoted by the government to reduce the growing stock of Plutonium) (AEFN 2002: 2).

\section{Political Influence}

It is difficult to evaluate the pronuclear groups' influence on political decisions because their policy preferences usually do not differ very much from that of its political allies in state agencies. However, the pro-nuclear countermovement also gained a say in policymaking through inclusion in government advisory councils (shingikai) and government organizations. Through these vehicles it articulated mainly the interests of its major sponsors, the nuclear industry, but also of the regions benefitting from financial support for hosting nuclear power plants. One of its aims is the preservation and expansion of existing financial resources. Continuing reliance on nuclear power and upholding the major pillars of nuclear power policy, for instance, developing a nuclear fuel cycle, is important for regions heavily engaged in nuclear power production and reprocessing like Aomori and Fukui.

Since the beginning of Japan's nuclear programme in 1954, various parts of society have been involved in the local and national forums of JAIF and the JAEC, the government's highest decision-making body in nuclear policy before 2011, coordinating related agencies and social groups (Yoshioka 2011). With the growth of the countermovement the government created formal posts for 'pro-nuclear civil society representatives,' some of them also equipped with decision-making powers. Since 1998 (when Arima became Minister of Education) a female 'civil society representative' is chosen at the highest level of administration for the Atomic Energy Commission to signify the inclusion of energy consumers into the nuclear power administration. The first such representative was a free TV moderator, featuring in numerous programmes sponsored by the utilities. From 1990 on she was member of the planning board of ETT, and from 1994 advisor to the JPC. She was succeeded by the leader of a pro-nuclear NPO in 2007. In 2010 the leader of Asuka Energy 
Forum was chosen as the successor (JAEC n.d.). In 2001, after the end of the nuclear power monitor system, the JAEC established a Subcommittee for Citizen Participation (Shimin Sanka Kondankai) and packed it with representatives of the 'pro-nuclear civil society' (JAEC 2009). Asuka's regular 'private' events in various locations appear to have been conducted parallel to the 'official' public hearings carried out by the JAEC (Asuka Energy Forum, 2002-2012). After 2011 it actually turned out that the NPOs were involved in mobilizing 'citizens' for the JAEC hearings (Weiss 2019b).

The political influence of the pro-nuclear movement can be seen in the Basic Energy Policy Law (Enerugī Seisaku Kihonhō) of 2001, which served to hedge liberalization plans originating within the state bureaucracy. From the 1990s, in the context of a global trend towards liberalization and privatization of public services, bureaucrats within MITI started to question the monopoly of the electricity companies. A partial liberalization was conducted to the effect that businesses were enabled to choose where to buy their electricity, but due to the regional monopolies of the utilities for private customers and their ownership of electricity grids the effects were limited ( $A S$ 2014b). To counter further liberalization, LDP politicians close to the energy companies drafted a Basic Energy Policy Law in 2001. It was criticized by opposition parties as 'aiming to cement the use of nuclear power' because the drafting followed defeats of the pro-nuclear coalition in regional non-binding referenda and it decided that 'local communities have a responsibility to cooperate in the siting of nuclear plants' (ESK 2002). The law was also criticized by a private think tank because 'the safety of the energy supply' - essentially meaning the use of nuclear power - was placed above 'the market principle' ( $A S$ 2001). It went largely unnoticed in the discussion that there was a paragraph included allowing 'non-profit organizations to take part in public acceptance activities' (ESK 2002). This paragraph served as the basis for a more important role of the 'pro-nuclear civil society.' NPOs and other groups began to act as subcontractors to the JAEC's public hearings, and METI's and MEXT's various social education programmes.

In this way the 'citizen representatives' in the JAEC's and METI's various advisory councils were in a position to argue for increasing the programmes they themselves benefitted from. An NPO leader, for instance, argued to expand a specific nuclear power PR workshop program in a METI advisory council and later happened become subcontractor for the same program with her NPO (Sugimoto 2013a, 2013c). In 2010 the 'pro-nuclear civil society' seemed powerful as never before. NPOs gained large sums for public enlightenment projects such as the search for a nuclear waste disposal site and donations 
by the nuclear industry (Sugimoto 2013b). The newly elected Democratic Party (DPJ) decided to increase the share of nuclear power production from about 30 to $50 \%$ and public opinion was in favour of nuclear power (Iwai and Shishido 2015).

\section{Changes after the Fukushima Nuclear Accident}

The Fukushima nuclear accident in 2011 was not only a major environmental catastrophe, but also a political disaster for the pro-nuclear campaign. During the course of events the countermovement found itself cut off from important decision-making bodies for the first time in history - if only for a short period. In the first months after the accident the DPJ government was occupied by the immediate countermeasures against widespread destruction caused by the Tsunami. Under the DPJ's Minister of Economy, Banri Kaieda, the pro-nuclear movement was able to retain its influence. In early April 2011 METI announced the building of a 'wise men group' (kenjinkai) to discuss future energy policy. Akito Arima, a key member of the 'pro-nuclear civil society,' was to head the commission ( $A S$ 2011a). In June 2011 the committee's name disappeared from the news. There were rumours in the media about arguments between Prime Minister Naoto Kan and Kaieda. A weekly magazine reported that an agency of METI had prepared the committee to stage a pseudo-discussion and the result (to stick to nuclear power) was already decided (Aera 2011). Kan, however, announced that nuclear power policy would be discussed from the scratch. He was pressured to step down in August 2011 by the LDP and critics within his own party, who threatened to block major policy proposals. However, under Yukio Edano, a top DPJ politician who became Minister of Economy under Kan's successor, a new committee to decide basic energy policy (Sōgō Enerugī Chōsakai Kihon Mondai Iinkai) staffed to one-third with experts sceptical towards nuclear power (while the chairman was a staunch supporter) was installed ( $A S$ 2011e). During Edano's term the 'pro-nuclear civil society' found itself sidelined by scholars and policymakers oriented towards liberalization. While Edano was in favour of restarting reactors as soon as possible, he took a tough position on Kyushu Electric Power (Kyūden), which had become caught up in a scandal touching the core of the 'pro-nuclear civil society.' Kyūden had called on its own employees as well as employees of its subcontractors to speak out for the restart of nuclear reactors during a public hearing event. Because these smaller companies depend on Kyūden for contracts, there was a high chance that such requests would be fulfilled. During the 
event, which was organized by the JPC, many of these mobilized 'citizens' voiced their support for a quick restart. However, the call for mobilization was leaked and became a major scandal. From mid-2011 similar scandals involving other utilities became public. It turned out that METI's organization responsible for nuclear safety and other METI agencies had actually requested the 'pro-nuclear citizens' to turn out at hearings $(A S$ 2011b). As a reaction to Kyūden's lukewarm handling of the incident, METI under Edano blocked a major extension of credit by the Development Bank of Japan to the company ( $A S$ 2011d).

In 2012, there was substantial infighting in the DPJ about energy policy. When it became clear that TEPCO was heading towards default due to the costs of the accident and that the government had to step in, the DPJ was supplied with additional leverage over METI and the nuclear industry (Ōshika 2011). The DPJ installed a committee to analyse the financial situation of TEPCO, which criticized the utility's use of monopoly profits for advertising etc. ( $A S$ 2011c). As a follow-up, a committee was appointed to check the use of electricity fees in case a utility applied for increasing electricity prices. This was an ad hoc measure to change the practice of the existing framework without a change of law, which would take more time. As a consequence, the utilities' freedom in calculating the 'costs for dissemination and development,' one of the pillars of resource supply for the pro-nuclear movement, was reduced (Komori 2012b).

The JAEC, the policy body with legal decision-making power in nuclear policy and one of the hosts of the 'citizen representatives,' got caught up in another scandal. In May 2012 it became public that it had conducted secret meetings with representatives of the nuclear industry and only the pro-nuclear members of one of its advisory councils ( $A S$ 2012e). It also became a target of pressure for reform and the DPJ built an advisory council to come up with proposals for reform. The JAEC was subsequently stripped of the power to decide the basic nuclear energy plans, something that had been decided every three years before.

The DPJ also installed a minister's conference to come up with a new comprehensive energy strategy. It offered three choices for the long-term future of nuclear power: 0,15 , or $20-25 \%$. As part of the policymaking process, deliberative polls on the future energy policy were conducted. They were outsourced to the PR firm Hakuhōdō, which gathered the opinions of citizen via the internet. During the first few meetings it turned out that, again, employees of the nuclear industry were among the citizens stating opinions (they had been picked from the pro-nuclear opinions in the internet). After severe criticism, employees of the nuclear industry were excluded from 
appearing as speakers at discussion events and the distribution of speakers was changed from one-third for every option to a bigger share for the $0 \%$ option, because the overwhelming majority of internet opinions had favoured it ( $A S$ 2012a). The (unintended) results of the poll conducted outside of the framework of the pro-nuclear campaign proved decisive to force the new DPJ leadership into a commitment to nuclear phase-out by 2030 ( $A S$ 2012c). While the initial DPJ statement was weakened after protests from Japan's largest business federation in September 2012, the challenge to the 'pro-nuclear civil society' was substantial.

\section{The Pro-nuclear Campaign in the Opposition}

During this period former Education Minister Akito Arima gathered his allies from the business, science and media communities and founded yet another group, the Energy Policy Discussion Group (Enerugī Seisaku Kondankai), to make an appeal to Prime Minister Noda in March 2012 (AS 2012b). ETT also had to descend into opposition and leave its headquarters within the JPC to relocate to the private Economic Marketing Centre (Keizai Kōhō Sentā) run by the largest business federation. The relocation appears to have been a reaction to increased media attention to its activities in the wake of the Kyūden scandal. The strongholds of the 'pro-nuclear civil society,' the prefectures and communities hosting a large number of nuclear power plants, were important in influencing the Noda government to back away from drastic changes in nuclear policy. When the Minister of the Economy, Edano, declared that he envisioned zero dependence on nuclear power in the future, while meeting with the governor of Fukui prefecture to discuss the restart of nuclear reactors under new ad hoc safety regulations in 2012, the governor refused to meet him again and forced Prime Minister Noda to publicly commit to nuclear power ( $M S$ 2012). When it became public that the government was considering reducing the amount of nuclear fuel processing in a facility built in Aomori, the prefecture's governor announced that the facility's nuclear waste would then be returned to where it came from, forcing the DPJ to abandon its plan (AS 2012f). After the Vice-Minister of the Economy announced that the government was considering stopping the development of the fast-breeding reactor Monju, the governor of Fukui and the mayor of the host community protested and pushed the DPJ government to reverse the decision $(A S$ 2012d).

The pro-nuclear movement was spared more drastic cuts by the second major funding source, the special budget for electricity sources (Dengen Tokubetsu Kaikei). The DPJ had announced a major revision of energy policy, 
including a review of the special budget to acquire funds for reconstruction after the Tsunami. Before this could be put to practice, however, it suffered a crushing defeat in the December 2012 lower house election and was almost eradicated as a political force in the subsequent elections. The new LDP government cancelled the revision and the pro-nuclear movement returned to the advisory councils ( $A S$ 2013). However, a legacy of the DPJ's changes in energy policy remains. During the creation of the new Nuclear Regulation Authority (NRA) under the umbrella of the Ministry of the Environment (also done in 2012 by a cooperation between the DPJ, the LDP and its later coalition partner, Kōmeitō), members of the 'pro-nuclear civil society' were kept out of influential positions (Koppenborg 2020). The NRA since then has become a major target of protests by 'pro-nuclear civil society' groups (see below).

\section{Framing after 2011}

After 2011, the framing of the 'pro-nuclear groups' has become more aggressive. Arima's National Nuclear Conference and other groups regularly criticise various media programmes and newspapers in their newsletters and in 'official statements' (e.g. EMHK 2019). Former Prime Minister Naoto Kan is being depicted by the pro-nuclear campaign as the man who plunged the nuclear administration into chaos, as is his party, the DPJ (Weiss 2019a). The pro-nuclear campaign, in alliance with conservative media and the LDP, was relatively successful in disseminating this framing. The host communities of nuclear power plants arguably also helped to frame the DPJ government as wavering and irresponsible. The next Prime Minister, Abe, was one of the initiators of this narrative. From an early point after the nuclear accident he accused DPJ Prime Minister Kan of interfering in the management of the accident, overestimating his own competence and not listening to experts (Weiss 2019a: 292-294). The Asahi Shinbun, a newspaper which had become critical of nuclear power after 3.11, suffered a major defeat when it was accused by parts of the media and the pro-nuclear campaign of misrepresenting TEPCO and the head of the Fukushima 1 nuclear power plant, who was a national hero, according to the pro-nuclear campaigners (Weiss 2019a: 478-489). They also harshly criticize the NRA for 'not functioning properly' because the new safety procedure takes too long in their eyes; they want the NRA to emphasize the safety of nuclear power plants. The pro-nuclear groups' homepages and newsletters also became more active in disseminating information on the negative effects and problems of renewable energy (e.g. NEK n.d.). Multiple groups handed 
petitions to the government calling for a full commitment to nuclear power and some have also called for the ending of the limitations put on nuclear PR (GKMK 2015). They paint a very dark picture of the future in case Japan does not spend more effort to restore nuclear power. In reaction to the Fukushima accident, the 'female' groups of the campaign increased their focus on radiation and food safety, but their framing also resonates with the changes towards a more negative framing of the government's policy in the 'male'-oriented groups, while using softer words and less direct accusations, warning, for instance, of 'hasty decisions in energy policy (AEFN 2012).'

\section{A Return to Power?}

The LDP government, which was elected in December 2012, proved hesitant to restore the 'pro-nuclear civil society' to full power in energy policy. In METI advisory councils, proponents of liberalization have retained influence and in 2016 the electricity market for consumers was liberalized. This keeps electricity companies under pressure to reduce costs and limits the potential for large-scale PR measures, like before the accident. As a consequence of the accident, METI aims to separate ownership of the electricity grid and electricity production by 2020, a reform, which could potentially further undermine the position of the utilities and their ability to support the 'pro-nuclear civil society.' However, at the same time, the government aims to guarantee the profitability of nuclear power by introducing a financial mechanism for supporting it ( $A S$ 2014a).

It is thus unclear, whether the financial basis and political influence of the 'pro-nuclear civil society' will be reduced significantly. Despite the changes in regulation of the electricity prices, regarding the 'output side' - the budgets of the pro-nuclear groups - there is no clear trend. A limited number of new groups and NPOs were actually founded after 2011. Arima again participated in the founding of at least three groups. They, however, appear to be mainly regroupings and fusions of older activities under new names (Weiss 2019b). The budget available for the 'pro-nuclear civil society' suffered some cuts after the accident. TEPCO was forced to significantly decrease its PR budget from about $€_{210}$ million in 2011 to about $€_{27}$ million in 2012 (Komori 2012b). Some groups were criticized directly in parts of the media for accepting large amounts of money from the state and the nuclear industry while claiming to be 'neutral citizens.' Some groups showed a tendency towards declining funding from public and corporate sources in the years immediately after the accident. After a few years, however, funding has risen again, while not 
completely returning to pre-3.11 levels (Weiss 2019b: 5-13). There were also internal discussions about whether to continue JAERO's funding or not, but it continues operations (Interview Funakoshi 2015).

After the chairwoman of Asuka, who was also a member of JAEC, was severely criticized by newspapers and the DPJ in the Diet for delivering propaganda for money, using her public vehicle for private NPO events, and conflating her public position with her NPO activities, another NPO representative - a radiation researcher - was awarded the 'citizen position' in the JAEC in 2013. The JAEC was stripped of its most important policy competences, which were transferred to METI under Prime Minister Abe, but it retains some functions, for instance, evaluating nuclear policy. In general, the pro-nuclear movement retained power in organizations less affected by scandals and subjected to DPJ reforms. This led to (limited) divisions between different government agencies. A MEXT advisory council created to decide over the future of Japan's fast-breeding reactor in 2016, for instance, was staffed with supporters of the pro-nuclear movement, Akito Arima being the chairman. The NRA had recommended that the ministry change the organization running the current fast breeder Monju (because it considered the current organization not suitable because of past mismanagement). MEXT officials reportedly were worried that the NRA could derail their efforts to continue the development of the nuclear fuel cycle $(A S$ 2015c).

\section{Conclusion}

The Japanese nuclear industry, in coordination with state agencies from the 1970 s on, has mobilized stakeholders with a direct or indirect interest in nuclear power through monetary and symbolic incentives to form a 'pro-nuclear civil society.' This pattern of building up and supporting a countermovement against groups challenging the hegemony of business and political elites resembles what has happened in the Japanese labour movement. While in terms of policy preferences it is difficult to separate the 'pro-nuclear activists' from their sponsors, the pro-nuclear movement cannot be simply analysed with a dichotomous conceptualization of 'the state' versus civil society. First of all, I would argue that the mobilization of local and professional communities for nuclear power was a key component of the strategy of the nuclear industry and officials to promote nuclear power and check the challenge from the anti-nuclear movement. It is a movement directed by a hegemonic developmental alliance mainly focused 
on mobilizing society to accept and support its aims, but parts of civil society took part in the movement and it came to actively employ a 'civil society rhetoric' and underline its 'civicness.'

Interestingly, the campaign was enabled by state subsidies and monopoly profits from a sector of the economy which resisted (neo-)liberalization efforts to a substantial degree. Contrasting Ogawa's case study (Ogawa, in this volume), because of the movement's clientelist character, 'co-optation' rather than 'co-production,' might be the more adequate term to describe its relation to the state and the nuclear industry. The campaign could be seen as a leftover of a fading developmental legacy, but its resilience could also point to a continuing pattern of state-society relations. Some of the 'volunteer' programmes and NPOs described in this chapter, for instance, were simply refurbishments from older programmes installed under a developmental regime.

The movement was able to retain or regain its most important resources, namely money and access to political decision-making, via the LDP and parts of the bureaucracy in METI and MEXT. Its very core, the foundations linking the nuclear industry, bureaucracy and local as well as professional communities (for instance, JAERO and JPC), emerged largely untouched from the political turmoil following the Fukushima accident. This alone could be enough to keep the movement alive. Nuclear scientists, host communities of power plants and cadres of the nuclear industry remain active in advocacy and the organization of local communities through 'social education' and the distribution of resources. A key resource, however, might have been lost during the accident and the following series of scandals. The legitimacy of the pro-nuclear movement has suffered a great deal. While the pro-nuclear movement succeeded in framing the DPJ and politicians aiming to overhaul nuclear policy as irresponsible and chaotic, public opinion strongly embraced nuclear scepticism after the accident (Iwai and Shishido 2015). While the aspect of legitimacy cannot be dealt with here extensively, a key question concerning the future development of the pro-nuclear movement is: To what extent will it be able to overcome its loss of legitimacy?

\section{References}

AEF. 2001-2012. Asuka Energī Fōramu Nyūsuretā. Asuka Enerugī Fōramu, no. 1-46.

http://www.asca-ef.org/public/contents/newsletter/index.html (10 June 2019). AEFN. 2001. Asuka Enerugī Fōramu Nyūsuretā, no. 1, 20 December. AEFN. 2002. Asuka Enerugī Fōramu Nyūsuretā, no. 2, 5 October. 
AEFN. 2012. Asuka Enerugī Fōramu Nyūsuretā, no. 45, 31 July.

Aera. 2011. 'Genpatsu Shishu no Scenario: Keisanshō Yabō no Kakuremino Enerugī Seisasku Kenjinkaigi.' 30 May.

Aldrich, Daniel. 2008. Site Fights: Divisive Facilities and Civil Society in Japan and the West. Ithaca: Cornell University Press.

Arima, Tetsuo. 2008. Genpatsu, Shōriki, CIA: Kimitsu Bunsho de Yomu Shōwa Rimenshi. Tōkyō: Shinchōsha.

AS. 1979. 'Genpatsu Kensetsu ni Kōchōkai: Kongo Shinsei no subete.' Asahi Shinbun, 23 January, p. 2.

AS. 1980. 'Kigyō ni Ikase, Shufu no Chie.' Asahi Shinbun, 24 July, p. 3.

AS. 1989a. 'Genpatsu Suishin o Kakageru Pasocon Netto Kaikyoku.' Asahi Shinbun, 22 February, p. 5 .

AS. 1989b. 'Han-hangenpatsu he Kanmin Kōsei, Kōhō ni 30-oku.' Asahi Shinbun, 10 September, p. 3.

AS. 1992. 'Gaiatsu he no Shisen: Genkai o kanjiru Hankaku Undō: Plutonium gap - ka.' Asahi Shinbun, 1 December, p. 1.

AS. 2001. 'Shijō genrikatsuyō o: Minkan Seisaku Kikan ga Taian.' Asahi Shinbun, 9 November, evening edition, p. 13.

AS. 2011a. 'Eneruḡ̄ Seisaku Kentōkai de Kaigisetchi, Kaieda Keisanshō.' Asahi Shinbun, 29 April, p. 6.

AS. 2011b. 'Genpatsu Shinpo "Yarase”: Kuni no Shiji Nanaken: Daisansha'I ga Saishūhōkoku.' Asahi Shinbun, 10 October, p. 38.

AS. 2011c. 'Keisanshō, Denkiryō no Arikata Kenshō: Gakushikisha no Kaigi Mōke Giron.' Asahi Shinbun, 18 October, p. 6.

AS. 2011d. 'Kyūden Tōshi 1000-oku En o Tōketsu: Yarase Konran Chōkika de Seitōgin.' Asahi Shinbun, 21 October, regional morning edition, Kyushu.

AS. 2011e. 'Sōgō Ene Chōsakai, I'in ni "Genpatsu Hihanha” mo.' Asahi Shinbun, 27 September, p. 2.

AS. 2012a. 'Chōshūkai "Yarase” Hihan: Denryokugaishain ga 'Genpatsushuishin'Iken: Seifu Hikeshi “Hatsugen Kinshi”.' Asahi Shinbun, 18 July, p. 3.

AS. 2012b. 'Genpatsu Saikadō o Motomeru Teigen: Zaikaijin ya Daigaku Kyōjura.' Asahi Shinbun, 16 March, p. 7.

AS. 2012c. 'Genpatsu Zero: Gosan no Seiken, Honmei 15\% Shiji Nobizu.' Asahi Shinbun, 23 August, p. 2.

AS. 2012d. 'Genpatsu Zero Senryaku Guragura, "Monju Hairo” sugu Shūsei, Noda Naikaku.' Asahi Shinbun, 19 September, p. 3.

$A S$. 2012e. 'Genshiryoku'i, Mura Taishitsu nao: Suishinha dake de Hikōkai Kaigi.' Asahi Shinbun, 26 May, p. 2.

AS. 2012f. 'Kodawaru Nishikawa Fukui-ken Chiji: Ōi Genpatsu Saikadō he no Handanshōten.' Asahi Shinbun, 3 June, p. 3. 
AS. 2013. 'Kasumu Datsugenpatsuron, Enerugī Kihonkeikaku, Giron Saikai.' Asahi Shinbun, 16 March, p. 8.

AS. 2014a. 'Genpatsu Saikadō o Tou: 2: Itami o Wasureta Mura.' Asahi Shinbun, 19 July, p. 7 .

AS. 2014b. 'Katei-muke Denki, Jiyūka he Michi: Denkijigyōhō Kaiseian, Kokkai de Seiritsu he.' Asahi Shinbun, 19 May, p. 4.

AS. 2015a. 'Jinsei no Okurimono: Watashi no Hansei: Butsurigakusha Arima Akito: 5: 85sai.' Asahi Shinbun, 4 December, p. 5 .

$A S .2015$ b. 'Jinsei no Okurimono: Watashi no Hansei: Butsurigakusha Arima Akito: 6: 85sai.' Asahi Shinbun, 28 December, p. 5 .

AS. 2015c. 'Monju Kentōkai Hossoku, Monbukagakushō: Arata na Un'ei Shutai Erabi.' Asahi Shinbun, 4 December, p. 2.

Avenell, Simon. 2012. 'From Fearsome Pollution to Fukushima: Environmental Activism and the Nuclear Blind Spot in Contemporary Japan.' Environmental History, 17 (2): 244-276.

Avenell, Simon. 2018. 'Japan.' Routledge Handbook of Civil Society in Asia. Akihiro Ogawa (ed.). New York: Routledge, pp. 17-32.

Broadbent, Jeffrey. 1999. Environmental Politics in Japan: Networks of Power and Protest. Cambridge: Cambridge University Press.

Ebina, Kenzō. 1992. Inaba Hidezō: Gekidō no Nihon Keizai to tomo ni 6o-nen. Tōkyō: Nishida Shoten.

EKSKH. 1998. Genshiryoku Suishin Undō no Susume. Enerugī to Kurashi-Shimin no Kai Henshūkyoku. Tōkyō: Utopia Kaihatsu Kenkyūjo.

EMHK. 2019. Enerugī Mondai ni Hatsugen suru Kai. http://www.engy-sqr.com/ index-leg.html (10 June 2019).

ESK. 2002. Enerugī Seisaku Kihonhō. http://elaws.e-gov.go.jp/search/elawsSearch/ elaws_search/lsg0500/detail?lawId=414AC1000000071 (10 June 2019).

ETT. 2017. Enkaku. Energy Think Together. http://www.ett.gr.jp/about/office.html (10 June 2019).

Fuchs, Christian. 2018. 'Authoritarian Capitalism, Authoritarian Movements and Authoritarian Communication.' Media, Culture \& Society, 40 (5): 779-791.

Garon, Sheldon. 1997. Molding Japanese Minds: The State in Everyday Life. Princeton: Princeton University Press.

Gerschenkron, Alexander. 1962. Economic Backwardness in Historical Perspective: A Book of Essays. Cambridge: The Belknap Press of Harvard University Press.

GHKK. 1997-2015. Genshiryoku Hōdōo Kangaeru Kaino Zenhōkoku. Genshiryoku Hōdō o Kangaeru Kai. http://www.kokumin.org/genshiryoku_houdou (10 June 2019). GKMK. 2015. Newsletter 33, 31 August. Genshiryoku Kokumin Kaigi. http://www. kokumin.org/231 (10 June 2019). 
GMHK. 2006. Energī Mondai ni Hatsugen suru Kai Katsudō Naiyō. Genshiryoku Mondai ni Hatsugen suru Kai. http://www.engy-sqr.com/profile2/katudounaiyou.htm (10 June 2019).

Gordon, Andrew. 1997. 'Managing the Japanese Household: The New Life Movement in Postwar Japan.' Social Politics, 4 (2): 245-283.

Gordon, Andrew. 1998. The Wages of Affluence: Labor and Management in Postwar Japan. Cambridge, MA: Harvard University Press.

GPAHI. 1991. Genshiryoku PA Hōsaku no Kangaekata. Genshiryoku PA Hōsaku I'inkai. http://labor-manabiya.news.coocan.jp/shiryoushitsu/PAhousaku.pdf (19 May 2016).

Group 1984. 1975. 'Nihon no jisatsu.' Bungei Shunjū 52: 92-124.

Heinrich, Volkhart F. 2005. 'Studying Civil Society across the World: Exploring the Thorny Issues of Conceptualization and Measurement.' Journal of Civil Society, 1 (3): 211-228.

HGK. 2002. 25-nen no Ayumi. Kanazawa: Hokuriku Genshiryoku Kondankai.

Hōgaku Shoin Henshūbu. 1999. Shōhi Seikatsu Advisor no Shigoto ga Wakaru Hon. Tōkyō: Hōgaku Shoin.

Honda, Hiroshi. 2005. Datsugenshiryoku no Undō to Seiji: Nihon no Enerugī Seisaku no Tenkan ha Kanō ka. Sapporo: Hokkaidō Daigaku Tosho Kankōkai.

Hook, Glenn. 1984. 'The Nuclearization of Language: Nuclear Allergy as Political Metaphor.' Journal of Peace Research, 21 (3): 259-275.

Hsu, Kan-Lin. 2012. 'Two Paradigms of the Developmental State Approach, with Special Reference to South Korea and Taiwan.' American Journal of Chinese Studies, 19 (1): 13-28.

Iwai, Noriko; Kuniaki Shishido. 2015. 'The Impact of the Great East Japan Earthquake and Fukushima Daiichi Nuclear Accident on People's Perception of Disaster Risks and Attitudes toward Nuclear Energy Policy.' Asian Journal for Public Opinion Research, 2 (3): 172-195.

JAEC. 1996. Heisei 8-nen Genshiryoku Hakusho. Tōkyō: Japan Atomic Energy Commission.

JAEC. 20o9. Genshiryoku I'inkai Shimin Sanka Kondankai no Katsudō ni tsuite. Japan Atomic Energy Commission. http://www.aec.go.jp/jicst/NC/iinkai/teirei/ siryo20o9/siryo24/siryo5-1.pdf (10 June 2019).

JAEC. N.d. Rekidai Genshiryoku I'in. Japan Atomic Energy Commission. http:// www.aec.go.jp/jicst/NC/about/iin/iino.pdf (10 June 2019).

JAERO. 1994. Genshiryoku Bunka o mezashite: 25-nen no Ayumi. Tōkyō: Japan Atomic Energy Relations Association.

Johnson, Chalmers. 1982. MITI and the Japanese Miracle: The Growth of Industrial Policy, 1925-1975. Stanford: Stanford University Press. 
Katz, Hagai. 2006. 'Strengthening the Conceptual Foundations of Civil Society Operationalizations: Discussing Heinrich's "Studying Civil Society across the World." Journal of Civil Society, 2 (2): 173-177.

Komori, Atsushi. 2012a. 'Genpatsu to Media 10: Kōhō ha Kensetsuhi.' Asahi Shinbun, 14 September, p. 11.

Komori, Atsushi. 2012b. 'Genpatsu to Media 240, Money 14, Kōkokutō no Nedan.' Asahi Shinbun, 21 September, evening edition, p. 16.

Koppenborg, Florentine T.M.A. 2020. 'Legal Fallout from the Fukushima Nuclear Accident: Reforming Nuclear Safety Administration in Japan.' Fukushima and the Law. Julius F. Weizdörfer; Kristian C. Lauta (eds). Cambridge: Cambridge University Press. Forthcoming.

Kozumi, Hiroshi; Shin'ichi Sasaki. 2010. Konnani Omoshiroi Kankyō Kanserā no Shigoto. Tōkyō: Chūō Keizaisha.

Mason, Robert. 1999. 'Whither Japan's Environmental Movement? An Assessment of Problems and Prospects at the National Level.' Pacific Affairs, 72 (2): 187-207.

McKean, Margaret. 1981. Environmental Protest and Citizen Politics in Japan. Berkeley: University of California Press.

Meyer, David; Suzanne Staggenborg. 1996. 'Movements, Countermovements, and the Structure of Political Opportunity.' American Journal of Sociology, 101 (6): 1628-166o.

Minakuchi, Satoshi. 2016. Keireki. http://www.gns.ne.jp/minakuchi/mioo_1.htm (10 June 2019).

MS. 2012. 'Kenshō, Daishinsai Ōi Saikadō Jimoto Dōi 'Shushō Kaiken shika nai,' Yuzuranu Fukui, Seifu Gosan.' Mainichi Shinbun, 5 July, p.1.

NEK. N.d. Nihon Enerugī Kaigi. http://enercon.jp/wp/wp-content/uploads/2012/o 9/8a2e4337a25c040odadodo5c8f71ef871.pdf (10 June 2019).

NSH. 1972. Kankyōmondai Sangyō Kaigi Kiroku: Seichō to Kankyō. Tōkyō: Nihon Seisansei Honbu.

NSH. 2005. Seisansei Undō 5onenshi. Tōkyō: Nihon Seisansei Honbu.

NSK. 2012. Kōshin Kenshū no Arikata ni kan suru Kentō Iinkai Hōkokusho. Nihon Sangyō Kyōkai. http://www.nissankyo.or.jp/adviser/qualifıed/download/ kousinkentou_houkokusyo.pdf (10 June 2019).

Ōshika, Yasuaki. 2011 'Kokuyūka Kyozetsu no Kōbōsen: Tōden Dokushō ano Hi ni Kaeritai.' Aera, 5 December, p. 64.

Pekkanen, Robert. 2004. 'After the Developmental State: Civil Society in Japan.' Journal of East Asian Studies 4 (3), 363-388.

REF. 2010. Teikan. Radiation Education Forum. https://ref.or.jp/file/profile_teikan. pdf (10 June 2019).

Sankei Shinbun. 2008. 'Arima-Zachō Ichimon Ittō,' 22 May, p. 7. 
Suga, Hidemi. 2012. Hangenpatsu no Shisōshi: Reisen kara Fukushima he. Tōkyō: Chikuma Shobō.

Sugimoto, Shūsaku. 2013a. 'Denryoku Gyōkai: Shinsaigo ni Shikin 1800-man En. Genshiryokuiin NPO ni.' Mainichi Shinbun, 25 March, p. 31.

Sugimoto, Shūsaku. 2013b. 'Genpatsu Propaganda: Denryokugyōkai kara Shikin Teikyō no NPO Kankeisha, Kōchōkai Yonkaijō de Hatsugen.' Mainichi Shinbun, 28 March, p. 30.

Sugimoto, Shūsaku. 2013c. 'Genpatsu Propaganda: Enechō Jigyō, Rokunen Juchū, Moto Genshiryoku Iin no NPO mo.' Mainichi Shinbun, 26 March, p. 8.

Suzuki, Akira. 2003. 'The Death of Union's Associational Life? Political and Cultural Aspects of Enterprise Unions.' The State of Civil Society in Japan. Frank J. Schwartz; Susan J. Pharr (eds). Cambridge: Cambridge University Press, pp. 195-213.

Suzuki, Akira. 2016. 'Japanese Labour Unions and Nuclear Energy: A Historical Analysis of Their Ideologies and Worldviews.' Journal of Contemporary Asia, 46 (4): 591-613.

Suzuki, Tatsuru. 1983. Denryoku Sangyō no Atarashii Chōsen. Tōkyō: Nihon Kōgyō Shinbunsha.

Taguchi, Fukuji. 196o. 'Chūseiren ni okeru Soshiki Mondai.' Nenpō Seijigaku: Nihon No Atsuryoku Dantai. Nihon Seiji Gakkai (ed.). Tōkyō: Iwanami Shoten, pp. $64-85$.

Utsumi, Hirofumi. 2012. 'Nuclear Power Plants in "The Only A-bombed Country": Images of Nuclear Power and the Nation's Changing Self-portrait in Postwar Japan.' The Nuclear Age in Popular Media. Dick Van Lente (ed.). London: Palgrave Macmillan, pp. 175-201.

Way, Lucian. 2014. 'Civil Society and Democratization.' Journal of Democracy, 25

(3): $35-43$.

Weiss, Tobias. 2019a. Aufder Jagd nach der Sonne: Das journalistische Feld und die Atomkraft in Japan. Baden-Baden: Nomos.

Weiss, Tobias. 2019b. 'Japan's 'Pro-nuclear Civil Society': Power in the Analysis of Social Capital and Civil Society.' Journal of Civil Society, 15 (4):326-52.

Yamaoka, Jun'ichirō. 2015. Nihon Denryoku Sensō: Shigen to Ken'eki, Genshiryoku o Meguru Tōsō no Keifu. Tōkyō: Sōshisha.

Yoshioka, Hitoshi. 2011. Shinpan Genshiryoku no Shakaishi. Tōkyō: Asahi Shinbunsha.

\section{Interviews}

Interview FNRAJG 2017. Former nuclear radiation advisor to the Japanese government, 2017.

Interview Funakoshi 2015. Makoto Funakoshi, Japan Atomic Energy Relations Organization (JAERO), 2015. 
About the Author

TOBIAS WeIss is Research Fellow at Heidelberg University, Germany. In January 2018, he finished his $\mathrm{PhD}$ at the University of Zurich. His main research focus is on civil society, mass media and politics in Japan. His most recent publications include Aufder Jagd nach der Sonne. Das journalistische Feld und die Atomkraft in Japan (Nomos, 2019); 'Journalistic Autonomy and Frame Sponsoring: Explaining Japan's "Nuclear Blind Spot" with Field Theory,' Poetics (2019); 'Japan's Pro-nuclear Civil Society: Power in the Analysis of Social Capital and Civil Society,' Journal of Civil Society (2019). 


\section{Part II}

Identity Politics 



\title{
5 The 'Pro-Establishment' Radical Right
}

\author{
Japan's Nativist Movement Reconsidered
}

\author{
Naoto Higuchi
}

\begin{abstract}
Japan has witnessed the rise of nativist demonstrations and hate crimes since the late 200os, leading the Diet to enact the country's first anti-racism law in 2016. The aim of this chapter is to examine the pro-establishment nature of Japan's nativist movement. The movement often criticizes the ruling right-wing establishment but should be regarded as a detachment force of the establishment in two ways. First, Japanese nativism is a variant of historical revisionism and the emergence of nativist violence is a 'by-product' of the rise of historical revisionism among the right-wing establishment in post-Cold War Japan. Although the nativist movement and the right-wing establishment are not directly associated with each other, the former took full advantage of the discursive opportunity opened by the latter. Second, the general public favours the nativist movement as part of the conservative establishment.
\end{abstract}

Keywords: xenophobia, radical right, Zainichi Koreans, racism, nationalism

On 11 April 2009, 200 demonstrators marched around an apartment of an undocumented Filipino family in Warabi (a suburban city of Tokyo), shouting, 'Illegal families get out!' This was organized by a nativist group named Zainichi Tokken o yurusanai Shimin no Kai (Association of Citizens against the Special Privileges of Koreans in Japan, hereafter Zaitokukai) established in 2007. This demonstration was rather exceptional for Zaitokukai, whose main target is Koreans in Japan, but became a catalyst for a dramatic increase

Chiavacci, David, Simona Grano, and Julia Obinger (eds), Civil Society and the State in Democratic East Asia: Between Entanglement and Contention in Post High Growth. Amsterdam, Amsterdam University Press 2020 DOI: 10.5117/ 9789463723930_CHO5 
Figure 5.1 Changes in Zaitokukai membership

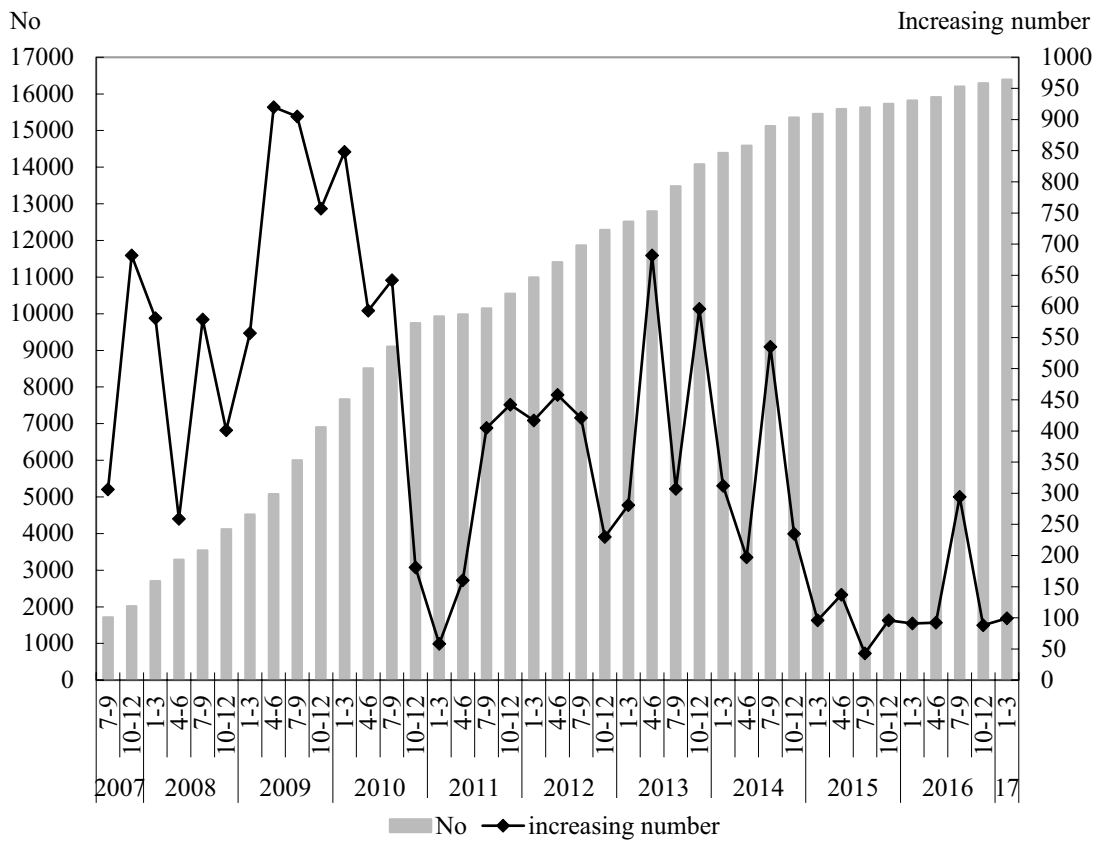

Source: Zaitokukai website (now closed)

in its membership (see Figure 5.1), ${ }^{1}$ having grown into the largest and the most well-known amongst nativist groups with more than 15,000 members. ${ }^{2}$ It was sympathetic public opinion to the Filipino family that paradoxically enhanced the visibility of Zaitokukai: its stance strongly resonated with those who disagreed with this trend.

On 3 June 2018, when nativists held a gathering in Kawasaki, a city known for being home to a Korea town, 400 anti-racist protesters surrounded 30 nativists and shouted, 'Racists go home!, keeping them out from a building planned for the venue. After a small scuffle between the two groups, nativists realized they had lost and finally brought the gathering to a halt.

Things had changed in the nine years between the two incidents. Although Japan has a long history of right-wing movements, their core ideologies were

1 However, this figure accounts for members who have registered by email; there is no obligation to disclose information concerning individuals or the payment of fees. Consequently, it would be more accurate to say that there are over 15,000 registered individuals rather than members.

2 Although there have been more than a dozen nativist organizations (Gill 2018), other groups failed not only to recruit a large number of members but to attract public attention. 
anti-communism and emperor-centred nationalism, having been rather indifferent to nativism. ${ }^{3}$ It seems, therefore, Zaitokukai came to the fore out of the blue, targeting Koreans who were a well-integrated ethnic minority in Japan. Although Zaitokukai claims Korean residents enjoy 'special privileges,' such as special permanent residency, the issuing of subsidies to Korean schools, favourable welfare provisions and the alias system (use of Japanese names), this is no more than a groundless rumour. Nevertheless, Japan saw the rise of Zaitokukai and this shocked many Japanese because it was the country's first nativist movement organizing anti-immigrant demonstrations.

The rise of anti-racist countermobilization in 2013 also surprised people enough to win the attention of the general public (Higuchi 2020). ${ }^{4}$ Since then, 'hate speech' has been a buzzword to describe behaviour like that shown by Zaitokukai. A Diet member group of the opposition was also established in May 2013 to urge the ruling coalition to legislate an anti-discrimination law. The ruling conservative Liberal Democratic Party (LDP) was reluctant to enact any anti-discrimination laws, but it finally yielded to the opposition, passing the Hate Speech Elimination Law in May 2016. Although the effectiveness of this law is limited, because it neither prohibits hate speech nor punishes it (Martin 2018), this is still a remarkable change all the more because it is Japan's premier law against racism.

After Zaitokukai founder Makoto Sakurai ${ }^{5}$ resigned in order to take responsibility for a physical assault against an anti-racism activist by Zaitokukai members at the end of 2014, the group quickly deteriorated. Figure 5.1 shows that few members have joined Zaitokukai since January 2015, except for a short period immediately after the enforcement of the Hate Speech Elimination Law, although it managed to overcome the first crisis at the end of 2010 when several members were arrested and charged with forcible obstruction of business. ${ }^{6}$ Finally, Zaitokukai stopped updating its webpage in

3 Here nativism refers to 'an ideology, which holds that states should be inhabited exclusively by members of the native group ("the nation") and that non-native elements (persons and ideas) are fundamentally threatening to the homogeneous nation-states' (Mudde 2007: 19).

4 The countermovement was initiated by a few anti-nuclear activists, but it has been a spontaneous protest independent on any groups. Recruited by social media, thousands of people - including Japanese leftists, Koreans, K-pop fans, and even right-wing activists - have protested against Zaitokukai events.

5 In 2003 , Makoto Sakurai (1973-) started his right-wing activity as a blogger posting anti-Korea content when he was a part-time worker in a municipality office of Tokyo. He is now the leader of the Japan First Party, which backed a dozen of candidates in local elections in April 2019 but failed to gain a seat.

6 In 2010, they attacked a Korean school in Kyoto and also crashed into the office of Tokushima's teacher's union. 
June 2017, and its activities came to a standstill. Although Sakurai launched another organization named the Japan First Party in 2017, aimed to field candidates for local elections, the movement was no longer able to recover its momentum.

The aim of this chapter is to reconsider the origins, nature, and breadth and depth of the power base of Japan's nativist movement. At first glance, Japan successfully forestalled the expansion of nativist groups. However, it is misleading if we regard them analogous to the European anti-establishment radical right, because the key to understanding Japan's nativist movement and its support base is their pro-establishment nature. Thus, I examine the hypothesis that behind the rise of the nativist movement lie changing interests of the right-wing establishment. ${ }^{7}$ More precisely, I argue that this is a 'by-product' of the rise of historical revisionism among the right-wing establishment in Japan.

In this chapter, I distinguish three types of actors ${ }^{8}$ : (1) the nativist movement as the new radical right, (2) rightist politicians (mostly of the ruling LDP) and organizations around the Japan Conference ${ }^{9}$ as the right-wing establishment, and (3) the LDP as a whole as the conservative establishment. The religious right and groups of war veterans (and their families) make up the organizational base for the right-wing establishment. The religious right is composed of Shinto and Buddhist organizations, including a considerable number of related cults (regarding the orientations of the religious right, see Ho, in this volume). These are characterized by strong political influence in close association with the LDP (Higuchi 2018). The religious right insists on historical revisionism as well as traditional

7 Here the nativist movement is defined as a social movement based on an ideology, which holds that states should be inhabited exclusively by members of the native group ('the nation') and that non-native elements (persons and ideas) are fundamentally threatening to the homogeneous nation-states (Mudde 2007: 19). The radical right in Japan refers to societal groups or parties that adopt nationalism and nativism/historical revisionism/traditionalism/anti-communism as their policies, to the far right of mainstream conservatives (Higuchi 2018). The definition of a 'right-wing establishment' is political elites who are hawkish but still belong to the mainstream. 8 Although Japan's radical right has a three-layered structure (Higuchi 2018), I will not refer to survivors of pre-war fascist organizations in this chapter. In post-war Japan, they created the public image of the radical right. Members of such organizations who held public office were purged in the process of post-war demilitarization by the US occupation power, but they kept close relationships with the conservative establishment (Szymkowiak and Steinhoff 1995). They also include quasi-outlaw cadres with connections to the mafia, making mass mobilization impossible (Smith 2014). But their anti-communist claims lost legitimacy and they have been on a course of decline in the post-Cold War period.

9 Nippon Kaigi (The Japan Conference), the largest nationalist group in Japan, was launched in 1997. 
ethics and emperor-centred nationalism, but has been rather indifferent to migrants and ethnic minorities.

At first sight, the nativist movement differs greatly from the right-wing establishment. Although some activists back their favourite politicians, the movement has little contact with the right-wing establishment, distancing itself from the 'established'-style radical right. In addition, the nativist movement often opposes policies of the ruling LDP, while the right-wing establishment has been staying in line with it. However, I argue nativists took full advantage of the opportunity that the right-wing establishment opened, which brought about the rise of the movement.

\section{Discursive Opportunities: An Analytical Viewpoint}

The notion of 'political opportunity structure' is widely used to explain the relation between social movements and politics. The basic premise of this is that the rise and fall of social movements are usually mediated by politics, which not only facilitates or constrains mobilization but also characterizes the nature of movements. Among the five important dimensions classified by Tarrow (1998: 76) (opening of access, political realignments, split within the elite, influential allies and declining capacity to repress dissent), influential allies have been the most important factor for Japan's right-wing movement because it has been in close association with the LDP's right-wing politicians. However, given that the nativist movement lacks contact with political elites, it is difficult to explain the rise of the movement in relation to institutional aspects of political opportunities. Instead, I focus on discursive opportunities that have provided favourable conditions for the nativist movement (Koopmans and Muis 2009; Koopmans and Statham 1999). Discursive opportunities refer to 'institutionally anchored ways of thinking that provide a gradient of relative political acceptability to specific packages of ideas' (Ferre 2003: 309). They prescribe which cause will stand out in a given political system at a given time; the credibility of a construction of reality; and the legitimacy of demands (Koopmans and Statham 1999: 228).

Activists can more easily gain visibility, resonance and legitimacy by constructing movements in accordance with elite discourse, as is the case with the rise of violence against asylum seekers and the revision of asylum rights in Germany in the 199os (Koopmans and Olzak 2004). This issue was a matter of maximum priority for politicians and the media for a year and a half and radical right violence increased, taking advantage of controversy over asylum 
seekers. The radical right adjusted themselves to the political circumstances that had caused asylum seekers to be perceived as an unbearable burden by some in Germany. Xenophobic violence might not have broken out if the discursive opportunities in Germany had not become anti-immigrant.

In contrast, migration has seldom attracted political interest in Japan, as I will explain later. However, politicians have been repeatedly uttering remarks to justify pre-war Japanese colonization and invasion of neighbouring countries (Wakamiya 2006). Regardless of whether or not the term 'hatred of Koreans' (kenkan) is used, a Japanese-style orientalism towards Korea is deeply rooted both politically and socially. However, even if we regard this enduring common fault of Japanese society as the cause, it cannot explain the rise of the nativist movement in the late 200os. We need to focus on changes in discursive opportunities over several decades. I argue the rise of historical revisionism served as a fertile ground for the nativist movement.

\section{Data}

In this chapter, I use a series of data related to the radical right in Japan. ${ }^{10}$

Data (1): I used the blog of Zaitokukai founder Makoto Sakurai. Because Sakurai's blog covers events from the beginning of the formation of the nativist movement and posts links to information about related events, information that is essential to coding can be gathered from it. Using this method, I collected information about 1,006 protest events occurring between 2007 and 2012.

Data (2): This data examines the interests of the right-wing establishment with the aim of elucidating the changes in its designation of enemies. I listed the titles, from 1982 to 2015, of issues of the major right-wing monthly journals Shokun! and Seiron, to which many right-wing politicians contributed: articles by the current Prime Minister Shinzo Abe appeared in these journals 42 times from 1993 to $2015 .{ }^{11}$ I used the data to deal with discourse that was further to the right than that of the conservative establishment.

Data (3): I use the data of an online survey we conducted with 77,084 greater Tokyo residents in December 2017. ${ }^{12}$ These data are used to map public sentiment towards social movements, political parties and foreign countries.

10 For details of the data used, see Higuchi (2016: Appendix) and Satō et al. (2018). Data collection was supported by JSPS KAKENHI Grant Number $17 \mathrm{Ho1005}$.

11 As Shokun! ceased publication in 2009; I replaced it with WiLL from that point onwards.

12 This survey was supported by Japan Society for the Promotion of Science (grant-in-aid for Scientific Research (A) ${ }_{17}$ Ho1005) in collaboration with Shun Harada, Yuko Hirabayashi, Barbara 
Data (4): I conducted interviews with 34 activists in the nativist movement from February 2011 to October 2012. Throughout my fieldwork, I asked activists to tell me their life histories leading to their participation in the movement. The attributes of participants were: gender -4 females and 30 males; age - four people in their 2os, thirteen in their 30 s, eleven in their 40s, four in their 5os, and two in their 6os.

\section{The Nativist Movement in the Right-wing Discursive Space}

\section{Opening Discursive Opportunities towards East Asia}

As Koopmans argues, it is assumed that the nativist movement developed in a given discursive space. Thus, we need first to trace how it changed over time by illustrating the interests of the right-wing journals through two graphs. Figure 5.2 plots the changes in the frequency with which the Soviet Union/ Russia, China, South Korea and North Korea appear in articles. Two broad changes emerge for the 1990s and the 200os from this graph. Throughout the 1980 s, the frequency for the Soviet Union, then the imaginary enemy of Japan, remained at a high level. Conversely, East Asian countries (China, South Korea and North Korea) appeared in only $4.8 \%$ of articles in the 1980 .

This was to change in the 1990s: although the Soviet Union continued to be of interest until its dissolution, after that point its ratio dropped dramatically and failed to return to its former levels. ${ }^{13}$ In the 1990 , right-wing journals lost interest in foreign countries, and in 2000 the figure for all four countries combined fell below $10 \%$. However, signs of the changes that would take off in the 2000 s were already visible in the 1990s, and Figure 5.3 shows the direction that this discourse was taking. Until the mid-1980s, the number of articles related to military affairs and defence sometimes exceeded $10 \%$. After the end of the Cold War, military affairs and defence ceased to make up the central concerns of the right-wing establishment, and in their place history-related articles exceeded $10 \%$ for the first time in 1997. One of the background factors to this was the fact that the right-leaning Sankei Shimbun Co. ${ }^{14}$ which

Holthus, Mitsuru Matsutani, Kikuko Nagayoshi, Hiroshi Ohata, Keiichi Satō and Woncheol Sung. Preliminary results are shown Satō et al. (2018).

13 The decreasing presence of the Soviet Union resulted in a striking reduction in discursive opportunities for old radical right groups, and may be seen as one of the causes of their decline. 14 Sankei is the smallest of Japan's five national newspapers and most clearly expresses rightist opinions. 
Figure 5.2 Frequencies of appearance of countries in right-wing journal articles, 1982-2015

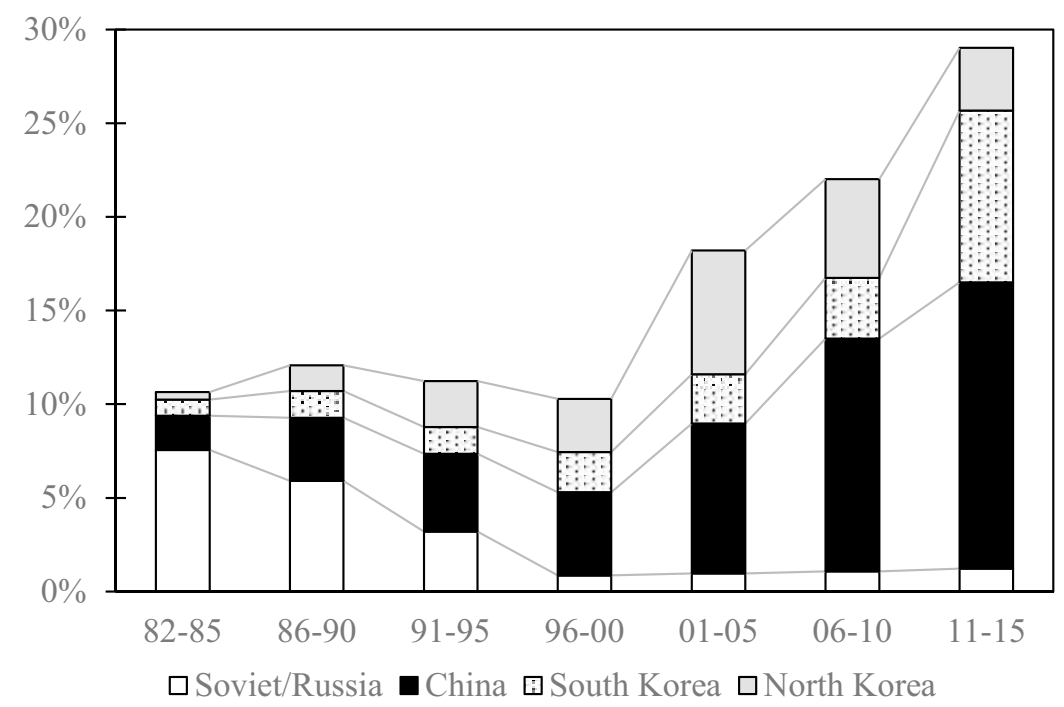

Source: Own analysis, for details see data (2) in the section on data sources

publishes Seiron, was backing new revisionist history textbooks in this year. The increasing importance of historical issues and the additional steady increase in the proportion of those related to foreign countries occurred from the second half of the 1990s, and this focus remains unchanged to the present day.

Figure 5.2 also shows the beginning of an increase in articles about foreign countries following the terrorist attacks on 11 September 2001 in New York, and a further increase with the 2002 visit to North Korea by Prime Minister Koizumi. This is not just a matter of passing interest: these articles reached and maintained a level of over $20 \%$. The only exception came at the time of the drubbing handed out by the change of the government from the conservative LDP to the centrist Democratic Party of Japan (DPJ) when it took office in 2009. With the advent of this century, there was an increase, amongst articles related to foreign countries, to around $20 \%$ of articles related to East Asia. Furthermore, leaving aside North Korea in 2003, which breathed new life into the abduction issue, it was China that attracted overwhelming attention (see the introduction by Chiavacci and Grano, in this volume). In line with the hypothesis presented in the introduction, East Asian countries had come to be seen as the biggest enemies. 
Figure 5.3 The rise of history as an issue for the radical right

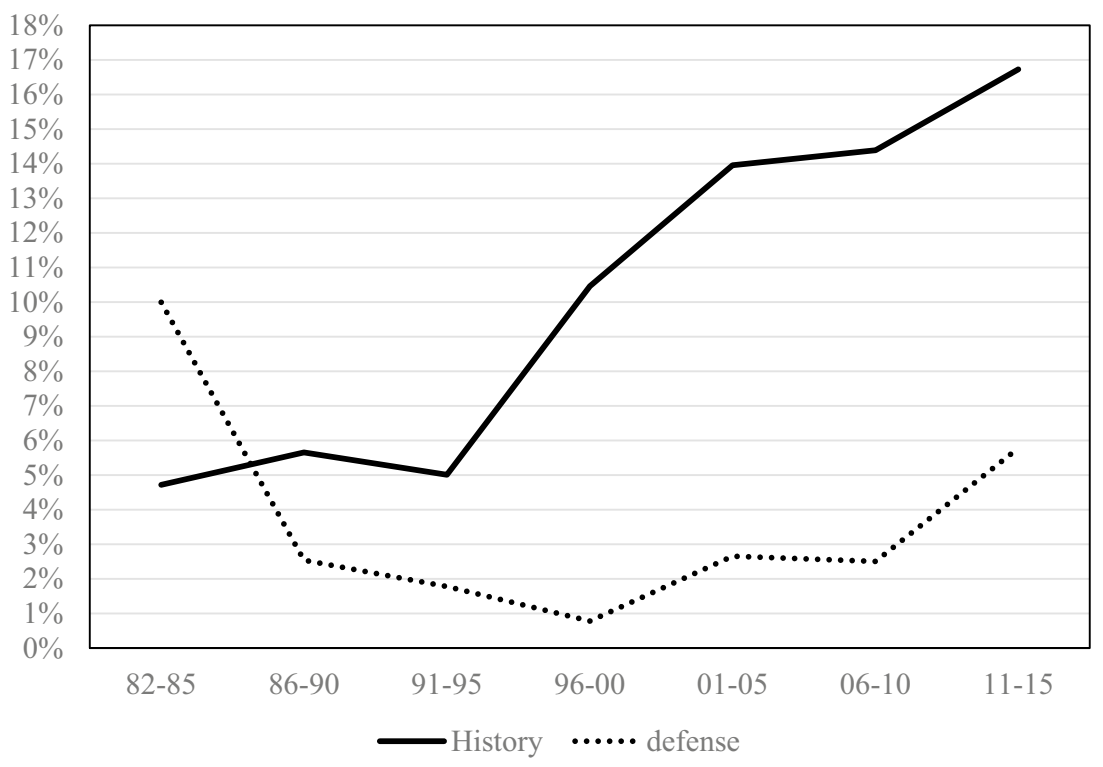

Source: Own analysis, for details see data (2) in the section on data sources

\section{Japan's Nativist Movement as a Detachment Force of the Right-wing Establishment}

When we compare the topics of right-wing journals and events by the nativist movement in Figures 5.4 and 5.5, we find both similarity and difference between the two. Nevertheless, the targets of Zaitokukai and right-wing journals roughly shifted together in the following ways. (1) Events and articles targeting East Asia fell in 2009 and then shot up in 2012, because both relentlessly bashed the DPJ government as a new threat during its rule for three years. (2) History-related events and articles increased in 2009 to champion Toshio Tamogami, the former Chief of Staff of Japan's Air Self-Defense Force who caused a problem by presenting a revisionist article, but the proportion fell once again in the following year.

This is an unexpected result, because the primary goal of the nativist movement is expulsion of Koreans in Japan as the name of Zaitokukai alludes. In fact, its targets are more varied. Figure 5.4 shows targets of events organized by Zaitokukai. In total, $28 \%$ of events called for attacking Koreans in Japan and $4 \%$ against other migrants such as Chinese and Filipinos. As a result, events targeting ethnic minorities were outnumbered by those related to neighbouring countries (33\%): nearly half $(45 \%)$ of events were related to history and East Asia. 
Figure 5.4 Issues in events related to Zaitokukai, 2007-2012

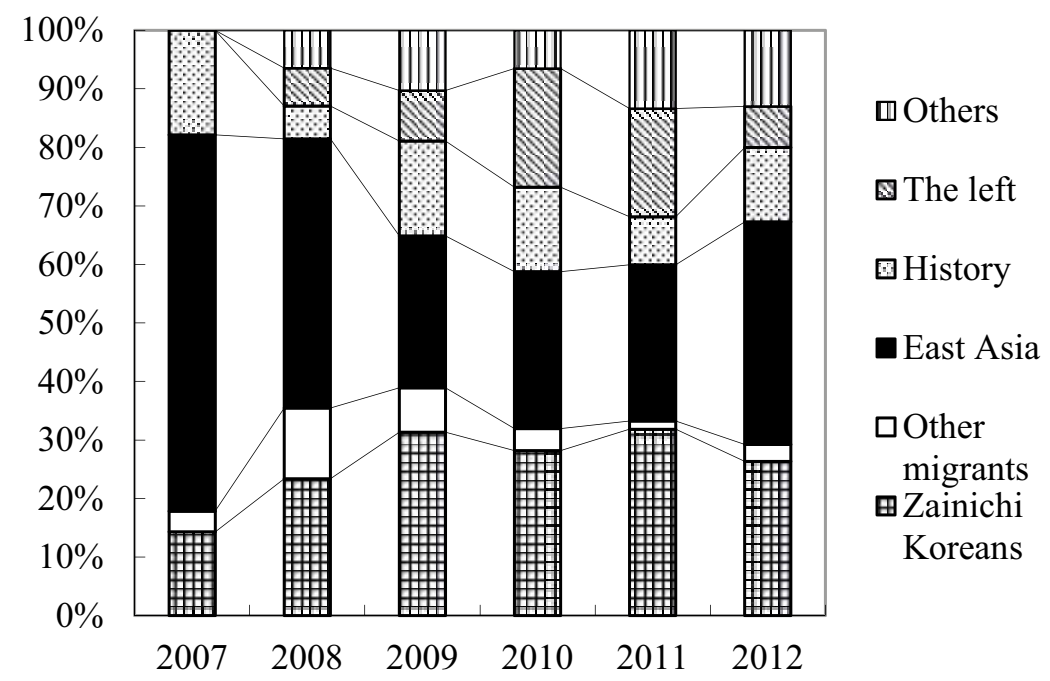

Source: Own analysis, for details see data (1) in the section on data sources

Figure 5.5 Topics of right-wing journals, 2007-2012

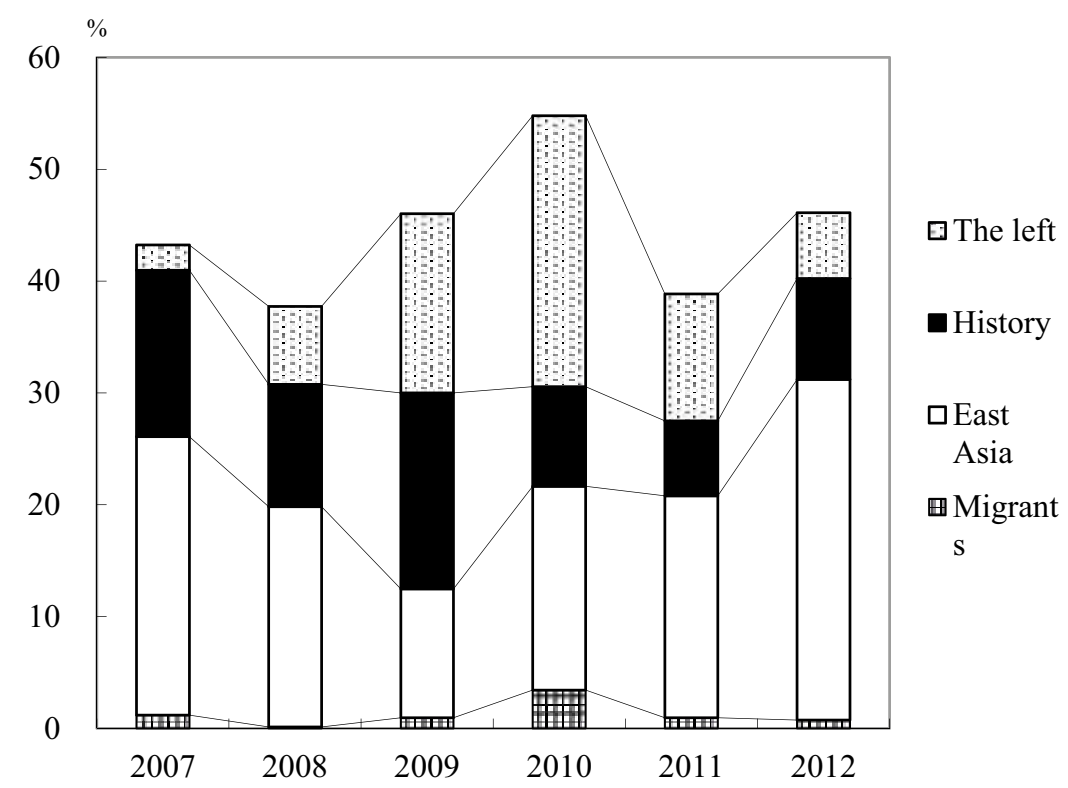

Source: Own analysis, for details see data (2) in the section on data sources 
This is because the core idea of the nativist movement is rooted in historical revisionism. The movement primarily followed the way paved by the right-wing establishment and then took its own line. The primary goal of Zaitokukai is to repeal the Special Immigration Control Act legislated for Koreans because they say it is a symbol that Koreans are bestowed 'special privileges.' This legal status is applied to those who are former colonial citizens and their descendants who have been living in Japan since before Japan's defeat in World War II. Under US military rule, the Japanese government stopped allowing these people (mostly Koreans) the right to choose their nationality. When the San Francisco Peace Treaty came into effect in 1952, former colonial citizens lost their Japanese citizenship, making their legal status unstable. Japan's reluctance to grant rights to former colonial citizens, as well as the division of the Korean peninsula, delayed fixing the legal status of Korean residents. Finally, Japan-South Korea bilateral negotiations reached an agreement to legislate the Special Immigration Control Act in 1991. Insistent criticism by Zaitokukai of the law exemplifies its revisionist desire to erase a dark chapter in Japan's history by expelling Koreans.

This is the most salient characteristic of Japan's nativism, which should be regarded as a variant of historical revisionism that tries to justify the disgraceful history of modern Japan. The rights and status of Koreans have been associated with the history of their migration under colonial rule, which reminds the Japanese of things they would rather forget. This is why the nativist movement persists in its focus on Koreans: a web poll conducted by Zaitokukai also showed that of the 5,272 people who voted $78 \%(4,123$ people) said the country that they 'hate the most' was South Korea (with $12 \%$ for China and $4 \%$ for North Korea). ${ }^{15}$ While anti-China and anti-Chinese movements have also been organized, these mobilized only a very small number of people, failing to attract attention. Koreans are well integrated into Japanese society and their population has now been overwhelmed by other immigrants, ${ }^{16}$ but they are the sole group that evokes the issue of colonial settlement.

15 The result of the vote was retrieved from the following webpage: http://www.zaitokukai. info/modules/xoopspoll/pollresults.php?poll_id=78 (6 June 2013).

16 Korean nationals number 452,701 or $17 \%$ of the total foreign population in Japan, according to the Ministry of Justice: 'Statistics on the Foreigners Registered in Japan' (https://www.e-stat. go.jp/stat-search/files?page=1\&layout=datalist\&lid=000001216283, retrieved 28 April 2019). They were the largest nationality group until this population was exceeded by Chinese nationals in 2007 . 
Table 5.1 Events leading to nativist movement membership

\begin{tabular}{|c|c|c|c|}
\hline Classification & Actual motive & & \\
\hline \multirow{4}{*}{ “Foreigner problem” } & Contact with foreign workers & 2 & \multirow{4}{*}{6} \\
\hline & Legalization for a Filipino family & 2 & \\
\hline & Voting rights for foreigners & 1 & \\
\hline & Hostility toward Korean residents & 1 & \\
\hline South Korea & Sport (Soccer World Cup, Olympics) & 2 & 2 \\
\hline North Korea & Abduction issue & 4 & 4 \\
\hline \multirow{4}{*}{ China } & Territorial dispute over Senkaku Islands & 1 & \multirow{4}{*}{5} \\
\hline & Anti-Japanese demonstrations in China & 1 & \\
\hline & Tianemen Square incident & 1 & \\
\hline & Beijing Olympics & 2 & \\
\hline \multicolumn{2}{|r|}{ Historical revisionism } & 8 & 8 \\
\hline \multicolumn{2}{|r|}{ Others } & 9 & 9 \\
\hline \multicolumn{2}{|r|}{ Total } & 34 & 34 \\
\hline
\end{tabular}

Source: Own analysis, for details see data (3) in the section on data sources

Such features also shape people's journey to nativist activism. Whilst all of the activists I met were keen to talk about how Koreans are harmful to Japan, the impetus for their activism varied. Although they became nativists, most of them did not recognize the 'evil conduct of Koreans' until joining the movement. ${ }^{17}$ Some had negative feelings towards Koreans, but most had gone about their lives without paying any attention to them: the majority of the activists I met did not have contact with foreigners living in Japan. Table 5.1 shows the results of Data 4, in which only six out of 34 activists whom I interviewed indicated hostility towards migrants or foreign residents as their initial interest leading to activism: antipathy towards neighbouring countries served as impetus for eleven, and eight felt sympathy with historical revisionism. Negative feelings towards neighbouring countries and historical revisionism are mutually reinforcing - repeated criticisms from South Korea and China easily turned historical revisionism into hate

17 Makoto Sakurai, the founder of Zaitokukai, also started his activity as an anti-South Korea blogger and then started to accuse Koreans in Japan. 
towards neighbouring countries, and those who felt antipathy towards Japan's neighbours accepted historical revisionism when they regarded these criticisms as unjustifiable intervention in domestic affairs.

Thus far there is nothing different between the right-wing establishment and the new radical right. The notion of discursive opportunities is based on the premise that the culture of social movements borrows part of the dominant culture and, for that reason, it operates under structural constraints (see Steinberg 1999). Most of the discourse of the nativist movement also can be seen as having been taken from the discourse of the right-wing establishment. It is not that the discourse of the right-wing establishment and the nativist movement are directly linked, but that of the latter can increase its appeal by appropriating that of the former.

\section{Nativism as a Variant of Historical Revisionism}

Nevertheless, the discourse of the nativist movement is more than a simple repetition of that of the right-wing establishment. It is true that fundamental changes in economic and political conditions in the region lie behind the rise of East Asian countries as adversaries (Chiavacci and Obinger 2018). During long-term economic stagnation since the 1990s, Japan began to view China and South Korea as economic rivals. The rise of China as a military superpower also brought about favourable conditions for the nativist movement (see the introduction by Chiavacci and Grano, in this volume).

In fact, Japan is a country of rather weak anti-immigrant sentiment (Igarashi and Nagayoshi 2019), making xenophobic claims unconvincing. A minor exception is anxiety about 'foreigner crime.' In Japan at the end of the 1980s, migrants or foreigners were basically seen as 'workers' looking for better-paid jobs under Japan's booming economy. By the latter half of the 1990s, they began to be criminalized by the National Police Agency (NPA) that emphasized the threat of foreigners to public security (Takaya 2007). As a result, the Japanese public is characterized by strong anxiety about migrants as potential criminals (Simon and Sikich 2007).

However, this neither gave nativists the chance for the rise of their movement nor turned the attention of the right-wing establishment to migration issues. While the nativist movement played a part in campaigns of the rightwing establishment, it is still distinguished by its insistence about Koreans and other migrants. One-third of events by Zaitokukai targeted Koreans and other migrants in Japan, while right-wing journals have been rather indifferent to them. Focus on migration in right-wing journal articles peaked at $3.5 \%$ in 2010 when the DPJ government planned to submit a law to grant voting rights 
to foreign residents (see Figure 5.5) ${ }^{18}$ These journals neither regard migrants or foreigners as a threat nor as a useful tool for political manoeuvring. As a result, right-wing journals have only once referred to the phrase 'special privileges for Koreans,' which is the primary concern of Zaitokukai.

So, how did the nativist movement make this half-opened discursive space their own? Table 5.2 simply shows the difference between Koreans and other migrants. Firstly, it indicates that the right-wing establishment showed some interest in foreign workers other than Koreans in the 1980s, although the number of articles is not so large. Almost all related articles appeared between 1988 and 1990, the era in which there were heated debates about introducing foreign workers. The tone of the articles was relatively neutral, discussing the pros and cons of accepting migrants. Since then, the right-wing establishment has lost interest in migration even while the NPA was engaged in a series of campaigns to criminalize migrants from the late 1990s: only one article related to migrants appeared from 1996 to 2000 and five articles from 2001 to 2005. Disregard by the right-wing establishment of migration issues resulted in the lack of successful nativist movements before Zaitokukai. When a right-wing organization named the National Socialist League (copying the Nazis) started an anti-Iranian migrant campaign in the early 1990s, it could neither attract public attention nor recruit new members. It then established an organization named the NPO Movement to Expel Foreigner's Crimes in 2004, which is one of harbinger groups of Zaitokukai, but this again failed to become a successful movement.

Table 5.2 Number of articles on foreign residents in right-wing journals

\begin{tabular}{|l|c|c|c|c|c|}
\hline & Other migrants & Koreans & South Korea & North Korea & History \\
\hline $1982-1990$ & 19 & 3 & 57 & 46 & 251 \\
\hline $1991-1995$ & 6 & 12 & 48 & 83 & 169 \\
\hline $1996-2000$ & 1 & 19 & 77 & 102 & 375 \\
\hline $2001-2005$ & 5 & 28 & 97 & 244 & 515 \\
\hline $2006-2010$ & 9 & 42 & 124 & 202 & 551 \\
\hline $2011-2015$ & 23 & 23 & 374 & 137 & 683 \\
\hline Total & 63 & 127 & 777 & 814 & 2544 \\
\hline
\end{tabular}

Source: Own analysis, for details see data (3) in the section on data sources

18 Then opposition LDP also launched a campaign against voting rights for permanent resident foreigners. 
Secondly, Table 5.2 also shows how right-wing journals were much more concerned about Koreans than other migrants between 1991 and 2010. It is no coincidence that an increasing number of articles on Koreans corresponded to those on history and South and North Korea. Articles related to Koreans in Japan focused mostly on three topics. (1) Voting rights for foreigners: the right-wing establishment believed that enfranchisement would risk paving the way for invasion by Koreans as enemies within. (2) Korean intellectuals: the right-wing establishment treated those intellectuals critical of Japanese historical revisionism as enemies. (3) The pro-North Korean community organization Chosen Soren (General Association of Koreans in Japan) and affiliated organizations: the right-wing establishment has been harshly attacking them (Itagaki 2015) each time a conflict breaks out between the two countries (e.g. development of nuclear weapons and abduction of Japanese by North Korea).

Yet the number of articles regarding Koreans in Japan has been much smaller than those dealing with the Korean peninsula and history. This indicates Koreans in Japan have been of secondary importance to the right-wing establishment. This is why harbingers of the nativist movement started from anti-Korea activities, with Zaitokukai founder Makoto Sakurai initially opening his webpage named 'South Korea as the Wonderland' in 2003. The nativist movement then succeeded when it added Koreans in Japan as its main target by expanding the discursive space that the right-wing establishment exploited.

As we can see, a wide array of targets helped to attract people with various motives to the nativist movement. Activists first became interested in the movement in accordance with their own interests, as Table 5.1 indicates. The diversity seen in initial motives of Zaitokukai activists reveals that Japan's nativist movement was born from a mixture of historical revisionism, hostility towards neighbouring countries and xenophobia. After joining the movement, activists learned the core ideology of Zaitokukai to be nativists moving against Koreans as nearby enemies. The core idea was nurtured in cyber space, in which many posted 'evidence' of 'special privileges of Koreans' being systematized, but this idea was basically adapted from discourse of the right-wing establishment (Higuchi 2016).

\section{Public Attitudes towards the Nativist Movement}

\section{Geopolitical Conditions Favourable to the Nativist Movement}

The mainstreaming of the radical right has become a popular topic (e.g. Akkerman, De Lange and Rooduijn 2016; Minkenberg 2013; Mondon 2013; Mondon and Winter 2017), and scholars often argue that radical right parties 
generally started from anti-system, populist or even fascist and pariah status, encountering ostracism by other parties, while some became accepted by mainstreaming themselves, gaining increasing support and seeking political office. Some mainstream parties also began to pedal policies similar to the radical right, while others (although reluctantly) invited them to ruling coalitions. In this sense, Japan's success to drive out the nativist movement seems exceptional.

The reality is quite the contrary: the nativist movement is under siege only because they went too far to be tolerated. Whilst its brutal attacks shocked the general public, its core ideologies - nativism, racism and xenophobia - were relatively supported. Figure 5.6 shows the results of Data 3, which illustrate the scores of feeling thermometers, in which o represents the coldest and 100 the hottest, towards social movements, political parties and neighbouring countries. ${ }^{19}$ As far as the results of the data indicate, the Japanese general public do not feel negatively towards the nativist movement even since the enactment of the Hate Speech Elimination Law in May 2016. The movement is even slightly (but statistically significantly) more favoured than the leftist anti-national security law movement that mobilized hundreds of thousands of demonstrators surrounding the Parliament House in 2015. ${ }^{20}$

The favourable public image of the nativist movement comes from antipathy towards neighbouring countries. Our respondents were much more negative about South Korea and China. More than a quarter of them demonstrated the least favourable attitudes (o degree) towards the two countries. Behind Zaitokukai's self-definition as a 'civic association' organized by 'ordinary citizens' lies latent public support for the movement. ${ }^{21}$ Although their reckless behaviour and escalating hate speech caused the downfall of Zaitokukai, strong antipathy towards Japan's neighbours opened a huge discursive space for nativists. ${ }^{22}$

19 For results of a similar survey, see Kobayashi et al. (2015).

20 This will be because of the disparity between the left and the right: $14 \%$ of our respondents saw themselves as left-wing and $24 \%$ as right-wing. Although the anti-national security movement was widely supported, demographically dominant rightists felt hatred towards it.

21 Japan's radical right disapprove of the use of words such as 'citizen' and 'civic,' which they believe are leftist terms; instead, they preferred words like 'patriot' or 'national.' As a result, Zaitokukai included 'citizens' in its name because its founders wanted to differentiate it from the right-wing establishment and regarded themselves as a rightist rival of leftist civic movements. In this sense, Zaitokukai's idea to include 'citizens' in its organization name was a breakthrough for Japan's radical right movement.

22 This is why I have proposed the notion of Japanese-style nativism, which refers to nativism rooted in relations with Japan's nearest neighbouring countries, and is based on the colonial 
Figure 5.6 Scores of feeling thermometer

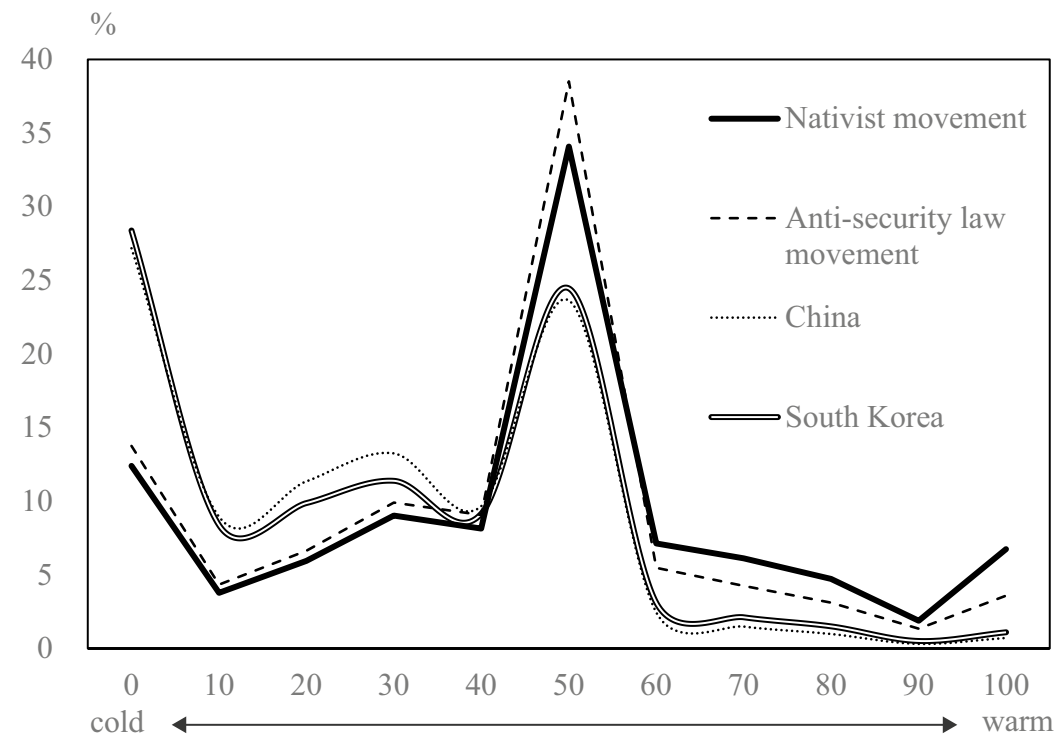

Source: Own analysis, for details see data (3) in the section on data sources

\section{The Radical Right on the Side of the Establishment}

Another feature of the support base for the nativist movement is its proestablishment nature. ${ }^{23}$ I performed an exploratory factor analysis using the same data as Figure 5.6. The analysis of the items shown in Table 5.3, which includes foreign countries, political parties and the nativist movement, resulted in a three-factor solution: East Asia, the Left and the Right. Given Zaitokukai's strong hostility towards Japan's neighbours, it is natural that the first three indices (China, South Korea and the nativist movement) comprise a single concept. Feelings towards the nativist movement first depend on East Asian geopolitical conditions: worsening bilateral relations have led to expansion of the support base of the movement. Indeed, hate towards Chinese and Koreans is different from general anti-immigrant sentiment: patriotism heightens the hostility towards them while it is not significantly related to anti-immigrant sentiment (Tanabe 2018).

settlement and the Cold War (Higuchi 2016).

23 The same data also revealed that those who voted for Makoto Sakurai during the Tokyo gubernatorial election in August 2016 showed significantly higher political trust than other respondents (Higuchi et al. 2019). 
Table 5.3 Result of exploratory factor analysis

\begin{tabular}{|c|c|c|c|c|}
\hline & \multicolumn{3}{|c|}{ Factor loadings } \\
\hline & & East Asia & Left & Right \\
\hline \multicolumn{2}{|l|}{ China } & 0.846 & 0.118 & 0.189 \\
\hline \multicolumn{2}{|l|}{ South Korea } & 0.872 & 0.115 & 0.119 \\
\hline \multicolumn{2}{|c|}{ Nativist movement } & -0.614 & 0.261 & 0.537 \\
\hline \multicolumn{2}{|l|}{ CDP } & 0.058 & 0.854 & -0.039 \\
\hline \multicolumn{2}{|l|}{$J C P$} & 0.097 & 0.841 & -0.137 \\
\hline \multicolumn{2}{|l|}{ LDP } & 0.080 & -0.250 & 0.781 \\
\hline \multicolumn{2}{|l|}{ USA } & 0.200 & 0.004 & 0.779 \\
\hline \multicolumn{2}{|l|}{ Eigenvalues } & 2.386 & 1.566 & 1.172 \\
\hline \multicolumn{2}{|c|}{$\%$ of variance } & 34.09 & 22.37 & 16.74 \\
\hline \multirow{2}{*}{$\begin{array}{l}\text { Factor } \\
\text { covariance }\end{array}$} & Left & 0.238 & & \\
\hline & Right & -0.075 & 0.036 & \\
\hline
\end{tabular}

Source: Own analysis (method of extraction: principal component factor analysis, factors are extracted from promax rotation), for details see data (3) in the section on data sources

Furthermore, the nativist movement also marked higher factor loadings for the third dimension along with the conservative LDP and the United States. Other surveys have also found a strong correlation between feelings towards the LDP and those towards the United States, which exemplifies support for the post-war Japanese political system characterized by long-term conservative rule and dependence on the United States. At first glance, it seems strange to find the nativist movement belonging to the same dimension, because the nativist movement is composed of grassroots groups organized by outsiders to the political arena (except for a few veterans of old right-wing organizations). However, it should be remembered that the changing enemies of the right-wing establishment brought the nativist movement into the world. They gained strength by taking advantage of the expanded discursive space. A simple look at the protest events hosted by the nativist movement shows that it demonstrates a high level of faithful response to discursive opportunities, and this makes it difficult to deny the political links to the right-wing establishment.

Figure 5.7 also suggests affinity of the nativist movement with the conservative establishment. This is based on the results of Data 3 , which 
asked respondents their feelings towards the nativist movement and South Korea. I plotted each category's average scores of feeling thermometers towards the former on the horizontal axis and those towards the latter on the vertical axis (o-10o degrees). The result shows that feelings towards the nativist movement and South Korea are negatively correlated. In addition, the nativist movement is far more preferred to South Korea: the average score of the former is 45 degrees and the latter 28 degrees.

Socio-economic status is weakly correlated to the scores of the two: all education background and most occupations concentrate near the intersection of dash lines that indicates average scores. ${ }^{24}$ Age and gender are more strongly correlated: younger people and women tend to dislike the nativist movement and to feel better about South Korea. ${ }^{25}$ However, the most statistically dispersed are relations between party support and both scores. Those supporting rightist parties such as the ruling LDP are more favourable to the nativist movement and more unfavourable to South Korea. $^{26}$

These results show that support for the nativist movement is not based on social class but on party identification; it is neither related either with ethnic competition, nor deprivation. ${ }^{27}$ Rather, it should be understood as 'pathological normalcy' (Mudde 2010) in the sense that the general public regard the movement as part of the conservative establishment. As we saw in Table 5.3, feeling towards the nativist movement is positively correlated with the conservative establishment and negatively with East Asian countries. The movement bridges sympathy with conservatism and antipathy towards neighbouring countries. In addition, Japanese are much more 'tolerant' of hate speech against Koreans than against other minorities such as women and the disabled (Kohno and Nishizawa 2019), which suggests that the discourse of the nativist movement has legitimacy. The pathological movement is supported as something normal.

The nativist movement was launched in concert with the conservative shift in the LDP in this century (Park 2015) but aimed to stimulate the conservative establishment to be more hawkish from its position on the

24 Household income and stratum identification are also poorly related to both scores.

25 This is due to the recent growth in the popularity of Korean pop culture.

26 The defeat of the LDP in the 2009 general election brought about new parties on the right of it, as is the case with JRP (Japan Restoration Party) and Kokoro (The Party for Japanese Kokoro). But both have been falling into decline: while JRP is still popular in the Kansai area, Kokoro is moribund.

27 Other studies in Japan also found a weak relationship between social class or economic deprivation and nativism (Higuchi 2019). 


\section{Figure 5.7 Scores of feeling thermometers towards the nativist movement and South Korea}

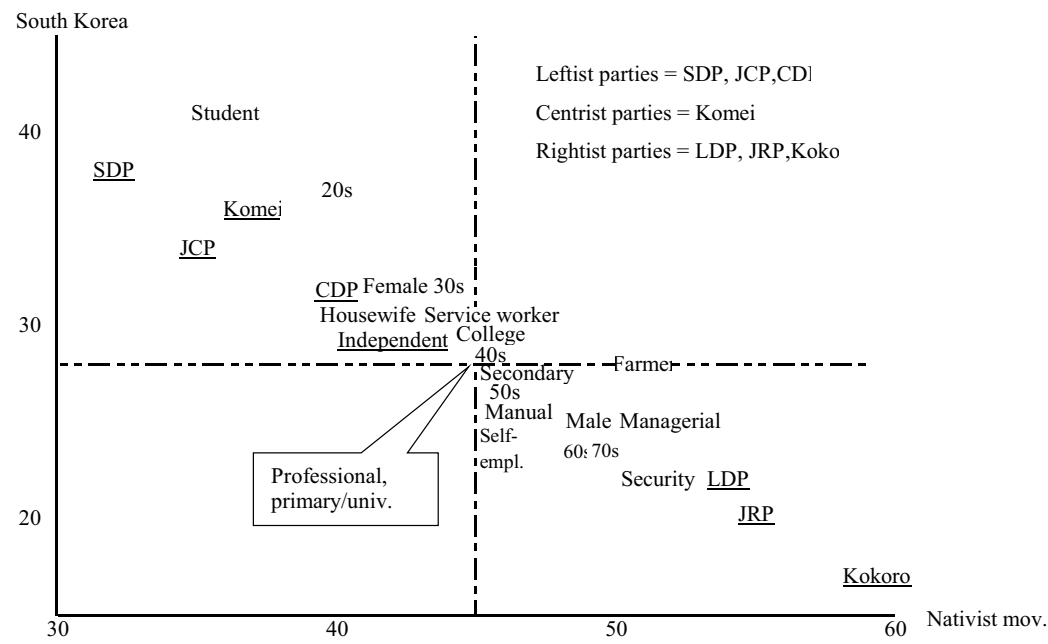

Source: Own analysis, for details see data (3) in the section on data sources

right of the right. This is why they call themselves 'action conservatives' (Yamaguchi 2013): founders of the nativist movement accuse the rightwing establishment, such as the Japan Conference, of embracing 'armchair' activism. They claim other organizations limit themselves to conventional repertoires of action such as gatherings and petitions. Although they share political views with the right-wing establishment, they believe more direct actions are needed to reach their goal.

\section{Conclusion}

On 14 October 2018, 130 nativists marched around downtown Tokyo, shouting 'We don't need immigrants! LDP, repeal the immigration policy!' The Japan First Party, established by the leader of Zaitokukai, organized demonstrations in six cities against a new policy to introduce unskilled migrant workers. They explained the background of the demonstration as follows: 'We decided to start protest actions against the immigration policy by the centre-left ruling coalition of the LDP and Komei Party. ${ }^{28}$ 
Like its European counterparts, which have often been labelled as 'antisystem,' 'protest,' or 'countercultural,' Japan's nativists appear to be protesting the conservative establishment. Given its criticism of Shinzo Abe, the core pillar of the right-wing establishment, it sounds somehow strange to regard Japan's nativist movement as pro-establishment. As we have examined in this chapter, however, Japan's nativists have built a support base to back up the right-wing establishment, which began to look on East Asia as the primary enemy. The root of the problem lies not in anti-immigrant sentiments but in the fact that the nativist movement in Japan took full advantage of deeprooted support for historical revisionism and hostility towards neighbouring countries among its political elites. Although LDP politicians superficially criticize hate speech by the nativist movement, they have never regarded its historical revisionism as a problem. Such attitudes of the conservative establishment brought about the legitimacy of the nativist movement, just as in Art's (2006) comparison of the German and Austrian cases. He pointed out that Austrians tended to be afraid to face their war responsibilities, regarding themselves as victims of Nazism. Behind the rise of the Austrian radical right lies a political culture tolerant of fascism.

In addition, geopolitical conditions during the Cold War, in which Japan played a new role as the primary ally of the United States in Asia, also excused - at least partly - Japan's crime of colonization prior to World War II. Lukewarm policies regarding the colonial settlement allowed the rightwing establishment to preserve historical revisionism until its legitimacy was heightened in the post-Cold War era. Conflict regarding recognition of history is not only unresolved but has become one of the most important and difficult issues hindering reconciliation in East Asia. Japan saved the initial cost of stabilizing bilateral relations with newly established neighbouring states by disregarding its responsibility towards them. In the long term, however, Japan is still paying for its ignorance of the past, as exemplified by the rise of historical revisionism and the nativist movement climbing on the bandwagon.

\section{References}

Akkerman, Tjitske; Sarah L. de Lange; Matthijs Rooduijn. (eds). 2016. Radical Right-wing Populist Parties in Western Europe: Into the Mainstream? Abingdon: Routledge.

Art, David. 2006. The Politics of the Nazi Past in Germany and Austria. Cambridge:

Cambridge University Press. 
Chiavacci, David; Julia Obinger. 2018. 'Towards a New Protest Cycle in Contemporary Japan? The Resurgence of Social Movements and Confrontational Political Activism in Historical Perspective.' Social Movements and Political Activism in Contemporary Japan: Re-emerging from Invisibility. David Chiavacci; Julia Obinger (eds). London: Routledge, pp. 1-23.

Ferre, Myra Marx. 2003. 'Resonance and Radicalism: Feminist Framing in the Abortion Debates of the United States and Germany.' American Journal of Sociology, 109: 304-344.

Gill, Tom. 2018. 'The Nativist Backlash: Exploring the Roots of the Action Conservative Movement.' Social Science Japan Journal, 21 (1): 175-192.

Giugni, Marco; Ruud Koopmans; Florence Passey; Paul Statham. 2005. 'Institutional and Discursive Opportunities for Extreme-Right Mobilization in Five Countries.' Mobilization, 10 (1): 145-162.

Higuchi, Naoto. 2016. Japan's Ultra-Right. Melbourne: Trans Pacific Press.

Higuchi, Naoto. 2018. 'The Radical Right in Japan.' The Oxford Handbook of the Radical Right. Jens Rydgren (ed.). Oxford: Oxford University Press, pp. 681-697. Higuchi, Naoto. 2019. 'Haigai Shugi Heno Shakaigakuteki Approach: Shakaigakuteki Setsumei no Kento to Nihon heno Shisa' [Sociological perspectives on nativism and xenophobia]. Emotion Studies, 4: 17-25.

Higuchi, Naoto. 2020. 'When Hate Becomes Illegal: Legislation Processes of the Anti-Hate Speech Law in Japan.' Hate Speech in Asia and Europe: Beyond Hate and Fear. Myungkoo Kang; Marie-Orange Rivé-Lasan; Wooja Kim; Philippa Hall (eds). London: Routledge, pp. 112-126.

Higuchi, Naoto; Kikuko Nagayoshi; Mitsuru Matsutani; Kōhei Kurahashi; Fabian Schäfer; Tomomi Yamaguchi. 2019. Netto Uyoku toha Nanika [What is Japan's alt-right?]. Tōkyō: Seikyūsha.

Igarashi, Akira; Kikuko Nagayoshi. 2019. 'Imin Haiseki: Yoron ha Ikani Seitoka Shite Irunoka' [Exclusion of migrants: How does the public justify it?]. Imin Seisaku toha Nanika: Nihon no Genjitsu kara Kangaeru. Sachi Takaya (ed.). Kyōto: Jinbun Shoin, pp. 145-165.

Itagaki, Ryuta. 2015. 'The Anatomy of Korea-phobia in Japan.' Japanese Studies, 39 (1): 49-66.

Kobayashi, Tetsuro; Christian Collet; Shanto Izengar; Kyu S. Hahn. 2015. 'Who Deserves Citizenship? An Experimental Study of Japanese Attitudes toward Immigrant Workers.' Social Science Japan Journal, 18 (1): 3-22.

Kohno, Masaru; Yoshitaka Nishizawa. 2019. 'Hate Speech Kisei he no Sanpi ha dō Kimaru no ka' [What determines attitudes towards the regulation of hate speech?]. Chūō Kōron, 133 (4): 166-18o.

Koopmans, Ruud; Jasper Muis. 2009. 'The Rise of Right-wing Populist Pim Fortuyn in the Netherlands: A Discursive Opportunity Approach.' European Journal of Political Research, 48 (5): 642-664. 
Koopmans, Ruud; Paul Statham. 1999. 'Ethnic and Civic Competitions of Nationhood and the Differentiated Success of the Extreme Right in Germany and Italy.' How Social Movements Matter. Marco Giugni; Doug McAdam; Charles Tilly (eds). Minneapolis: University of Minnesota Press, pp. 225-252.

Koopmans, Ruud; Paul Statham; Marco Giugni; Florence Passy. 2005. Contested Citizenship: Immigration and Cultural Diversity in Europe. Minneapolis: University of Minnesota Press.

Koopmans, Ruud; Susan Olzak. 2004. 'Discursive Opportunities and the Evolution of Right-wing Violence in Germany.' American Journal of Sociology, 119 (1): 198-230.

Martin, Craig. 2018. 'Striking the Right Balance: Hate Speech Laws in Japan, the United States, and Canada.' Hastings Constitutional Law Quarterly, 45 (3):455-532.

McCammon, Holly J.; Harmony D. Newman; Courtney Sanders Muse; Teresa M. Terrell. 2007. 'Movement Framing and Discursive Opportunity Structures: The Political Success of the US Women's Jury Movements.' American Sociological Review, 72 (5): 725-749.

Minkenberg, Michael. 2013. 'From Pariah to Policy-maker? The Radical Right in Europe, West and East: Between Margin and Mainstream.' Journal of Contemporary European Studies, 21 (1): 5-24.

Mondon, Aurelien. 2013. The Mainstreaming of the Extreme Right in France and Australia: A Populist Hegemony? Surrey: Ashgate.

Mondon, Aurelien; Aaron Winter. 2017. 'Articulations of Islamophobia: From the Extreme to the Mainstream?' Ethnic and Racial Studies, 40 (13): 2151-2179.

Mudde, Cas. 2007. Populist Radical Right Parties in Europe. Cambridge: Cambridge University Press.

Mudde, Cas. 2010. 'The Populist Radical Right: A Pathological Normalcy.' West European Politics, 33 (6): 1167-1186.

Park, Cheol Hee. 2015. 'The Three-Layered Structure of Japan's Conservative Political Shift.' Seoul Journal of Japanese Studies, 1 (1): 1-28.

Satō, Keiichi; Shun Harada; Kikuko Nagayoshi; Mitsuru Matsutani; Naoto Higuchi; Hiroshi Ōhata. 2018. '3.11 go no Undō Sanka: Han Datsu Genpatsu Undō to Han Anpo Hōsei Undō he no Sanka o Chūshin ni' [Social movement participation after 3.11: Focusing on participation in the anti- and de-nuclearization movement and the anti-security law movement]. Tokushima Daigaku Shakai Kagaku Kenkyū, 32: 1-84.

Simon, Rita J.; Keri W. Sikich. 2007. 'Public Attitudes toward Immigrants and Immigration Policies across Seven Nations.' International Migration Review, 41 (4): 956-962.

Smith, Nathan. M. 2014. 'Facing the Nation: Sound, Fury, and Public Oratory among Japanese Right-wing Groups.' Sound, Space and Sociality in Modern Japan. Joseph D. Hankins; Caroline S. Stevens (eds). London: Routledge, pp. 37-56. 
Steinberg, Marc W. 1999. 'The Talk and Back Talk of Collective Action: A Dialogic Analysis of Repertoires of Discourse among Nineteenth-Century English Cotton Spinners.' American Journal of Sociology, 105 (3): 736-78o.

Szymkowiak, Kenneth; Patricia G. Steinhoff. 1995. 'Wrapping up in Something Long: Intimidation and Violence by Right-wing Groups in Postwar Japan.' Terror from the Extreme Right. Tore Bjørgo (ed.). London: Frank Cass, pp. 265-298.

Takaya, Sachi. 2007. 'Gaikokujin ni Taisuru Shokumu Shitsumon to Chian Seisaku' [Police questioning of and public order policies with regard to 'foreigners']. 'Gaikokujin,' Minzokuteki Minority to Jinken Hakusho. Gaikokujin Jinkenho Renrakukai (ed.). Tōkyō: Akashi Shoten.

Tanabe, Shunsuke. 2018. 'Gendai Nihon Shakai ni okeru Haigaishugi no Genjō: Keiryō Bunseki ni yoru Seiri to Kitei Yoin no Kentō' [Nativism in contemporary Japan: Analyzing causal mechanisms by quantitative analysis]. Haigaishugi no Kokusai Hikaku: Senshin Shokoku ni okeru Gaikokujin Imin no Jittai. Hideki Tarumoto (ed.). Kyōto: Minerva Shobō.

Tarrow, Sidney. 1998. Power in Movement: Social Movements and Contentious Politics, $2^{\text {nd }}$ ed. Cambridge: Cambridge University Press.

Wakamiya, Yoshifumi. 20o6. Wakai to Nationalism: Shinpan Sengo Hoshu no Ajiakan. Tōkyō: Asahi Shinbunsha.

Yamaguchi, Tomomi. 2013. 'Xenophobia in Action: Ultranationalism, Hate Speech, and the Internet in Japan.' Radical History Review, 117: 98-113.

\section{About the Author}

Naoto Higuchi is Professor of Sociology at the Waseda University, Japan. He received his PhD at Hitotsubashi University. Well-known for his research in ethnic and migration studies as well as social movement studies, he has published a large number of articles and chapters in English, Japanese and Korean in scientific publications. His recent research outputs in English on the rise of new radical right groups in Japan include Japan's Ultra Right (Trans Pacific Press, 2016), 'The Radical Right in Japan,' in The Oxford Handbook of the Radical Right, edited by Jens Rydgren (Oxford University Press, 2018) as well as 'When Hate Becomes Illegal: Legislation Processes of the Anti-Hate Speech Law in Japan,' in Hate Speech in Asia and Europe: Beyond Hate and Fear, edited by Myongkoo Kang (Routledge, 2020). 


\title{
6 The Religion-Based Conservative Countermovement in Taiwan
}

\author{
Origin, Tactics and Impacts*
}

Ming-sho Ho

\begin{abstract}
Taiwan's conservative movement to defend the threatened traditional morality and sexualities is an intellectually fascinating case of countermovement, yet an oft-neglected aspect of Taiwan's civil society. This article locates its origins in the preceding change of Taiwan's Christian community. Protestant and Catholic leaders pioneered the opposition to gender equity and a more relaxed attitude on sexuality, and, over the years, they gained support from other religions. I will analyse the contestations over the issues of abortion, same-sex marriage and gender equity education. On the whole, the conservative movement has largely failed to turn back the clock. However, their presence was powerfully felt and had the potential to usher in a new political alignment that moved beyond the pre-existing cleavage.
\end{abstract}

Keywords: conservatism, countermovements, same-sex marriage, abortion, Christianity

After the termination of martial law in 1987 , Taiwan has witnessed a persistent stream of social movements, making possible a number of social and political reforms. However, it would be erroneous to see Taiwan's civil

* This study is made possible by a grant by Taiwan's Ministry of Science and Technology (105-2420-H-002-051-MY3). I appreciate the comments from Namhee Lee, Hwa-jen Liu, Malte Philipp Kaeding, Ying-chao Kao and Samson Yuen. The author thanks Huang Chun-hao for the assistance.

Chiavacci, David, Simona Grano, and Julia Obinger (eds), Civil Society and the State in Democratic East Asia: Between Entanglement and Contention in Post High Growth. Amsterdam, Amsterdam University Press 2020 DOI: 10.5117/ 9789463723930_CHo6 
society as populated only by progressive organizations and individuals. In fact, not all protest activism aims at promoting tolerance, protection of minorities and the rights of the disadvantaged. According to Tilly (2005: 435), democratization necessarily equalizes access to power so that the ways different social groups pursue their interests tend to converge. Street protest used to be the signature political activity of the disfranchised, but once its efficacy has been successfully demonstrated, such a 'weapon of the weak' lends itself to be imitated and usurped by more affluent and established constituencies. Countermovements, defined as 'the mobilization of sentiments initiated to some degree in opposition to a movement' (Zald and Useem 1987:249), are an expectable phenomenon in the wake of an intensive period of progressive mobilizations or reforms.

In the United States, the New Left movements of the 1960s invited the conservative backlash in the 1970s, as countermovements in opposition to abortion, civil rights and women's liberation mushroomed (Lo 1982; Mottl 1980). McAdam and Kloos (2014: 104-106) maintain that these conservative reactions have left an enduring political consequence by pushing the Republican Party further towards the right. In Taiwan, following decades of democratization, it should not come as a surprise that those sentiments that oppose changes find protest making a ready-to-use tool to have their voices heard. Incidents such as the attempts to oppose education reforms, the mobilization of power company workers to defend nuclear energy and employer resistance to labour protection (Ho 2005b: 414-416) fall into the category of countermovements. Nevertheless, there has been little scholarly attention on this topic, as most of the existing literature is devoted to proreform activism, rather than their opponents in civil society. In an edited volume on social movements under the Ma Ying-jeou government (2008-2016) (Fell 2017), there were thirteen chapters that analysed environmental, student, labour, women's and other progressive movements, but none of them took a look at the conservative ones. A literature review of the 134 journal articles on Taiwan's social movements published from 1980 to 2014 (both in English and in Chinese) did not find a single piece that focused on conservative movements (Ho et al. 2018). Such lopsided scholarship fails to do justice to the multifarious and complex contentious politics in contemporary Taiwan.

This chapter redresses this imbalance by taking a closer look at one conservative countermovement. Around the turn of the century, Taiwan's religious leaders initiated a campaign to defend traditional family values and gender norms that were increasingly eroded by cultural modernization that brought about what they identified as the perverse tendency of 'sexual 
liberation.' Over the years, abortion, same-sex marriage and gender equity education have successively emerged as the arenas where conservatives and progressives engaged in fierce combat. This article will first describe the genesis of this religion-based countermovement and how it evolved into a sustained campaign with considerable political influences. Secondly, I will offer an interim assessment of its impact. On the policy fronts, conservatives have failed to arrest Taiwan's transition to a more equal and multicultural society. Nevertheless, they succeed in rallying a considerable pool of supporters, thereby making further progressive reforms more difficult and threatening to usher in a new political realignment. Being a latecomer in protest politics as well as a reaction to the reforms secured by the women's movement and the gender movement, conservatives took pains to imitate the tactics and framing of their opponents.

In this chapter 'conservatism' refers to the effort to restore traditional values in opposition to cultural modernity as exemplified by multiculturalism. Giddens (1991: 241) notices the transition from a 'politics of life chance' (income distribution, for instance) to a 'politics of lifestyle,' which is at its core about 'self-actualization' in an increasingly reflective and changeable world. Thus, conservatism in the cultural sense represented a backlash against the politics of lifestyle in the name of a hallowed orthodoxy. Habermas (1985: 88-93) identified three common components of the 'neoconservatism' in the 1970s West: (1) the suspicion of critical intellectuals, (2) the assumption that rational science, universalistic morality and avant-garde art had lost their validity, and (3) traditional values viewed as a solution to contemporary social problems. Habermas viewed the newer conservatism as a reaction to the 'new social movements' of women, peace and ecology, which all promoted democratization of the everyday world. In the context of Taiwan, anti-intellectualism and anti-modernization did not emerge as a perceivable force; hence, the more appropriate use of the term 'conservatism' should be restricted to the third aspect mentioned by Habermas. Taiwan's conservatism was characterized by opposition to the women's movement and the gender movement, which challenged patriarchal values and promoted equality and the diversification of identities. It should be noted that conservatism thus defined is strictly cultural and is unrelated to other public disputes concerning Taiwan's political future (independence or unification), economic redistribution or environmental protection. As shown in the following, the opposition activists to abortion and same-sex marriage adopted a nonpartisan approach by emphasizing that they represented mainstream voices. Hence, Taiwan's cultural conservatives are not organizationally linked to those conservative tendencies in other issues. 
The term 'countermovement' also requires some upfront clarification here. I use it to refer to those organized campaigns that specifically oppose the goals of another pre-existing movement. Since most social movements strive for progressive changes in Taiwan and elsewhere in the world, countermovements emerge as a backlash and hence are conservative in orientation. Theoretically, it is possible to have 'progressive countermovements' - say, anti-Trump protests in the US - but such usage is rare and easily confusing. Understanding that the great majority of countermovements are conservative, it is still important to conceptually separate 'countermovement' and 'conservatism.'

\section{The Religious Roots of the Conservative Movement}

With the noticeable exception of the Presbyterian Church, the oldest and largest Protestant denomination in Taiwan, religious organizations have not played a significant role in the transition to democracy, as most religious leaders either shied away from public issues or toed the line defined by the Kuomintang (KMT) regime (Rubinstein 1991: 29). The Presbyterian Church's advocacy for political reforms and political independence in the $1970 \mathrm{~s}$ incurred the government's repression. Some Presbyterian pastors provided lessons on the tactics of non-violent resistance, thus cultivating a cohort of pro-democracy, labour and indigenous activists, adding new blood to the nascent wave of social protests in the late 1980 s. However, politically engaged Presbyterians were an exceptional minority to their largely conformist co-religionists. ${ }^{1}$ The campaign to end child prostitution in the late $1980 \mathrm{os}$ was mounted by some Christian welfare organizations and it later evolved into an anti-human trafficking movement with international linkages (Ho 2010: 544$)$. However, the goals were consensual and mainstream, rather than motivated by an explicitly conservative agenda.

Outside Christian minorities, Taiwan's economic success and the growth of the middle class enabled a Buddhist renaissance that laid down a political culture of civility, tolerance and cosmopolitanism (Madsen 2007). Such civic virtue helped democracy to take root; nevertheless, Buddhist leaders seldom took a stand in political and social disputes. Traditional folk religion, which arguably attracted the most followers in Taiwan, was intimately involved with the rise of environmental protests in the mid-1980s (Ho 2005a; Weller

1 The protests by New Testament Church followers in the mid-1980s represented another rare exception of anti-KMT militancy among Christians (Rubinstein 1994). 
1999: 115-121). Yet, its essentially localistic orientation entailed that its influences could not extend beyond the community borders. Before the transition to democracy was accomplished with the first peaceful power turnover in 2000, the political visibility of religion-based activism remained minimal.

Before Taiwan's Christian communities spearheaded a conservative intervention into public life, there had been a change in its ecology as a more individualistic, inward-looking and conformist tendency began to take root. In 1987 , a collaborative campaign by major Protestant denominations to revive the faith was launched. The so-called Year 2000 Evangelism (Liangqian Nian Fuyin Yundong) aimed to increase the Christian population to two million by the turn of the century. The campaign introduced the methods, materials and training pioneered by evangelicals in the US, Singapore and Hong Kong. In particular, there was an emphasis on applying biblical principles to everyday life so as to 'solve family problems, youth problems, faith problems, and social problems' (Shia 1993: 9). Although the campaign failed to meet the growth target, it laid the foundation for the rise of a conservative countermovement in many ways. First, it was a reflection of the political and ethnic cleavage during the authoritarian era. Taiwan's Protestant communities used to be divided by Taiwanese-speaking churches (best presented by the Presbyterians) and Mandarin-speaking ones. The Mandarin-speaking churches tended to be composed of mainlanders who embraced the KMT ideology of anti-communism. With the participation of some Presbyterians, this evangelic campaign blurred the pre-existing divide and consolidated the Mandarin-speaking pastor leadership. As a result, a more conservative outlook with emphasis on family values became more widespread among Taiwan's Protestants, hastening the secular decline of the social gospel direction once championed by the Presbyterian Church (Interview NMM 2017). Moreover, Year 2000 Evangelism proceeded with a series of joint prayers and training on a regional basis. As a result, citywide connections between Christians spanning across denominations came into being in many places, thereby weakening the loyalty of churchgoers to their own denominations. Later, when conservative Protestants mobilized for lobbying, protests or electoral campaigning, these networks served as a solid organizational basis (Interview TGF 2017). Not surprisingly, when a gay pride event was first held in 2000, the leading clergymen of Year 2000 Evangelism were among the first to voice criticism. ${ }^{2}$

2 The rise of Taiwan's religious conservatism is part of a global phenomenon. The US evangelical campaign is certainly an important source of inspiration for Taiwan activists; however, the influences from Hong Kong, Singapore and South Korea are probably more direct, given their 
The Catholic conservative movement began with the establishment of the Human Life Ethics Center (HLEC), originally affiliated with Fu Jen Catholic University, in 1999. While the Protestant activism started with an ambitious proselytization campaign, the Catholic stream initially focused on life education. In the name of teaching students to cherish personal dignity, religious doctrines were brought onto the campus. The HLEC launched an energetic campaign to distribute an American anti-abortion documentary, Eclipse of Reason, in high schools as a supplementary material for 'life education' or 'health education' (Kuan 2011). The HLEC also promoted the value of chastity to discourage pre-marital sex. Taiwan's Catholic leaders articulated their opposition to surrogate motherhood, gene cloning and the legalization of the morning-after pill on the grounds that these new technologies were said to violate the sanctity of life.

Protestant and Catholic Christians made up a minority in Taiwan - in a 2015 survey they were $6 \%$ of the population (Fu et al. 2016: 168) - yet they pioneered the conservative movement. They achieved this through mounting three campaigns that targeted abortion, same-sex marriage and gender equity education, respectively.

\section{The Anti-abortion Campaign}

With the passage of the Genetic Health Act in 1984, abortion became a lawful procedure for women who wanted to terminate pregnancy voluntarily. The only restrictions were that minors needed parental consent and married women required that from their spouses. The legalization of abortion did not come as a result of feminist advocacy, but rather as a top-down decision to implement a population-planning policy. During the legislative review, members of the KMT old guard criticized the act for its negative impact on the 'anti-communist mission' and on traditional Chinese culture, and the nascent women's movement activists stood behind the government by avoiding the use of confrontational terms such as 'women's rights' or 'bodily autonomy' (Ku 1995). After the toned-down debate in the mid-1980s, abortion did not emerge as a controversial topic until the religious conservatives launched their campaign. Prior to that, some Democratic Progressive Party (DPP) lawmakers proposed a revision to remove the required spousal consent

cultural similarities and the language. Some US right-wing conservative organizations have working relationship with the local campaigners, but it is not an outright export of the 'cultural war' to Taiwan. 
and some feminists raised a similar demand in the 1990s. However, these demands consciously proceeded in a low-profile manner in order not to stir up a backlash.

In 2002, 61 lawmakers from KMT, DPP and other parties proposed a revision to the law in order to protect 'foetal rights' as a result of lobbying by Catholic and Protestant groups. The amendment aimed to restrict abortion by requiring compulsory consultation and adding a six-day waiting period to the abortion process. With the participation of major Buddhist organization leaders, the following year witnessed the formation of the League of All Citizen Movements to Respect Life (Zunzhong Shengming Quanmin Yundong Da Lianmeng). To ward off the anti-abortion drive, in 2003 feminists, with the support of 56 lawmakers, unveiled another revision to the law that took away spousal consent and mandated school authorities to promote sex and gender equality education. To outbid the pro-abortion forces, in 2005 the conservatives put forward another revision that required high schools to implement abstinence-only sex education. The DPP government was clearly caught in the middle of the warfare between the religious conservatives and the feminists as it intensified. Health officials attempted to broker a compromise version of the law in the hope of satisfying the opposing demands. In 2006, a revision proposed by the executive branch established a three-day waiting period and at the same time abolished spousal consent. Three feminists on the Committee for the Promotion of Women's Rights, a cabinet-level policymaking body that focused on gender issues, immediately resigned in protest (Cheng 2015: 22).

After the flare-up in 2006, both camps continued to propose different revisions, but the identical version from the Executive Yuan was sent in for review in 2008 and 2012, spanning the transition from Chen Shui-bian's era to Ma Ying-jeou's. As a result, the existing legal regulation on abortion since 1984 was left intact as neither side was able to secure a unilateral change. In hindsight, the stalemate was not so much a victory for the women's movement, but rather the diversion of conservatives' attention to the more 'alarming threat' posed by the LGBT movement.

\section{The Opposition to Same-sex Marriage}

The 199os saw the flourishing of the LGBT movement in Taiwan as lesbians and gays began to set up their campus clubs, bookstores, churches and support groups (Damm 2011: 157-159). The official registration of the Taiwan Tongzhi (LGBT) Hotline Association in 2000 represented a milestone for the 
sexual minority to claim a public role. The new century witnessed a growing government acceptance of this newly visible identity movement. Ma Ying-jeou had carefully cultivated a pro-LGBT image during his electoral campaign for Taipei mayor in 1998. In 2003, the city government subsidized the annual Taiwan Gay Pride. When Chen Shui-bian became the president in 2000, he vowed to promote the values of human rights, since it was the first time that Taiwan's opposition party had come to power. In the Basic Law of Human Rights Protection Bill, drafted in 2001, lesbian and gay couples were allowed to form families and adopt children; this, however, did not materialize (Lo 2010).

In 2006, Hsiao Bi-khim, a DPP lawmaker, initiated a bill to legalize samesex marriage. Hsiao's draft was quickly voted down by an emergency intervention of religious conservatives who were able to mobilize sympathetic lawmakers. ${ }^{3}$ The brief skirmish had contrasting impacts on both camps. For LGBT activists, the failure demonstrated it was still too early to place the legalization of same-sex marriage on the agenda, and hence pursuing civil partnership was thought to be a more realistic path (Chien 2012:191-194). Prior to the encounter, Taiwan's religious conservatives had paid little attention to the same-sex issue. A 2003 assessment concluded that the oppositional forces were too weak, so LGBT activists were not considered to be a force that needed to be dealt with (Lai 2003: 104). The conservatives were therefore caught off guard because they had underestimated the advance of the LGBT movement. Consequently, in 2007 Catholic and Protestant conservatives formed a coalition to defend marriage as a heterosexual union - the Taiwan League for Preserving Family (Taiwan Weihu Jiating Lianmeng) - the first countermovement organization to safeguard the traditional family as well as the harbinger of subsequent conservative mobilizations.

The establishment of the Taiwan Alliance to Promote Civil Partnership Rights (TAPCPR) (Taiwan Banlu Quanyi Tuidong Lianmeng) in 2009 opened a new chapter for the LGBT community to assert their legal rights. TAPCPR advocated a multiple strategy to liberalize the legal regulations on marriage and family, and in 2013, one of its demands, the equal right to marriage for same-sex couples (hunyin pingquan), was sponsored by DPP lawmakers and was ready for the first reading in the legislature. However, the attempt to liberalize marriage was effectively neutralized by a stronger operation by conservatives. The League of Taiwanese Religious Groups Caring for Family (Taiwan Zongjiao Tuanti Aihu Jiating Dalianmeng) was formed, which not only included the previously involved Catholics and Protestants, but now

3 See the announcement by the Taiwan Tongzhi (LGBT) Hotline Association, https:/goo.gl/ Astnq7 (11 August 2017). 
obtained the support of the Unification Church and Buddhist leaders. On 30 November 2013, a massive rally to 'protect' the next generation's 'well-being' was held, which was claimed to attract 300,000 participants. ${ }^{4}$ The Presbyterian Church, which was previously torn between its liberal and conservative wings, decided to take a theological stand to affirm the sanctity of heterosexual marriage and family with a pastoral letter in January 2014, which, however, engendered various interpretations within the church. As a result, the attempt to liberalize the Civil Code's definition of marriage ended before the first reading was finished.

While conservatives were able to ward off the challenge for equal rights in marriage in 2013 with the help of some KMT lawmakers, they were apprehensive of the party's declining political strength, particularly after its major defeat in the local election in 2014, largely as a consequence of the Sunflower Movement (Ho 2019a). The Sunflower Movement involved a 24-day student-led occupation of the national legislature in opposition to a free trade deal with China. The incident was the largest episode of political contention to occur in Taiwan since its democratization, and its peaceful and arguably successful conclusion left an enduring impact in the country's political landscape. Threatened by the prospect that the DPP might win the presidency and the legislative majority in the general election in 2016 as well as the surge of support for the openly pro-LGBT New Power Party (NPP) and the Social Democratic Party (see Kwan and Fell, this volume), conservatives launched a new party, the Faith and Hope League (FHL, Xinxin Xiwang Lianmeng). FHL started a signature-collecting campaign for a referendum that any future changes in marriage should be put to a popular vote. In the end, FHL received $1.7 \%$ of the vote in proportionate representation and failed to obtain any parliamentary seats. Although it claimed to have collected more than 150,00o signatures, its referendum application was vetoed by a government committee.

The general election in 2016 resulted in the worst-case scenario for conservatives, as the DPP surged to control both the presidency and the legislature and the NPP emerged as the third-largest party. Spearheaded by LGBT-friendly DPP and NPP lawmakers, the second attempt to liberalize the Civil Code for same-sex marriage was put onto the agenda in October. The conservatives launched a series of large-scale emergency rallies in November and December to oppose the revision and at the same time mounted grassroots campaigns to pressure the pro-gay lawmakers. Some DPP lawmakers balked at providing full-scale support for same-sex marriage by proposing 
a special law for same-sex couples to minimize its impact. As a result, the effort to revise the Civil Code only finished the first reading without being able to be reviewed and processed in the subsequent procedure.

In March 2017, the Constitutional Court decided to adjure the same-sex marriage case, thereby taking over the dispute from the legislative arena. Partly because around half of the judges newly appointed by the DPP government were liberal in orientation, the court ruled on May 24 that marriage rights for same-sex couples should be respected and decreed a two-year period for its eventual realization (Ho 2019b). The landmark decision represented a decisive setback for the conservatives as the ruling of the Constitutional Court was very difficult to challenge via existing channels. In the referendums that accompanied the local election in November 2018, same-sex marriage opponents gained a clear victory by winning the popular endorsement to define marriage as a union of a man and a woman. Navigating the narrow path between the Constitutional Court decision and the voter preference expressed in the referendums, the DPP government managed to legislate a special law that allowed same-sex couples to obtain the same rights with heterosexual couples in May 2019. The draft was passed with the support of 56 DPP, 7 KMT, and 5 NPP lawmakers, making the country the first in Asia to implement marriage equality.

\section{Gender Equity Education}

Compared to the issues on abortion and same-sex marriage, the dispute over gender equity education appeared smaller in scale because it represented a flanking manoeuvre by conservatives to oppose the legal recognition of the LGBT community. Due to the feminists' advocacy, Taiwan's government began to implement gender equity education (originally called 'equity education for both sexes' [liangxing pingdeng jiaoyu]), with a ministry-level committee established in 1998, and a special law enacted in 2004. The earlier emphasis was on prevention of sexual assault and sexual harassment, hence largely free from dispute. In 2011, conservatives rose to oppose the implementation of a curriculum that taught students to avoid bullying behaviour targeting 'gender temperaments, sexual orientation, or gender identity' (Chen 2014). Their main argument was that the government should not create a category to 'normalize' the LGBT population and 'protect' their 'deviant' behaviours.

The Taiwan True Love Alliance (Taiwan Zhen'ai Lianmeng) was then formed and its lobbying succeeded in obtaining the legislature's support 
in preventing the Ministry of Education from implementing the pro-LGBT curriculum guidelines. The contention focused on a teacher manual for use in junior high schools which encouraged students to explore their sexual orientation and gender temperaments. With the intervention of feminists and gender movement activists, the new curriculum guidelines still included 'gay and lesbian education' and only a relatively minor concession was made to appease the conservative opponents (Huang 2017a: 267-269). In 2014, the government appointed two scholars associated with the Taiwan True Love Alliance to the Ministry of Education's Commission on Gender Equity Education, marking the first time openly anti-gay persons were allowed into the agency. In 2018, the conservatives won a referendum to exclude 'same-sex education' from the teaching of gender equity education. In response, the Ministry of Education revised the related bylaw to replace the term with a lengthier description, 'different gender, gender characteristics, gender temperaments, gender identity, and sexual orientation,' and insisted on the necessity of teaching understanding and tolerance for sexual minorities.

While conservatives were mostly unsuccessful in forestalling the advance of a more inclusive gender equity education at the national policy level, they appeared more adaptive with local participation channels. The gender equity education plan included ad hoc commissions at city/county and school levels, which made it possible for conservatives to prevent what they identified as 'inappropriate materials' to be used in schools. Conservatives mobilized parents to pressure local authorities or schools to include 'chastity' and 'moral character' teaching materials in the gender equity education (Interview TT 2017).

\section{The Consequences and Implications}

Table 6.1 summarizes these three campaigns of Taiwan's conservatives. Religion-based conservatives were mostly unsuccessful in realizing their main agenda in spite of their activism over a decade, as Taiwan's government and society gradually evolved in a more tolerant and inclusive direction. Nevertheless, the countermovement left enduring impacts by reconfiguring the existing state-society pattern in many ways.

First, let us look at the timing of its emergence. Zald and Useem (1987: 254) maintained 'a countermovement is likely to emerge if the movement appears to be accomplishing its goals.' Countermovements came into being when the previously privileged sectors felt threatened but still possessed the resources to resist (Andrews 2002: 919; Meyer and Staggenborg 1996: 
Table 6.1 Three Conservative Campaigns in Taiwan

\begin{tabular}{|l|l|l|l|}
\hline Target Issues & Abortion & Same-sex Marriage & $\begin{array}{l}\text { Gender Equity } \\
\text { Education }\end{array}$ \\
\hline $\begin{array}{l}\text { Periods of Intensive } \\
\text { Mobilization }\end{array}$ & $2002-2006$ & $\begin{array}{l}2006-2007 \\
2013-2014 \\
2015-2017\end{array}$ & $\begin{array}{l}2011-2012 \\
2016-2018\end{array}$ \\
\hline $\begin{array}{l}\text { The Leading } \\
\text { Organtermovement } \\
\text { Their Founding Year }\end{array}$ & $\begin{array}{l}\text { League of All Citizen } \\
\text { Respect Life (2003) }\end{array}$ & $\begin{array}{l}\text { Taiwan League for } \\
\text { Preserving Family } \\
\text { (2007) }\end{array}$ & $\begin{array}{l}\text { Taiwan True Love } \\
\text { Alliance (2011) }\end{array}$ \\
\hline $\begin{array}{l}\text { Policy Results } \\
\text { (1) Failure to restrict } \\
\text { the abortion access } \\
\text { (2) Preventing the } \\
\text { feminist attempt to } \\
\text { remove the spousal } \\
\text { consent }\end{array}$ & $\begin{array}{l}\text { Failure to stop the } \\
\text { Constitutional } \\
\text { of same-sex marriage }\end{array}$ & $\begin{array}{l}\text { (1) Failure to stop the } \\
\text { inclusion of LGBT } \\
\text { education in school } \\
\text { (2) The attempt to } \\
\text { insert conservative } \\
\text { curriculum locally as } \\
\text { undecided }\end{array}$ \\
\hline
\end{tabular}

Source: Own compilation

1638-1639). The characterization of a countermovement as a status quomaintaining reaction is applicable to the campaigns against same-sex marriage and gender equity education, but not to the abortion issue. In 2002, Taiwan's religious conservatives actually mobilized to modify an abortion regime that had been in place for nearly two decades. In retrospect, the anti-abortion agitation signified the first joint public intervention by religious leaders. At that time, they were largely unfamiliar with the rules of the game. A Lutheran pastor remembered that they did not mount follow-up actions after petitioning in 2003 because they thought the lawmakers would automatically carry out their promise to narrow the access to abortion. They later found out that large-scale rallies and demonstrations are a necessary means to prod legislators to redeem their promises (Interview TGF 2017). Afterwards, Taiwan's conservatives apparently became more sophisticated, which explained why they could quickly launch preventive actions on same-sex marriage in 2006 and on gender equity education in 2011.

The rise of conservatives as political actors modified and complicated the interactions between social movements and the state. Previously, reform advocates mobilized in the name of civil society and challenged the government as the latter stood for the existing order; now civil society became divided and a complicated three-way interaction among movements, countermovements and the state ensued. Inevitably, the rise of countermovements increased the cost of concession for government officials in their 
dealings with progressive movements (Luders 2016: 206). The shift in the political landscape brought a greater challenge to the women's movement than to the LGBT community because the former traditionally prioritized state agencies as a source for change. Feminist leaders had successfully maintained their presence in the government via a number of participatory channels, such as the Executive Yuan's Gender Equity Committee (formerly the Committee for the Promotion of Women's Rights) and the Ministry of Education's Commission on Gender Equity Education. These policy interventions have been identified as 'state feminism' in Taiwan, which offered a critical leverage to implement pro-women measures (Huang 2017; Hwang and Wu 2017; Peng 2008; Yang 2004). The rise of conservatives threatened to neutralize these participatory channels. As said above, the KMT government appointed anti-gay representatives to the Commission on Gender Equity Education in 2014. Again, in the wake of the pro-LGBT ruling of the Constitutional Court, the DPP government made a promise to nominate conservatives to alleviate their opposition, although the promise did not materialize. ${ }^{5}$

Other policy channels pioneered by Taiwan's human rights movement were in danger of being 'usurped' by conservatives. In 2013, conservatives sent their delegates to take part in the review meetings of the Convention on the Elimination of All Forms of Discrimination against Women (CEDAW) with the intention to offset the demand for marriage equality (Interview TAPCPR 2017). In the 2017 review meeting of two human rights conventions (the International Covenant on Civil and Political Rights and the International Covenant on Economic, Social and Cultural Rights), anti-gay activists filed shadow reports that asserted that the promotion of lesbian and gay rights violated the rights of heterosexual persons. ${ }^{6}$ With the conservatives' participation, it has become more difficult to promote progressive changes by these official mechanisms. There was evidence that governmental agencies and bureaucrats learnt to take an unclear policy stand to avoid controversies. The Department of Health proposed three identical revision drafts on abortion (in 2006, 2008 and 2012) in a futile attempt to appease both camps. The Ministry of Justice appeared reluctant to include the same-sex marriage issue in its human rights review. Its officials avoided taking a stance so that when proponents and opponents were engaged in a heated battle in the legislature in 2016, the executive branch remained conspicuously silent. 
In terms of mobilizing structure, the conservative countermovement represented the mirror image of Taiwan's feminist movement. The former possessed a stronger mobilizing capacity and political influences at the local level due to the church connections, whereas the latter enjoyed a number of tactical advantages at the national level because of the 'femocrat' network. The conservative activists I interviewed commonly complained about the bias of the mainstream media that tended to underreport their rallies and demonstrations so that they had to rely on the church-managed newspapers and TV channels. One Buddhist leader in the League of Taiwan Guardians of the Family embraced a conspiracy theory that held that the government pressured the mainstream media to ignore the anti-LGBT events (Interview NTCBA 2017). On the other hand, the LGBT activists whom I interviewed were surprised to find that conservatives were able to launch initiatives in the name of parents and obtain support from local councillors. While the conservative countermovement appeared pyramid-shaped with a mass followers, their rivals were more represented by individual professionals. Weng and Fell (2006: 159) have described Taiwan's women's movement as 'rootless' due to its lack of a mass base. As such, women and gender activists find it difficult to compete with the conservatives when it came to staging large-scale rallies. In several confrontations, opponents of same-sex marriage easily outnumbered its supporters.

Finally, although the conservative countermovement has not succeeded in realizing its policy demands so far, its political ascendancy was clearly felt and threatened to usher in a new political realignment. Previously, they considered the KMT as their natural ally and occasionally were able to secure the support from individual DPP politicians. The dwindling of the KMT's political strength prompted the formation of the FHL as a religion-based conservative party in 2015. Led by a pro-unification mainlander politician Joanna Lei, the FHL struggled to convince the voters that it signified an independent choice beyond the DPP/KMT rivalry. With the eruption of the same-sex marriage dispute in 2016, political opportunities for conservatives surfaced. DPP lawmakers who supported marriage equality began to face angry complaints from their voters. Southern Taiwan has been the DPP's stronghold, as the party won a clear sweep there in 2016 by obtaining all 22 legislative seats located below the Zhuoshui River, and yet the grassroots reaction was particularly strong there. As a result, many southern lawmakers shifted to the 'special law' position or decided to keep silent in order to avoid the controversy (Interview DPP 2017a). The DPP mayors' symbolic gesture to hoist a rainbow flag on International Human Rights Day was met with strong protests, and even local DPP politicians were not supportive 
(Interview DPP 2017b). Particularly deleterious to the DPP was the defection of some Presbyterian leaders. A Presbyterian pastor in Tainan who took part in the pro-democracy movement in the past now led a campaign to recall the DPP lawmaker Wang Ding-yu after he expressed a pro-gay stance. Acknowledging that many of his church followers were staunch DPP supporters, he insisted on prioritizing the LGBT issues because a person's partisan identity should not impede 'the moral judgement on what is right and what is wrong' (Interview PTCMRC 2017). Two southern presbyteries issued a strongly worded statement to challenge the Constitutional Court's pro-gay ruling.7 It remains to be seen how the disenchantment on the part of DPP's conservative rank and file will affect its support.

An unpublicized survey by a Taiwanese think tank ${ }^{8}$ in December 2016 indicated the anti-gay marriage sentiment cut across the partisan divide. Among the $58.6 \%$ of respondents who indicated their disapproval or strong disapproval, $34.3 \%$ was from the pan-green camp (29.7\% DPP and $4.6 \%$ NPP supporters) and $36.9 \%$ from the pan-blue camp (29.6\% KMT, $5.3 \%$ People First Party, and 1.1\% New Party supporters). If these conservative citizens were successfully persuaded to defect by voting for a new party, they could have represented a bona fide independent force. As mentioned in the introduction by Chiavacci and Grano (in this volume), East Asian conservative movements appear to share a pro-establishment origin and outlook, and they have not evolved into the radical populist strain nowadays commonly seen in the West. Taiwan's conservative opponents to abortion, same-sex marriage and gender equity education fitted into this description because they tended to characterize themselves as 'nonpartisan' and 'apolitical' parents who were concerned about their children's well-being and social stability. As such, this framing helped gain sympathy from pan-green and pan-blue voters. The conservative countermovement had powerfully demonstrated its strength without having given rise to a viable political force. Yet, it has the potential to do so as favourable opportunities have emerged. Just like the US Supreme Court decision Roe v. Wade (1973) that energized the anti-abortion movement (Luker 1984: 126-127), the landmark decision of Taiwan's Constitutional Court in 2017 might give a short-term boost to the LGBT movement, while planting the seed of a stronger backlash. The future viability of a culturally conservative party hinges upon the following

\section{Christian Daily, https://goo.gl/8z17ct (16 August 2017).}

8 Taiwan Thinktank is a policy research organizations with links to DPP politicians. The author was briefly involved with its opinion survey program. The data cited here came from one poll result, which was not announced for some political reason. 
factors: (1) whether the KMT can recoup after the unprecedented defeat in 2016 and regain the allegiance of its previous voters, (2) whether the DPP can stem the haemorrhage of its conservative voters, and (3) whether the conservative countermovement can expand its reach beyond its religious network. All these remain to be observed.

\section{The Learning Curve of a Countermovement}

In a 2007 interview, a Catholic priest recounted his experience in initiating a pro-family campaign ${ }^{9}$ :

We were praying every day for God's guidance. Especially since we [the HLEC] were the first institute in the Chinese society in Taiwan, we needed to proceed cautiously under God and every effort was a new trial. If we caused harm, it would have damaged all Christians. [...] When we began to enlist the support of the churches on the draft [to restrict access to abortion], many thought it was enough to 'spread the gospel.' They did not want to engage in politics for fear of involvement with the political parties.

Since religious conservatives had been political outsiders for a long time, they had to build everything from scratch. Most of their leaders and followers were new to movement politics. An FHL legislative candidate in 2016 admitted her only previous experience with social movements was participation in commemorating the Tiananmen Incident in 1989 (Interview FHL 2017). As a latecomer, conservative activists encountered a political arena that has been largely shaped by progressive movements. Even the detail about how to manage a petition booth, for instance, had to been learned from their opponents. A recall campaign leader acknowledged having consulted DPP activists with experience of street activism. 'They recommended the use of songs, banners, and slogan to promote ourselves, and we had to learn by doing' (Interview SL 2017).

Countermovements were likely to adopt their opponents' tactics when the latter demonstrated their utility (Burstein 1991: 512). When it came to contestations over media representation, countermovements tended to 'piggyback' on their rivals in order to make use of the journalistic balance norm (Rohlinger 2002: 495). In the case of Taiwan's conservative countermovement, its religious basis allowed it to bring certain protest repertoires 
that were not available to the secular movements, for example, the use of mass prayers and the 'exorcism' of gays and lesbians. However, while these actions might have strengthened the solidarity among faithful followers, they turned out to be useless, if not counterproductive, in appealing to the non-Christian majority. Lesbian and gay activists wasted no time in highlighting these seemingly bizarre, outlandish and even superstitious gestures and ways of speaking to the public. An FHL activist explained her experience (Interview FHL 2017):

I learnt from my last electoral campaign that people would not pay attention to me if I told them God wanted me to affect the election. So I had to learn to speak the language of people, not that of God. I could not say, 'God ruled the world.' I needed to address their immediate concerns. Some Christians used to say that gay people would go to hell. But saying things like that made us seem cruel.

As such, conservative leaders took pains to downplay their religious backgrounds. What was initially called the League of Taiwanese Religious Groups Caring for the Family was renamed as the League of Taiwan Guardians of the Family in order to hide its religious identity (Huang 2017b: 122).

There were many incidences where conservatives consciously imitated the tactics practiced by preceding movements. The FHL's 2015 signaturecollecting campaign to demand that any change of the legal definition of marriage would need to be approved by a referendum was clearly inspired by a preceding campaign to revise the referendum law. The attempts to storm the legislature in order to disrupt the review meeting as well as the subsequent claims of police violence against them in December 2016 could be seen as an echo of actions taken by the Sunflower Movement. ${ }^{10}$ The ensuing campaign to unseat avowedly pro-gay lawmakers closely followed the script of post-Sunflower recall campaign, which targeted some KMT lawmakers.

While the women's movement and the gender movement have established a number of advocacy organizations that have gained public visibility and credibility, conservatives managed to set up their own to present their claims. For instance, while the Gender/Sexuality Rights Association of Taiwan (Taiwan Xingbie Renquan Xiehui) has been a recognized representative of the LGBT community, another emerged - the Gender Human Rights Preservation Association of Taiwan (Taiwan Xingbie Renquan Weihu Cujin Xiehui) - making opposite demands. Similarly, the Taiwan Gender Equity 
Education Association (Taiwan Xingbie Pingdeng Jiaoyu Xiehui), a veteran campaigner for tolerance, now faced a challenge by an explicitly anti-gay organization, the Taiwan Gender Education Development Association (Taiwan Xingbie Jiaoyu Fazhan Xiehui). ${ }^{11}$ Forming parallel and confusingly sounding organizations not only diluted the conservative groups' religious origins, but also helped to bring out an alternative voice in civil society.

The rhetoric and framing by conservatives evolved as their countermovement became more mature. According to the observation of an LGBT activist, the early use of fire-and-brimstone language by conservatives actually backfired by alienating the public; later on, they refrained from cursing lesbian and gays by concentrating their message on the 'protection of the family.' The activist acknowledged that the revised rhetoric made the anti-gay campaign more socially acceptable (Interview TAPCPR 2017). In place of references to Sodom and Gomorrah, conservative activists had learnt how to avoid using explicitly discriminatory language. The typical statement of their revised position was that they 'respected' lesbians and gays, but they opposed the 'homosexual movement' with its sexual liberation agenda which was bound to bring about promiscuity, cause gender confusion and foster the AIDS epidemic. Conservatives mastered the art of conveying their message by using their opponents' vocabulary. For example, 'sexual bullying' was a term created to name and fight against the marginalization of LGBT students. Conservatives quickly usurped this notion by arguing that 'normal' students (read: heterosexual ones) were now being 'bullied' by gender equity education which was said to 'encourage homosexuality.'12

Studies found that the movement claims previously used by progressives were often taken over and redefined to match the conservative agenda. The examples included the use of 'multiculturalism' to refer to white separatism (Berbrier 1998) and church schools (Davies 1999), 'civil rights' to mean anti-abortion activism (Johnson 1999), and 'community control of schools' to support the kinds of religious schools favoured by the Christian Right (Naples 2002). Regardless of the creditability of these reinterpretations, these incidences indicated that ideas and notions which were invented by progressive movements and introduced into the public domain lent themselves to be re-appropriated by those who resisted change. Conservatives borrowed these pre-existing movement frames precisely because the latter had gained legitimacy, more or less. 
Particularly after the flare-up of the dispute over same-sex marriage at the end of 2016, such 'frame borrowing' became more frequent. Opponents of same-sex marriage self-styled themselves as a 'citizen movement' (gongmin yundong), ${ }^{13}$ a term that had become a popular way to characterize protest activism leading up to the Sunflower Movement in 2014. Some student protesters named their action as a 'Gypsophila paniculata movement' (mantianxing yundong), ${ }^{14}$ meaning 'baby's breath movement,' following Taiwan's time-honoured practice of characterizing a successful student movement by the name of a flower (such as the Sunflower Movement or the Wild Lily student movement of 1990). The legislative process on the Civil Code revision was also criticized as a 'black box review' (heixiang shencha), ${ }^{15}$ reminiscent of the way the KMT government dealt with a controversial free-trade agreement with China. Finally, while feminists championed the idea of gender mainstreaming and successfully incorporated it into government policies, conservatives attempted to implement their version of 'family mainstreaming' (jiating zhuliuhua) ${ }^{16}$ in the same way.

Taiwan's LGBT movement started with a non-essentialist assumption of gender identity and sexuality, which were seen as culturally constructed and fluid, whereas conservatives tended to see them as natural, biologically determined or designed by God. As early as the mid-199os, there had been a Christian association that aimed at 'helping' lesbians and gays to find their 'God-created' gender roles in Taiwan. ${ }^{17}$ While there has been a long history of 'curing' lesbians and gays by coercion, medicine or faith, the recent development witnessed a breakthrough in framing. Some conservatives began to embrace a 'post-homosexual' (houtong) theory, which viewed homosexuality in a person as a transient and unstable identity that would eventually return to the normal one. Same-sex marriage opponents staged reverse 'coming out' ceremonies in which post-homosexual people shared their personal stories. A typical narrative contained two plot elements: (1) traumatic experiences (incest or childhood sex abuse) had led to gender confusion and same-sex behaviour, and (2) they found true happiness after accepting their 'natural' gender and sexuality. ${ }^{18}$ The post-homosexual theory actually turned the table on LGBT activists by claiming their identity was not fixed and thus malleable to intervention or correction.

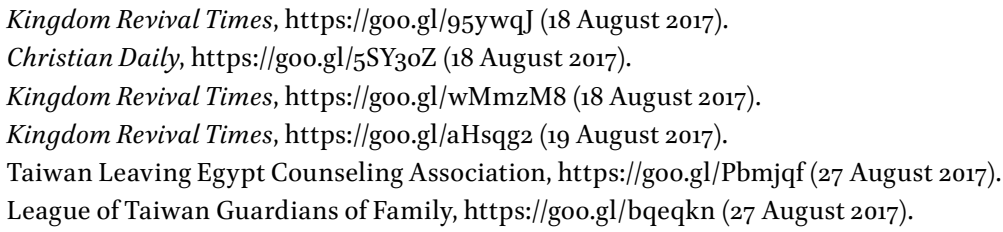


Like their global counterparts, Taiwan's conservative countermovement imitated the tactics and framing used by the rival movements. The resulting surge of social movements during Ma Ying-jeou's government (2008-2016) meant that conservatives had a large menu from which they could learn on how to package their messages. Taiwan's conservatives were eager students of the movement activism that preceded them, partly because they made an effort to shed their religious roots by learning the art of being a secular movement.

\section{Conclusion}

The conservative opposition to abortion, same-sex marriage and gender equity education is an intellectually fascinating case of the development of a countermovement, one that intended to undo the achievements accomplished by the Taiwan women's and gender movements. An analysis of Taiwan's civil society would be incomplete if we fail to take these campaigns into consideration, because they were equally self-organized, mass based and policy oriented, just like their progressive rivals.

This chapter has argued that the emergence of a religion-based countermovement has a historical origin in that Taiwan's Protestant Christians underwent a profound ecological change which facilitated the hegemony of conservative evangelicals. Protestant and Catholic leaders pioneered the opposition to gender equity and multiculturalism, and over the years, they gained support from other religions. On the issues of abortion, same-sex marriage and gender equity education they have largely failed to turn back the clock; yet, their emergence threatens to usher in a new political alignment in Taiwan. As a countermovement, Taiwan's conservatives were latecomers to movement politics. They have demonstrated remarkable adaptability, however, by imitating tactics and framing from their opponents successfully. Their further evolution and impact remain to be observed.

Finally, does the emergence of the conservative movement signify a cultural change in Taiwan, in the sense that more and more people are embracing traditional values regarding sex, gender and family as a conscious choice? Demographic evidence indicates that Taiwanese are marrying late, giving birth to fewer children and more likely to divorce over the years. In other words, people are increasingly choosing a lifestyle that clearly deviates from the idealized family pattern. The growing acceptance of lesbians and gays is particularly noticeable among members of the younger generation. The Taiwan Social Change Survey data shows a significant rise in tolerance. 
In 1991, only $11.4 \%$ of respondent approved of same-sex marriage, a figure that rose to $54.2 \%$ by $2015 .{ }^{19}$ Therefore, the conservative movement in Taiwan does not originate from a society-wide value change, nor does it represent a mainstream voice. More likely, conservative activists are resisting the inevitable trend of cultural modernity - one that values individual autonomy and freedom - that is gradually taking root in Taiwan.

\section{References}

Andrews, Kenneth T. 2002. 'Movement-Countermovement Dynamics and the Emergence of New Institutions: The Case of "White Flight" Schools in Mississippi.' Mobilization, 8 o (3): 911-936.

Berbrier, Mitch. 1998. "Half the Battle": Cultural Resonance, Framing Processes, and Ethnic Affectation in Contemporary White Separatist Rhetoric.' Social Problems, 45 (4): 431-450.

Burstein, Paul. 1991. "Reverse Discrimination” Cases in the Federal Courts: Legal Mobilization by a Countermovement.' Sociological Quarterly, $3^{2}$ (4): 511-528.

Chen, Chao-Ju. 2014. 'Fanzhi Yundong Zuowei Qiji: Xingbie Pingdeng Jiaoyufa Shizhounian de Xinchufa' [Countermovements as an opportunity: A new beginning on the tenth anniversary of the Gender Equity Education Act]. Xingbie Pingdeng Jiaoyu Jikan, 69: 63-71.

Cheng, Ling-fang. 2015. 'Erling Yier Nian Rengong Liuchan Xiufa Zhengyi zhi Fenxi' [An analysis of the controversy over proposed revisions to Taiwan's abortion legislation in 2012]. Taiwan Weizhi, 34 (1): 21-36.

Chien, Tsu-chieh. 2012. 'Cong Tongxing Hunyin dao Duoyuan Jiating: Chaoxiang Qinmi Guanxi Minzhu hua de Lifa Yundong' [From 'same sex marriage' to 'pluralistic family arrangements': The legislative movement for democratic intimate relationships]. Taiwan Renquan Xuekan, 1 (3): 187-201.

Damm, Jens. 2011. 'Discrimination and Backlash against Homosexual Groups.' Politics of Difference in Taiwan. Tak-wing Ngo; Hong-zen Wang (eds). London: Routledge, pp. 152-180.

Davies, Scott. 1999. 'From Moral Duty to Cultural Right: A Case Study of Political Framing in Education.' Sociology of Education, 72 (1): 1-21.

Fell, Dafydd. 2017. Taiwan's Social Movements under Ma Ying-jeou. London: Routledge.

Fu, Yang-chih et al. 2016. Taiwan Shehui Bianqian Jiben Diaocha Jihua:Diqiqi Diyici Diaocha Jihua Zhixing Baogao [Summary report of the Taiwan Social Change 
Survey: The first year of the seventh round]. Taipei: Academia Sinica Institute of Sociology.

Giddens, Anthony. 1991. Modernity and Self-Identity: Self and Society in the Late Modern Age. Stanford: Stanford University Press.

Habermas, Jürgen. 1985. 'Neoconservative Culture Criticism in the United States and West Germany: An Intellectual Movement in Two Political Cultures.' Habermas and Modernity. Richard Rorty (ed.). Oxford: Polity Press, pp. 78-94.

Ho, Josephine Chuen-juei. 2010. 'Queer Existence under Global Governance: A Taiwan Exemplar.' Positions, 18 (2): 537-554.

Ho, Ming-sho. 2005a. 'Protest as Community Revival: Folk Religion in a Taiwanese Anti-Pollution Movement.' African and Asian Studies, 4 (3) 237-269.

Ho, Ming-sho. 2005b. 'Taiwan's State and Social Movements under the DPP Government (2000-2004).' Journal of East Asian Studies, 5 (3): 401-425.

Ho, Ming-sho. 2019a. Challenging Beijing's Mandate of Heaven: Taiwan's Sunflower Movement and Hong Kong's Umbrella Movement. Philadelphia: Temple University Press.

Ho, Ming-sho. 2019b. 'Taiwan's Road to Marriage Equality: Politics of Legalizing Same-sex Marriage.' China Quarterly, 238: 482-503.

Ho, Ming-sho; Chun-Hao Huang; Chun-Ta Juan. 2018. 'The Institutionalization of Social Movement Study in Taiwan: A State-of-the-Field Report.' International Journal of Taiwan Studies, 1 (1): 115-140.

Huang, Chang-ling. 2017a. 'Uneasy Alliance: State Feminism and the Conservative Government in Taiwan.' Taiwan's Social Movements under Ma Ying-jeou. Dafydd Fell (ed.). London: Routledge, pp. 258-272.

Huang, Ke-hsien. 2017b. '“Cultural War" in a Globalized East: How Taiwanese Conservative Christianity Turned Public during the Same-sex Marriage Controversy and a Secularist Backlash.' Review of Religion and Chinese Society 4: 108-136.

Hwang, Shu-ling; Wei-ting Wu. 2017. 'Dang Fuyun Chongzhuang Guojia: Fuquanhui Tuidong Xingbie Zhuliuhua de Hezong Lianheng Celue' [When the women's movement confronts the state: Multiple strategies for promoting gender mainstreaming]. Taiwan Shehuixue, 22: 1-55.

Johnson, Victoria. 1999. 'The Strategic Determinants of a Countermovement: The Emergence and Impact of Operation Rescue Blockades.' Waves of Protest: Social Movements Since the Sixties. Jo Freeman; Victoria Johnson (eds). New York: Rowman \& Littlefield, pp. 241-266.

$\mathrm{Ku}$, Yenlin. 1995. 'Funu Yundong yu Gonggong Zhengce de Hudong Guanxi: Duotai Hefa Hua yu Pingdeng Gongzuo Quan Celue Renxi' [The interaction between women's movement and public policy: An analysis of strategies in abortion legalization and equal employment opportunity]. Taiwan de Guojia yu Shehui. Michael Hsin-huang Hsiao; Cheng-kuang Hsu (eds). Taipei: Dongda, pp. 151-174. 
Kuan, Hsiao-wei. 2011. 'Fan Duotai Yundong yu Rengong Liuchan fa Lunshu' [The anti-abortion movement and discourses on abortion law]. Shehui Yundong de Nian Dai: Wanjin Ershi Nian Lai de Taiwan Xingdong Zhuyi. Ming-sho Ho; Hsiu-hsin Lin (eds). Taipei: Socio, pp. 215-256.

Lai, Yu-lin. 2003. 'Taiwan Tongzhi Yundong de Jigou Hua: Yi Tongzhi Zixun Rexian Weili' [The institutionalization of the Taiwan Tongzhi Movement: A case study of the Taiwan Tongzhi Hotline Association]. Nuxue Xuezhi, 15: 79-114.

Lo, Cheng Chung. 2010. Beichu Mai de Caihong Qi [The betrayed rainbow flag]. https://goo.gl/ztKRh6 (11 August 2017).

Lo, Clarence Y.H. 1982. 'Countermovements and Conservative Movements in the Contemporary US.' Annual Review of Sociology, 8: 107-134.

Luders, Joseph E. 2016. 'Feminist Mobilization and the Politics of Rights.' The Consequences of Social Movements. Lorezno Bosi; Marco Guigni; Katrin Uba (eds). Cambridge: Cambridge University Press, pp. 185-214.

Luker, Kristian. 1984. Abortion and the Politics of Motherhood. Berkeley: University of California Press.

Madsen, Richard. 2007. Democracy's Dharma: Religious Renaissance and Political Development Taiwan. Berkeley: University of California Press.

McAdam, Doug; Karina Kloos. 2014. Deeply Divided: Racial Politics and Social Movements in Post-war America. Oxford: Oxford University Press.

Meyer, David S.; Suzanne Staggenborg. 1996. 'Movements, Countermovements, the Structure of Political Opportunity.' American Journal of Sociology, 101 (6):1628-1660.

Mottl, Tahi L. 1980. 'The Analysis of Countermovements.' Social Problems, 27 (5): 620-635.

Naples, Nancy A. 2002. 'Materialist Feminist Discourse Analysis and Social Movement Research: Mapping the Changing Context for "Community Control." Social Movements: Identity, Culture and the State. David S. Meyer; Nancy Whittier; Belinda Robnett (eds). Oxford: Oxford University Press, pp. 226-246.

Peng, Yenwen. 2008. 'Dang Guanliao Yushang Fuyun: Taiwan Tuidong Xingbie Zhuliuhua de Jingyan Chutan' [When bureaucrats meet feminists: Exploring the progress and challenges of gender mainstreaming in Taiwan]. Dongwu Zhengzhi Xuebao, 26 (4): 1-58.

Rohlinger, Deana A. 2002. 'Framing the Abortion Debate: Organizational Resources, Media Strategies, and Movement-Countermovement Dynamics.' Sociological Quarterly, 43 (4): 479-507.

Rubinstein, Murray A. 1991. The Protestant Community on Modern Taiwan: Mission, Seminary, and Church. New York: M.E. Sharpe.

Rubinstein, Murray A. 1994. 'The New Testament Church and the Taiwanese Protestant Community.' The Other Taiwan: 1945 to the Present. Murray A. Rubinstein (ed.). New York: M.E. Sharpe, pp. 445-473. 
Shia, Chung-Chien. 1993. 'Liangqian Nian Fuyin Yundong de Guoqu Xianzai yu Weilai' [The past, present, and future of Year 2000 Evangelism]. Xin Shizhe Zazhi, 14: 5-9.

Tilly, Charles. 2005. 'Regime and Contentions.' Handbook of Political Sociology: States, Civil Societies, and Globalization. Thomas Janoski; Robert R. Alford; Alexander M. Hicks; Mildred A. Schwartz (eds). Cambridge: Cambridge University Press, pp. 423-440.

Wang, Chao-wen. 2005. 'Jiaopai Hezuo de xu yu Shi' [The reality and fiction of collaboration between denominations]. Xin Shizhe Zazhi, go: 11-14.

Weller, Robert P. 1999. Alternative Civilities: Democracy and Culture in China and Taiwan. Boulder: Westview.

Weng, Hui-chen; Dafydd Fell. 2006. 'The Rootless Movement: Taiwan's Women's Movement in the KMT and DPP Eras.' What Has Changed? Taiwan before and after the Change in Ruling Parties. Dafydd Fell; Henning Klöter; Chang Bi-yu (eds). Wiesbaden: Harraowitz, pp. 147-164.

Yang, Wan-Ying. 2004. 'Fuquanhui dao Xingbie Pingdeng Weiyuanhui de Zhuan Bian: Yi Geguo Jia Nuxing Zhuyi de Bijiao Guandian Fenxi' [From the Committee for Promotion of Women's Rights to the Committee for Gender Equality: A state feminism study from comparative perspective]. Zhengzhi Kexue Luncong, 21: 117-147.

Zald, Mayer N.; Bert Useem. 1987. 'Movement and Countermovement Interaction: Mobilization, Tactics, and State Involvement.' Social Movements in an Organizational Society. Mayer N. Zald; John D. McCarthy (eds). New Brunswick: Transaction, pp. 247-272.

\section{Interviews}

Interview DPP 2017a. Lawmaker of the DPP (Democratic Progressive Party), 17 April 2017.

Interview DPP 2017b. Chief Executive Officer, Taichung City party branch of the DPP (Democratic Progressive Party), 5 July 2017.

Interview FHL 2017. Faith and Hope League legislative candidate in Taichung City, 25 May 2017.

Interview NMM 2017. Editor-in-chief of New Messenger magazine, 14 August 2017. Interview NTCBA 2017. President of New Taipei City Buddhist Association, 29 May 2017.

Interview PTCMRC 2017. Pastor of the Presbyterian Church, Minzu Road, Tainan, 9 June 2017.

Interview SL 2017. Leader of Stability League of Taipei City, New Taipei City and Keelung City, 12 June 2017 
Interview TAPCPR 2017. Secretary General of the Taiwan Alliance to Promote Civil Partnership Rights, 28 June 2017.

Interview TGF 2017. Spokesperson of the League of Taiwan Guardians of the Family, 31 May 2017.

Interview TT 2017. Branch Director, Taiwan Tongzhi (LGBT) Hotline Association, Kaohsiung, 19 June 2017.

\section{About the Author}

Ming-SHO Ho is Professor of Sociology at National Taiwan University, Taiwan. He specializes in social movements, labour and environmental issues in Taiwan. His recent works have been published in Environmental Politics, Sociological Inquiry, Sociological Perspectives, China Quarterly and the Journal of East Asian Studies. He has also published Working Class Formation in Taiwan: Fractured Solidarity in State-Owned Enterprises, 1945-2012 (Palgrave Macmillan, 2014), and Challenging Beijing's Mandate of Heaven: Taiwan's Sunflower Movement and Hong Kong's Umbrella Movement (Temple University Press, 2019). 



\title{
$7 \quad$ The Relationship between Mainstream and Movement Parties in Taiwan
}

\author{
Case Studies of the New Power Party (NPP) and the Green \\ Party Taiwan-Social Democratic Party Alliance (GPT/SDP)
}

Tommy Chung Yin Kwan and Dafydd Fell

\begin{abstract}
Since democratization began in the mid-1980s, Taiwan's party system has been dominated by two parties, the Kuomintang (KMT) and the Democratic Progressive Party (DPP). However, smaller parties have at times played an important role, bringing diversity into the system, stressing different issues and representing neglected communities. These small parties tended to be those that split off from the mainstream parties, while alternative social movement parties struggled to be electorally relevant. The picture changed recently with the rise of two different types of movement parties, the New Power Party (NPP) and the Green Party Taiwan/Social Democratic Party Alliance (GPT/SDP). In this chapter we examine the relationship of these new players with the mainstream party, DPP, offering some thoughts on how the relationship affected the development of these alternative parties.
\end{abstract}

Keywords: Taiwan, small parties, movement parties, party system

Social movements are generally considered as outsiders in political systems. Nevertheless, movement activists can always supplement the extra-institutional tactics by participating in party politics to bring their issues on to the legislative agenda. In Taiwan, social movements have long faced the challenge of how to engage with political society. One option is to remain aloof of party politics and just try to influence or lobby political

Chiavacci, David, Simona Grano, and Julia Obinger (eds), Civil Society and the State in Democratic East Asia: Between Entanglement and Contention in Post High Growth. Amsterdam, Amsterdam University Press 2020 DOI: 10.5117/ 9789463723930_CH07 
parties from the outside. Nevertheless this runs the risk of losing political influence. To switch from street politics to the legislature in Taiwan, there are arguably three options for the social activists. Firstly, they can work with one of the two established mainstream parties, and it has been particularly common to see alliances with the Democratic Progressive Party (DPP) (Ho 2003). An alternative is to work with, or form, social movement-oriented parties. Here there are two main options. They can work with a more DPPallied movement party such as the New Power Party (NPP) or with parties autonomous from the DPP, such as the Green Party Taiwan (GPT).

The Sunflower Movement in 2014 was by far the largest social movement since Taiwan's democratization. It arose not only due to concerns about the China factor, but also was a response to what Chiavacci and Grano (in this volume's introduction) call 'new social anxieties and increasing normative diversity.' After being ignited by the abrupt attempt of passing the CrossStrait Service Trade Agreement by the government in the legislature, the movement quickly escalated into a mass movement comprising different issues, ranging from social justice to labour and environmental politics as 'it was a culmination of a long series of contentions and a confluence of diverse streams of many CSOs in the past few years' (Hsu 2017). After the Sunflower Movement, the NPP had carried forward the dynamics of the movement to participate in the electoral politics of Taiwan. Compared to the rookie NPP, the GPT is a veteran in Taiwan politics, existing for more than two decades, despite its limited progress in terms of votes and seats. As mentioned in the chapter by Chiavacci and Grano as well as the one by Grano (in this volume), environmental protection movements have been the key social movement involved in Taiwan's political transition - for example, the GPT is a movement party that emerged out of an environmental CSO. The cases of NPP and the GPT offer us an excellent chance to contrast the development of movement parties in Taiwan.

A number of studies on small parties have theorized about how their relationships with mainstream parties can affect their development trajectories (Meguid 2008). Therefore, in this study we examine the relationship between two different types of movement parties, the NPP and GPT/SDP ${ }^{1}$ with a mainstream party, the DPP, and consider how this relationship has affected their recent development.

Since democratization began in the mid-1980s, Taiwan's party system has been dominated by two parties, the Kuomintang (KMT) and the DPP.

1 The Social Democratic Party (SDP) officially ran in an alliance with the GPT in the 2016 campaign. 
However, smaller parties have played an important role, bringing diversity into the system, stressing different issues and representing neglected communities. ${ }^{2}$ Taiwan's smaller parties can be divided into two types. These are splinter parties and alternative parties. Splinter parties are those that split away from one of the two mainstream parties, often because of disagreements over policy issues or matters of nomination. Lucardie (2000:176) has termed them 'purifier parties' that cling 'to an existing ideology, which it feels is diluted or betrayed by one (or more) of the established parties. ${ }^{3}$ The classic Taiwanese case is the New Party, which was established by KMT defectors in 1993 (Fell 2006). These can be distinguished from alternative or niche parties that Lucardie (2000: 177) calls 'prophetic parties,' which stress new issues and ideologies that have been ignored or neglected by the mainstream parties. ${ }^{4}$ Given that many of these alternative parties owe their origins in Taiwan's social movements, Ho and Huang have recently termed them as 'movement parties' (Ho and Huang 2017). The most researched Taiwanese party in this category is the GPT, which was established in 1996 (Fell and Peng 2016). The NPP and SDP are more recently established examples of movement parties.

A key feature in Taiwan's party system has been that the splinter parties have fared better electorally than the movement parties. Before the emergence of the NPP, splinter parties had a far better record in winning significant numbers of votes and seats, however, they tended to see their support levels collapse within one or two electoral cycles. A critical factor in explaining the development of smaller parties is in their relationship with mainstream parties. In the case of splinter parties, once the mainstream parties appear to be returning to party ideology, then the purifier parties' supporters and politicians may return, often leading to a collapse in the purifier's electoral base. The decline of the New Party and People First Party are good examples of this pattern, losing support as their original party, the KMT, appeared to return to more orthodox positions on national identity (Fell 2005, 2014). 5 In contrast, movement parties in Taiwan have struggled to get any of their candidates elected at either the local or national level. Rochon has proposed that while splinter parties will initially perform better, alternative parties would perform better, 'once they had carved out an electoral niche

2 For a discussion of the development of Taiwan's small parties, see Fell $(2005,2014)$ as well as Ho and Huang (2017).

3 Rochon (1985) terms these as 'challenger parties.'

4 Rochon (1985) calls these 'mobilizers.'

5 The orthodox stance on national identity refers to a pro-national unification position, embracing the idea of Chinese national identity. 
for themselves' (Rochon 1985). At least prior to 2016, Taiwan's case seemed to support the first part of Rochon's argument but not the latter part.

As the film director Wan Jen reminds us in his hilarious cross-Strait romantic comedy, It Takes Two to Tango. In other words, we need to consider the approaches of both the mainstream and smaller alternative parties in this relationship. In a classic study on small parties, particularly the prophetic parties, Bonnie Meguid (2008) argues that the best way to understand the development of challenger parties is by looking at the strategies of the mainstream parties. She suggests that mainstream parties can take dismissive, accommodative or adversarial strategies towards the prophetic parties' core issues. In other words, when mainstream parties pursue dismissive strategies the niche parties' core issue is likely to decease in salience and its electoral support will decline. Where the mainstream party adopts accommodative strategies then the issue may rise in salience but because the mainstream party may take over issue ownership, it, rather than the niche party, will benefit electorally. The ideal scenario for the niche party is where the mainstream party takes oppositional or what Meguid (2008) calls 'adversarial attitudes,' as this will raise niche party issue salience, reinforce niche party issue ownership, and she suggests, enhance the small parties' electoral performance.

Nevertheless Spoon (2011) does remind us that the strategies of small parties can also affect their survival. She argues that if such parties can reach a balance between their ideals and vote maximization, then small parties can survive, even in the 'most unfavourable' institutional settings, for instance, the Green Party's victory in Brighton Pavilion in the 2010 UK general election. We are thus interested to see whether the small parties' relationship with larger parties can help us to understand the recent fate of movement parties in Taiwan. In our selected cases, the NPP adopted a much more welcoming strategy to cooperate with the DPP, while the GPT/ SDP maintained distance with the mainstream parties.

To analyse the relationship between mainstream and movement parties, we consider what are the options for small parties in dealing with the mainstream parties? How did the different approaches to mainstream parties adopted by the NPP and the GPT/SDP lead to different electoral fortunes? In the first section of this chapter, we will define the concept of the 'movement party' to discuss their major characteristics. Then we will consider movement parties by examining the case of two such parties in recent years, the NPP and the GPT. In both cases, we analyse the relationship between these small parties and the mainstream parties. We also offer some thoughts on why these parties adopted such strategies and how the relationship affected the development of these alternative parties. 


\section{The Concept of a Movement Party}

Sidney Tarrow (2015: 94) denotes that 'movements frequently give rise to parties when movement activists transfer their activism to institutional politics.' The transition of activists from extra-institutional protests to institutional party politics often involves the formation of movement parties. Since social movements can bring 'significant change in the distribution of ideological views among voters,' Anthony Downs (1957:115) argues that the outbreak of social movements provides a good opportunity for new parties to be launched successfully. According to Herbert Kitschelt (2006: 280), 'movement parties are coalitions of political activists who emanate from social movements and try to apply the organizational and strategic practices of social movements in the arena of party competition.' Representing the unrepresented salient issue is the raison d'être of movement parties. They are filling the void left by mainstream parties. In other words, they are prophetic parties that stress new issues. Kitschelt (2006: 280-281) further lists three general characteristics of movement parties. First of all, they often lack a formal organizational structure compared with office-seeking mainstream parties. Second, they focus on a small set of issues instead of a broad political platform. Third, the formation of movement parties does not necessarily mark the abandonment of extra-institutional demonstrations of the social activists, they can alternatively switch their battlefield from the parliament back to the street.

Movement parties often find themselves falling into the dilemma of whether they should invest in organizational structure to become more mainstream to broaden their support base and, ultimately, increase their electoral fortunes or remain as a single-issue party. Developing a more general party platform to appeal to more issues could target more constituencies, however, it would easily lead to accusations that it has become another purely 'office seeking' mainstream party. Movement parties have a rather long history in Taiwan, which could be dated back to the Workers' Party in the 1980 os (Ho and Huang 2017). Ho and Huang (2017:344) argue that the electoral victory of NPP in 2016 'represents the culmination of nearly three decades of effort by civil society activists to elect their own representatives, rather than relying on the sponsorship of more established politicians.' Nevertheless, Fell is more cautious, categorizing the NPP as 'a hybrid party, with both alternative and splinter party features' (Fell 2016: 58). Therefore, from the perspective of Taiwan's party system, the emergence of NPP is an important case to analyse and explain. 


\section{The Emergence of the NPP}

The NPP was established in January 2015 following the split of the activists' group the Taiwan Citizen Union (TCU). The TCU was originally formed before the Sunflower Movement, with the aim of nominating candidates to run in the 2016 parliamentary election in order to 'break the dominance' of the mainstream parties (TCU 2014). The manifesto of the TCU was signed by 35 activists and professionals, including the founding members of the later-formed NPP, for instance, Lin Fong-chen, Huang Kuo-chang and Chiu Hsien-chih.

On 18 March 2014, the Sunflower Movement broke out and the legislative chamber was occupied by activists for over three weeks. Much about the NPP, from its personnel to its electoral campaigns, clearly show that the party owed its origin to the Sunflower Movement. The NPP leader, Huang Kuo-chang, was one of the leaders in the Sunflower Movement. Other prominent figures in the movement, including the charismatic student leaders Chen Wei-ting, Wei Yang and Lin Fei-fan, openly endorsed NPP candidates in the 2016 Legislative Yuan election by featuring in the NPP's electoral campaigns. ${ }^{6}$ In the campaigns they never shied away from showing their close ties with the Sunflower Movement. An example is the NPP's party list TV ad. This ad opens with the Sunflower slogan 'Reject the Cross-Strait Service Trade Agreement (CSSTA)' and shows images of Sunflower protests as well as the Sunflower occupation itself. Later in the ad their party list candidate Jang Show-ling is described as an 'Anti-CSSTA Fighter' in the campaign. ${ }^{7}$ In the NPP's manifesto, it says that 'We promise to continue to be an activist party. Wherever there are injustices, the NPP will be there. NPP will always push for reform, fighting for the people. ${ }^{8}$

\section{The Significance of the NPP}

In the 2016 Legislative Yuan election, the NPP won three seats in the singlemember district election and two seats in the proportional representation

6 For example, see Lin Fei-fan's video advertisement: https:/www.youtube.com/watch? v=SBjFo_d96Og (12 December 2019), and Chen Wei-ting's endorsement: https://goo.gl/vNMpdM (12 December 2019).

7 Advertisement featuring the Sunflower Movement: https://www.youtube.com/watch?v =06p8i 5 FxiGg (12 December 2019).

8 New Power Party, 'Women de Chengnuo' (Our promise), https://bit.ly/31illrW (12 December 2019). 
elections. ${ }^{9}$ These five seats made the NPP the third-largest party in the parliament. The victory of the NPP also signifies a change of the political landscape in Taiwan. Previously, small parties in Taiwan, for instance, the PFP and Taiwan Solidarity Union (TSU), were purifier parties (Fell 2014). Party members broke away from mainstream parties to form the new parties. In contrast, the newly formed NPP has many of the attributes of a prophetic party (Lucardie 200o). Its candidates did not have previous election experience before with mainstream parties and it focused more on new issues (Fell 2016: 52). It could be argued that it is the first movement party to win more than a single parliamentary seat in Taiwan..$^{10}$ The room for small parties in Taiwan under the current legislative electoral system is small (Fell 2014). The success of the NPP has at the same time replaced the TSU in the parliament and allowed it to overtake the PFP to become the third-largest party. The third-largest-party status was reaffirmed by the party identification surveys conducted by the Election Study Center, NCCU. In December 2016 the NPP's party identification was 4.1\%, higher than the PFP's $2.3 \%$ and one year later there was a slight decline in the NPP's support to $3.8 \%$, compared to the PFP's 1.3\% (ESC 2019). In other words, in both seats and support rates, the NPP has become the third party in Taiwan ahead of the traditional splinter small parties.

\section{The Ambiguous Relationship with the DPP}

The 2014 Sunflower Movement was not merely against the Cross-Strait Service Trade Agreement; it was about the underlying quality of democracy. Dafydd Fell denotes that from the slogan of Sunflower Movement - 'Protect Democracy, Return the CSSTA' - the movement was caused by a perception of the failure of regular party politics (Fell 2017b). Thus, the movement was not only targeting the then governing party, the KMT, but also the whole establishment, including the largest opposition party, the DPP. The formation of the NPP is the perpetuation of the Sunflower Movement. To a certain extent, it intended to keep some distance from the DPP. In its manifesto, it states that the alternation of governing party could not solve

9 NPP won $6.1 \%$ of vote in the party list election, see Central Election Commission, http:// engweb.cec.gov.tw/ (12 December 2019).

10 The sole exceptions are the GPT's one National Assembly seat in 1996 and the Chinese Social Democratic Party's single seat in 1992. The Worker's Party did hold a seat in the Legislative Yuan for over two years but in that case the legislator had been elected for the DPP in 1986 and defected mid-term. 
the societal problem in Taiwan, but the formation of the NPP is to break the 'political imagination' in Taiwan. ${ }^{11}$ This is in line with the TCU's aim before the Sunflower Movement.

The NPP is a product of the Sunflower Movement and, thus, it theoretically and fundamentally distanced itself from the DPP. Nevertheless, the two parties did come close to an alliance in the NPP's initial period. The DPP adopted an accommodative approach to the NPP after its foundation. The DPP party leader, Tsai Ing-wen, openly welcomed the foundation of the NPP by saying that 'even if the new party [the NPP] does become a competitor of the DPP, we [the DPP] will continue to work with these friends and maintain a friendly relationship' (LT 2015a).

The relationship between the NPP and the DPP has often been ambiguous, especially when it is compared with another nascent movement party, which also split from the TCU, the Social Democratic Party (SDP). The SDP did not endorse and cooperate with the DPP during the election. Conversely, the NPP adopted a semi-alliance strategy with the DPP. It worked closely with the DPP to cooperate on the nomination of candidates. In the three single-member districts seats that the NPP won, the DPP did not nominate candidates and openly supported the NPP candidates. ${ }^{12}$ The cooperation between the DPP and NPP did not only involve the DPP giving way to the NPP, it also happened the other way round. In the New Taipei City ( $1^{\text {st }}$ District $)$, the founding member of the NPP, Feng Kuang-yuan, gave way to a DPP candidate, Lu Sun-ling, in order to avoid a DPP-NPP competition within the same district. In the end, Lu successfully won the seat in that district (Lin 2015a).

In addition, the NPP also nominated eight 'token candidates,' which means that they were 'mission-oriented' and nominated only for the sake of promoting the party list election. Among these candidates, seven out of eight 'token candidates' were nominated in the same district that the DPP had nominated candidates, they campaigned for the NPP party list election but did not campaign for their own district election ( $L T 2015 \mathrm{~b})$. It is noteworthy to point out that some DPP candidates voiced their dissatisfaction towards these 'token candidates' as they might still get a considerable number of votes in the single-member district elections under the party label of the NPP even without campaigning. In addition, there was one district where there was open tension between the DPP and NPP candidates - in Hsinchu City, where the NPP nominated one of its founders, Chiu Hsien-chih, to stand 
against the veteran DPP politician Ke Chien-min. However, despite this being a traditionally safe KMT district, the DPP's Ke narrowly came out on top.

The NPP openly endorsed and supported the DPP presidential election candidate, Tsai Ing-wen, in the electoral campaign (Fell 2016: 52). Huang, the NPP leader, pleaded with voters that 'although I and Chairlady Tsai are not from the same party, our heart is Taiwanese. We both support reform. [...] Please vote for Chairlady Tsai to save the government! Please vote for me to change the parliament!'3 The emphasis of Taiwanese identity highlighted the fact that it was a shared value for the DPP and NPP, which allowed cooperation between the two parties.

Both parties also jointly formed a united electoral campaign headquarters during the elections. ${ }^{14}$ For instance, a number of DPP politicians, including the high-ranking figure Chen Ju, openly campaigned for Huang. She supported Huang and claimed that Huang's NPP represented 'a progressive power' (Lin 2015c). Moreover, in an NPP PR election ad there is a scene where the NPP's Huang shares a stage with Tsai. The ambiguous relationship is clear in the NPP campaign in which the party says: 'We will gain over half seats in parliament, that is, the DPP plus NPP getting a majority. We will take responsibility for supervising the DPP ([government]' (Lin 2015b).

However, the semi-alliance between the NPP and DPP did ultimately backfire when it came to the electoral fortunes of the NPP, especially in the PR seats. The NPP originally expected to win four or five seats on the PR list (Ho and Huang 2017). The DPP attempted to adopt an accommodative strategy towards the NPP in its own PR list nomination, as it nominated eight social movement activists on the PR list to appeal to the social movement supporters. Moreover, the DPP, sensing the threat that the NPP posed to its PR list, decided to adopt a strategy of highlighting these social movement candidates in the final weeks. These candidates thus featured heavily in both newspaper and TV advertising as election date approached. ${ }^{15}$ The DPP's accommodative strategy also applied to its issue approach in the campaign. For example, Tsai's advertisements made appeals to core social movement themes that the DPP had largely neglected in recent earlier campaigns, such as marriage equality and land justice. We will return to this in more detail in the section on the GPT.

13 New Power Party, 'Xieshou Nuli Rang xia Yidai you Weilai' (Working together for a better future), https://bit.ly/35ATruF (12 December 2019).

14 Ibid.

15 For example, see the DPP's newspaper ads on the front pages of the Liberty Times on 8 and 9 January 2016. 


\section{Overlapping between the NPP and the DPP}

The party platform of the NPP reflects a degree of institutionalization of the party. It is far more than a single-issue party. In its party platform, it discusses nearly every issue in Taiwan and advocates a series of policy reforms, ranging from national identity, constitutional reform, to environmental politics, multiculturalism and child care. It operates like a mainstream catch-all party. In the official party introduction, the 'normalization of Taiwan as a nation-state' is the first principle and it is no different to Taiwan Independence. ${ }^{16}$ In other words, the DPP and the NPP hold similar positions in support of Taiwan's independence.

However, the broad spectrum of its party platform actually reflects the many facets of the Sunflower Movement. The major activists group during the movement, the Democratic Front against the Cross-Strait Service Trade Agreement (DFACSSTA), comprised a total of 37 civil society organizations, including the feminist group Awakening Foundation, the Taiwan Rural Front and the Taiwan Labour Front. This shows the occupation of the Legislative Yuan represented far more voices than only opposition to the CSSTA. As a product of the Sunflower Movement, the NPP also developed a complete and well-rounded party platform. However, this risked the NPP appearing to overlap with and too closely resemble the DPP. The distinction between the DPP and the NPP was blurred. The DPP could easily adopt an accommodative approach to focus on the same issues. As a result, voters would find it increasingly hard to distinguish between the two and, in the long term, the mainstream party would benefit electorally.

\section{The NPP and Other Smaller Parties}

Thus far we have mainly focused on the relationship between the NPP and the DPP. However, previous studies have also shown that competition and cooperation between rival smaller parties can also be critical in their development. One such example had been the way the PFP hollowed out the NP's support between 2000 and 2001 (Fell 2017a). One key element in the NPP's success was the way it took an accommodative approach towards the TSU's ownership of the anti-China message. Both parties used such appeals in their TV advertisements. For instance, in the NPP's TV ad we see a protest

16 New Power Party, 'Jiben Zhengce Zhuzhang' (Our policy), https://bit.ly/31g8tDo (12 December 2019). 
scene against the meeting between Ma Ying-jeou and Chinese President Xi Jinping, while the TSU warned of Taiwan becoming another Hong Kong. However, the NPP's vote share and the collapse of the TSU's vote share in 2016 suggests the NPP's accommodative strategy had allowed it to steal the ownership of the issue.

In summary, NPP adopted a semi-alliance approach with the DPP. Although there were instances of competition and arguments in the cooperation, both parties benefitted from the alliance. The NPP became the third-largest party in Taiwan and the DPP won historic presidential and parliamentary victories in 2016. However, the alliance also made the NPP less distinctive and less like as a 'prophetic party' compared with the older movement party, the GPT.

\section{The Green Party Taiwan (GPT)}

Taiwan's Green Party was established in January 1996. Thus, it can be seen as part of the second wave of movement parties following the first wave, which was dominated by leftist parties (Fell 2005). Although Ho argues the GPT was part of the attempt by the environmental movement to regain autonomy from the DPP, it also had an ambiguous relationship with the party in the GPT's early history (Ho 2003). For instance, in 1996 party figures were divided over whether they should support the DPP's candidate in the first direct presidential election. In the GPT's initial phase, despite being largely ignored by the DPP, the mainstream parties did leave some scope for the GPT to emerge. The ruling KMT had an openly pronuclear policy and the DPP was showing mixed signals on environmental issues (Ho 2003). After the GPT's promising start in 1996, it failed to make a breakthrough in the 1998 local elections. The party then collapsed and appeared to have followed the same pattern as the leftist parties of ceasing to contest elections. ${ }^{17}$

The GPT that emerged in the aftermath of the 2008 national elections was distinct enough to be seen as a brand-new party. The membership, leadership and core issues were quite distinct from its predecessor. In addition to its emphasis on environmental issues, the party broadened its appeal on subjects such as LGBT rights and labour issues. A further key change was that it had a much clearer position on keeping a distance from its former ally, the DPP. On the back of the party's new approach it was 
able to develop electorally to move to the brink of becoming Taiwan's first relevant alternative party by the eve of the 2016 national elections.

What explains the changed relationship with the DPP? The first place to start was the experience of the DPP's first time in power (2000-2008). There were quite high expectations when the DPP came to power and it did appoint a number of key environmentalists into government positions. Most notable were Chen's first environmental minister, Edgar Lin, and Chang Kuo-long in Chen's second term. However, in interviews with GPT members and supporters there was a high degree of dissatisfaction with the DPP government (Fell and Peng 2016: 78). A notable sore point was the DPP's failure to deliver on its anti-nuclear pledges, in particular, the resumption of construction of the fourth nuclear power station. It also failed to resolve the issue of the nuclear waste disposal site on Lanyu Island. ${ }^{18}$ The sense of betrayal comes through quite strongly in the award-winning documentary How Are You, Gongliao? (2004) made by prominent GPT supporter Tsui Shuhsin. Increasingly, the DPP was viewed as taking a similar developmentalist approach to its predecessor, the KMT. In order to stay in power, the DPP was seen as compromising with big business to the detriment of the environment and the rights of workers. For example, a number of GPT figures interviewed spoke of their frustrating experience while serving on the Environmental Impact Assessment Committee (Fell and Peng 2016: 77-78).

We also found a strong sense of anti-DPP sentiment among many GPT members and supporters interviewed. This was partly due to similar frustrations from their experiences of DPP rule, but also we found many GPT supporters came from families that did not have clear political affiliations or whose parents were Pan Blue supporters. In fact, when we examine the GPT's electoral record and where it nominated, we can see that non-DPP voters have made up a significant portion of its support base.

One way that we can see the dislike of the DPP was in the case of the Pan Han-sheng candidacy in Taipei in 2012. Pan Han-sheng was the closest the GPT had to a political star and was standing for election to the legislature from Taipei City District 7. In this case an informal agreement was reached between Pan and the DPP to allow him to stand with DPP backing. Given that this was not the result of a party-to-party agreement, it was a controversial case of collaboration. Although the DPP did offer Pan support, some in the party opposed him and a rebel DPP candidate did stand. Towards the end of 2012, long after the election, a GPT focus group found high levels of resentment directed at Pan for the way he handled the campaign. The vast 
majority of interviewees were critical with only a small number focusing on the fact that Pan was the GPT's top vote getter and helped raise party visibility.

When we asked GPT voters it was clear they had a clear preference for taking a non-allied positions regarding the mainstream parties. In fact, when asked why voters preferred the GPT one of the most common answers we found was distaste for mainstream parties. A quote from a previous interviewee said that 'in fact you can't say the GPT particularly attracts me, but that the other parties hold no attraction at all to me' (Fell and Peng 2017: 187). We found many younger generation voters were critical of what they saw as the repetitive debates over national identity between mainstream parties. The inconsistent record of the DPP in supporting environmental issues also strengthened GPT supporters' decision to vote for the GPT.

We can see that the mainstream parties' strategies towards niche party issues favoured the GPT in 2012. The Fukushima accident had raised the salience of the nuclear issue and in addition other value shifts benefitted the GPT, such as growing support for LGBT rights. The ruling KMT had adopted a highly developmental position and was still pushing ahead with the fourth nuclear power station (Fell and Peng 2016). The DPP candidate in 2012, Tsai Ing-wen, did mention a nuclear-free homeland but it was no longer a core member of the anti-nuclear movement. When it came to social movement-related issues, the DPP stance corresponded to Meguid's (2008) dismissive approach.

The experience of 2012 meant there would not be a repeat of the Pan experiment. In fact, the tensions were so high that Pan ended up establishing a brand-new party, the Trees Party, to contest the 2014 local elections. In many ways 2014 was the GPT's most professional campaign to date. One problem was that the party did not contest seats in its traditional stronghold of Taipei, leaving this for the Trees Party. The GPT's desire to avoid even the impression of an alliance with the DPP was made clear in the case of Yang Zhi-xiang. Yang had been nominated as a GPT candidate in the Hsinchu city council election but his nomination was revoked partly due to his joining the Taiwan Independence Election Alliance. ${ }^{19}$ By the end of the election, the GPT won two seats and had become the most significant movement party. However, there was trouble brewing as rather than joining the GPT, there were moves a foot to create a new social movement party (discussed in the previous section), initially known as the TCU. 
On the surface 2016 should have been the moment that the GPT made its great breakthrough at the national level. It was the largest and oldest alternative party, with a fine track record of involvement in a range of social movements. With the advent of the Sunflower Movement, there was a sense of optimism in the social movement sector. The GPT had made a breakthrough at the local level in Taoyuan and Hsinchu in 2014. Moreover, the GPT had established an alliance with the newly formed SDP, a party that had strong candidates in Taipei. In interviews even on the eve of the election there was optimism that the party had a real chance to break through the magic $5 \%$ required to win party list legislative seats. However, when the results were announced, it was the NPP that was celebrating and the GPT was left bitterly disappointed. Despite the fact that it had run a much better funded and organized campaign than in the past, the GPT was only able to increase its vote share from 1.7 to $2.5 \%$. The GPT's relationship with both the mainstream parties and other challenger parties can help us to understand this failed breakthrough in 2016 .

The KMT (and NP) were even more adversarial on issues related to social movements, however, this probably had only limited impact on the GPT because the KMT concentrated its attacks on the DPP and the NPP. Similarly, both the DPP and NPP attempted to claim ownership of key issue areas on which the GPT was campaigning. For instance, both the DPP and NPP campaigned for marriage equality, attempting to steal this once GPT-owned issue. Thus, to a certain extent, the GPT was not able to benefit from the rising salience of its core issues.

We can also measure the relationship through nomination practice. While the DPP left the NPP three seats to contest against the KMT, it only gave one such seat to the SDP's Fan Yun, in one of the safest KMT seats in the country. The DPP was more willing to offer seats to the PFP or KMT defectors than those on the SDP/GPT alliance. We have discussed the way the DPP attempted to adopt an accommodative strategy towards the NPP niche issues in the final weeks of the campaign. This probably had a detrimental effect on both movement parties, as their eventual PR list was below what some had been expecting. Another way the DPP threatened the GPT was through its nomination strategies. It chose to nominate two former GPT co-convenors on its PR list and a former GPT National Assembly candidate. They were Yu Wan-ju, Chen Man-li and Wang Jung-chang. The damage was more severe in the case of $\mathrm{Yu}$, as she had officially only ceased to be co-convenor in early $2015 .^{20}$ In fact, all three featured prominently in DPP newspaper and TV 
ads in the final weeks. ${ }^{21}$ Thus, we can say that the DPP was using a mix of adversarial and accommodative strategies to deal with the GPT.

We can see the antagonistic relations between the GPT and the DPP in the case of Fan Yun. Fan was the only SDP/GPT Alliance candidate that the DPP did not nominate a candidate to run against and so her cooperation with the DPP was closely scrutinized by GPT members. Her level of cooperation was much lower than that seen in the Pan case, but when she did appear publically with the DPP's Tsai Ing-wen, she was subjected to harsh criticism from GPT members. After the election, she admitted that she had underestimated the cleavage between the DPP and the GPT members. Another example is that Fan participated in the DPP candidate Ke Chien-ming's book launch two weeks before the election. Fan claimed that she showed up as an audience member. However, GPT and other social activists, including Chen Wei-ting, heavily criticized Fan's cooperation with the DPP. The GPT issued a statement to criticize Fan's behaviour as 'incompetent' and voice their discontent to Fan and the SDP (LT 2016). Once again, we can see how the GPT tried to avoid even the slightest impression that it was a DPP ally.

Looking back at the 2016 results, what lessons can we draw for the GPT in terms of its relationship with other parties? The DPP's strategy was actually very successful as it not only limited the seats of its ally party (NPP) but also prevented the emergence of a genuine alternative party in the GPT. What of the GPT? Did it make mistakes in its inter-party relations? The failure to create either a single united alternative party or at least an electoral alliance of the three or four social movement parties played a role. It even handled relations with its ally poorly, to the degree that it would not be able to recreate the GPT-SDP alliance in 2020. If there had been a single united alternative party in 2016, though it might not have won district seats, it probably would have performed well enough to win party list seats. During the campaign there was clear tension between the NPP and GPT, as they fought for a similar set of voters on the party list. Even the presence of the small Trees Party undermined the GPT's fortunes, particularly in the party list contest. This could have been avoided if the party had been able to bring Pan back into the fold or to establish an alliance. In other words, for the GPT the poor relationship with other challenger parties also contributed to the failed breakthrough.

Could the GPT have performed better if it had followed the NPP's model of a semi-formal alliance with the DPP? We think this is unlikely for a couple 
of reasons. The GPT had limited appeal to the DPP as it did not nominate strong district candidates and by the eve of the election the DPP was strong enough that it could probably have won more seats by offering up fewer seats to other parties. It is hard to imagine GPT members and supporters accepting such an agreement. In many ways the GPT's distance from the DPP was one of its few clear selling points at a time it was being squeezed by the NPP and DPP. Moreover, the way the NPP's PR vote collapsed also reveals the dangers of too close an alliance with a mainstream party.

\section{Conclusion and Future Prospects}

In this chapter we have examined the development of two of Taiwan's movement parties with reference to their relationship with mainstream parties. We have examined both sides of the relationship. In other words, we followed Meguid's (2008) framework to look at the strategies that mainstream parties adopted towards small parties. In addition, we examined the alliance strategies adopted by our two case study movement parties. We showed that an examination of this two-way relationship can help us to explain the development of such movement parties. At least in the short term the NPP's hybrid issue approach, combined with its alliance with the DPP, did allow it to break into parliament at the first attempt.

An important finding of our chapter is that in addition to the relationship between small and large parties, an important variable is the interrelationship among rival challenger parties. In other words, forming relationships between parties is the key to thriving in Taiwan's party system. As we have shown, in 2016 the mutual relationship between the smaller alternative parties did have a major effect on their election fortunes. The failure to develop a single united movement party, or at least a viable alliance of similar parties was critical in the GPT's failure to capitalize on the momentum it had been building since 2012. Without cooperating with mainstream parties, will the movement parties be able to coordinate nomination and avoid multiple movement party candidates fighting for the same district? Will they be able to develop a system for mutual support for movement party candidates to reduce campaigning costs?

We can get some idea from the local elections in 2018 . These were naturally more straightforward as these were using the MMD electoral system, so small parties could potentially win seats without mainstream alliances. The DPP had enjoyed historic success at the local level in 2014 and thus it was not surprising it lost seats in 2018 to the KMT as a result of widespread 
disappointment in Tsai's government. There were large numbers of voters unconvinced by either the KMT or the DPP. Nevertheless, there were no signs that any of the older splinter parties are able to step back in and take advantage, as they continued to lose seats in 2018. Therefore, this was another historic window of opportunity for the alternative parties. Compared to 2014 or 2016, the field for movement parties was much more crowded with the NPP, GPT, SDP, Labour Party and Taiwan Statebuilding Party all running serious campaigns. As the 2018 campaign developed it became clear that there were tensions between the main challenger parties, especially between the NPP and the others. In the end, the election resulted in significant numbers of movement party politicians entering local assemblies for the first time, with sixteen seats for the NPP, three for the GPT and one for the SDP.

Looking further ahead to national elections in 2020, the challenges for the movement parties will show similarities and differences in their inter-party relations. If the NPP tries to follow a similar strategy to 2016, it is possible voters will punish it in the way they have other parties that allied too closely to mainstream parties, as predicted by Rochon. In fact, the movement party approach perpetuated since the Sunflower Movement received support from voters. However, the more institutionalized and catch-all party-like structure of the NPP could easily lose its movement party features. Its close ties with the DPP means that it runs the risk of losing autonomy in the policies it advocates. Whether the NPP can anchor itself to the party system in Taiwan remains to be seen, however, the early success of the NPP in the 2016 elections has undoubtedly shown that a semi-alliance strategy is a possible way for small parties to thrive under the unfavourable political environment in Taiwan. If the NPP does decide to remain in a semi-alliance with the DPP, then there should once again be an opportunity for a genuine alternative party. Whether this will be the GPT, a new SDP-GPT alliance or something else, is still uncertain at the time of writing in the autumn of 2019.

\section{References}

Downs, Anthony. 1957. An Economic Theory of Democracy. New York: Harper.

ESC. 2019. Party Preferences. Election Study Center, National Chengchi University. https://esc.nccu.edu.tw/course/news.php?Sn=165 (12 December 2019).

Fell, Dafydd. 2005. 'Success and Failure of New Parties in Taiwanese Elections.' China: An International Journal, 3 (2): 212-239.

Fell, Dafydd. 2006. 'The Rise and Decline of the New Party: Ideology, Resources and the Political Opportunity Structure.' East Asia, 23 (1): 47-67. 
Fell, Dafydd. 2014. 'Measuring and Explaining the Electoral Fortunes of Small Parties in Taiwan's Party Politics.' Issues and Studies: An International Quarterly on China, Taiwan, and East Asian Affairs, 50 (1): 153-188.

Fell, Dafydd. 2016. 'Small Parties in Taiwan's 2016 National Elections: A Limited Breakthrough?' American Journal of Chinese Studies, 23: 41-58.

Fell, Dafydd. 2017a. 'Merger and Takeover Attempts in Taiwanese Party Politics.' Issues and Studies: An International Quarterly on China, Taiwan, and East Asian Affairs, 53 (4).

Fell, Dafydd. 2017b. 'Social Movements in Taiwan after 2008.' Taiwan's Social Movements under Ma Ying-Jeou: From the Wild Strawberries to the Sunflowers. Dafydd Fell (ed.). London: Routledge, pp. 1-17.

Fell, Dafydd; Yen-Wen Peng. 2016. 'The Electoral Fortunes of Taiwan's Green Party: 1996-2012.' Japanese Journal of Political Science, 17 (1): 63-83.

Fell, Dafydd; Yen-Wen Peng. 2017. 'The Revival of Taiwan's Green Party after 2008.' Taiwan's Social Movements under Ma Ying-Jeou: From the Wild Strawberries to the Sunflowers. Dafydd Fell (ed.). London: Routledge, pp. 177-198.

Grano, Simona A. 2015. Environmental Governance in Taiwan: A New Generation of Activists and Stakeholders. London: Routledge.

Ho, Ming-sho. 2003. 'The Politics of Anti-nuclear Protest in Taiwan: A Case of Party-Dependent Movement (1980-200o).' Modern Asian Studies, 37 (3): 683-708. Ho, Ming-sho; Chun-hao Huang. 2017. 'Movement Parties in Taiwan, 1987-2016.' Asian Survey, 57 (2): 343-367.

Hsu, Szu-chien. 2017. 'The China Factor and Taiwan's Civil Society Organisations in the Sunflower Movement.' Taiwan's Social Movements under Ma Ying-Jeou:From the Wild Strawberries to the Sunflowers. Dafydd Fell (ed.). London: Routledge, pp. 134-153.

Kitschelt, Herbert. 20o6. 'Movement Parties.' Handbook of Party Politics. Richard S. Katz; William Crotty (eds). London: Sage, pp. 278-29o.

Lin, Jingtang. 2015a. 'Feng Guangyuan tui xuan Wu Yusheng: Yaoqing Lu Sunling Gongkai Bianlun' [Feng Guangyuan withdrawn from election: Wu Yusheng invites Lu Sunling to debate publicly]. Apple Daily.

Lin, Jingtang. 2015b. 'Shidai Liliang: Yu Minjin Dang he pan Guohui Guoban' [NPP: Work with DPP to secure a majority in the parliament]. Liberty Times, 19 July.

Lin, Jingtang. 2015c. 'Tsai Ingwen, Hong Ciyong Jingxuan Zongbu Chengli Chen Ju Zhantai' [The establishment of Tsai and Hong's campaign office: Chen Ju shows support]. Liberty Times, 15 November.

LT. 2015a. 'Shidai Liliang jin Chuang dang Tsai Ingwen Gei Zhufu' [President Tsai Ing-wen welcomed and wished the newly formed NPP good luck]. Liberty Times, 25 January. 
LT. 2015b. 'Shidai Liliang Tui Renwu Xing Liwei lu Hiceng Buman' [The pan-green camp is angered by the NPP's nomination of 'token candidates']. Liberty Times, 27 November.

LT. 2016. 'Fan Zun Chuxi Lao Ke Xinshu Hui Chenweiting Bengkui Re' [Fan Yun attends Old Ke's new book conference]. Liberty Times, 2 January.

Lucardie, Paul. 200o. 'Prophets, Purifiers and Prolocutors towards a Theory on the Emergence of New Parties.' Party Politics, 6 (2): 175-185.

Meguid, Bonnie. 2008. Party Competition between Unequals: Strategies and Electoral Fortunes in Western Europe. Cambridge: Cambridge University Press.

Rochon, Thomas R. 1985. 'Mobilizers and Challengers toward a Theory of New Party Success.' International Political Science Review, 6 (4): 419-439.

Spoon, Jae-Jae. 2011. Political Survival of Small Parties in Europe. Ann Arbor: University of Michigan Press.

Tarrow, Sidney. 2015. 'Contentious Politics.' The Oxford Handbook of Social Movements. Donatella della Porta; Mario Diani (eds). Oxford: Oxford University Press, pp. 86-107.

TCU. 2014. 'Kuaile Canzheng: Gongming zuhe Faqi Xuanyan.' Taiwan Citizen Union, 3 February. https://bit.ly/32jjswL (12 December 2019).

\section{About the Authors}

Tommy Chung Yin KwAn is a PhD candidate in the Department of Politics and International Studies at the School of Oriental and African Studies (SOAS), University of London, UK, currently focusing on the relationship between political parties and social movements in Taiwan. He was a visiting associate at Academia Sinica. He is also a writer and a regular contributor to the Chinese-language Hong Kong newspaper Ming Pao. He comments on the political and cultural scenes in Hong Kong and Taiwan.

DAFYdD J. Fell is Reader in Comparative Politics with special reference to Taiwan at the Department of Politics and International Studies of the School of Oriental and African Studies (SOAS), University of London, UK. He is also the Director of the SOAS Centre of Taiwan Studies. He has published numerous articles on political parties and electioneering in Taiwan. His latest book as single author is Government and Politics in Taiwan, $2^{\text {nd }}$ ed. (Routledge, 2018) while his latest edited book is Taiwan's Social Movements under Ma Ying-Jeou: From the Wild Strawberries to the Sunflowers (Routledge, 2017). 



\title{
8 New Immigration, Civic Activism and Identity in Japan
}

\author{
Influencing the 'Strong' State
}

David Chiavacci

\begin{abstract}
This chapter discusses immigrant advocacy groups' influence in Japan's immigration policy. For three decades Japan has been a new immigration country. However, immigration policy has been marked by ideational and institutional fragmentation, resulting in a deadlock lacking bold reforms and immunizing state actors to external pressure. Against this backdrop, civil advocacy has been surprisingly influential. While civic groups have generally not been included in decision-making bodies, they have altered the perception of immigration. By analysing reforms combating human trafficking, this chapter identifies factors that resulted in indirect influence of civic advocacy in this case, allowing us to gain a differentiated understanding of the limited but still significant influence of civic activism on Japan's ‘strong' state in immigration policy.
\end{abstract}

Keywords: strong state, Japan, immigration policy, civil society, human trafficking

This chapter discusses the influence and role of Japan's immigration advocacy groups in immigration policy. It analyses their impact on public and political debate, in policy implementation and in political decision-making concerning immigration. Japan has undergone a transformation into a new immigration country with a highly continuous inflow of new immigrants in the last three decades (see Figure 8.1). Up to the mid-1980s, Japan's foreign population consisted almost exclusively of so-called oldcomers, which

Chiavacci, David, Simona Grano, and Julia Obinger (eds), Civil Society and the State in Democratic East Asia: Between Entanglement and Contention in Post High Growth. Amsterdam, Amsterdam University Press 2020 DOI: 10.5117/9789463723930_CHo8 
Figure 8.1 Registered foreign residents in Japan, 1955-2015 (projection until 2020)

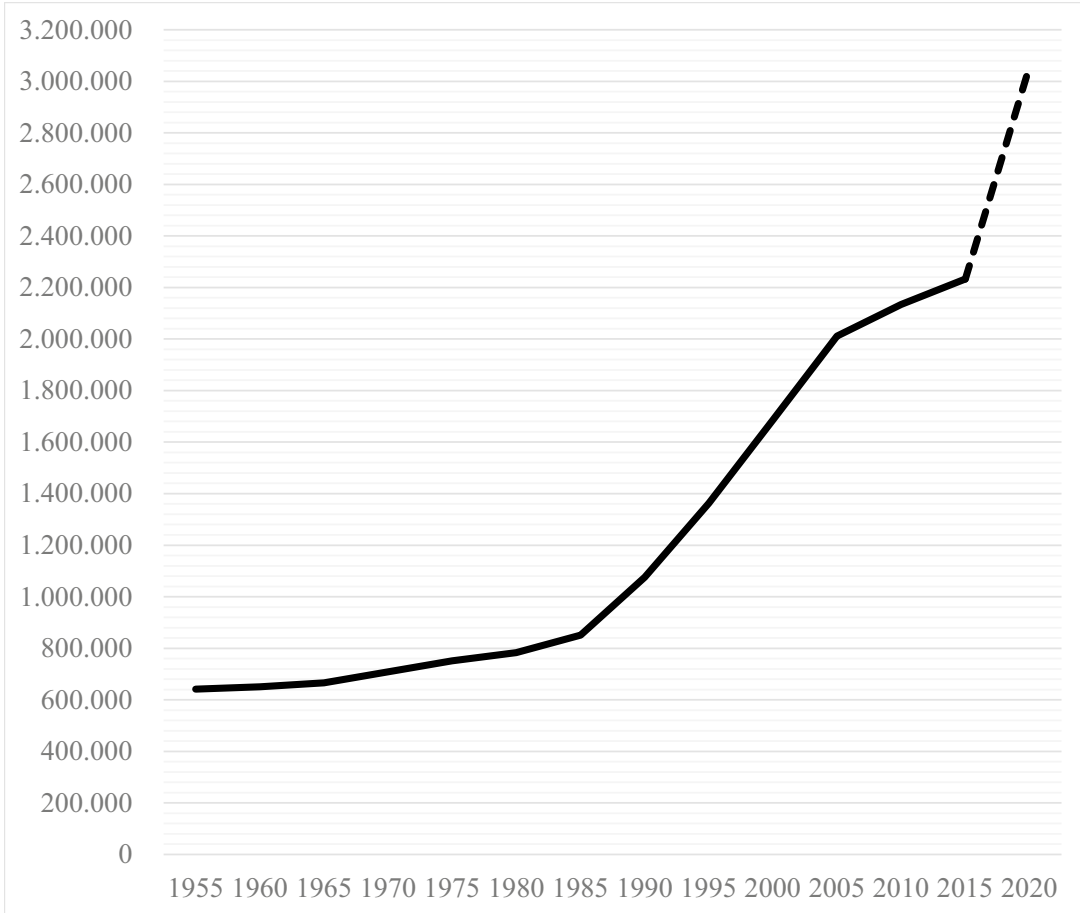

Note: Projection until 2020 own extrapolation based on increase of foreign population by about 330,000 from 2015 to 2017 . Still, in view of admission policy reforms introduced in early 2019 , an even stronger increase is actually expected.

Source: MOJ (1975-2017)

had migrated to Japan's main islands during the colonial era, and their descendants. However, since the late 1980s, the increase of foreign residents has started to gain a new momentum through the inflow of newcomers. Japan's foreign population has increased three and half-fold over the last 30 years (MOJ 2018: 21). Today, Japan is one of the most important migration destinations among advanced industrial countries measured by the yearly net inflow of foreign population (OECD 2019: 295).

This transformation into an immigration country has been accompanied by large and intensive public and political debates about admission and integration policies as well as by new civic activism in the field of immigration. More concretely, the years since the mid-1980s have been marked by three phases of more intensive public and political discussions on immigration. The number of articles in three large national newspapers shows as indicator a clear fluctuation over time that allows us to identify 
Figure 8.2 Three public debates on immigration, 1985-2017

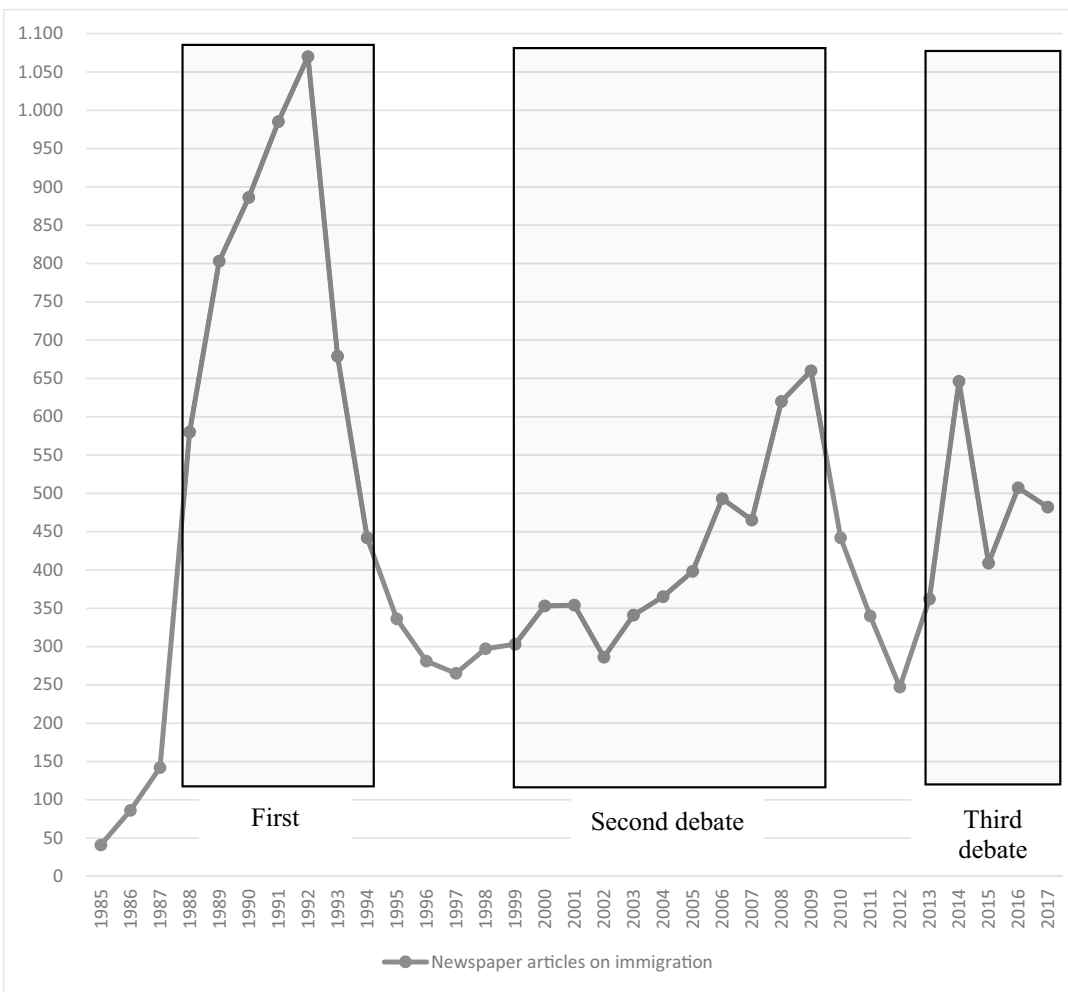

Source: Own figure based on full-text search in electronic databases of articles containing foreign workers (gaikokujin rōdōsha) or multicultural integration (tabunka kyōsei) in daily newspapers Asahi Shinbun (Kikuzō II), Mainichi Shinbun (Maisaku), Nihon Keizai Shinbun (Nikkei Telekom 21) and Yomiuri Shinbun (Yomidas Rekishitan)

these three debates and intermediate phases after two economic shocks and the following downturns (burst of the bubble economy in the early $1990 \mathrm{~s}$ and the worldwide economic crisis of 2007/2008) (see Figure 8.2).

An overview of the number of substantial reform proposals shows similar tendencies with a first policy debate around 1990, a second debate with a more intensive period from 2004 to 2008 and the beginning of a third debate since 2014 (see Table 8.1).

Questions of Japan's identity have played an important role in these immigration policy discussions. While the political-economic establishment has primarily debated about the advantages and disadvantages of immigration for Japan's economy, new immigration has increasingly also questioned Japan's self-view as an ethnically homogeneous nation. What kind of a society does Japan want to become and be in the future? Instead of 
Table 8.1 Substantial reform proposals in immigration policy, 1984-2018

\begin{tabular}{|c|c|c|}
\hline Period & Proposals & Proposals per year \\
\hline $1984-1988$ & 5 & 1.0 \\
\hline $1989-1993$ & 11 & 2.2 \\
\hline $1994-1998$ & 1 & 0.2 \\
\hline $1999-2003$ & 19 & 3.8 \\
\hline $2004-2008$ & 34 & 6.4 \\
\hline $2009-2013$ & 8 & 1.6 \\
\hline $2014-2018$ & 21 & 4.2 \\
\hline
\end{tabular}

Source: NDL (2008: 195-204) for 1984 to 2007 and own compilation for 2008 to 2018

focusing on economic benefits and costs calculations, immigrant advocacy groups (IAGs) have stressed the importance of protecting the human rights of newcomers and have tried to move the focus to Japan's duties and selfunderstanding as a good member of the international community.

Japan has often been described as a strong state with a weak civil society. Classical theoretical models of Japanese politics note the tendency of decision-making by closed networks between ministerial bureaucracy, the long-ruling Liberal Democratic Party (LDP) and certain economic interest groups (Muramatsu and Krauss 1984; Pempel and Tsunekawa 1979). These networks do not include civil society. Pekkanen (2006), for example, highlights Japan's dual civil society. In international comparison, a large share of the population participates in civil society activities and civil society organizations (CSOs) are very strong in providing services in daily life. In contrast, political advocacy of civil activists is very limited. Especially at the national level, where the voice of civil society is excluded from political decision-making.

Hence, one might expect a very limited impact of civil society advocacy in immigration policy. In fact, in all my interviews with civil society activists over the last fifteen years, their limited influence in national decisionmaking was a recurrent point of grievance (e.g. Interview IAG 2003, 2012). However, my analysis will show that IAGs have actually been able to gain quite some influence in agenda setting, formulation and implementation in immigration policy. Generally, they were able to do so not through direct participation in policymaking, but indirectly through influencing public debates as well as national and international partners. Their influence has surely been limited, but even Nippon Keidanren, by far Japan's most powerful economic advocacy group and a central member of the conservative establishment, complains about its marginal voice in immigration policy 
(Interview Nippon Keidanren 2006; Tsuda and Cornelius 2004: 451). In view of their organizational capabilities in comparison to Nippon Keidanren, the significant role and level of impact by IAGs is actually quite surprising (see also Shipper 2008).

\section{Japan's Immigration Policy: A ‘Strong' State}

Most research on social movements and civil society advocacy starts with the assumption that the state and its elites are a rather homogeneous entity antagonistic toward civil actors. Hence, the political-economic establishment is often not really analysed. However, state structures and interrelations between its elites are often highly complex and marked by internal conflicts. Immigration policy, in particular, is a policy field that is characterized by ideational heterogeneity that leads to 'strange bedfellows,' that is, cooperation and coalitions between actors that are clear opponents in most other policy fields. Hence, before our focus turns to civil society and IAGs, we have to discuss the ideational and institutional framework in Japan's immigration policy field in order to understand policymaking structures that civil society actors confront.

Research on Japanese policymaking and its efficiency depicts contradicting tendencies. On the one side, Chalmers Johnson (1982) has described Japan in his seminal analysis of its economic policy as a strong developmental state that successfully formulated and implemented an economic growth strategy. However, on the other hand, J.A.A. Stockwin and his collaborators (1988) have shown that Japanese politics is, in many other fields, marked by immobilism and standstill. The field of immigration policy has to be ascribed to the second group. The main factor behind this standstill is the institutional fragmentation of immigration policymaking in Japan. In contrast to the economic policy, no pivotal state agency in immigration policy exist. Officially, the Ministry of Justice (MOJ) is in charge of immigration policy, but its immigration bureau's staff is composed of bureaucrats from different ministries, which has undermined its internal coherence and sidelined it inside the MOJ. Ikuta (2000: 144) criticizes it as a 'mosaic agency' that is characterized by internal segmentation. Moreover, a number of other ministries are involved in immigration policy. Due to strong vertical integration of state agencies, coordination and cooperation between Japanese ministries is in many policy fields weak and suboptimal, but immigration policy has even be marked by open conflicts between ministries (Chiavacci 2011, 2020). Especially in immigration policy, Japan 
resembles a 'confederation of ministries' (Kyogoku 1987: 222-223). Moreover, this institutional fragmentation is not only confined to the bureaucracy. Political parties (and especially the LDP) are also internally split concerning immigration policy, and Japan's executive has never executed real leadership in immigration policy until very recently. ${ }^{1}$

Ideational diversity underpins and reinforces this institutional fragmentation. Policy actors look at and discuss immigration policy from completely different perspectives. For example, during the second immigration debate from the late 199os to the severe economic recession induced by the worldwide financial crisis in the late 2000 s, some wide-reaching immigration policy proposals were made for a much more active immigration policy in view of Japan's demographic ageing and its foreseeable labour shortages in the near future. One large working group of about $80 \mathrm{LDP}$ parliamentarians even proposed that Japan should radically change its restrictive immigration policy and become an immigration nation welcoming about ten million immigrants over the next half-century (LDP 2008). However, at the same time, a moral panic about rising criminality and declining public security swept Japan (Hamai and Ellis 2006). Increasing immigration and growing numbers of foreign residents were seen as one main factor for this supposed crime wave. Hence, many policymakers (including many LDP politicians) predicted the descendent of Japan into a swamp of chaos and lawlessness in the case of more immigration and urged to retain a restrictive immigration policy (Chiavacci 2011: 204-209, 2014: 125-130). The increasing role of politicians at the expanse of bureaucrats in those years might even have further strengthened fragmentation in immigration policy. One prime example is the changing position of the MOJ in immigration policy, first under Jinen Nagase and then Kunio Hatoyama, both LDP politicians who served as Minister of Justice in 2007. With Nagase as minister, the MOJ adopted a position in favour of an open immigration policy by proposing the acceptance of non-highly qualified foreign workers through an official guest worker programme that is responsive to labour market demands. A few months later, Hatoyama became minister and, under his leadership, the MOJ returned to a security perspective on immigration and again promoted

1 The years 2018/2019 look like a period of important reorientation of Japan's immigration policy. Since Japan had become an immigration country in the later 1980s, it is the first time that the cabinet under Prime Minister Shinzō Abe exerted executive leadership in immigration policy. This resulted in the passing of comprehensive reforms in December 2018 that are currently implemented (ISA 2019). The analysis of these reforms and their potential impact is beyond the scope of this chapter. Still, we have to note that these reforms and their possible extension in the coming year could mark a historic turning point in Japan's immigration policy. 
a very restrictive immigration policy, rejecting the establishment of any new guest worker programmes. Overall, in the immigration policy field, 'Japan' as a coherent and strategic actor does not exist. Japan's immigration policy is the result of a highly complex policymaking process characterized by internal conflicts that takes place in the absence of a dominant ideational framework or strong political leadership.

The general immobilism and absence of a coherent long-term strategy due to ideational diversity and institutional fragmentation is clearly notable when taking a closer look at Japan's immigration policy, which shows a huge gap between the official and real immigration policy. Officially, Japan has a very restrictive immigration policy. It is only accepting highly qualified foreign workers in defined job fields that are explicitly named in its immigration law as a positive list. However, in contrast to this fundamental framework, about $80 \%$ of the new foreign residents are de facto working in jobs not included in this positive list (Bungei Shunjū 2008: 295). This gap is not due to an incapacity of the state to control immigration, but to a number of 'side door' policies that result in the acceptance of a significant number of foreign workers outside of the highly qualified job fields. These side doors like the exceptional treatment of Japanese emigrants and their descendants (nikkeijin) or the transformation of foreign trainee system into a de facto guest worker programme are the main results and novelty of the limited reforms in immigration policy over three decades until very recently. In other words, while the front door remained closed for all non-highly qualified foreign workers, new side doors were increasingly opened for them. No political actor was strong enough to open the official front door, but some political entrepreneurs succeeded in introducing side doors, often almost by accident, in a highly complex and conflictive policymaking processes (for details, see Chiavacci 2011:123-145). Once opened, no political actors in favour of a truly restrictive immigration policy were strong enough to close these side doors again because they quickly led to significant immigration flows and structural dependences in some industrial sectors. In fact, since the late 199os, even the well-known Japanese export sectors in car and consumer electronics manufacturing have been structurally dependant on foreign workers (Kamibayashi 2004). This dependence also explains why these side doors have been incrementally opened more over the years and why Nippon Keidanren and other business associations started to lobby in the late 1990 s for a more active immigration policy. The new immigration to Japan that started in the late 1980 s with undocumented immigration was cemented through immigration flows through new established and slowly further opened side doors. Japan silently became an immigration country 
despite the often-repeated official statement over the years by members of the administrative and political elites that Japan is not an immigration country.

However, as already mentioned above, Nippon Keidanren was not able to exert a significant influence on immigration policy by opening the front door or introducing new side doors. A labour market perspective was never dominant, and the institutional fragmentation increased the immunity of important state actors against outside pressures, even from such a formidable lobby machine like Nippon Keidanren. As Suleiman (2003: 32) pointed out, states that 'appear weakest because of the fragmentation of the state structure may be more resistant to powerful interests.' The Japanese state in immigration policy is prime example for this. Its internal fragmentation leads to its immunity to external pressure, but undermines any strategic development of immigration policy. This is why I write of a 'strong' state with 'strong' in quotations marks.

\section{Emergence and Status of Immigrant Advocacy Groups: Another Case of Strong Social Service Providers and Weak Advocacy Capabilities?}

If we turn then to Japanese immigrant advocate groups, we would expect that their influence on immigration policy is marginal. As mentioned above, political opportunity structures for civil society groups are, in general, very unfavourable for advocacy in national policymaking. In contrast to important economic interest groups, they are not members of the elite circles, in which policy ideas are discussed informally behind closed doors, and normally only hand-picked civil society actors are invited to participate or testify in deliberation councils (shingikai), in which policies are then formally developed. Hence, civil society activists are generally excluded from decision-making in national politics. Moreover, in Japan civil society groups are normally local organizations with few resources. In comparison to civil society organizations in other advanced industrial countries, they often have very tight budgets and small numbers of professional staff. Hence, civil society in Japan structurally lacks the prerequisites to generate pressure on the elite circles. In view of the missing voice of civil society in national politics in general, Pekkanen (2006) has labelled Japan's civil society as 'members without advocacy.' Moreover, civil society is especially weak regarding social protest. During the first three post-war decades, Japan had large social movements and political activism that pressed for alternative models of national development in clear contradiction to the 
conservative establishment and staged huge and quite often violent protest events. However, in the mid-1970s, this protest cycle came to a sudden end (Chiavacci and Obinger 2018). In the following four decades until the Fukushima nuclear incident in 2011, social movements and confrontational political activism did not completely disappear in Japan, but they focused on issues on the local level and were no longer a national force. For example, in the field of nuclear energy many local and regional anti-nuclear organizations and movements existed and they were quite successful in blocking about 8 o nuclear energy projects (Hirabayashi 2013: 37), but in comparison to many Western countries, the Japanese anti-nuclear movement was much weaker on the national level (Hasegawa 2011).

Still, a large share of the population is active in civil society organizations in Japan, especially if we also include local neighbourhood associations, to which most Japanese belong (Pekkanen et al. 2014). However, the strong point of these civil society organizations is not advocacy, but social services for the local communities. Ogawa (2009) sees them in this context not as a check or counterweight to the state and elite circles, but as an exploited extension of them. The introduction of a new non-profit organization (NPO) law in 1998 resulted in a strong increase of recognized NPOs. However, in Ogawa's view this does not imply the rise of civil society as a new political force in Japan, but, on the contrary, 'a calculated reorganization of the Japanese public sphere designed to establish a small government in the post-welfare state through the transfer of social services originally delivered by the state to volunteer-driven NPOs' (Ogawa 2009: 174). ${ }^{2}$ In the immigration field, the overwhelming majority of CSOs are primarily helping foreign residents in their daily life. Hence, following Ogawa, one might even critically ask if the state has strategically co-opted civil society and Japanese volunteers in the immigration field. Is the state using CSOs and NPOs as cheap local social service providers and as a substitute for a much more expensive integration policy run by the state?

In fact, civil society actors themselves soon realized their limitations. Often founded in parallel to the rising number of foreign residents in local communities, they performed crucial services for the new immigrants and started to cooperate with local administrations. However, in view of the strong centralization of the state, many policy problems could only be solved on the national level. Hence, IAGs started to form national networks

2 Moreover, Weiss (in this volume) shows in his analysis of nuclear energy policy that the pro-nuclear establishment successful created and maintained CSOs and civic activism for the dissemination of nuclear energy support among the general public. The conservative establishment formed and guided CSOs in order to attain its political goals in Japan. 
and umbrella organizations in order to establish and sustain their lobbying efforts in national agenda setting and decision-making. Still, even the resources of large organizations are very limited. According to their 2016 financial reports, the Asian People's Friendship Society (APFS) and the Solidarity Network with Migrants Japan (SMJ) - arguably Japan's two most important immigrant advocacy organizations - have a yearly income of about US\$90,000-100,000 raised through membership fees and donations. This is about 600 times smaller than the yearly revenues of Nippon Keidanren. In other words, if Nippon Keidanren is an aircraft carrier with escort vessels then immigration advocacy organizations are small fishing boats. In view of this gap, we might expect IAGs to have no impact at all, but in fact they have been able to gain a surprising degree of influence. We shall look at the mechanisms that led to this influence on three levels: (1) framing of immigration policy, (2) implementation of immigration policy, and (3) formulation of immigration policy.

\section{Framing of Immigration Policy}

As mentioned above, immigration policy in Japan is marked by ideational diversity. IAGs regard immigration primarily in the perspective of international human rights and tried to promote this frame in public opinion and among decision-makers. ${ }^{3}$ They have published quite a number of books and booklets (e.g. GJHI 2013; GRMN 2009; GSUN 2004, 2008) in which immigration is framed as a human rights issue and have organized demonstrations and campaigns in order to sensitize Japan's population for human rights problems in immigration policy. IAGs have actively tried to place their arguments in Japan's mass media and to influence public opinion (Shipper 2005: 321-324, 2008: 172-180).

To which degree were IAGs able to influence public debate on immigration and to bring to the fore a human rights perspective? The main counterdiscourse to human rights in Japan is surely the topic of foreign criminality. Immigrants cast into this frame are not primarily seen as human beings with human rights, but as potential criminals who contribute to increased crime rates and constitute a menace to public security. From the

3 This is not a new development in view of Japan's transformation into a new immigration country. Lawyers and civil society activists concerned about oldcomers in Japan also utilized human rights and international norms to provide the framework and arguments supporting the improvement of their rights and right to earn a livelihood (Gurowitz 1999; Miyazaki 1970). 
Figure 8.3 Foreigners' crime and human rights frames, 1985-2017

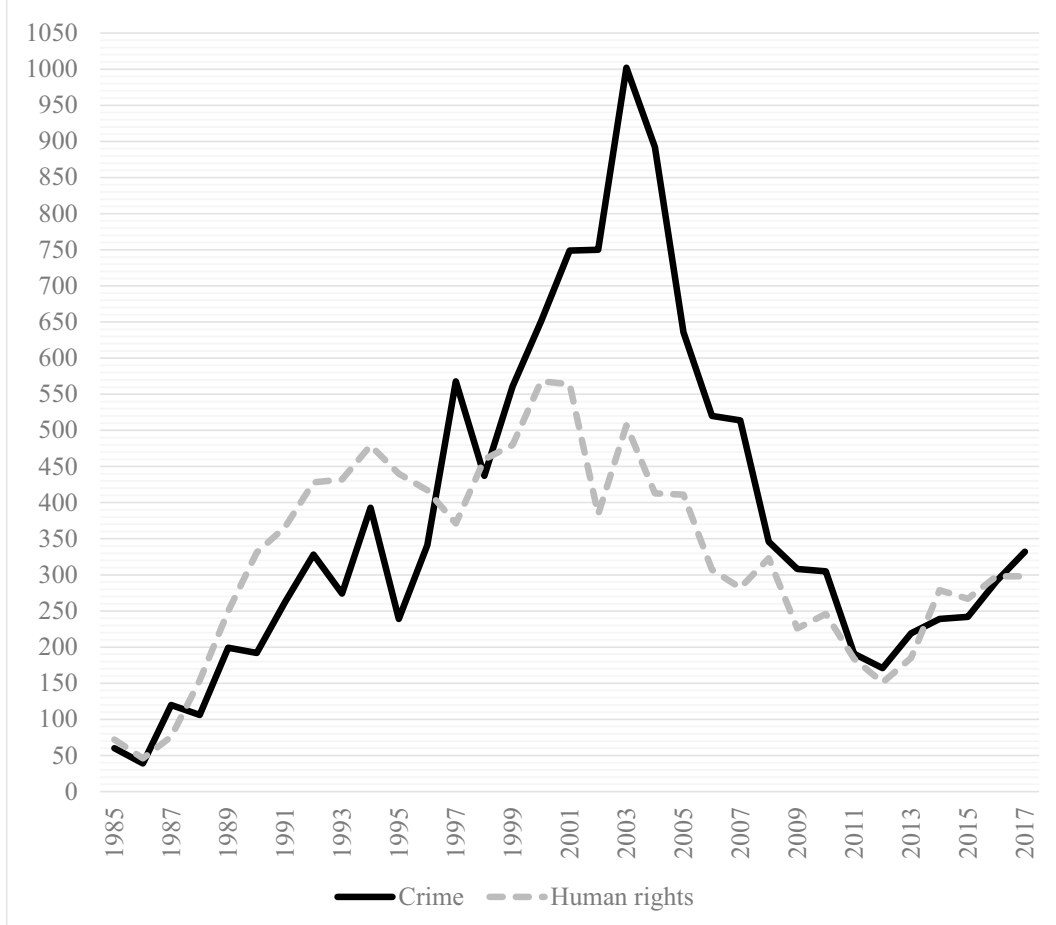

Source: Own figure based on full-text search in electronic databases of articles containing foreigner (gaikokujin) and crime (hanzai) or foreigner and human rights (jinken) in daily newspapers Asahi Shinbun (Kikuzō II), Mainichi Shinbun (Maisaku), Nihon Keizai Shinbun (Nikkei Telekom 21) and Yomiuri Shinbun (Yomidas Rekishitan)

very beginning of the new immigration, this frame was present in Japan. The National Police Agency (NPA), for example, started in 1987 to include in its yearly white paper on police a chapter about foreign criminality and highlighted the increase in criminal acts by foreigners (NPA 1987). Still, if we compare the media coverage in the four largest Japanese newspapers, we see that actually about a third more articles on human rights and foreigners were published than on crimes and foreigners from the late 1980 os to the mid-199os (see Figure 8.3). However, the frame of foreigner crimes became much stronger. Due to a number of police scandals, a moral panic started in the late 1990s, which proclaimed a huge crime wave and an end of public security (Hamai and Ellis 2006). Although statistic did not justify in any way such drastic narratives (Shipper 2005: 306-307; Yamamoto 2004: 41-47), foreigners were identified as one main culprit for rising crime in this crime panic. The impact in public discourse is obvious (see Figure 8.3). During 
the second debate, the number of articles on foreigners and crime is about $50 \%$ higher than about foreigners and human rights.

Correspondingly, public opinion shifted. In the governmental survey on human rights, the share of persons who were in favour that foreigners receive the completely same protection of their human rights as Japanese nationals fell from about two-thirds in earlier surveys since new immigration had begun to about 54\% in 2003 (CAO 2003: 188-189). A large survey in Tokyo in 2006 showed the new priority of crime and public security. An overwhelming majority of nearly $80 \%$ of the interviewees were in favour of giving priority to combating foreign criminality instead of protecting the human rights of foreign nationals (Higuchi 2006: 38). And in the large international survey on national character carried out by the International Social Survey Programme in 2003, the share of respondents who agreed or fully agreed with the statement 'An increase in immigrants leads to rising crime rates' was over $70 \%$ in Japan, far above nearly all Western countries (Chiavacci 2011: 208).

In view of these data, one might reach the conclusion that the impact of the IAGs was negligible and that their voices were drowned in the noise of the crime panic. However, without IAGs questioning the discourse on foreign criminality and trying to keep present the frame of human rights, the dominance of the 'foreigners as threat' discourse would surely have been even more overwhelming. In fact, based on the number of newspaper articles on foreigners and human rights that increased on average per year during the second debate by $25 \%$ in comparison to the first debate (see Figure 8.3 ), the rising activities of IAGs were not unsuccessful. It was, however, not enough to counter the crime panic that led to an increase of over $150 \%$ in the case of articles covering foreigners and criminality in the second debate. Still, one could also argue that the IAGs played an important role in rebalancing media coverage in the long term. As Figure 8.3 shows, in the ongoing third debate since 2014, about the same number of articles on both topics has been published up to now. Recent surveys show that the crime panic has stalled and that the frame of 'foreigners as criminals' has become much weaker (CAO 2012, 2017; Murata 2014).

\section{Implementation of Immigration Policy}

IAGs have not only tried to influence public perception of immigration and frames in immigration policy, but they have also tried to gain a voice in immigration policy implementation and formulation through advocacy. Let us begin our analysis with policy implementation, which is especially 
important in the case of Japan as laws and regulations are often formulated in very general ways and, hence, there is a large degree of administrative and political room in their implementation.

Generally, IAGs have been excluded from decision-making bodies, but they started to visit politicians and bureaucrats directly in order to make their voice and point of view heard in policymaking circles. Over the years, IAGs were able to establish ties with political parties and ministries and to gain more influence (Hosoki 2016: 301-306; Milly 2014: 110-130). Still, if we look at these efforts in comparison to Nippon Keidanren's activities, a difference of several levels is evident. Nippon Keidanren has fully embedded permanent networks with politicians and bureaucrats. For example, the LDP's Forward Policy Unit hosts eleven researchers of Nippon Keidanren. Hence, this think tank, which should officially enhance the LDP's autonomous policymaking capabilities, is de facto a liaison office between Nippon Keidanren and the LDP (Momoi 2018).

However, three factors have allowed IAGs to gain some leverage despite their limited resources. First, the high degree of expertise. IAGs can rely on voluntary participation and support by lawyers and scholars. Their voices might not be strong, but they are recognized as being well informed in decision-making circles. Second, no economic interest. In contrast to economic interest groups like Nippon Keidanren, IAGs are convincing idealistic actors because they do not profit themselves from political decisions. Third, sharing of ideational stance with powerful actors. A human rights perspective is not completely absent in decision-making circles. Japan's immigration policy has often been described as being based on its economic interests and/or its goal to maintain an ethnically homogeneous population. However, as described above, among elite actors ideational perspectives and motives are much more complex. The Ministry of Foreign Affairs (MOFA) regards immigration policy as an element of Japan's foreign policy, and it would like to secure Japan's international reputation by preserving international standards like human rights. The Ministry of Health, Labour and Welfare (MHLW) sees it as one of its main duties to secure the application of Japanese labour laws to all foreign workers. The Ministry of Justice is generally very conservative and stresses control over immigration as a part of public security, but it is also in charge of Japan's human rights policy. Even many conservative politicians believe that respect for international human rights is in the self-interest of Japan if it is to realize its aspiration to be a leading member of the international community (Gelb and Kumagai 2018). Of course, there are significant differences concerning the priority of human rights and its envisaged level of implementation. IAGs would like Japan to be an ideal actor fully protecting the human rights of its 
immigrants. Many members of the establishment envision Japan as a good actor in the international community - one that is not criticized for having a dehumanized immigration policy. Still, there are common perspectives concerning Japan's identity between the two groups.

The impact of IAGs in immigration policy implementation is often not graspable, but in some cases its influence can be traced back and identified quite clearly. A prime example is the policy implementation granting 'special status of residence' to irregular immigrants. The Japanese state has always declined to have an amnesty programme, in which irregular immigrants would be pardoned collectively and granted rights of residence because it is argued that this would create incentives for more irregular immigration. However, in accordance with immigration law, the MOJ has the discretion to allow upon application special residence based on a case-by-case assessment (Kondō et al. 2010).

In September 1999, IAGs started a public campaign for the recognition of irregular immigrants with public rallies and press conferences. The goal was to raise public awareness of the issue, to give irregular immigrants a human face and to increase pressure on the MOJ for a more liberal implementation of its policy to grant special residence. At the end of the campaign in 2006, 43 of the 64 irregular immigrants who participated in the campaign had received special residence permissions by the MOJ (Yoshinari 2015: 46-50). Moreover, in reaction to the campaign, the $\mathrm{MOJ}$ started to publish guidelines that clarified the factors that would increase the chances of a positive evaluation of a request for special residence. Most IAG activists whom I interviewed regarded the outcome of the campaign and the influence of IAGs to be ambivalent by pointing out, for example, that 'only two-thirds of the applicants have received residence permits. Hence, the outcome was only partially successful, and we have not accomplished our original goals' (Interview IAG 2012). However, in view of the whole context and in contrast to their self-assessment, the outcomes document the substantial influence of IAGs in policy implementation.

First, it is important to note that in the foreign criminality discourse described above irregular immigrants, in particular, were identified as potential criminals and as a threat to Japan's public security (Chiavacci 2011: 265; Shipper 2005). The 1999 white paper on police argued, for example (NPA 1999: 17):

Among the undocumented immigrants who originally came to Japan for work purposes, many get involved in criminal activities, which are more profitable than illegal work. The large number of undocumented immigrants becomes a hotbed of crime by foreigners. 
Figure 8.4 Granted special permits of residence, 1995-2017

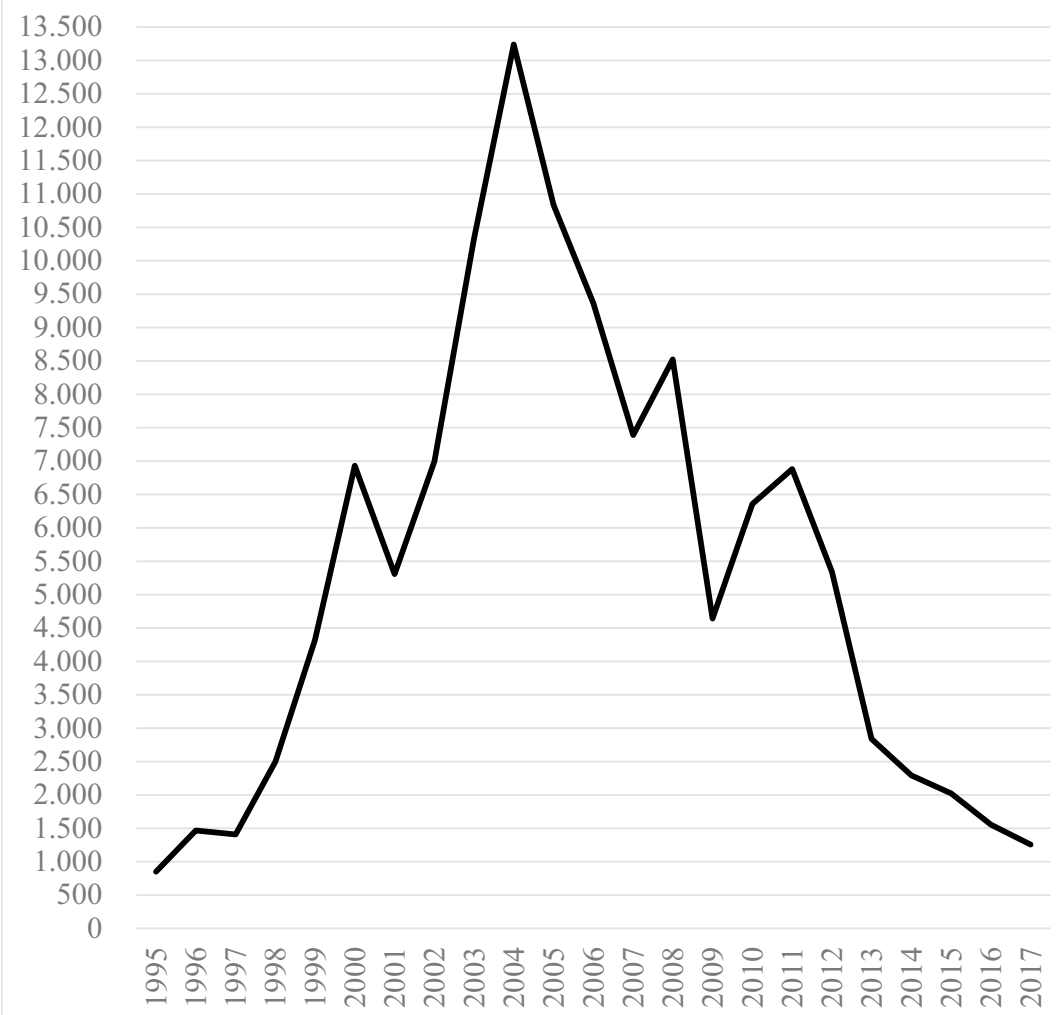

Source: MOJ (1975-2018)

Although there has never been any proof (not even in the official crime statistics) for this argument, irregular immigrants are singled out as potential criminals. The impact on public opinion about irregular immigrants was immense. In the 2004 survey on public security, for example, the increase of irregular immigrants was the most often identified factor for rising crime in Japan (CAO 2004). Hence, it had been reasonable to expect that the Japanese state would be especially rigorous in handling irregular immigrants and truly restrictive in granting them special residence status. However, in fact, the policy of granting of special status of residence for irregular immigrants has been quite liberal to the point that we can speak of a non-official legalization programme. In fact, from 1999 to 2012, the MOJ has granted over 100,000 special residence permits (see Figure 8.4), which explains about half of the stark fall in officially recorded irregular immigrants from 277,000 (1999) to 67,000 (2012) in Japan (CAO 1975-2017). IAGs and their campaigns had a 
significant impact on the large size of legalization despite the huge public backlash against irregular immigrants.

Still, the recognition of irregular immigrants by the MOJ and the influence of IAGs on it are not the only factors for the stark fall of irregular immigrants in Japan. From 2003 onwards, the government ran a campaign for 're-establishing' Japan as secure country. Reducing the number of irregular immigrants was a central element of this campaign. Several stricter regulations were introduced for example, a reporting obligation for employers of foreign workers (gaikokujin koyōjōkyō no todokede) - which resulted in a significant drop in the number of irregular immigrants (Suzuki 2017). In general, IAGs were not in favour of introducing these new measures. They argued that the discourse of foreign criminality and of irregular immigrants as a security threat was completely overblown and that the priority should be not on security considerations, but on guaranteeing the human rights of irregular immigrants. However, in contrast to the policy implementation, they had no significant influence on policy formulation. Still, in the next section, we will discuss some cases and constellations in which IAGs exerted some influence in policymaking.

\section{Formulation of Immigration Policy: Indirect Lobbying through National and International Partners}

As described above, IAGs have tried to gain a voice in immigration policymaking, but their impact through direct lobbying has been very limited because they were de facto sidelined from decision-making by generally not being invited into deliberation councils or their hearings. However, IAGs have gained some influence indirectly through national and international organizations. On the national level, IAGs have closely cooperated with the Council of Cities with High Concentrations of Foreign Residents. This council was founded in 2001 and currently has 28 members. Like IAGs, the municipalities organized in this council realized that local integration policy has strong limitations without a comprehensive integration policy on a national level. As local governments, they had a stronger voice in national policymaking and developed demands for a national integration policy in coordination with IAGs. While Japan still has no comprehensive integration policy on the national level, the efforts of this council had at least some successes like the establishment of a small section in charge of policies for foreign residents in the Cabinet Office. ${ }^{4}$

4 Please note that sub-national politicians have not always been partners of IAGs. In the early 2000s, for example, Shintarō Ishihara, governor of Tokyo at the time, and some other prefectural 
A second avenue of indirect lobbying and influence of IAGs has been their reporting to international actors like UN treaty body commissions or the International Labour Organization (ILO). By providing international organizations with alternative viewpoints to the national administration, IAGs were important information sources for the final reports of these organizations, which often had much more influence on the Japanese government than the direct lobbying efforts of the IAGs. This constitutes a classic example of the 'boomerang effect' (Keck and Sikkink 1998) in which NGOs circumvent national obstruction through international cooperation and alliances. Still, even this international path of lobbying has in general clear limits. An exception are the new policies against human trafficking and new restrictions in the issuing of entertainer visas. By taking a closer look at the policy process that led to their introduction, we are able to identify factors that normally limit the impact of the international path of lobbying of IAGs.

Human trafficking and its links to sex work was for long time an issue that ranked very low on the international agenda and was poorly funded. However, since the late 1990s, it has gained much more attention. Not only international organizations like the United Nations (UN) or the ILO, but also powerful actors like the US or the EU have enacted new legislation and introduced new measures against human trafficking (Patterson and Zhuo 2018). Japan was very early and strongly criticized for its entertainer visa policy in this context.

'Entertainer' is one of the visa categories included in the positive list of occupations in the immigration laws for which Japan grants foreign nationals a working visa. Officially, this visa category is for actors, musicians, models etc. that come to Japan. However, in reality, the overwhelming majority of foreign nationals that enter Japan with an entertainer visa are working in the large entertainment milieu and red light districts. From the late 1970 s onwards, the number of foreign 'entertainers' entering Japan, who are nearly only women, started to expand (see Figure 8.5). Up to today, the entertainer visa is numerically by far the most important working visa category for foreigners entering Japan. The working conditions in the different establishments in Japan's entertainment business vary strongly. Some business models clearly involve prostitution, but it would be wrong 
Figure 8.5 Foreign Nationals Entering Japan with a Working Visa, 1976-2017

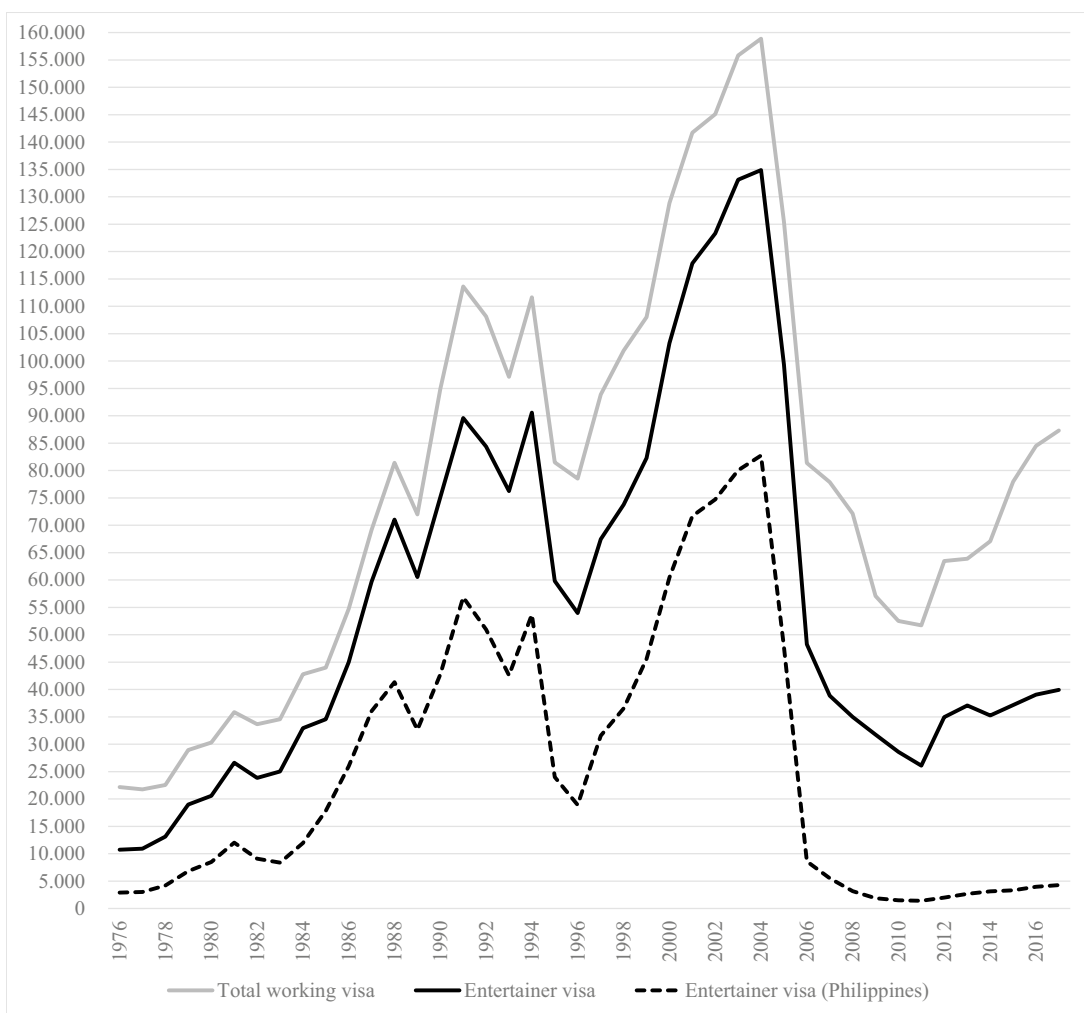

Source: MOJ (1975-2017)

to qualify all foreign entertainers simply as sex workers in the narrow meaning. Still, the official regulations allowing establishments to employ foreign entertainers are very strict, and the activities of foreign entertainers as hostesses, barmaids, dancers etc. were normally in clear contradiction to these regulations. This can be seen in the temporary but dramatic drop in the number of foreign entertainers granted visas in 1995 and 1996 (see Figure 8.5), when the director of the Tokyo Immigration Office acted to more strictly enforce the regulations by controlling establishments and determined that a staggering $93 \%$ of them did not fulfil the official requirements for the visas (Sakanaka 2005: 80-87).

Japanese and international IAGs working in the field of human trafficking strongly condemned Japan's entertainer visa policy, which opened in their view the door to debt bondage and forced sex work. Together with international organizations, they demanded not only a stricter enforcement of existing regulations in issuing entertainer visas, but also new legislation 
to combat human trafficking. They were also important information sources for international organizations like the ILO (2004) or IOM (1997) that strongly criticized Japan for its entertainer visa policy and passivity in combating human trafficking. However, these national and international voices had at first a very limited influence.

Ministries and agencies started to discuss among themselves new measures against human trafficking, but differences in opinion (as is so often the case in immigration policy) led to a deadlock and immobilism (Chiavacci 2011: 255-256). In April 2001, the Gender Equality Bureau of the Cabinet Office set up the Specialised Research Committee on Violence against Women (SRCVW, Josei ni tai suru Bōryoku ni kan suru Senmon Chōsakai). The main focus of the committee was domestic violence, sex crimes, prostitution, and sexual harassment, but it discussed also human trafficking issues. The committee included representatives from CSOs, but they were handpicked and did not include any representative from IAGs. The commission's final report in March 2004 contained also some very general recommendations regarding human trafficking (SRCVW 2004: 12), but in view of the committee composition it was hardly surprising that it basically followed the arguments presented in its hearings by representatives of ministries and agencies. It neither demanded any new legislation against human trafficking nor questioned the lax implementation of the regulations concerning entertainer visas in its final report. Up to this point, the policy formulation followed the 'normal' path of immobilism and limited influence by IAGs. However, foreign pressure (informed through IAGs) soon reached a completely new level.

In 2000, the US Congress had passed a new bill against human trafficking. As a part of this new legislation, the US Department of State (DOS) started to publish a yearly report in which countries worldwide (apart the US) were ranked regarding their efforts to combat human trafficking (DOS 2001-2019). The first reports adopted a system with three tiers and Japan was included in the second tier of countries that do not fully comply with minimal requirements defined by the US, but who undertake considerable efforts against human trafficking. However, in the 2004 report, a new group with a watch list of second tier countries was introduced. These countries were expected to introduce new legislation and measures against human trafficking. Otherwise, they were running the risk to be downgraded to Tier 3 countries that did not fulfil the basic requirements and also did not show significant efforts in curbing human trafficking. The DOS relied strongly on information from the IAGs and especially from the Japan Network against Trafficking in Persons (JNATIP), which had been founded in 2003, for assessing Japan. It placed Japan 
in its 2004 report in the Tier 2 watch list (DOS 2004). Actually, it had originally planned to include Japan in the Tier 3 list that compromised only outsiders of the international community like North Korea or Myanmar, but 'upgraded' it to the Tier 2 watch list after Japanese officials assured that it would introduce new policies and measures to combat human trafficking, including a stricter policy in issuing of entertainer visas (YS 2004). Still, to be on US's watch list regarding human trafficking was a huge embarrassment for Japan. At the time, Japan was attempting (ultimately unsuccessfully) to secure a permanent seat on the UN Security Council. And since 1998, it promoted human security as a main pillar in its foreign policy. In short, Japan's foreign policy was completely undermined by the 2004 report, which showed that even the US - its closest and most important ally - regarded Japan as a problem case regarding human trafficking. The speaker of the Japanese government declined to comment on the 2004 report after its publication $(A S 2004 \mathrm{~b})$, but the statements of Hiroyuki Hosoda, at the time Chief Secretary of State, documents its impact on the government. When asked in parliament about the 2004 report and the efforts of the government to curb human trafficking, he answered (Sangiin 2004: 14):

Regarding human trafficking, I have received various reports, and I have also attended the second meeting of the related inter-ministerial liaison commission in July of this year and have asked the involved ministries and agencies for aggressive efforts.

Even among embassies in Tokyo this has become a huge topic. In other words, it is extremely embarrassing for Japan, and must be corrected, absolutely. There are victims, first and foremost women, and many cases are emerging. We, in the government, have to work aggressively so as not to have these kinds of cases.

From a, at best, secondary topic in government circles, human trafficking had been catapulted onto the agenda of the cabinet. The cabinet secretariat not only took the lead and set up an inter-ministerial liaison commission in order to formulate new legislations and policies against human trafficking, but the Chief Secretary of State got personally involved to make clear to all actors participating that this was an issue of highest priority. The LDP, which had never regarded it as necessary to become active in the human trafficking problem, set up its own project team, which demanded new policy measures and a stricter issuing of entertainer visas ( $A S$ 2004a). These activities led to a comprehensive and fast reaction. In short time, only a few months, a new law supporting measures for victims of human trafficking as well as a much stricter awarding of entertainer visas were realized. The 
government also set up a permanent coordination body and formulated an action plan, which was revised in 2009 and 2014 (Ōno 2017: 211-217). The impact of the stricter entertainer visa policy was very large, especially on the number of Philippine entertainers entering Japan, which dropped from 2004 to 2006 by nearly $90 \%$ (see Figure 8.5 ).

In comparison to other indirect lobbying efforts by the IAGs, the case of human trafficking was exceptional due to its impact. Japan was exposed and shamed for its failure to render due support to victims of human trafficking. It saw its identity as 'cultural nation' and as a good member of international community questioned (Ōno 2017: 193-194). The accuser was none other than the US, its most important ally and the global hegemon.

In the 2005 report on human trafficking, the US recognized Japan's effort and upgraded it again to Tier 2 (DOS 2005: 132):

The government has made an impressive start in providing assistance to trafficking victims, including implementation of a national action plan with modest, additional resources for government-run shelters and private shelters. The government made substantial efforts to improve the legal framework by drafting penal code revisions which specifically criminalize trafficking and increase penalties for trafficking-related offenses. During the reporting period, the government undertook major reforms to significantly tighten the issuance of entertainer visas to women from the Philippines, a process used by traffickers to enslave thousands of Philippine women in Japan each year.

However, in the following years, the Japanese foreign trainee system came under criticism in the US human trafficking reports. Officially the trainee system is part of Japan's overseas developmental aid. Foreign workers from developing economies are brought to Japan as trainees to learn new skills and to contribute of the economic development of their home country after their return. However, as said above, from the early 1990s onwards, the trainee system has been primarily a guest worker programme that allows Japanese companies, and especially SMEs, to employ cheap foreign labour in occupation sectors that are shunned by Japanese workers due to their poor working conditions. IAGs had criticized the trainee programme for many years, but now it came increasingly under international scrutiny. It was identified as a being connected to human trafficking of foreign workers and as leading to infringements of their human rights.

This criticism was not only coming from the US (see e.g. UN 2010), but again the US and its reports on human trafficking were the main foreign pressure on Japan. While the IAGs were still rather ignored by decision-making circles 
in Japan, the US Department of State strongly relied on them as important information source and partner in fighting human trafficking. In the 2017 report, for example (DOS 2017), local IAGs are explicitly mentioned several times and obviously used as reliable sources. Ippei Torii (Secretary General of SMJ) even received the Trafficking in Person Report Hero Award in 2013 from the US government.

The Japanese government has reacted to this pressure by strengthening governance and oversight of the foreign trainee system. The IAGs had a significant impact in these developments. Based on his very detailed and careful analysis of these reforms in the foreign trainee system, Kremers (2014: 715) identifies them as the crucial actors that 'were able to change the attitude of other political actors and interest groups and as a result tipped the scales in the policy-making process.' While it would surely still be wrong to describe IAGs as a powerful political actor fully integrated into the elite decision-making circles, they have become a political voice that can no longer be simply ignored.

The Democratic Party of Japan (DPJ) government from 2009 to 2012 provided a window of opportunity. In the truly historic elections of 2007 and 2009, the LDP lost its majority in both chambers of the parliament. ${ }^{5}$ When still in opposition, the DPJ had already cooperated with the IAGs in formulating their own reform proposal of the foreign trainee system by inviting the SMJ as external advisor into its responsible working committee (Kremers 2014: 735-736). Once in power, it was much more open to cooperate with the CSOs, which resulted in much better access to the decision-making process for the IAGs, which were invited to hearings. However, since the elections of 2012, the LDP has returned to power, which has sidelined IAGs from decision-making bodies again. Moreover, US pressure on Japan concerning human trafficking has also decreased. In the reports of 2018 and 2019, Japan was still being criticized in several aspects, but it was moved to the Tier 1 list of countries fully compliant with the minimum standards relating to human trafficking set by the US. Hence, the window of opportunity for IAGs to affect the human trafficking issue in Japan has closed again.

\section{Conclusion}

Since the late 1980s, Japan has become a new immigration country. However, this has not transformed Japan into an immigration state that has clear 
long-term vision and strategy concerning immigration. On the contrary, due to its internal fragmentation on the ideational and institutional level, Japan's immigration policy has been marked over three decades until very recently by immobilism, that is, very limited, incremental and path-depending reform steps in contrast to far-reaching debates and reform proposals. This led also to clear gaps between Japan's official and real immigration policy. However, this resulted also in an especially 'strong' Japanese state concerning immigration against external pressure. Due to its internal fragmentation, it is even difficult for such powerful pressure groups like Nippon Keidanren to significantly influence immigration policy and its reform, especially in the field of admission policy.

In view of this, the ability of the IAGs to impact frames, implementation and reforms in immigration policy has been quite striking. Like other CSOs in Japan, IAGs have very limited staff and resources, but they were able to gain some influence in the making of immigration policy. They may seem to be too idealistic in their framing of immigration and their emphasis on human rights, but this idealism paired with the absence of vested interests in immigration policy gave them much credibility. Moreover, their ideal of Japan as a country that honours its international duties and protects the human rights of all people, including the foreign ones, is a national identity that is actually shared at least partly by some of the very important and powerful actors of the decision-making elites and large parts of the population. Hence, their argumentation strikes a cord with many powerful actors in immigration policy. The influence of IAGs is the largest on the level of policy frames and policy implementation. They upheld a human rights perspective in Japan when the country was flooded by a crime panic, in which foreigners and especially irregular foreign residents were seen as a threat to public security and blamed for its decline. In a more dynamic perspective, we can even argue that this crime panic and the identification of foreigners as culprits has been an important factor for the rise of IAGs as a counterforce. This wave of xenophobic statements was surely an important motivation for many people to become active and fight for human rights and decency. Following an argument made by Arrington (2016) in the context of victim movements in Japan and South Korea, we can also argue that the fact that these IAGs had to fight for a long time to get more access to elites and to be heard was another factor for their ability to mobilize more activists and establish themselves.

On the level of immigration policymaking, the influence of IAGs is most limited, but even in this area we cannot ignore their role. IAGs were able to have their strongest impact indirectly through international networks. Still, 
the new measures against human trafficking and reforms concerning the entertainer visa are an exceptional case. Not only international organizations, but especially the US as Japan's main ally exerted huge international pressure on Japan and led to temporary political salience and a centralization of immigration policymaking and very fast and comprehensive reforms. Still, without the IAG as an independent as well as respected actor and information source, this international pressure would never have reached the level it did.

Immigration and immigration policy will continue to be an important issue for Japan, which will also raise the basic question of who Japan wants to be. Currently, new immigration reforms are formulated and implemented in view of Japan's demographic development and increasing labour shortage. IAGs will continue to play an important role in these developments and Japan's future and future identity.

\section{References}

Arrington, Celeste L. 2016. Accidental Activists: Victim Movements and Government Accountability in Japan and South Korea. Ithaca: Cornell University Press.

AS. 2004a. 'Kōgyō Biza no Hakkyū, Jimin "Genkakuka o"' [Issuing of entertainer visas, LDP 'more strict application']. Asahi Shinbun, 19 November, evening edition, p. 2.

AS. 2004b. 'Nihon, "Yōkanshi" ni: Bōryokudan no Kanyo o Shiteki' [Japan, 'Be careful': Involvement of gangster pointed out]. Asahi Shinbun, 15 June, evening edition, p. 1.

Bungei Shunjū. 2008. 'Dēta Fairu 31: Gaikokujin Rōdōsha no Ukeire Kankyō ha dō natte iru ka?' [Data File 31: How is the acceptance of foreign workers changing?]. Nihon no Ronten 20o8: Mata Rūru ga kawatta. Bungei Shunjū (ed.). Tōkyō: Bungei Shunjū, pp. 294-295.

CAO. 2003.Jinken Yōgo ni kan suru Yoron Chōsa [Public opinion survey on human rights]. Tōkyō: Cabinet Office.

CAO. 2004. Chian ni kan suru Yoron Chōsa [Public opinion survey on security]. Tōkyō: Cabinet Office.

CAO. 2012. Chian ni kan suru tokubetsu Yoron Chōsa [Special public opinion survey on security]. Tōkyō: Cabinet Office.

CAO. 2017. Chian ni kan suru Yoron Chōsa [Public opinion survey on security]. Tōkyō: Cabinet Office.

Chiavacci, David. 2010. 'Divided Society Model and Social Cleavages in Japanese Politics: No Alignment by Social Class, but Dealignment of Rural-Urban Split.' ContemporaryJapan, 22 (1/2): 47-74. 
Chiavacci, David. 2011. Japans neue Immigrationspolitik: Ostasiatisches Umfeld, ideelle Diversität und institutionelle Fragmentierung [Japan's new immigration policy: East Asian context, ideational diversity and institutional fragmentation]. Wiesbaden: VS Verlag.

Chiavacci, David. 2014. 'Future Workforce? Discourses on and Realities of Foreign Workers in Japan.' Governing Insecurity in Japan: The Domestic Discourse and Policy Response. Wilhelm Vosse; Verena Blechinger-Talcott; Reinhard Drifte (eds). London: Routledge, pp. 115-140.

Chiavacci, David. 2020. 'Japan's New Immigration: Gap in Admission Policy and Diversity in Socio-economic Integration.' Routledge Handbook of Contemporary Japan. Hiroko Takeda; Mark Williams (eds). London: Routledge. Forthcoming.

Chiavacci, David; Julia Obinger. 2018. 'Towards a New Protest Cycle in Contemporary Japan? The Resurgence of Social Movements and Confrontational Political Activism in Historical Perspective.' Social Movements and Political Activism in Contemporary Japan: Re-emerging from Invisibility. David Chiavacci; Julia Obinger (eds). London: Routledge, pp. 1-23.

DOS. 2001-2019. Trafficking in Persons Report. Washington, DC: Department of State. Gelb, Joyce; Naoko Kumagai. 2018. 'Gender Equality in Japan.' Routledge Handbook ofJapanese Foreign Policy. Mary McCarthy (ed.). London: Routledge, pp. 337-352.

GJHI (ed.). 2013. Gaikokujin Jisshūsei: Sabetsu - Yokuatsu - Sakushu no Shisutemu [Foreign trainees: Discrimination, repression and system of exploitation]. Gaikokujin Jisshūsei Henshū I'inkai. Tōkyō: Gakushū no Tomosha.

GRMN. 2009. 'Kenshūsei' to iu na no Dorei Rōdō: Gaikokujīn Rōdōsha Mondaito korekara no Nihon [Slave labour under the name of 'trainee': The foreign worker problem and Japan's future]. Gaikokujin Rōdōsha Mondai to korekara no Nihon. Tōkyō: Kadensha.

GSUN (ed.). 2004. Gaikokujin Hōimō: 'Chian Akka'no Sukēpugōto [Foreigner siege net: The scapegoating of 'worsening security']. Gakokujin Sabetsu Uotchi Nettowāku. Tōkyō: Gendai Jinbunsha.

GSUN (ed.). 2008. Gaikokujin Hōimō, 2: Kyōka sareru Kanri Shisutemu [Foreigner siege net, 2: Strengthening control system]. Gakokujin Sabetsu Uotchi Nettowāku. Tōkyō: Gendai Jinbunsha.

Gurowitz, Amy. 1999. 'Mobilizing International Norms: Domestic Actors, Immigrants, and the Japanese State.' World Politics, $5^{1}$ (3): 413-445.

Hamai, Koichi; Thomas Ellis. 20o6. 'Crime and Criminal Justice in Modern Japan: From Re-Integrative Shaming to Popular Punitivism.' International Journal of the Sociology of Law, 34 (3): 157-178.

Hasegawa, Koichi. 2011. 'A Comparative Study of Social Movements for a Post-nuclear Energy Era in Japan and the USA.' East Asian Social Movements: Power, Protest, and Change in a Dynamic Region. Jeffrey Broadbent; Vicky Brockman (eds). New York: Springer, pp. 63-79. 
Higuchi, Naoto. 2006. 'Taminzoku Shakai no Kyōkai Settei to Esunikku Bijinesu.' [Demarcation of multi-ethnic society and ethnic business]. Taminzoku Nihon no Misekata: Tokubetsuten 'Taminzoku Nihon' o megutte. Hiroshi Shōji; Mi Seon Kim (eds). Suita: Ningen Bunka Kenkyū Kikō Kokuritsu Minzokugaku Hakubutsukan, pp. 33-43.

Hirabayashi, Yūko. 2013. “'Genpatsu Okotowari” Chiten to Hangenpatsu Undō' ['Nuclear energy rejection' and the anti-nuclear movement]. Ōhara Shakai Mondai Kenkyūjo Zasshi, 661: 36-51.

Hosoki, Ralph I. 2016. 'The Potential Role of Migrant Rights Advocacy in Mitigating Demographic Crises in Japan.' Japan's Demographic Revival: Rethinking Migration, Identity and Sociocultural Norms. Stephen Robert Nagy (ed.). Singapore: World Scientific, pp. 285-336.

Ikuta, Tadahide. 2000. Kanryo: Japans's Hidden Government. New York: ICG Muse.

ILO. 2004. Human Trafficking for Sexual Exploitation in Japan. Geneva: International Labour Organization.

IOM. 1997. Trafficking in Women to Japan for Sexual Exploitation: A Survey on the Case of Filipino Women. Geneva: International Organization for Migration.

ISA. 2019. Aratana Gaikoku Jinzai no Ukeire oyobi Kyōsei Shakai Jitsugen ni muketa Torikumi [Framework for the acceptance of new foreign human resources and for the realization of a symbiotic society]. Tōkyō: Immigration Services Agency of Japan (Shutsunyūkoku Zairyū Kanrichō).

Johnson, Chalmers. 1982. MITI and the Japanese Miracle: The Growth of Industrial Policy, 1925-1975. Stanford: Stanford University Press.

Kamibayashi, Chieko. 2004. 'Gaikokujin Rōdōsha to Chūshō Kigyō' [Foreign workers and small and medium-sized enterprises]. Chi'iki Keizai no Saisei to Kōkyō Seisaku. Yasuhiro Horie (ed.). Tōkyō: Chūō Keizaisha, pp. 51-74.

Keck, Margaret E.; Kathryn Sikkink. 1998. Activists beyond Borders: Advocacy Networks in International Politics. Ithaca: Cornell University Press.

Kondō, Atsushi; Yoshikazu Shiobara; Eriko Suzuki (eds). 2010. Hiseiki Taizaisha to Zairyū Tokubetsu Kyoka: Ijūshatachi no Kako - Genzai - Mirai [Non-regular residents and special residence permits: Past, present and future of migrants]. Tōkyō: Nihon Hyōronsha.

Kremers, Daniel. 2014. 'Transnational Migrant Advocacy from Japan: Tipping the Scales in the Policy-making Process.' Pacific Affairs, 87 (4): 715-741.

Kyogoku, Junichi. 1987. The Political Dynamics ofJapan. Tokyo: University of Tokyo Press.

LDP. 2008. Jinzai Kaikoku! Nihongata Imin Seisaku no Teigen: Sekai no Wakamono ga Ijū shitai to akogarere Kuni no Kōchiku ni mukete [Open Japan to human resources! Proposal for a Japanese-style immigration policy: To build a country 
where young people around the world want to move]. Tōkyō: Liberal Democratic Party (Gaikokujinzai Kōryū Sokushin Gi'in Renmei).

Milly, Deborah J. 2014. New Policies for New Residents: Immigrants, Advocacy, and Governance in Japan and Beyond. Ithaca: Cornell University Press.

Miyazaki, Shigeki. 1970. Shutsunyūkoku Kanri: Gendai no 'Sakoku' [Immigration control: Modern 'isolation']. Tōkyō: Sanseidō.

MOJ. 1975-2018. Shutsunyūkoku Kanri [Immigration control]. Ministry of Justice, Immigration Bureau. Tōkyō: Ōkurashō Insatsukyoku.

Momoi, Yuri. 2018. 'How Japan Lost Its Policymaking Skills: Triangle of Politicians, Bureaucrats and Business Struggles to Meet Challenges.' Nikkei Asian Review, 26 March. https://asia.nikkei.com/Politics/How-Japan-lost-its-policymakingskills (12 December 2019).

Muramatsu, Michio; Ellis S. Krauss. 1984. 'Bureaucrats and Politicians in Policymaking: The Case of Japan.' American Political Science Review, 78 (1): 126-146.

Murata, Hiroko. 2014. 'Nihonjin ga motsu Kuni he no Aichaku to ha' [Japanese people's attachment to their country]. Hōsō Kenkyū to Chōsa, 5: 16-31.

NPA (ed.). 1987. Shōwa 62-nen Keisatsu Hakusho: Kokusaika no Shinten ni Taiō suru Keisatsu Katsudō [1987 White paper on police: Police reactions towards the progress of internationalization]. National Police Agency, Keisatsuchō. Tōkyō: Ōkurashō Insatsukyoku.

NPA (ed.). 1999. Heisei 11-nen Keisatsu Hakusho: Kokkyō o koeru Hanzai to no Tatakai [1999 White paper on police: Fighting transnational crime]. National Police Agency, Keisatsuchō. Tōkyō: Ōkurashō Insatsukyoku.

OECD. 2019. International Migration Outlook 2019. Paris: Organisation for Economic Co-operation and Development.

Ogawa, Akihiro. 2009. The Failure of Civil Society? The Third Sector and the State in Contemporary Japan. Albany: State University of New York Press.

Ōno, Sera. 2017. 'Nihon ni okeru Jinshin Torihiki Taisaku no Gendankai' [Current stage of the measures against human trafficking in Japan]. Hito no Kokusai Idō to Gendai Nihon no Hō:Jinshin Torihiki - Gaikokujin Rōdō - Nyūkan Hōsei. Shirō Ōkubo; Makoto Hizume; Mikio Yoshida (eds). Tōkyō: Nihon Hyōronsha, pp. 189-219.

Patterson, Orlando; Xiaolin Zhuo. 2018. 'Modern Trafficking, Slavery, and Other Forms of Servitude.' Annual Review of Sociology, 44: 407-439.

Pekkanen, Robert. 2006. Japan's Dual Civil Society: Members without Advocates. Stanford: Stanford University Press.

Pekkanen, Robert; Yutaka Tsujinaka; Hidehiro Yamamoto. 2014. Neighborhood Associations and Local Governance in Japan. London: Routledge.

Pempel, T.J.; Keiichi Tsunekawa. 1979. 'Corporatism without Labor: The Japanese Anomaly.' Trends toward Corporatist Intermediation. Philippe C. Schmitter; Gerhard Lembruch (eds). Beverly Hills: Sage, pp. 231-270. 
Sakanaka, Hidenori. 2005. Nyūkan Senki: 'Zainichi' Sabetsu, 'Nikkeijin' Mondai, Gaikokujin Hanzai to, Nihon no Kinmirai [War record of the Immigration Office: 'Zainichi' discrimination, the 'Nikkeijin' problem, foreign crime and the near future of Japan]. Tōkyō: Kōdansha.

Sangiin. 2004. Dai 161-kai Sangiin Naikaku Iinkai Kaigi Kiroku: Dai 4-go (2004-nen 11-gatsu 4-nichi) [Record of the $161^{\text {st }}$ House of Councillors Committee Meeting: No. 4 (4 November 2004)]. Tōkyō: Kokuritsu Insatsukyoku.

Shipper, Apichai W. 2005. 'Criminals or Victims? The Politics of Illegal Foreigners in Japan.' Journal ofJapanese Studies, 31 (2): 299-327.

Shipper, Apichai W. 2008. Fighting for Foreigners: Immigration and Its Impact on Japanese Democracy. Ithaca: Cornell University Press.

Shiratori, Hiroshi (ed.). 2010. Seiken Kōtai Senkyo no Seijigaku: Chihō kara kawaru Nihon Seiji [The political science of regime change elections: Rural regions altering Japanese politics]. Kyōto: Mineruva Shobō.

SRCVW. 2004. Josei ni tai suru Bōryoku ni tsuite no torikumubeki Kadai to sono Taisaku [Issues to be addressed and countermeasures concerning violence against women]. Tōkyō: Specialized Research Committee on Violence against Women (Josei ni tai suru Bōryoku ni kan suru Senmon Chōsa Kaigi).

Stockwin, J.A.A.; Alan Rix; Aurelia George; James Horne; Daiichi Itō; Martin Collick (eds). 1988. Dynamic and Immobilist Politics in Japan. Houndmills: Macmillan.

Sugawara, Taku. 2011. Yoron no Kyokkai: Naze Jimintō ha Taihai shita no ka [Misreading public opinion: Why was the LDP defeated?]. Tōkyō: Kōbunsha.

Suleiman, Ezra. 2003. Dismantling Democratic States. Princeton: Princeton University Press.

Suzuki, Eriko. 2017. 'Gaikokujin Senbetsu Seisaku no Tenkai: Shinkō suru senbetsuteki Haijo' [Development of the Selective Immigration Policy: Proceeding selective exclusion]. Imin Ukeire no Kokusai Shakaigaku: Senbetsu Mekanizumu no Hikaku Bunseki. Akihiro Koido (ed.). Nagoya: Nayoga Daigaku Shuppankain, pp. 310-336.

Tsuda, Takeyuki; Wayne A. Cornelius. 2004. 'Japan: Government Policy, Immigrant Reality.' Controlling Immigration: A Global Perspective. Wayne A. Cornelius; Takeyuki Tsuda; Philip L. Martin; James F. Hollifield (eds). Stanford: Stanford University Press, pp. 439-476.

UN. 2010. Report Submitted by the Special Rapporteur on Trafficking in Persons, Especially Women and Children, Joy Ngozi Ezeilo: Addendum Mission to Japan. New York: United Nations.

Yamamoto, Ryoko. 2004. 'Alien Attack? The Construction of Foreign Criminality in Contemporary Japan.' Japanstudien, 16: 27-57.

Yoshinari, Katsuo. 2015. 'Tenkanki no Gaikokujin Shien Undō' [Turning point of the support movement for foreigners]. Shimin ga Teian suru korekara no Imin 
Seisaku: NPO Hōjin APFS no Katsudō to Sekai no Unkō kara. Katsuo Yoshinari; Tetsuo Mizukami; Yoshiaki Noro (eds). Tōkyō: Gendai Jinbunsha, pp. 45-6o. YS. 2004. 'Jinshin Baibai: Nihon Seifu no Hannō okure ni Hihan aitsugu' [Human trafficking: Reaction of Japanese government criticized]. Yomiuri Shinbun, 20 November, morning edition, p. 13.

\section{Interviews}

Interview IAG 2003. Representative of an immigrant advocacy group, 2003. Interview IAG 2012. Representative of an immigrant advocacy group, 2012. Interview Nippon Keidanren 2006. Representative of Nippon Keidanren, 2006.

\section{About the Author}

David Chiavacci is Professor in Social Science of Japan at the University of Zurich, Switzerland. His research covers political and economic sociology of contemporary Japan in a comparative perspective. He is known for his publications on social movements, social inequality as well as Japan's new immigration and immigration policy. His recent publications include Re-emerging from Invisibility: Social Movements and Political Activism in Contemporary Japan (Routledge, 2018, co-edited with Julia Obinger) and Japanese Political Economy Revisited: Abenomics and Institutional Change (Routledge, 2019, co-edited with Sébastien Lechevalier). 



\section{Part III}

Neoliberalism and Social Inclusion 



\title{
9 Japanese NPOs and the State Re-examined
}

\author{
Reflections Eighteen Years On
}

Akihiro Ogawa

\begin{abstract}
This chapter builds on long-term research at SLG, a pseudonym for a non-profit organization (NPO) in eastern Tokyo, established under the 1998 NPO Law. Incorporated as an NPO in 2000, SLG is one of the largest civic society organizations promoting lifelong learning in Japan. Over nearly two decades, SLG offered more than a hundred courses to the local community. However, SLG faced a crisis and risked dissolution in 2018 due to the municipal government's decision to cut its funding. This chapter argues that SLG was a successful case of neoliberalism-oriented public administration, pursuing decentralization and reduced costs; at the same time SLG did not encourage independent, citizen-oriented activities. This chapter documents current discussions at SLG, reflecting the reality of a Japanese civil society landscape in which NPOs are central.
\end{abstract}

Keywords: NPOs, neoliberalism, new public management, new public governance, co-production

My field site SLG (pseudonym) is a non-profit organization (NPO) established in 2000. Located in a traditional downtown district of eastern Tokyo, which I will henceforth call Kawazoe (pseudonym), SLG promotes communityoriented lifelong learning. I have been observing this organization since September 2001 and thus my research commitment to SLG now spans nearly 20 years. It is one of the largest lifelong learning NPOs in Japan, in terms of the number of its members and the size of its budget. Furthermore, it offers

Chiavacci, David, Simona Grano, and Julia Obinger (eds), Civil Society and the State in Democratic East Asia: Between Entanglement and Contention in Post High Growth. Amsterdam, Amsterdam University Press 2020 DOI: $10.5117 / 9789463723930 \_C H 09$ 
more than a hundred courses per year to the local community, in a very innovative way. That is, at SLG, local resident-volunteers create courses for local residents and this course creation reflects the spirit of community development: they decide what they want or need to learn by themselves in support of their own local community. A total of some 260,000 local residents have studied at SLG since 2001, when it was first established.

This chapter presents a new dynamism between the state and civil society in contemporary Japan, shedding light on NPOs. It is based on my long-term research project. NPOs have been important actors in the Japanese civil society landscape since the late 199os and are established under the Law to Promote Specified Non-profit Activities, colloquially known as the NPO Law. They were the product of a Japanese social movement following the 1995 Great Hanshin earthquake when more than one million volunteers acted to aid victims of the disaster. The government bureaucracy's ineffective efforts to deal with this tragedy paled in comparison to the impressive work of volunteers, then resulting in the institutionalization of volunteerbased NPOs in 1998 (see Pekkanen 2000 for the legislative process). In fact, this was a momentous Japanese civil society project that has given rise to nearly 70,000 NPOs (CAO 2018) over the past two decades. These NPOs have increasingly taken on responsibility for local communities' social welfare, becoming progressively more significant in both providing services and creating social change to better meet the emerging needs of service users. My field site SLG is part of this macro-landscape of Japanese civil society.

My research project at SLG was originally part of my doctoral dissertation, which analysed the institutionalization of NPOs - a new type of civil society organization (CSO) in Japanese society. Employing ethnographic methods such as participant observation, I have been actively involved in this organization, first as an unpaid staff member of the secretariat, and later as a regular volunteer. Meanwhile, I have been an action-minded researcher at SLG since my graduate days (Greenwood and Levin 1998); in other words, I have not simply acted as a traditional silent observer, but have actively collaborated with other secretariat staff members and volunteers to solve real problems that arise at SLG. My long-term engagement in SLG has culminated in the production of two books - The Failure of Civil Society? (Ogawa 2009b) and Lifelong Learning in Neoliberal Japan (Ogawa 2015), as well as journal articles and book chapters (e.g. Ogawa 2004, 2006, 2008, 2009a, 2009c, 2012, 2013).

In 2017, SLG was in a state of crisis and may be dissolved as an NPO later in 2018, due to a decision by the municipal government to cut its funding. The government's logic for so doing goes as follows: The local lifelong learning 
centre, the public building in which SLG is housed, will be renovated next year. During that time, SLG will be unable to offer its lifelong learning courses or to function as a social service delivery provider on behalf of the government. Thus, the government will not fund SLG in the upcoming fiscal year, starting in April 2018. Notice of this was given in April 2017, one year in advance, and SLG was asked to withdraw from the building by 31 March 2018.

Following the notice by the municipal government, SLG volunteers began exploring other possibilities or tools to extend their current communityoriented learning. Practically speaking, SLG stakeholders believe that what SLG has created in the community over the past two decades should not disappear simply due to lack of money. Meanwhile, the head of SLG announced in May 2017 to all 20 of its paid secretariat staff members that SLG would not renew their single-year employment contracts after 1 April 2018. The government funding has largely been used for employment, primarily of local people. Kawazoe is an industrial district with a dense concentration of middle- and small-sized factories, but its businesses have lost momentum under the sluggish economy over the past two decades in Japan. Thus, the government funding created jobs in the local community. Given notice well in advance, the SLG employees have already begun job hunting. Fortunately, the Japanese labour market is currently favourable, probably due to the positive effects of Abenomics - the economic policies advocated by Shinzo Abe since 2012, which combine the 'three arrows' of monetary easing, fiscal stimulus and structural reforms. In this chapter, I will document my current research into the relationship between the state and civil society as a record of my long-term commitment to SLG. The institutionalization of SLG represents a distinctive way of moulding civil society in the international third sector scholarship. Their current discussions reflect the reality of the Japanese civil society landscape over the past two decades, in which NPOs were centred.

\section{Neoliberalism and NPOs}

One of the major arguments I have made in previous work is that Japanese NPOs are a key form of agency in neoliberalism. I argue that neoliberalism is opening up a space for civil society, claiming that ' $\mathrm{t}$ ] he institutionalization of NPOs is a calculated reorganization of the Japanese public sphere designed to establish a small government in the post-welfare state through the transfer of social services originally delivered by the state to volunteer-driven NPOs' (Ogawa 2009b: 174). The institutionalization of NPOs was indeed a political 
project implemented by the Japanese neoliberal state to mould its population or the state-individual relationship in a specific manner under the name of civil society. Globally, a key feature of neoliberal governmentality since the 1980 s has indeed been the devolution of social services. For example, civil society organizations came to play programmatic roles previously assumed by the state. They assumed a new 'function' under neoliberal structural adjustment programmes imposed by the World Bank and the IMF (Goldman 2005: 270-271). Meanwhile, at a local level, SLG delivers social services, or a range of lifelong learning opportunities, that were originally provided by the municipal government. This is in line with the method adopted by neoliberal politics, primarily to achieve cost cutting, as has been pointed out by many third sector research scholars such as Salamon and Anheier (1998), Pollitt and Bouckaert (2011), and Bruce and Chew (2011). This trend is evident across the globe in different national and regional contexts. Japan indeed provides prominent examples of such devolution policies in social services (see Hayashi, in this volume), and substantial work has also been undertaken by Alford and Yates (2016) and Alford (2009, 2002) in Australia and in Anglo-Saxon countries, for example, the UK's Compact.

While neoliberal ideology criticizes state intervention, neoliberal practices involve 'coercive, disciplinary forms of state intervention in order to impose market rule upon all aspects of social life' (Brenner and Theodore 2002: 5). To explain this kind of neoliberal governance, Peck and Tickell (2002) identify two interrelated practices: 'roll-back neoliberalism' and 'roll-out neoliberalism.' 'Roll-back neoliberalism' refers to 'the active destruction or discreditation of Keynesian-welfarist and social-collectivist institutions (broadly defined)' (Peck and Tickell 2002: 384, italics in the original). This is simply known as 'privatization' or 'sharing or delegating of authority to non-governmental agents' (Handler 1996: 78-80). Following the macroeconomic crisis condition in the 1970s, Margaret Thatcher of the UK and Ronald Reagan of the US favoured the neoliberalism-oriented policy practice in the 1980s. The Japanese conservative government also promoted this policy; for example, in the 1980s, Prime Minister Yasuhiro Nakasone privatized the Japanese national railroad, which is currently called JR. Later in the 20oos, Prime Minister Junichirō Koizumi expanded the neoliberal state-sponsored restructuring programme by creating Japan Post to replace the government-run Postal Services Agency.

Meanwhile, 'roll-out neoliberalism' refers to 'the purposeful construction and consolidation of neoliberalized state forms, modes of governance, and regulatory relations' (Peck and Tickell 2002: 384, italics in the original). As Peck and Tickell (2002: 388-389) argue, when the shallow neoliberalism of 
Thatcher and Reagan encountered their institutional and political limits in the early 1990s, the neoliberal projects gradually metamorphosed into more socially interventionist and ameliorative forms, epitomized by the Third-Way contortions of the Bill Clinton and Tony Blair administrations. Since then, new forms of institution-building and governmental intervention have been licensed within the broadly defined neoliberal project. This is also true in the context of Japan. Although the terms 'privatization' and 'decentralization' suggest a withdrawal by the state from the field of social welfare, the ways in which the policies have been carried out have, perhaps counterintuitively, strengthened and expanded the state's role in the provision of social welfare services, as argued by Haddad (2011: 37). This development was supported by an 'activist state' model, which Pharr (2003: 324$)$ claimed was used successfully by the Japanese to institutionalize specific kinds of civil society groups in order to promote state ideology through funding and tax incentives.

The neoliberal state is nowadays concerned with the roll-out of new forms of institutional 'hardware' (Peck and Tickell 2002:389), one of which is the new public management (NPM) that has been expanding since the 1980 . NPM consists of the transfer of principles and management techniques of business and markets from the public sector to the private sector. It has good chemistry with neoliberal governance, which aims at minimized government costs with less public activity performed in accordance with the efficiency principle of the free market. Japan adapted and then innovated this management style from Western systems (Westney 1987), while techniques and rhetoric were filtered through Japanese cultural and political factors (Jun and Muto 1995). Furthermore, Yamamoto (2009) explains that NPM-style decentralization and agencification in Japan drew on UK executive agency examples and rhetoric; however, actual flexibility in the management of Japanese agencies was partially stifled by central control manifested through budgeting practices.

Japanese NPOs, including my case SLG, would well fit to this NPMinspired market-based orientation, and even to 'new public governance' civil society reforms, which intend to enhanced effectiveness, flexibility and democratic quality of public services (see Howlett et al. 2017). NPOs played an active role in operating this setup of the institutional hardware. My NPO - SLG - has been called kōsetsu min'ei in Japanese, which means 'established by public authorities like the municipal government but operated by citizens or residents.' In the terminology of third sector research scholarship, Japanese NPOs of this type would be categorized as GONGOs (government-organized non-governmental organizations) or 'GONPOs' in 
the Japanese context, as dubbed by Asahi Shimbun (2009), a major daily. These comprise organizations created by the political process but that operate quasi-independently of the agencies that established them, as well as organizations that implement government-created responsibilities to oversee areas of economic or professional activity (Salamon and Sokolowski 2016: 1534). SLG could also be described as the local government contracting out the provision of social services, more specifically the offering of lifelong learning courses, as part of its attempts to reduce the size of the state under neoliberal ideology (Pollitt and Bouckaert 2011).

Government funding was a major source of income for SLG from the time of its establishment. In fact, the municipal government injected a total of one billion yen (US\$9 million) into SLG over its eighteen years. Because of its mobilization of local volunteers, the costs of creating lifelong learning courses have been almost halved when compared to the cost of government provision of the same type of services. Thus, based solely on the cost, I would argue that SLG was a successful case of neoliberalism-oriented public administration, which pursues decentralization and cost cutting. Meanwhile, however, SLG has failed to diversify its sources of income as a civil-society organization, although its directors have continuously made serious efforts to change the funding structure, by, for example, raising money from local businesses.

\section{State-Society Relations Framed by ‘Co-production’}

With the promulgation of the 1998 NPO Law, the patterns of non-state provision of welfare services in the country changed dramatically. The Japanese government transformed the pattern of social welfare service delivery through privatization and decentralization policies. The resulting pattern continued and expanded existing and largely informal organizations and activities, and fostered the rapid development of a more privatized and decentralized non-profit sector or NPOs dedicated to the delivery of social welfare services. SLG was an experienced public service delivery partner.

Nowadays, the state adopts a stewardship role in moulding civil society in a direct manner, as has been well argued by civil society scholars such as Cohen (1999), who points out the state's fundamental role in helping civil society to develop. In fact, Evers (2013: 155) has asserted that the state, and more precisely democratic statehood, is directly involved in the civil society debate, not only in terms of providing protection and support for the activities of others but also as a cofounding agency. Recently, it has more often been argued that civil society organizations are partners of 'co-production' 
with the state, a currently renewed academic interest building upon work by early scholars like Ostrom (1973) and Parks et al. (1981).

The 2009 Nobel Laureate of Economics Elinor Ostrom (1996: 1073) used 'co-production' to describe a process through which 'inputs from individuals who are not "in" the same organization are transformed into goods and services.' The term 'co-production' suggests a relationship between 'regular producers' (policymakers and practitioners) and 'clients' (service users) (Ostrom 1999), specifically where the 'client' acts not as a 'consumer' of services, but as a 'co-producer' of them (Ostrom 1999: 1073).

The term 'co-production' was rarely used in Japanese studies when I began my research at SLG as a doctoral project. At that time, 'partnership' or 'devolution' were popular terms used to describe such policy collaboration (Ogawa 2009b). The term 'co-optation' was also used, as civil society organizations are co-opted to the state (Ogawa 2009a). Meanwhile, as an anthropologist, I argued the phenomenon in a different way, coining the term 'volunteer subjectivity,' employing Foucault's governmentality (Ogawa 2004, 2008, 2009b). I examined the mobilization of volunteer subjects in Japanese society, and gradually came to realize that the agent was surely the state. The state's motivation was anchored in the idea that volunteer activities could be organized under NPOs to replace the government's own provision of social services. This new Foucauldian subjectivity was expected to contribute to a new space for civil society under the neoliberal regime.

In the framework of co-production, Ostrom analysed the role of citizens in the provision of public services; co-production is a design for democratic governance and social inclusion (Ostrom 1990; see also Parks et al. 1981). Victor Pestoff et al. (2012) recently expanded on the concept of co-production in 'new public governance' scholarship, and argued that co-production can achieve higher-quality services and/or results in the provision of more services, often at a lower price, than is possible without citizen participation. For the state, co-production is an administrative technique of making citizens engage in the improvement of public services. As Lam and Dearden (2015:64) point out, this 'goes beyond assuring that the users' voices are heard, to engaging service users in developing and deciding on solutions that will affect them.' For citizens, meanwhile, co-production is a participative tool that actively involves them in public affairs. Although co-production emerged and developed as a concept that emphasized citizens' engagement in policy delivery, its meaning has evolved in recent years to include both individuals (citizens and quasi-professionals) and civil society organizations like NPOs collaborating with government agencies in both the design and management of services as well as their delivery (see Pestoff and Brandsen 2010). 
SLG is an important case of developing the capacity of the NPO sector in Japan to apply co-production to social services or lifelong learning courses in the local community. Local volunteers create learning contents, mobilizing their local knowledge and networks. The state, meanwhile, funds these citizen-based activities, while local volunteers raise money autonomously. The creation of courses for local lifelong learning was a co-production activity between volunteers and the state: It sought to shift the balance of power, responsibility and resources in society from professionals to ordinary citizens under such a strong state as Japan, as it involved citizens in the production and delivery of their own services. I would argue that neoliberal politics, a dominant political ideology since the 1980 s in Japan, has indeed created such a space for civil society organizations to be active in public affairs. Furthermore, I can point out that the neoliberal state employing the practice of co-production offers ordinary individuals new opportunities to participate in various arenas of action, 'to resolve the kind of issues hitherto held to be the responsibility of authorized government agencies' (Burchell 1996: 29). In co-production design (Durose and Richardson 2016), citizens are all potentially creative makers in their own right. For policy design, this means seeing citizens as 'co-designers'; doing so 'turn[s] people into participants. [...] [T]hey become innovators and investors, adding to the system's productive resources rather than draining them as passive consumers waiting at the end of the line' (Leadbeater and Cottam 2007: 98).

\section{Mission Completed}

To revert to the SLG case, one of the reasons the municipal government cut the SLG budget was that the government's policy mission is now complete. By its 'policy mission,' I refer to the promotion of lifelong learning activities in the local municipality, which was clearly articulated in the government's policy document on lifelong learning in the 1990s (SWG 1990, 1999a, 1999b). Thus, SLG was created as part of the municipal government's framework of lifelong learning policy. It was planned as an alternative place for learning for local residents in the community as an extension programme to higher education institutions like universities, which often provide learning opportunities. Japan is unquestionably a society that highly values lifelong learning. Informal learning was guaranteed under the Social Education Law in 1949, shortly after World War II, and such learning is recognized as a legal right for ordinary people. 
Although documented in full elsewhere (e.g. Ogawa 2009b: 71-77), I will here briefly introduce the history of SLG: The municipal government opened the local lifelong learning centre, in which SLG is currently housed, in 1994. This represented the first attempt to build such a facility in a Tokyo metropolitan municipality. By way of background, this move was also made in direct response to the national enactment of the Law for the Promotion of Lifelong Learning in 1990, which prescribed measures such as the establishment of a Lifelong Learning Council at the national and local levels to promote lifelong learning, provisions for the development of lifelong learning in designated communities, and surveys to assess the learning demands of local residents.

The local lifelong learning project in Kawazoe was buoyed by the euphoric sentiment of the 'bubble' economy in the late 1980s and early 1990s. However, by the time the lifelong learning centre opened, the local government faced huge fiscal difficulties due to the decline in tax revenue. It then occurred to the municipal government to create a local residents' group to operate the centre. The government mobilized local residents as volunteers and assigned them the task of creating lifelong learning courses, thereby delegating an active role of government as defined by the education laws. SLG was originally established as an informal citizens' group in 1995 and then re-organized as an NPO under the 1998 NPO Law. SLG would not generate any additional cost to the government through its establishment as a formal organization, and it even reduced the cost while fulfilling its objectives, due to the mobilization of volunteers as unpaid human resources. This was also in line with the neoliberal ideology of practice.

SLG changed the traditional style of state-led learning (see Kawanobe 1994); instead, local residents explored the intellectual demands of residents, found teachers, negotiated with them, and wrote course plans, including tuition content. In return, the government funded the salaries of the secretariat staff who conducted the administrative work for course operation. It also dispatched staff members to the SLG secretariat to help with administrative work. The head post of the secretariat was occupied by retired officials as part of amakudari, literally meaning 'descent from heaven' - a system whereby retiring Japanese bureaucrats gain employment and executive positions in the private sector. This practice facilitated communication with the government.

SLG garnered strong national attention in the late 1990 s and early 2000s, and similar types of lifelong learning activity flourished countrywide. Many visited SLG to learn about course creation, while SLG people also visited their counterparts elsewhere. In the mid-20oos, such interactions 
were expanded to form a national network of bunka borantia, or 'culture volunteers' in direct translation, who were volunteers in local public facilities for lifelong learning, such as citizens' public halls, libraries, museums - that is, traditional social education facilities in Japan (see Ogawa 2015: 74-78). SLG hosted the fourth national conference of bunka borantia in 2008.

In my previous work, I labelled bunka borantia 'knowledge-constructing subjects' (Ogawa 2015: 73). While interacting with the neoliberal state, the bunka borantia are active in learning, producing, accumulating and applying a certain, appropriate knowledge to survive in and deal with the constant changes in their daily lives. I argued (Ogawa 2015: 74) that a profound shift from the Keynesian welfare state to that of neoliberal politics represents a deliberate cultural restructuring and engineering based upon the neoliberal model that Michael Peters (2001) calls the 'entrepreneurial self'. In tandem with the development of bunka borantia, Japan's policy on promoting atarashii kōkyō, or the 'new public commons,' in the late 2000s, strongly encouraged the building up of such a disciplinary subjectivity.

One of the tangible results observed in the area of Kawazoe was that lifelong learning activities flourished. Copying exactly SLG's style of course creation, other public facilities in the local community, including the environmental centre, the women's centre, and the history museum, mobilized local resident-volunteers, who were assigned to create courses on their topics of choice, such as gender, recycling and local history. Compared to SLG's courses, these courses became more focused and detailed, reflecting the specific interests of each centre. While SLG targeted a general audience, mostly the aging population, such emerging lifelong learning opportunities target specific audiences. One course created at the women's centre, for example, focused on childrearing, targeting young fathers. In fact, the demographics of Kawazoe have been changing since the early 2000 s as new high-rise tower apartments are constructed in the area and new young families join the local community. As its demography changes, the demand for new learning grows. However, SLG was unable to respond to this specific demand and I have observed local residents' interests obviously shifting from SLG to the newer learning opportunities that became available. Indeed, some of the SLG volunteers moved to other public facilities to support their course creation as well as to respond to the new learning demands in the community. The numbers of SLG course takers also declined, particularly in the past three years.

Thus, one of the government officers informed SLG management in April 2017 that its mission has now been completed. In the 1980 s, the municipal government began a discussion on the promotion of lifelong learning, and 
30 years later, lifelong learning is now fully rooted in Kawazoe. I would argue that the renovation of the building was a good excuse for the government to cease its funding. From conversations with government officials over the past couple of years, I had the sense that they were looking for the right time to do so. This seemed not to have been a sudden decision; it was planned in advance but not communicated effectively with SLG management.

Since the mission was deemed complete, there was unlikely to be additional funding from the government. I fully understand that this is the logic of public administration, in which funding is project based. Otherwise, a new proposal to the municipal government from SLG or vice versa would be expected. However, SLG had not produced any new proposals or even predicted future developments to the government. Nor had it taken the formal initiative to lead community learning at the next stage in a timely manner before SLG dissolved.

While I would argue that the government intentionally stepped in at this moment, there were a number of signals that change was imminent. For example, lifelong learning policymaking was originally overseen by the Education Board of the municipal government, while SLG funding was provided under the education categories of the municipal budget. However, in April 2017, lifelong learning policymaking moved to the community development department, which also oversees interactions with civil society organizations in the municipality. Thus, SLG is now being treated as one such civil society organization. No special consideration for funding would be made. Previously, because of the historically close relationship with the government mentioned earlier, SLG almost automatically received funding from the government. At the same time, lifelong learning policymaking was downgraded from the department level to the section level and is now overseen by just two people. Nevertheless, there was no active engagement with these structural changes from the SLG side.

\section{Where Is SLG Heading?}

'Mission completed' - Most SLG people agreed with this comment by the government official. In fact, the head of SLG recently wrote in the in-house newsletter that '[o]ur ship is now full of cargo. We get off on the shore, drop the cargo and organize it.' When I enquired what he actually meant by this, he told me that we are moving to the next stage: 'SLG has been providing lifelong learning opportunities to a very broad audience. We are like a department store for lifelong learning. The recent learning activities 
could be more tailored. Times have changed.' Devolution was a fashion and it was successful at delivering social services under neoliberal politics, but what is next?

SLG dissolved in March 2018. People at my field site are now considering its next move, and as an action-minded researcher, I am part of this discussion. One current argument at SLG is whether to develop courses that could compete with other lifelong learning providers as described above. To this end, an area studies course has been created, or what I would call Kawazoe studies - a comprehensive area studies subject that studies local history, culture and people's lives, combined with classroom lectures and field visits in traditional downtown Tokyo. This course would be expandable in the future since SLG foresees a continuing intellectual demand on the course. The numbers enrolling in Kawazoe studies courses is solid and the head of SLG believes that it can propose Kawazoe studies to the government to secure further funding. Kawazoe studies is a core part of the community-oriented lifelong learning that SLG has pursued. Not limited to local residents, such a course might draw in a new audience, including tourists coming to the Tokyo Olympics/Paralympics in 2020.

Another issue raised by SLG was that the organizational form - as an $\mathrm{NPO}$ - is no longer an effective tool for materializing citizens' interests in public affairs. SLG people realized that while such an organizational form might effectively facilitate the practice of a neoliberal state, it would not be conducive to citizen-oriented activities. Too many documents need to be submitted to the government every year, which accounts for SLG's hiring of 20 administrative staff to complete these documents, in addition to their regular business. Instead, another form, such as ippan shadan höjin (general incorporated associations), seems to represent another potential tool to extend their interest. ${ }^{1}$ The major difference between NPOs and general incorporated associations is the simplification of administrative work for the latter. For example, to establish a general incorporated association, at least two people jointly craft teikan, or the articles of incorporation, and the notary office simply certifies those articles together with the registration fee of

1 The establishment of general incorporated associations is part of the reform of public interest corporations (PICs, kōeki hōjin). Under the old Civil Code, article 34, PICs are required to apply to be converted to one of six types of newly enacted incorporated organizations: zaidan höjin (public interest incorporated foundations), shadan höjin (public interest incorporated associations), ippan zaidan hōjin (general incorporated foundations), ippan shadan hōjin (general incorporated associations), kōeki zaidan höjin (public interest incorporated foundations), and kōeki shadan hōjin (public interest incorporated associations). See http://www.koueki-houjin. net/shadan/ and http://www.jfc.or.jp/eng/introduction/ (10 February 2018). 
112,000 yen (US\$1,000). This registration takes one to four weeks to complete and no other procedure is required. Meanwhile, for NPOs, the Cabinet Office or prefectural governments certify the articles of incorporation with no registration fee, but registration takes five to six months to complete. Following the incorporation, they are supervised by the Cabinet Office or prefectural government, and are required to submit annual reports. Meanwhile, there are no such requirements for general incorporated associations to submit documents to the government. Lastly, NPOs are limited to 20 designated areas of activity, which often limits SLG's activities. SLG was registered in four areas: contributing to informal education, community development, arts and sports, and information society. There are other areas in which SLG could be active, but committing to different areas, including community safety, children's welfare, or occupational training, is illegal under the NPO Law, which lacks and sometimes limits the imagination regarding new course creation at SLG. The 1998 NPO Law was itself problematic on some points, as I have already pointed out (Ogawa 2009b: 159-16o). Meanwhile, the Act of the General Incorporated Associations does not designate any specific areas of activity. Citizens freely choose their own activities. Thus, ippan shadan hojjin seems the most citizen-friendly among these public interest entities.

\section{Conclusion}

My research at SLG provides an important case study for considering the relationship between the state and civil society in contemporary Japan. To situate this chapter within the current discourse of third sector research, it can be seen that neoliberalism created a space for grassroots voices through such practices as co-production. Amongst Japanese NPOs, SLG is a leading case because it has been well tailored to provide and innovate for new social needs; as a result, it has created a rich diversity of enabling and locally embedded social services (cf. Table 1 in Evers 2009: 246). Further, SLG volunteers have tapped into their 'entrepreneurial selves.' Armed with what I called 'civic knowledge' (Ogawa 2015: 78), I believe they have been well empowered as independent, active citizens.

SLG was indeed established as part of local efforts to delegate power to citizens in a participatory governance structure for a pluralistic democracy. Thus, the civil society discussion should not be limited to issues of strengthening third sector-based service provision, as recent research has focused more on gains in civility and civicness (cf. Evers 2013: 158; Evers 2009). In 
this sense, I understand SLG volunteers to comprise what Wagner (2012: 321) calls 'civic volunteers' - that is, volunteers are no longer a means to an end, but an end in itself, by realizing in their daily lives as citizens the organizational mission they serve.

Meanwhile, however, power has not decentralized sufficiently. The practice of co-production was expected to change the power structure. When NPOs entered Japanese society, my memory is that people expected state-held power to be decentralized towards local people, active citizens and communities. However, neither Japanese NPOs, nor the form of governance since the late 1990s, represent a decline in state power as they are, in fact, mostly instituted and controlled by the state, and the state has retained its power and resources, most notably over money. At SLG, decision-making, in particular, strategies for innovation or long-term planning, was indeed always top-down; it came from the municipal government, although detailed planning, such as course creation, was mostly conducted by local-resident volunteers. As Montgomery (2016: 1993) points out, many civil society actors find themselves enmeshed within forms of governance that force them to compete in order to be efficient service delivery providers that play by the rules of the neoliberal game. He also points out that despite neoliberalism's claims being articulated under the rubric of participation, its outcomes will only serve to entrench the existing vertical distribution of power in society (Montgomery 2016: 1997). The case of SLG presents the internal, complex dynamics of power between the state and civil society, which directly reflects this neoliberal ideology.

Those involved in SLG - that is, its local residents-volunteers - are stepping onto the new stage. Montgomery (2016) calls the style of governance used by SLG 'technocratic governance' with its neoliberal foundations, as the state mobilizes the technologies of governance to reduce the space for political dissent. Meanwhile, the new paradigm, which he calls the 'democratic paradigm,' sees social innovation as a tool to politicize the very space that neoliberals have sought to depoliticize, challenging the vertical power distribution and seeking to replace it with horizontal alternatives. I observe that SLG is now in transition to the next 'democratic paradigm.'

After eighteen years, SLG has now begun actual bottom-up mobilization for much better social services delivery and social commitment to the local community. Instead of this being simply the end, however, I observe that former SLG people actually have a chance to empower themselves through co-production activities with the municipal government. They are starting to take the initiative in providing necessary services for their own community 
in another organizational form. For the moment, however, they are unsure about collaboration with the government since they do not feel the necessity to do so. They can provide their own community-oriented lifelong learning programme, and in the future, they might include the municipal government if they deem it necessary to do so. The current action reflects upon their persistent concerns regarding how civil society organizations should be, and they should collaborate with the government. Based on the experiences over the past two decades, their strong belief is that civil society should not be manufactured by the state, and citizens should be independent of the government. Civil society is an arena where grassroots people have access to public affairs, and both stakeholders - citizens and the state - should take equal positions to make democracy sustainable. SLG was a successful case of a government project. However, as a civil society project, it failed.

Their new activity will enrich the Japanese civil society landscape by adding a new case study and might lead to another effective method for service delivery that we need to consider. The development of SLG that is now underway may be situated within a much larger picture of the changes in relations between the state and civil society under the shift in the political regime from neoliberalism to 'post-neoliberalism'2 (e.g. Christensen and Laegreid 2008; Torfing and Triantafillou 2013). I will continue to watch these new developments with interest.

\section{References}

Alford, John. 2002. 'Why Do Public Sector Clients Co-Produce? Towards a Contingency Theory.' Administration \& Society, 34 (1): 32-56.

Alford, John. 2009. Engaging Public Sector Clients: From Service Delivery to CoProduction. New York: Palgrave Macmillan.

Alford, John; Sophie Yates. 2016. 'Co-Production of Public Services in Australia:

The Roles of Government Organisations and Co-Producers.' Australian Journal of Public Administration, 75 (2): 159-175.

Asahi Shimbun. 2009. 'Kanmin “Kyodo” he Shiko' [Exploring 'collaboration' between the public and the private]. 30 January.

2 This is an emerging term as some claim new public management is dead (Dunleavy et al. 2006) and has been replaced by various alternatives, including post-NPM, 'new public governance' (Osborne 2010) and the 'neo-Weberian state' (Lynn 2008; Pollitt and Bouckaert 2011). One of the strong criticisms in post-NPM scholarship concerns the strong focus on output efficiency, which encourages disregarding the importance of democratic values and equity. 
Brenner, Neil; Nik Theodore. 2002. 'Cities and Geographies of "Actually Existing Neoliberalism."' Spaces of Neoliberalism: Urban Restructuring in North America and Western Europe. Neil Brenner; Nik Theodore (eds). Malden: Blackwell, pp. 1-32.

Bruce, Ian; Celine Chew. 2011. 'Debate: The Marketization of Voluntary Sector.' Public Money and Management, 31 (3): 155-157.

Burchell, Graham. 1996. 'Liberal Government and Techniques of the Self.' Foucault and Political Reason: Liberalism, Neo-liberalism and Rationalities of Government. Andrew Barry; Thomas Osborne; Nikolas Rose (eds). London: UCL Press, pp. 19-33. CAO. 2018. NPO no Kazu [Number of NPOs]. Cabinet Office. https://www.npohomepage.go.jp/about/toukei-info/ninshou-seni (10 February 2018).

Christensen, Tom; Per Laegreid. 2008. 'NPM and Beyond: Structure, Culture, and Demography.' International Review of Administrative Sciences, 78 (2): 209-216. Cohen, Jean L. 1999. 'American Civil Society Talk.' Civil Society, Democracy and Civic Renewal. Robert Fullinwider (ed.). Lanham: Rowman \& Littlefield, pp. 55-85.

Dunleavy, Patrick; Helen Margettts; Simon Bastow; Jane Tinkler. 20o6. 'New Public Management Is Dead - Long Live Digital-Era Governance.' Journal of Public Administration Research and Theory, 16 (3): 467-494.

Durose, Catherine; Liz Richardson (eds). 2016. Designing Public Policy for CoProduction: Theory, Practice and Change. Bristol: Policy Press.

Evers, Adalbert. 2009. 'Civicness and Civility: Their Meanings for Social Services.' Voluntas: International Journal of Voluntary and Nonprofit Organizations, 20 (3): 239-259.

Evers, Adalbert. 2013. 'The Concept of "Civil Society": Different Understandings and Their Implications for Third Sector Policies.' Voluntary Sector Review, 4 (2): 149-164.

Goldman, Michael. 2005. Imperial Nature: The World Bank and Struggles for Social Justice in the Age of Globalization. New Haven: Yale University Press.

Greenwood, Davydd J.; Morten Levin. 1998. Introduction to Action Research. Thousand Oaks: Sage.

Haddad, Mary Alice. 2011. 'A State-in-Society Approach to the Nonprofit Sector: Welfare Services in Japan.' Voluntas: International Journal of Voluntary and Nonprofit Organizations, 22 (1): 26-47.

Handler, Joel F. 1996. Down from Bureaucracy: The Ambiguity of Privatization and Empowerment. Princeton: Princeton University Press.

Howlett, Michael; Anka Kekez; Ora-ORN Poocharoen. 2017. 'Understanding CoProduction as a Policy Tool: Integrating New Public Governance and Comparative Policy Theory.' Journal of Comparative Policy Analysis, 19 (5): 487-501.

Jun, Jong S.; Hiromi Muto. 1995. 'The Hidden Dimension of Japanese Administration: Culture and Its Impact.' Public Administration Review, 55 (2): 125-134. 
Kawanobe, Satoshi. 1994. 'Lifelong Learning in Japan.' International Review of Education, 40 (6): 485-494.

Lam, Busayawan; Andy Dearden. 2015. 'Enhancing Service Development and Service Delivery through Co-Design.' Voluntary Sector Review, 6 (1): 61-80.

Leadbeater, Charles; Hilary Cottam. 2007. 'The User Generated State: Public Services 2.o.' Public Matters: The Renewal of the Public Realm. Patrick Diamond (ed.). London: Politicos, pp. 95-114.

Lynn, Laurence E. 2008. 'What Is a Neo-Weberian State? Reflections on a Concept and Its Implications.' Journal of Public Administration and Policy, 1 (2): 17-30.

Montgomery, Tom. 2016. 'Are Social Innovation Paradigms Incommensurable?' Voluntas: International Journal of Voluntary and Nonprofit Organizations, 27 (5): 1979-200o.

Ogawa, Akihiro. 2004. 'Invited by the State: Institutionalizing Volunteer Subjectivity in Contemporary Japan.' Asian Anthropology, 3 (1): 71-96.

Ogawa, Akihiro. 2006. 'Initiating Change: Doing Action Research in Japan.' Dispatches from the Field: Neophyte Ethnographers in a Changing World. Andrew Gardner; David M. Hoffman (eds). Long Grove: Waveland Press, pp. 207-221.

Ogawa, Akihiro. 2008. 'Induced” Voluntarism: A New Role for Schools?' The Demographic Challenge: A Handbook about Japan. Florian Coulmas; Harald Conrad; Annette Schad-Seifert; Gabriele Vogt (eds). Leiden: Brill, pp. 721-732.

Ogawa, Akihiro. 2009a. 'The Construction of Citizenship through Volunteering: The Case of Lifelong Learning.' Japan's Politics and Economy: Perspectives on Change. Patricia A. Nelson; Marie Söderberg (eds). London: Routledge, pp. 86-98. Ogawa, Akihiro. 200gb. The Failure of Civil Society? The Third Sector and the State in Contemporary Japan. Albany: State University of New York Press.

Ogawa, Akihiro. 2009c. 'Japan's New Lifelong Learning Policy: Exploring Lessons from the European Knowledge Economy.' International Journal of Lifelong Education, 28 (5): 601-614.

Ogawa, Akihiro. 2012. 'Risk Management by a Neoliberal State: Construction of New Knowledge through Lifelong Learning in Japan.' Discourse: Studies in the Cultural Politics of Education, 34 (1): 132-144.

Ogawa, Akihiro. 2013. 'Lifelong Learning in Tokyo: A Satisfying Engagement with Action Research in Japan.' Anthropology in Action:Journal of Applied Anthropology in Policy and Practice, 20 (2): 46-57.

Ogawa, Akihiro. 2015. Lifelong Learning in NeoliberalJapan: Risk, Knowledge, and Community. Albany: State University of New York Press.

Osborne, Stephen P. (ed.). 2010. The New Public Governance: Emerging Perspectives on the Theory and Practice of Public Governance. London: Routledge.

Ostrom, Elinor. 1990. Governing the Commons: The Evolution of Institutions for Collective Action. Cambridge: Cambridge University Press. 
Ostrom, Elinor. 1996. 'Crossing the Great Divide: Coproduction, Synergy, and Development.' World Development, 24 (6): 1073-1087.

Ostrom, Elinor. 1999. 'Coping with Tragedies of the Commons.' Annual Review of Political Science, 2: 493-535.

Ostrom, Vincent. 1973. The Intellectual Crisis in American Public Administration. Tuscaloosa: University of Alabama Press.

Parks, Roger B.; Paula C. Baker; Larry Kiser; Ronald Oakerson; Elinor Ostrom; Vincent Ostrom; Stephen L. Percy; Martha B. Vandivort; Gordon P. Whitaker; Rick Wilson (eds). 1981. 'Consumers as Co-Producers of Public Services: Some Economic and Institutional Considerations.' Policy Studies Journal, 9 (7): 1001-1011. Peck, Jamie; Adam Tickell. 2002. 'Neoliberalizing Space.' Antipode, 34 (3): 452-472. Pekkanen, Robert. 200o. 'Japan's New Politics: The Case of the NPO Law.' Journal ofJapanese Studies, 26 (1):111-148.

Pestoff, Victor; Taco Brandsen. 2010. 'Public Governance and the Third Sector.' The New Public Governance. Stephan P. Osborne (ed.). London: Routledge, pp. 223-237. Pestoff, Victor; Yayoi Saito; Johan Vamstad (eds). 2012. New Public Governance, the Third Sector, and Co-Production. London: Routledge.

Peters, Michael A. 2001. 'Education, Enterprise Culture and the Entrepreneurial Self: A Foucauldian Perspective.' Journal of Education Enquiry, 2 (2): 58-71.

Pharr, Susan J. 2003. 'Conclusion: Targeting by an Activist State: Japan as a Civil Society Model.' The State of Civil Society in Japan. Frank J. Schwartz; Susan J. Pharr (eds). Cambridge: Cambridge University Press, pp. 316-336.

Pollitt, Christopher; Geert Bouckaert. 2011. Public Management Reform: A Comparative Analysis: New Public Management, Governance, and the Neo-Weberian State. Oxford: Oxford University Press.

Salamon, Lester M.; Helmut K. Anheier. 1998. 'Social Origins of Civil Society: Explaining the Nonprofit Sector Cross-nationally.' Voluntas: International Journal of Voluntary and Nonprofit Organizations, 9 (3): 213-248.

Salamon, Lester M.; S. Wojciech Sokolowski. 2016. 'Beyond Nonprofits: ReConceptualizing the Third Sector.' Voluntas: International Journal of Voluntary and Nonprofit Organizations, 27 (4): 1515-1545.

SWG. 1990. Koryū, Sōzō, Mirai [Interactions, creation, and future]. Sumida Ward Government. Tōkyō: SWG.

SWG. 1999a. Kumin niyoru Shōgai Gakuhsū Soshiki no Arikata ni tsuite [On creating an organization promoting lifelong learning by local residents]. Sumida Ward Government. Tōkyō: SWG.

SWG. 1999b. Kumin niyoru Shōgai Gakushū Soshiki no Hōjinka ni mukete [Towards incorporating resident-based lifelong learning organization by local residents]. Sumida Ward Government. Tōkyō: SWG. 
Torfing, Jacob; Peter Triantafillou. 2013. 'What's in a Name? Grasping New Public Governance as a Political-Administrative System.' International Review of Public Administration, 18 (2): 9-25.

Wagner, Antonin. 2012. "Third Sector" and/or "Civil Society”: A Critical Discourse about Scholarship Relating to Intermediate Organizations.' Voluntary Sector Review, 3 (3): 299-328.

Westney, D. Eleanor. 1987. Imitation and Innovation: The Transfer of Western Organizational Patterns to Meiji Japan. Cambridge, MA: Harvard University Press. Yamamoto, Kiyoshi. 2009. 'Public Sector Management Reform in Japan.' International Handbook of Public Management Reform. Shaun Goldfinch; Joe L. Wallis (eds). Cheltenham: Edward Elgar, pp. 336-350.

\section{About the Author}

Akiniro Ogawa is Professor in Japanese Studies at the University of Melbourne, Australia. His research interests include civil society, social movements, politics, peace strategies, security, as well as issues facing education and energy. His research is international in scope and comparative in focus. He is currently leading the Asian Civil Society Research Network. He is editor of Routledge Handbook of Civil Society in Asia (Routledge, 2017). He is also the author of The Failure of Civil Society? The Third Sector and the State in Contemporary Japan (SUNY Press, 2009), which won the Japan NPO Research Association Book Award in 2010, and Lifelong Learning in Neoliberal Japan: Risk, Knowledge, and Community (SUNY Press, 2015). 



\title{
10 Changing Patterns of South Korean Social Movements, 196os-2010s
}

\author{
Testimony, Firebombs, Lawsuit and Candlelight ${ }^{1}$ \\ Jin-Wook Shin
}

\begin{abstract}
This chapter examines the changing patterns of South Korean social movements from the 1960 s to the 2010 s in terms of their constituents, their communication and mobilization structure, and the way in which they influenced institutional politics. Some long-term trends that require particular attention include: the extension of participants from cultural elites and organized activists to a huge number of ordinary citizens; the shift of the structure of the field of social movements from the inter-organizational ties of committed activists to highly decentralized networks of organizations, communities and individuals; and a change in the major way of affecting institutional politics from the moralized acts of cultural elites through strategic actions by movement organizations to large-scale protests led by networked citizens directly pressuring the actors of institutional politics.
\end{abstract}

Keywords: democratization, civil society, social movements, protest, contentious

This chapter examines the changing patterns of South Korean social movements from the 1960 s to the 2010 s in terms of their constituents, issues, communication and mobilization structure, and the way in which they

1 This work was supported by the Ministry of Education of the Republic of Korea and the National Research Foundation of Korea (NRF-2018S1A3A2075609).

Chiavacci, David, Simona Grano, and Julia Obinger (eds), Civil Society and the State in Democratic East Asia: Between Entanglement and Contention in Post High Growth. Amsterdam, Amsterdam University Press 2020 DOI: 10.5117/ 9789463723930_CH10 
influenced institutional politics. It also traces the historical processes in which new elements of culture and agency are born, develop and combine with pre-existing elements in a particular way to generate new configurations. It is impossible to explore many big topics in social movement research for various movement sectors over a half-century period. Of course, this chapter does not aim to do so. The intent of this chapter is much more moderate, namely, to reconstruct changes in the typical patterns of South Korean social movements based on prior studies and to ask what long-term trends these changes show and what their theoretical and political meanings will be.

The four words in the subtitle of this chapter - 'testimony,' 'firebombs,' 'lawsuit,' and 'candlelight' - respectively symbolize the most salient features of the period from the 1960 s to the 1970 , from 1980 to the late 1980 s, from the 1990 s to the mid-200os, and from the early 2000 s to the 2010s. They may be understood in terms of what social movement studies have called 'collective action repertoires,' but in this chapter they also refer to the key actors in each period and the particular way in which they affected institutional politics. In the historical context of South Korea, the four symbolic words represent (1) moral accusation by cultural elites committed to social problems, (2) the disruptive protest actions of organized radical groups against dictatorship, (3) the reform movements led by professionalized social movement organizations after the transition to democracy, and (4) the politics of influence through decentralized contentious actions by networked citizens in the twenty-first century.

South Korea is an interesting case for tracing the historical changes in social movements and their relationship to institutional politics. There are three reasons for this. First, South Korea has experienced rapid development and radical changes in political, economic and technological aspects. Accordingly, the subjects of social movements, their mode of action and the source of influence have also experienced distinct changes within a short period of time. Therefore, the South Korean case is appropriate to observe dynamic changes in social movements during the near past. Second, in South Korea, democratization movements played a key role in the resistance to and the breakdown of the authoritarian regime. Moreover, civil society organizations contributed greatly to the reform process since the introduction of democracy in 1987. Therefore, there are many salient examples in South Korean contemporary history for analysing the changes in the way social movements influenced institutional politics. Third, in the twenty-first century, a new form of spontaneous, decentralized and large-scale action of citizens occurred many times in South Korea and often had a grave impact 
on the government policies and power relations in party politics. Therefore, a historical consideration of the case of South Korea will help understand the specific characteristics of the most recent trends in social movements and their implications from a global perspective.

Methodologically, the primary interest of this chapter is to describe the most characteristic features of each historical period in the form of ideal types. As is well known, such an ideal type is an ideational construct that highlights, exaggerates, and idealizes certain aspects of a much more complex reality. However, following Simmel (1992: 50-51), this chapter attaches more importance to reconstructing the typical aspects of concrete historical and cultural reality than pursuing conceptual abstractions (like Max Weber). Accordingly, the following pages will not simply present distinctive features of each period one after another, but will try to provide an analysis of the processes and configuration in which the new elements that are specific to the later periods are combined with the traditions in a particular way and the old elements that appeared to have vanished reappear in history and are connected with the new dominant trends.

This chapter will first deal with the period from the early 1960 s to the late 1980 s under military dictatorship, then the period from the 1990s to the mid-2ooos under a democratic regime, and, finally, the period from the early 2000 s to the late 2010 s in which the latest developments have happened. Conclusively, the notable long-term trends in the historical changes in South Korean social movements and their implications will be discussed.

\section{Protest Movements under Dictatorship}

\section{The Emergence of Civil Society from a History of Violence}

In 1945, Korea was liberated from the occupation of Japan (1910-1945) and restored its national sovereignty. Since the Republic of Korea was established in the southern area of the Korean Peninsula in 1948, South Korea has been under authoritarian rule for nearly 40 years until the end of dictatorship and the introduction of democracy in 1987. The South Korean people, who had already experienced the rule of the Japanese military-police complex for more than 30 years, continued to live in a history dominated by state violence. The Korean War (1950-1953), the military confrontations under the Cold War order, the two military coups in 1961 and 1979, and the military massacre of the democratization movement in 1980 are merely some among the most widely known events. Under military dictatorship, kidnapping, 
torture, confinement, execution, surveillance and threats were not exceptional events but a constant and essential part of daily life.

Despite the long dominance of state violence, the political dynamics of South Korea is not characterized by the sorrow of the victims only, but also by the clash between a 'strong state and [a] contentious society' (Koo 1993). In particular, during the four decades from the establishment of the Republic of Korea to the breakdown of the dictatorship, the antagonism between the authoritarian ruling elites and the resistant civil society was one of the biggest cleavages in South Korean politics and society. The civil society of South Korea was born as a response to the authoritarian-bureaucratic state and thus had a resistant character from the beginning.

The April Revolution of 1960 - when hundreds of thousands of people nationwide participated and protested against the corruption and abuse of power of the Rhee Syng-Man regime (1948-1960) - achieved the resignation and exile of Rhee. This event was not only the first case of realizing vertical accountability against political power that had lost its legitimacy, but it also established the typical pattern of South Korean citizen politics in which a concentrated and large-scale citizen protest exerted a strong influence upon state power. Nevertheless, the Second Republic, which was established by a democratic election after the April Revolution, was soon collapsed by a military coup led by General Park Chung-Hee.

The coup of 1961, which launched a long period of dictatorship in South Korea, was not an accidental event, but rather was prepared with a high probability by the nation's previous history. What Moore (1966) saw as a constellation vulnerable to a fascist path to modernization existed in South Korea. The military not only grew in size during the Korean War, but also belonged to the first to acquire modern bureaucracy, technology and discipline. The bourgeoisie, on the other hand, was neither economically nor politically independent, and there was no radical peasantry. Against this historical background, the military rulers could greatly repress citizens' basic rights and political-cultural pluralism. They suppressed the political expression and participation of the citizens, restricted the actions of the opposition parties and frequently dispatched police to labour disputes. Above all, comprehensive monitoring and terror by the Korean Central Intelligence Agency (KCIA) was the most terrible aspect of the military dictatorship. Although in South Korea, unlike in Taiwan under the Kuomintang dictatorship, party competition and regular elections were not denied in principle, everyday control by the state power and political intervention in the electoral process made the operation of the institutions of democratic pluralism virtually impossible. 
However, such state violence did not totally suppress all freedom. An independent civil society has grown steadily and in constant confrontation with the authoritarian rulers and their allies within society since the 1960 . What made such a development possible was above all the democratization movements, but a great number of groups that wanted to join and act together beyond the limits allowed by the state contributed to the gradual expansion of civil society. They included religious groups that worked for industrial workers and the urban poor; student movement organizations and communities at the university; autonomous labour movements that have grown since the early 1970s; and the scholars, artists, writers and journalists who played a role in diverse movement sectors. These civil society organizations and their participants became influential actors in Korean politics and society after the collapse of the dictatorship.

\section{Politics of Testimony by Cultural Elites}

In South Korea, violent revolts and sporadic resistance have been present since at least the 1950s, but from the 1960 s the protest movement made clear its identity and goals by turning into a democratization movement. Paradoxically, under authoritarian rule, the collective action repertoires typical to democratic nations (such as public assemblies, street rallies and press conferences) have become increasingly dominant in South Korea. Throughout the 196os and 1970s independent civil society forces emerged everywhere the complete control of state violence has failed.

During the Park Chung-Hee regime (1961-1979), several national-level social movement organizations began to grow. In the mid-196os, the first nationwide student movement organization that emerged was led by Christian students. More importantly, organizations affiliated with religious institutions (such as the Gatoliknodongcheongnyeonhoe (Catholic Youth Workers, JOC), the Protestant Dosisaneopseongyohoe (Urban Industrial Mission, UIM), the Christian Academy, and the YMCA) extended their activities to provide cultural, educational or legal support for workers, peasants and the urban poor. Many of them refrained from making direct political challenges, but their existence had significant political implications and consequences. In particular, they were increasingly monitored and oppressed by the authoritarian regime as they have spread 'dangerous' ideas of universal human dignity and equality.

In the early 1970s, Park's one-man dictatorship was strengthened after the enactment of the so-called Yushin [Revitalizing] Constitution in 1972. What is interesting is that the democratization movement became more active and 
politicized as the repression of human rights and civil liberties became harsher. In contrast to the case of Taiwan, in which middle-class activists with moderate goals played a key role during the period before the end of dictatorship (Ho 2010; Hsiao 1996), the reinforcement of political violence in South Korea during the 1970s resulted in the extension of politicized protesters into a wide range of civil society groups which have focused on charity and gradual social reform.

To explain why the enhanced repression in Korea did not lead to the decline, but rather to the extension, of protest is well beyond the scope of this chapter. What can be said in the present context is that the shared values and organizational collaboration between various movement sectors seem to have been of great significance in maintaining the movements. In the mid-1970s, the oppositional politicians and the leaders of student movements formed the Mincheonghakryeon (Alliance of Democratic Youth and Students), a nationwide solidarity organization for resistance against the dictatorship, and theorized the sammin (three min) ideology declaring political democracy (minju), social justice and equality (minjung) and national independence and inter-Korean reconciliation (minjok) as the highest goals to accomplish. Meanwhile, the religious institutions, too, raised their voices, advocating democracy and human rights. In particular, the Christians - Catholic or Evangelical - contributed hugely to the political and moral influence of democratization movements in general (Chang 1998; Chang and Kim 2007; Kang 2000). For example, the activities of the Jeonguiguhyeonsajedan (Catholic Priests Association for Justice), the Cheonjugyoingweonuiwonhoe (Catholic Human Rights Committee) and the Gidokgyogyohoehyeopuihoe (National Council of Christian Churches in Korea) put a considerable political burden on the dictatorship.

Another important event of the 1970s was the resurgence of the labour movement, which had been nearly destroyed in the course of the Korean War and the militarization of Korean politics. After the suicide by self-immolation of a young worker, Jeon Tae-Il, in 1970, an independent labour movement, which will eventually be called Minjunodongundong (Democratic Trade Union Movement), began to establish independent trade unions, defend workers' rights and oppose the government's repressive practices. The resistance took place primarily in the light-industry manufacturing sectors (such as textiles, clothing and electronics), which at that time had an important strategic position in South Korea's industrialization. Workers who worked in such industries - mostly young female workers from rural areas - developed a sense of solidarity and collective identity by sharing the pain of hard work, economic hardship and abuse in the workplace (Koo 2001; Nam 2000; Yoon 2001). 
Such changes in the area of religion, universities, politics and factories need to be properly evaluated when we explore the social foundations of South Korean civil society and democracy. Many leaders of the democratization movement of the 1980 s, as well as the key symbolic figures in today's South Korean democracy, have the roots in this period. Despite their significance, social movement organizations in the 1970s were nothing but small and scattered oases within the political desert of South Korean society. It took a long time before they had enough structural and associative power (Wright 2000) to threaten the regime through collective action.

Under such conditions, the democratization movements and other independent civil society forces of the 1960s and 1970s relied heavily on loose networks and declarative acts of prominent dissidents, including oppositional political leaders and cultural elites. Movement organizations gradually accumulated local changes, but their political and social influence at the national level could be amplified only by the act of declarations by a small number of cultural elites, such as religious leaders, professors, teachers, journalists and artists. For that reason, the violence committed by the military and the secret police was often targeted at the leaders with moral influence.

However, the state terror resulted in a paradoxical effect of creating the sacred symbols of innocence and conscience by making the victim a martyr and a prophet. Yeoksa-wa-jeungoen (History and testimony), the title of a book written by Ahn Byung-Mu (1972), one of the theologians who established Minjung theology in South Korea (comparable to the Liberation theology of Latin America), identified the enormous power of the act of testimony in an era of repression, concealment and distortion. However, the power of the testimony of history was soon relativized by the advent of a new history - the Gwangju massacre in May 1980.

\section{Massacre and the Radicalization of Protest Movements}

In the late 1970s, as resistance against the dictatorship spread across the country, President Park Chung-Hee seriously considered using violent repression by mobilizing the military. Kim Jae-gyu, the then-chief of the KCIA, opposed it, but when he failed to dissuade Park, he assassinated the president in October 1979. After the death of Park, expectations of a restoration of democracy grew, but the so-called New Army Group (Singunbu) led by General Chun Doo-Hwan and Roh Tae-Woo, who had been supported by Park Chung-Hee during the 1970s, staged a coup in December. In the spring of 1980, massive protests called the Seoul Spring occurred and a series of 
rallies demanding democracy continued nationwide. To put down the challenges, Chun Doo-Hwan and Roh Tae-Woo mobilized the army and the Special Forces in Gwangju, a capital city in the south-western region of South Korea. As a result, hundreds of people were killed either during the military operation or as a consequence of the wounds and trauma caused by the operation, which is called the Gwangju massacre.

The massacre of 1980 and the defeat of democracy taught a serious lesson for South Korean civil society: The 'truth' without the organized power of the people acting together was helpless against the machine gun and the bayonet of the state, and its price was the blood of innocent humans. Documents of the then-protest groups show that they became increasingly convinced that what they needed was the power of the organized people in order to clarify the truth of Gwangju, in order not to repeat the tragedy of Gwangju, and, ultimately, in order to end the rule of violence.

Under the Chun Doo-Hwan regime (1980-1987), the ideological radicalization of the resistant groups and the strengthening of their organizational power have progressed rapidly. Attempts have been made to expand and consolidate popular organizations, and anti-fascist, anti-capitalist and anti-imperialist ideas have spread, particularly among university student activists. They systematically and strategically mobilized the action units which were organized hierarchically from the national level through the regional and university level to the individual departments and secret associations at each university.

The activities of the student movements in the 1980s were not always provocative. Given the fact that intelligence agents, police and their collaborators were ubiquitous, an impetuous collective action could be a fatal error exposing organizations and sacrificing activists. However, once they decided to act, the act was usually highly disruptive. In an environment in which no political expression of dissent was tolerated, students used sudden assemblies, demonstrations and occupations as the means of action to inform the people and the world of the voice of resistance. They were also armed with firebombs and iron pipes to extend the duration of demonstration once the police arrived to stop them.

It is true that violent actions can be detrimental to social movements when they are negatively framed by mass media (Gamson 1990), but, under certain circumstances, disruptive actions can be effective when the pains and claims of the powerless are so systematically repressed that they are not delivered to the public (Piven and Cloward 1977). South Korean student activists wanted to bring out the truth of the massacre and the voices against dictatorship to the ordinary citizens of their country and to the outside 
world, but the media was being strictly controlled by the state. They chose to attract attention from the public and the foreign media by highly provocative actions. So, the firebombs became the symbol of the South Korean student movements of the 1980 s.

The transition of South Korean democratization movements from the pastors and intellectuals of the early days to the young and much more radical figures of student fighters throwing firebombs and occupying government buildings was a drastic change. However, it would be a mistake to think that the subjects of the democratization movements of the 1970 s were simply replaced by the new generations. In reality, they both continued their fight alongside each other and were closely connected to each other organizationally and personally. The Minjuheonbeopjaengchui Gukminundongbonbu (Alliance of People's Movements for a Democratic Constitution), a coalition organization that played a leading role in the successful democratic uprising in June 1987, was launched at historic Myeongdong Cathedral and was composed of respected spiritual leaders who led the resistance movements in the 196os and 1970s. Moral authority and political disruption met and amplified their power to go beyond the violence of the dictatorial state.

\section{Reform Movements after the End of Dictatorship}

\section{The Differentiation of Civil Society under Democracy}

In June 1987, a democratic uprising involving more than two million people nationwide took place. The scale of the protests was incomparably greater than that of 1979-1980, and above all, white-collar, middle-class citizens were at the forefront of resistance. Because of the unprecedented size and intensity of the protest, the military had to abandon their original plan to use violent repression like in Gwangju in 1980 to extend the regime and eventually promised to introduce a democratic system, including direct presidential election, in response to citizens' demands. It was the end of decades of dictatorship and the beginning of a protracted process of democratization in South Korea.

After the end of the authoritarian regime, the political opportunities of civil society organizations gradually expanded. The oppression of public authorities over the contentious claim making by civil society organizations was weakened. In addition, the attitudes of the institutional sectors such as the government, political parties, enterprises, and the press became more open and cooperative to communication with civil society. Meanwhile, civil 
society organizations participated in advisory activities for the government, played a leading role in the legislation in the National Assembly, encouraged corporate social responsibility, and initiated cooperation with the mainstream media. This kind of change was particularly remarkable during the period from 1998 to 2007 under President Kim Dae-Jung, a symbolic figure of the democratization movements in Asia, and President Roh Moo-Hyun, a former human rights lawyer.

However, even after the democratic transition, the expansion of civil liberties and rights was limited and selective. Moreover, the confrontational oppression-resistance relationship between the state and civil society did not disappear. In the first free election of 1987 , Roh Tae-Woo, one of the military bosses, was elected as president. The first democratically elected government showed a change both in domestic and foreign policies, but soon reinforced the suppression of political opposition and labour disputes. Although Kim Young-Sam, a former democratic dissident, was elected as the first civilian president in 1992, his election victory was a consequence of the much criticized coalition of his Unified Democratic Party with the Democratic Justice Party, which was a successor party organized by the former dictators.

In these limited and ambiguous democratization processes, the political environment of social movements varied greatly, depending on the issues and the movement sectors. The freedom of expression, of the press, of thought and association of the middle classes expanded considerably, but the organization and collective action of the lower classes were systematically controlled. Class-based movements, such as the labour and peasant movements, were still under surveillance and suppression by state power and corporations. In response to this situation, trade unions that inherited the tradition of the Democratic Trade Union Movement of the 1970s and 1980 s formed the Jeonnohyeop (National Council of Trade Unions) in 1990 to continue a militant trade union movement. In 1995, the Minjunochong (Korean Confederation of Trade Unions), based upon the powerful trade unions of big conglomerates like Hyundai, was established.

It is true that the South Korean workers' organizations acted more frequently and radically than in other countries of East Asia during the 1990s (Liu 2005). However, the labour movements continued to decline after the late 199os. The unionization rates rose for a short period of time from 1987 to 1989, but after the Asian financial crisis in 1997, fell to less than $10 \%$ as the number of irregular workers increased and the labour market segmentation deepened. Organized workers could play a limited role in political and social reforms and had great difficulty in being recognized as representatives of 
the entire working class. Militant workers' struggles in South Korea were sometimes referred to as an example of 'social movement unionism,' but such a view may make a mistake of 'romanticizing' the more complex reality of the South Korean labour movements (Park 2007).

On the other side, a new wave of reform movements relying on more moderate and institutionalized means of action and seeking support from and the participation of a broader spectrum of citizens grew rapidly during the same period. Participants in these movements often referred to themselves as simin undong (citizens' movements) in a sense distinguished from minjung undong (class-based movements). The fact that the conceptual distinction between simin undong and minjung undong became increasingly popular in the first half of the 1990s was a sign showing that the South Korean social movements were rapidly differentiating under democracy. The differences that have remained latent under the big slogans such as 'democratization,' 'anti-dictatorship,' and 'anti-fascism' came to the surface. Such differences were embodied in different organizations and inter-organizational ties that shared the movement goals, problem definition, strategies and means of action.

The actual relationship between the differentiated sectors was, however, far more complex than the conceptual division. On the one hand, some citizens' movements ruled out class issues definitely and refused to cooperate with organizations with class-specific goals. In such a context, the distinction between 'legal, popular, and peaceful citizens' movements' versus 'illegal, radical, and violent class-oriented movements' served as a linguistic device for stigmatizing the class-based movements. Pastor Seo Kyung-Suk, who first presented this conceptual division in a systematic form, became a leader of New Rights in the 200os. On the other hand, many of those who founded and led progressive citizens' movements were participants in the democratization movement and the radical student movements of the 1980 , and they actively cooperated with workers' organizations throughout the 1990s (Kim 2006: 103-104). Progressive citizens' movements had a significant impact on national policy reforms in the area of economic, labour and social policies. Moreover, a number of local and community-based organizations for social services and support of socially disadvantaged people emerged in the name of citizens' movements.

\section{The Citizens' Movements: Their Influence and Its Dark Side}

The citizens' movements have been active in various fields of reform, including political democratization, economic reform, social welfare, environment, 
women, education, peace, human rights and consumer rights. Their activities in these sectors partially overlapped with those of other movement groups of the same or earlier period, which were not called 'citizens' movements.' Yet the citizens' movements had an orientation and identity to distinguish themselves from democratization movements during the authoritarian era and the minjung movements of the 1990s. First, in terms of the ideology of movements, they pursued solidarity in diversity, respecting the differences of movement ideologies within a broad consensus of values instead of requiring ideological homogeneity among the movement sectors and organizations. Second, in terms of the goals of movements, they emphasized concrete reform of law, institutions and practices, although they, too, emphasized the need for fundamental changes in social structure. Third, they would not directly defend particular class interests but sought broad support for reform by means of a kind of hegemonic strategy of connecting particular reform agendas with universalistic appeals to the 'common good' or the 'public good.'

The citizens' movements played a decisive role in a wide range of reform activity, including the monitoring of the government and the parliament; advancements in political institutions; economic democratization; protection of human rights; expansion of civil liberties; improvement in gender equality; and the introduction of environmental policy paradigms. In particular, organizations that had rich human, organizational and financial resources replaced many of the roles which are normally expected of government and political parties in a representative democracy. The South Korean political parties were lacking the ability to produce and legislate new policies under a democratic system because they could not develop properly during the long period of dictatorship. Thus, competent leaders of the citizens' movements and scholars, lawyers and members of other expert groups associated with the movement organizations greatly contributed to legal and institutional reforms in many sectors (Lee and Park 2009). In this sense, they performed a 'proxy representation' function, replacing the less developed party politics (Cho 2000: 286).

The significance of the citizens' movements in the overall reform processes after the end of dictatorship has to do with the tradition of strong commitment of South Korean civil society to national politics. In contrast to many Japanese NGOs focusing on local activities, for example, many civil society organizations in South Korea have been highly politicized and interested in influencing politics and policy at the national level (Lee and Arrington 2008). The major examples of the 1990 s citizens movements are the Gyeongsilryeon (Citizens' Coalition for Economic Justice), founded in 1989, 
and the Chamyeoyeondae (People's Solidarity for Participatory Democracy), founded in 1994. They grew into a 'comprehensive citizens' movement' (Cho 2000; Kim 2006), which had a very broad range of areas of activity, including economic, labour, welfare and political reform and the monitoring of administrative, legislative and judicial institutions. In addition, nationwide movement organizations concentrating on specific sectors, such as the Yeoseongdancheyeonhap (Korean Women's Association United), founded in 1987, and the Hwangyeongyeonhap (Korean Federation for Environmental Movements), founded in 1993, provided innovative ideas, knowledge and policy contents to the government, political parties and the media.

In terms of means of action, their activities centred on solving problems and providing realizable alternatives through institutionalized channels, such as the court, political parties, the government and the media. Although they also used conventional means of action, such as rallies and demonstrations, for putting public pressure on institutional actors, such campaigns as such were not of essential importance within their overall strategic scheme. In response to such changes in behaviour, the key actors of the movement have also changed. In addition to experienced leaders and fully employed activists of the movement organizations, members of expert groups, including lawyers, scholars, and employees of various non-profit research institutions, have played a crucial role. In contrast, most of the members and sympathizers of the movements normally contributed either by paying their dues, making donations or occasionally volunteering in the campaigns.

\section{The Institutionalization of Social Movements and Its Consequences}

The changes mentioned above imply that the institutionalization of social movements has been progressing in South Korea in many respects since the 1990s. Institutionalization of social movements has two aspects. If one is a growing recognition and acceptance of social movements by the institutional sectors of politics and society, the other is that the movement actors tend to resort to institutionally established routines. In South Korea since the 1990s, social movements have gradually gained recognition as a 'normal' component of society, while at the same time favouring institutionalized goals and means of action. These trends may be interpreted as an aspect of the tendency towards a 'social movement society' (Neidhardt and Rucht 1993; Meyer and Tarrow 1998b).

There were some typical ways of mobilizing institutional channels by the citizens' movements: raising issues and promoting alternatives through 
the support of friendly media; introducing new policies or reforming old institutions in cooperation with political parties and politicians in the parliament; and providing policy contents to the bureaucrats and putting pressure for acceptance, sometimes in consultation with high-ranked officials in the presidential office and the government ministries. The movement organizations often combined such constructive activities with offensives against the veto forces whom they blamed for being responsible for the problem and resisting the reform. For that aim, the essential means of action that has become increasingly important was the lawsuit. The citizens' organizations exploited the legal disputes to attract popular support and to draw responses from politicians while making an issue of various problems, such as corruption, abuse of power, dereliction of duty, irregularity and unconstitutionality.

The radical shift of action repertoires by the citizens' movements is evident, but it does not necessarily mean that the institutionalized action methods were always quantitatively dominant. According to Jung (2011) and Kim (2009a), the frequency of non-institutional protest events such as street demonstration increased during the period of the Kim Young-Sam government (1993-1998), declined under President Kim Dae-Jung (1998-2003), and rose again under the Roh Moo-Hyun government (2003-2008). Notwithstanding such ambiguities in the quantitative trends, it seems to be clear that the institutionalized means of action of the citizens' movement were the most effective in achieving important reforms at this time. Additionally, in many cases, popular actions (such as public assemblies, street rallies and signature campaigns) have eventually been linked to activities in and with the government, the parliament, the media and the courts.

However, the process of professionalization and institutionalization as described above did not only imply progress in social movements, but also caused considerable problems inside the movements and triggered new sorts of conflict. First, as the experienced activists and expert groups came to hold key positions in the movements, ordinary citizens became increasingly marginalized in the planning and performance of the movements. The fact that such processes of institutionalization involve both the aspect of inclusion and that of marginalization (Meyer and Tarrow 1998a: 21) became a source of the emergence of new dynamics of change. Second, as the progressive movement organizations, particularly the big ones, formed a reform alliance with the liberal regime since the late 199os, the citizens' trust in the civil society groups began to decline (Kim 2009b). While leaders of the citizens' movements often prioritized the achievement of reform by any means, the scepticism about their political independence has grown as 
many movement figures were appointed as high-ranking officials and played important roles in the policymaking of the government (Kim 2006: 118).

Third, under the liberal regime, the so-called New Right movements emerged. Anti-communist right-wing groups became active, leading to the intensification of ideological and political confrontation 'within' civil society in the place of the conventional cleavage of 'the state versus civil society.' The right-wing groups promulgated diverse ideologies and reform visions stretching from belligerent anti-leftist extremism to radical market liberalism, but they collaborated in their struggle against the liberal-progressive parties and civil society forces. They emerged as a reaction to the crisis of the conservative parties in the mid-200os after a series of electoral success of the progressives and, later, could exert significant influence over the process of the conservative turn in politics and public opinion from the late 2000s (Shin 2015).

As such, the institutionalization of the citizens' movements not only has resulted in many significant reforms, but also created problems that later turned out to be a cause of transformation in the contentious politics of South Korea. Actually, more and more citizens in the 2ooos wanted to distance themselves from every political party and influential organization of civil society and, eventually, created an entirely new and independent way of conducting contentious politics. The symbol of such a change was the 'candlelight.'

\section{Citizen Politics in the Twenty-first Century}

\section{From Organizational to Networked Social Movements}

In the previous pages, we saw that since the 199os, professionalized civil society organizations have achieved reform goals through institutionalized means, whereas the democratic movements of the 1980 s have continued to conflict with the authoritarian state through their provocative actions. The two periods are sharply contrasted not only in terms of the environment of the social movement, but also of the movement participants' recognition of reality, their goals and modes of action, and the institutional recognition. What is common to them, however, is that 'organizations' and their strategies have played a decisive role, even if the support of the unorganized citizens were essential to the success of the movement. Still in the 1990s, many of the movement activists called them 'mass,' that is, an object of conscientization, persuasion and mobilization. 
This situation has changed completely since the early 200os. The South Korea of the twenty-first century saw a sudden rise and spread of spontaneous and decentralized collective actions by loosely connected individuals and communities, which Manuel Castels (2012) called 'networked social movements.' A new form of protest called chotbuljiphoe (candlelight protest) symbolizes this trend: The gathering of a great number of citizens spreads rapidly by independent communication, networking and coordination; participants share information and exchange opinions via the internet and smartphones; and they plan their actions, consult about action methods, and recruit further participants without connection with political parties or movement organizations; the constituents are greatly diversified in terms of their age, sex, occupation and prior experience of protest action.

Over the past few years, such new forms of resistance have emerged and spread in many parts of the world. Elements that social movement researchers have often considered as mutually exclusive coexisted in these new protests (consciousness and spontaneity, collectivity and individuality, online communication and offline gatherings) and were combined in various ways in one and the same movement. The Arab Spring of 2010-2011, Spain's movement of the indignados from 2011, the Occupy Wall Street Movement in the United States in 2011, the Hong Kong Umbrella Revolution and the Sunflower Movement in Taiwan in 2014 are well-known examples. New citizen politics in South Korea shares the contexts and characteristics of these global trends in many respects.

What is particularly interesting in the case of Korea is that not only did large-scale protest actions involving millions of people take place repeatedly within a short period of time, but also in many cases they have had a strong and immediate impact on government action, election politics and power relations at the national level. Although participants pursued independence from all institutional political forces and ostensibly claimed to be 'nonpolitical,' their actions were in reality targeted at highly political issues and aimed at exercising influence upon national politics. They were more interested in institutional politics and more active in institutionalized forms of political participation such as voting than non-participants (Lee 2009).

Obviously, the form of the candlelight vigil itself is not new at all. It not only has a long history in religious rituals, but also has been a popular form of gathering in the modern social movements, such as in the German peace movement and the Indian women's movement. It was also often used by religious groups in the South Korean democratization movements until the 1980 s. The novelty of the Korean candlelight protests in the twenty-first century is that individual citizens connected by the internet and the SNS 
could amplify their issues and increase the number of protest participants extremely rapidly; effectively combine spectacular physical gatherings and online communications; and exert immediate political pressure on the government and political parties. For example, the candlelight protest in 2004 led to a surprising election victory of the reform-oriented party and thus completely changed the power relations in the state; the protest in 2008 blocked the neoliberal policy lines of the newly formed conservative administration; and the protest in 2016-2017 succeeded in impeaching the president, who was accused of corruption and power abuse in a peaceful and constitutional way.

\section{The Birth, Growth and Success of Candlelight Protests, 2002-2017}

We can identify the exact date when the 'candlelight protest' emerged as a term referring to a new form of collective political expression of citizens in South Korea. On 27 November 2002, a citizen suggested on the internet that a small memorial meeting be held in front of Seoul Metropolitan City Hall. In three days, a small number of citizens gathered with candles in their hands. It was a candlelight vigil to commemorate the two middle school girls who died by being hit by an armoured vehicle of the US army stationed in South Korea in June of that year. This incident was considered a mere accident at the time and did not attract public attention at all. However, the problem began with the fact that the South Korean court did not have jurisdiction over the case under the Status of Forces Agreement (SOFA) between the United States and South Korea. In November of that year, the two US soldiers responsible for the accident were acquitted in the US military court and returned to the United States. This was a trigger. The size of candlelight vigils increased rapidly in a few weeks and exceeded 100,000 in mid-December. Citizens communicated on the internet and held a candlelight vigil every weekend, asking for the revision of the SOFA and the establishment of a peace regime on the Korean Peninsula. The rise of candlelight vigils has had a significant impact on the presidential election held in late December. Former human rights lawyer Roh Moo-Hyun, who was but a peripheral figure in Korean politics, won a dramatic victory in the election.

The political influence of the candlelight protest was confirmed again just two years later. President Roh Moo-Hyun, who had a strong reform tendency, repeatedly clashed with established politicians and political parties after his inauguration, and the National Assembly impeached him for violating political neutrality in March 2004. About $70 \%$ of the citizens 
opposed impeachment, according to several polls by the time, and some of them directly expressed their opinions, continuing candlelight vigils and street marches at the city centre of Seoul. The protest in 2004 were not only larger than in 2002, but also had a more direct political impact. The Yeollin Woori Party, which was a small party supporting President Roh, won a majority of seats in the general election held in April when the candlelight protests were underway. In May of that year, the Constitutional Court overturned the impeachment.

Since 2008, as the conservative Lee Myung-Bak and Park Geun-Hye governments have regressed to quasi-authoritarian politics, the candlelight protests have grown remarkably in size, frequency and intensity. Lee MyungBak, who was one of the bosses of Hyundae conglomerate, took office in February 2008. The candlelight protests, which lasted about four months from spring to summer, brought about a new stage in the development of South Korean social movements in the twenty-first century. The protest was triggered by the conclusion of the US-Korea Agreement on the Import of US Beef Products in Korea in April of that year. Many South Koreans worried about mad cow disease, or BSE (bovine spongiform encephalopathy), because the agreement allowed the import of the SRMs (specified risk materials). Surely, there are similar cases of protest related to anxiety about mad cow disease in other countries (Ho and Hong 2012; Lewis and Tyshenko 2009; Setbon et al. 2005). However, the issue in Korea was highly political in nature.

Many South Koreans blamed the Lee Myung-Bak administration not only for ignoring the health rights of the people, but above all for placing no importance on public opinion. The key word in the initial phase of the protest was 'communication.' The major target of blame was the government's unilateral policy decision and implementation without efforts to communicate with citizens and to reflect the majority opinion of the public. The issue soon expanded into a heated debate over the aggressive neoliberal policies of the new government. The key issues of the protest were often summarized as ' $5+1$,' namely: large-scale construction projects by the government, privatization of the public sector, privatization of medical services, reduction of public support for education, government control of broadcasting, and 'beef.' The candlelight protest in 2008 is often called the 'beef protest,' but, in reality, it was the opposition to political re-authoritarianization and neoliberalization that intensified and politicized the protest.

In terms of scale, the protest that started with a relatively small number of citizens in April 2008 expanded very rapidly, reaching an estimated 0.6 million in mid-June. This scale was well above the candlelight vigils in 2002 and 2004. What is surprising in terms of duration is the fact that even 
though the mobilization by movement organizations has played a minimal role, the protest continued for about four months with tens of thousands of participants on average. The participants maintained the protests by the online-street spiral, in which they linked online communication to the offline protests while sharing online the experience of their offline gatherings (Lee et al. 2010).

If in the first candlelight vigils of the early 2000 s, tensions between movement organizations and networked individuals became visible even though the former still played a role, the candlelight vigils in 2008 was an event in which the latter definitely became the new 'leaderless' leader of the social movement in South Korea (Jho 2009). The majority of participants were citizens with little or no prior experience of protest; their age, sex and occupation were much more diversified than in the past. The active participation of the youth, housewives and young couples with their children, who have been rare in places of political rallies in the past, attracted much attention. Online communities with millions of members, which were usually non-political in nature, suddenly turned into spaces of political debate and strategic discussion. The protest of 2008 could not bring about any substantial change in party politics because it took place right after the conservatives won a victory in the presidential and parliamentary election. Nevertheless, the Lee administration had to abandon many important policy intentions, such as the reduction of public welfare and the privatization of the water supply, electricity, and medical services.

After the decline of the protest in 2008, large-scale candlelight protests continued addressing various issues, including police violence, political control of broadcasting, educational policy and the intervention of intelligence agency in the presidential election. It was, above all, the candlelight protests in 2016-2017 for the impeachment of the then-President Park Geun-Hye that showed the political influence of the new citizens' activism in the most dramatic way. Park Geun-Hye, daughter of former dictator Park Chung-Hee, was elected president in December 2012, and the former key figures of the authoritarian rule of the 1970s returned to the highest positions of the government. The Park administration restricted freedom of expression, media, assembly and demonstration. Moreover, suspicions had been raised repeatedly that the president and high-ranked officials were involved in corruption and that the president's private friends exerted a huge influence on the government's decisions. However, the presidential office kept major state institutions under its control, including prosecutors, police and the judiciary, while the opposition parties lacked sufficient political resources. It was the candlelight protest that started to bring a change to this situation. 
The protest began on 29 October 2016, and lasted until 11 March 2017, a day after the Constitutional Court's final approval of the impeachment. The cumulative number of participants exceeded seventeen million. On 26 November 2016, when the protest reached its peak, more than two million people participated nationwide. Every Saturday, about 20 times, hundreds of thousands of citizens gathered in the centre of Seoul to demand the resignation or impeachment of the president, criticizing abuses of power, political corruption and the privatization of state power. Not unlike the candlelight vigils over the past decade, the participants were very diverse in respect of their age, sex and occupation; most of them communicated and decided to participate independently of political parties and movement organizations. The protest was peaceful and orderly. The police reported that there was not a single incident of violence and not one arrest during the four months. By demonstrating such peace and order, the participants wanted to gain friendly media coverage and broad public support. In this way, they were also able to exert maximal pressure on the legislators and the government.

On 3 December 2016, the National Assembly voted 234 to 56 in favour of impeaching President Park for five major reasons: violation of the constitutional principle of people's sovereignty and rule of law; abuse of presidential power; violation of the duty to protect the right to life; violation of criminal law such as bribery; and violation of free speech. On 10 March 2017, the Constitutional Court unanimously approved the impeachment proposal and dismissed President Park. The reasons for impeachment were the violation of the people's sovereignty and the rule of law, as well as the abuse of presidential power. A presidential election was held within 60 days after the impeachment decision and a new government came into being. The candlelight protest showed a typical example of 'politics of influence' promoting the work of democratic-constitutional institutions through powerful but self-limiting actions from below.

\section{Submerged Networks and the Encounter of Histories}

New subjects of political activism in South Korea, symbolized by the 'candlelight,' show a tendency to come onto the public stage when they find it necessary to act about an issue and return to their everyday life after the decline of the protest waves, instead of constantly committing themselves to movement organizations or establishing a new one. This kind of pendulum movement between appearance and disappearance of acting citizens in South Korean politics continued for the first two decades of the twenty-first 
century. The retreat of the citizens from contentious politics does not imply here 'exit' as opposed to 'voice,' to borrow from Albert Hirschman's concepts (Hirschman 1970).

Today, the private world of the citizens includes as its indispensable component a variety of loose but broad communication networks connected by online public spheres, internet communities and the SNS. Information, knowledge, opinions and communication about public issues are inherent in the private lives of individuals. In this sense, it would be accurate to say that the citizens holding the candles did not disappear, but rather that they 'submerged' when they left the political space. For they are not isolated individuals, but part of what Alberto Melucci called the 'submerged networks' (Melucci 1989), and these dispersed and fragmented forces in everyday life may suddenly 'emerge' at the centre of politics in a moment when they encounter specific triggering events. The characteristics of civil society that Charles Taylor described as 'amphibian' (Taylor 1990) now are being generalized among the citizens.

The reason why the conflict between a 'strong state and [a] strong civil society' (Oh 2012) has intensified in South Korea in the twenty-first century can be found in the fact that the citizens' desire and capacity for political participation have become stronger, whereas institutional politics was still dominated by old behavioural patterns or even regressed into re-authoritarianization. In particular, the fact that the Lee Myung-Bak and Park Geun-Hye administrations have not just pursued conservatism in policy, but turned the nations' democracy and rule of law backward, has had two significant consequences for South Korean civil society. One is the politicization of a widespread citizenry which came to more consciously attach value to democracy and the rule of law after experiencing the violation of them. The other is that the newly politicized citizens encountered in the process of political participation the former participants of the democratization movements of the prior periods and their symbols, rituals, protest cultures and narratives of their experience of violence and resistance against it.

Just as in 1987 the symbolic figures of the democratization movements of the 1970s fought together with the citizens of younger generations who filled the square in front of Seoul Metropolitan City Hall, the leaders of the movements that have grown since the 199os formed the Bisanggukminhaengdong (People's Emergency Action for Park's Resignation) to support the citizens who stood in the same place in 2016-2017. Although such experienced activists could not claim to be leaders of the protest like in the 199os, they managed to find their role within a decentralized movement ecology of the twenty-first century. Moreover, during the candlelight protests, not only 
was the story of Park Geun-Hye's abuse of power and corruption told, but accounts of the violence committed by the state under the dictatorship and the sacrifices of those who resisted it were passed on to the younger generations and to the older citizens who had not been much interested in politics and history. They learned slogans, poems, protest songs and the lived experiences of the 1970 s and 1980s, while at the same time the former dissidents learned new cultures and ways of communication. As such, social movements in South Korea underwent a great change during the past half century, but, at the same time, different histories met each other in every new present and created a new mosaic.

\section{Discussion and Conclusion}

The history of South Korean civil society and social movements for decades from the 1960 s to the 2010 s shows some long-term trends.

The first one is a tendency of the expansion of movement participants. The subjects of South Korean social movements have been continuously widened from a small number of cultural elites and organized student activists who led the protest movements in the 1970s and 1980s; through an increasing number of professional movement organizations that grew under democracy during the 1990s; to millions of 'candlelight citizens' in the twenty-first century who communicate, network, mobilize and strategize independently. Most recently, the trend towards the political activism of citizens and the changes in the logic of institutional politics, which Ulrich Beck had predicted in the 1980 s (Beck 1986), are becoming more and more salient and are being generalized across ideological, generational, occupational and gender differences.

Here we need to specify the exact nature of this change. First of all, the individualization of the unit of action does not necessarily suggest the decline of associational life. In the case of South Korea, the participants of the candlelight protests were more frequently affiliated in voluntary associations and more active in voting behaviour than non-participants. However, it is noticeable that while on the whole, the movement participation is becoming normal, the specifically class-based movements are continuing to shrink. The growing inequalities in many aspects after the Asian financial crisis in 1997, including income, employment and assets, are becoming important political agenda in electoral competition and party politics, but mobilization from below on the issues of inequality are not led primarily by class organizations such as trade unions, but by a broad network of civil 
society communities and associations. Last but not least, the generalization of political activism is ambivalent from a normative point of view. Not only actions pursuing universalistic values but also those opposing them are now emerging and spreading rapidly.

The second trend is that the structure of the field of social movements has moved from the simple coexistence of a limited number of weakly organized actors until the 1970s; through a centralized system of organizations and inter-organizational ties in the 1980s; to a set of loose networks of diverse organizations and inter-organizational networks in the 1990s; and, finally, to a highly decentralized field within which a huge number of social networks, communities and individuals communicate and interact.

Until the 1970s, progressive religious groups, student movements, democratic dissidents and the labour movements were still poorly organized and the connection between the groups was not solid. After the military massacre of 1980, the democratization movements considerably reinforced their organizational capacity and a nationwide structure of solidarity. After the end of dictatorship, the field of social movements has become diversified in terms of ideology, goals, and issues. From the early 2ooos, individual citizens, non-movement communities and social networks gained great importance in the rise, spread and success of contentious actions. These recent changes drastically increased the complexity of the movement ecology and reduced the predictability and strategic manageability of the progress of mobilization.

Finally, the third trend is a change in the way social movements and protest actions affect institutional politics. South Korean citizens could move politics and society: (1) until the 1970s, by a strongly moralized act of cultural elites testifying the repressed 'truth,' e.g. democracy, equality, or human dignity; (2) then, by disruptive actions of radical activists of the $1980 \mathrm{os}$ to attract the attention of the public and to impose political burden over the dictators; (3) after the introduction of democracy in 1987, by disputes, negotiations and cooperation of the civil society organizations with the institutional sectors like the government, politicians, media and the court; and, finally, (4) after the considerable expansion of citizenship under democracy during the 1990 s and 2000s, by means of massive self-mobilization of individual citizens and their power of influencing public opinion and, thereby, putting substantial political pressure on the government and political parties.

The most recent changes in South Korea may be interpreted, to borrow from Reinhard Bendix (1977), as a premature decline of 'functional representation' and the rapid rise of political dynamics based on 'plebiscitarian principle,' in which the state and individuals face each other without allowing the 
intervention of the institutionalized intermediary channels. This specific configuration generates a particular ambiguity in the meaning of recent upsurges in 'people power.' During the decades of authoritarian rule, South Koreans did not have the opportunity of expanding their citizenship. The end of dictatorship in 1987 could have brought substantial change in this respect, but while the rights of individuals have been improved gradually, organized civil society remained extremely underdeveloped for various reasons that cannot be discussed further here. Under such historical conditions, Korean citizens in the twenty-first century have created a unique methodology of quickly collectivizing themselves without the hard work of organization and instantly influencing powerful actors without changing the deeper power structure.

The recent development of South Korean social movements - the expansion of the participants, the decentralization of the field and the increasing power of spontaneous protests - suggests both new democratic potentials and the persistence of old problems. Therefore, we may be able to expect a sustainable progress towards the social ideals that can be justified normatively only by deliberately dealing with such ambivalence.

I will conclude this chapter by briefly mentioning the implications that the transformations of South Korean civil society and social movements described here have had for the broader relationships between the state and civil society in the nation - although a detailed discussion on this issue goes well beyond the goals and scope of this chapter.

As mentioned in the introduction, autonomous actors of South Korean civil society have developed their organizations, collective identities and political consciousness in the process of resistance to the authoritarian state. Therefore, scholars have characterized the state-society relationship in South Korea until the late 1980 s by conceptual schemes such as 'strong state versus contentious civil society' or 'strong state versus strong civil society' (Koo 1993; Oh 2012). Actually, it seems clear that South Korea's state-society relationship did not take the form of 'strong societies, weak states' (Migdal 1988), which was characteristic of many developing countries. However, we need to recognize the relationship between the state and civil society in Korea on the basis of a more differentiated conceptualization about what 'strengths' and 'weaknesses' of the state and civil society mean.

The literature on the power of the state over society has illuminated the diverse aspects of state capacity, including coercive, administrative, legislative and extractive capacities and the capability of collaborating with societal actors to implement public goals (Evans et al. 1985; Hall 1986; Mann 1993; Skocpol 1979; Tilly 199o). During the period of dictatorship, the South Korean state certainly had a powerful coercive capacity, but that was 
not the whole story. During this period, not only has the administrative capacity of the South Korea government greatly expanded, but also the relationship between the state bureaucracy and the fast-growing economy has become closer. South Korea's authoritarian-developmental state had strong transformative capacities to implement its growth-oriented national goals (Evans 1995; Johnson 1982, 1999; Wiess 1998).

On the other hand, due to the suppression of democracy, the legislative and democratic regulatory capacity of political parties and the state bureaucracy remained extremely low, while the growth-centred state has enhanced its taxation capacity, which is one of the most important preconditions for the redistributive function of the modern state, only to a limited extent. In that sense, South Korea's state has long been strong in some respects but weak in others. To borrow from the well-known conceptual pairs elaborated by Michael Mann $(1988,1993)$, it was not just a 'despotic' state, but had many limitations in developing the 'infrastructural' capacities to penetrate into society in a collaborative relationship with society.

Civil society actors in South Korea, who have confronted a state that possessed powerful coercive and administrative capacities but lacked democratic and redistributive capabilities, pursued values such as democracy and human rights, economic equality and justice, and reconciliation between the two Koreas. They were struggling to realize 'heterodox' (Eisenstadt 1998) projects of social and political development, which were obviously antithetical to the authoritarian, growth-oriented and anti-North Korean orientation of the political centre. Furthermore, they continued to use strategies and action methods that substantially threatened and challenged political power. For these reasons, the relationship between the public authorities and civil society actors was essentially conflict-ridden throughout the whole periods under the authoritarian regime.

Since the 1990s, the relationship between the state and civil society in South Korea has undergone qualitative changes in many respects, although the legacies of the civil society actors' distrust of and opposition to the state still are vital. Three changes seem to have particular significance.

The first one is the differentiation and the growing complexity of the institutional domains of both the state and civil society. As the structure of the state and civil society has become more plural, a complex relationship has developed between diverse actors of the state and party politics, on the one side, and equally variegated actors in civil society, on the other side. Thus, the dichotomy of 'the state versus civil society' has been relativized in its significance. Second, the interplay between institutional politics and social movements has brought about both conflict and cooperation. Challengers 
of social movements still are criticizing governments and political parties and urged change, but as the political environment has become more open under democratic system, more opportunities have been given to social movements to cooperate and negotiate with actors in institutional politics. The third change is the increasing interpenetration between the state and civil society. On the one hand, civil society leaders, agendas and policy proposals are increasingly coming into the administrative and legislative institutions of the state. On the other hand, the field of civil society tends to be divided along the lines of cleavages in the institutional politics. As a result, there emerged a complex constellation of conflicts and alliances between political and civil society actors having various interests and ideas.

In short, if the relationship between the state and civil society in South Korea was clearly oppositional and confrontational during the decades from the 1960 os to the 1980 , their new relationship during the subsequent decades from the 1990s to the 2010 s is characterized by increasing complexity and contingency. In response to such changes, the South Korean state and civil society now have the task of innovating their mutual relationships by developing new capacities corresponding to the new environments. The South Korean state has to find ways of achieving public goals by raising administrative efficiency, strengthening capacities of democratic regulation and institutionalizing the participation of citizens in public issues. Meanwhile, civil society actors should not be contented with criticizing the government and politicians, but have to make more efforts to create what Amitai Etzioni (1968) has called 'the active society,' in which citizens are aware of the common purpose, are committed to activities for actualizing those purposes and potent in their capacity to create and maintain such a social order. The question of how to fulfil these demanding tasks will continue to be of importance in South Korea in the future.

\section{References}

Ahn, Byung-Mu. 1972. Yeoksa-wa-jeungeon. Seoul: Dahagidokgyoseohoe.

Beck, Ulrich. 1986. Risikogesellschaft: Aufdem Weg in eine andere Moderne. Frankfurt: Suhrkamp.

Bendix, Reinhard. 1977. Nation-Building and Citizenship: Studies of Our Changing Order. Berkeley: University of California Press.

Castels, Manuel. 2012. Networks of Outrage and Hope: Social Movements in the Internet Age. Cambridge: Polity Press. 
Chang, Paul Y.; Byung-Soo Kim. 2007. 'Differential Impact of Repression on Social Movements: Christian Organizations and Liberation Theology in South Korea (1972-1979).' Sociological Inquiry, 77 (3): 326-355.

Chang, Yun-Shik. 1998. 'The Progressive Christian Church and Democracy in South Korea.' Journal of Church and State, 40: 437-465.

Cho, Hee-Yeon. 200o. 'Democratic Transition and Changes in Korean NGOs.' Korea Journal, 40 (2): 275-304.

Eisenstadt, Shmuel Noah. 1998. Die Antinomien der Moderne. Die jakobinischen Grundzüge der Moderne und des Fundamentalismus. Frankfurt: Suhrkamp.

Etzioni, Amitai. 1968. The Active Society: A Theory of Societal and Political Processes. New York: Free Press.

Evans, Peter B. 1995. Embedded Autonomy: States and Industrial Transformation. Princeton: Princeton University Press.

Evans, Peter B.; Rueschemeyer, Dietrich; Skocpol, Theda (eds). 1985. Bringing the State Back In. Cambridge: Cambridge University Press.

Gamson, William. 1990. The Strategy of Social Protest. Belmont: Wadsworth.

Hall, Peter A. 1986. Governing the Economy: The Politics of State Intervention in Britain and France. New York: Oxford University Press.

Hirschman, Albert O. 1970. Exit, Voice, and Loyalty: Responses to Decline in Firms, Organizations, and States. Cambridge, MA: Harvard University Press.

Ho, Ming-sho. 2010. 'Understanding the Trajectory of Social Movements in Taiwan (1980-2010).' Journal of Current Chinese Affairs, 39 (3): 3-22.

Ho, Ming-sho; Chen-shuo Hong. 2012. 'Challenging New Conservative Regimes in South Korea and Taiwan: Comparison of the Anti-American Beef Protests.' Asian Survey, $5^{2}$ (4): 643-665.

Hsiao, Hsin-Huang Michael. 1996. 'Social Movements and Civil Society in Taiwan.' Copenhagen Journal of Asian Studies, 11: 7-26.

Jho, Whasun. 2009. 'The Transformation of Cyberactivism and Democratic Governance in Korea: The Role of Technology, Civil Society, and Institution.' Korea Observer, 40 (2): 337-368.

Johnson, Chalmers. 1982. MITI and the Japanese Miracle: The Growth of Industrial Policy, 1925-1975. Stanford: Stanford University Press.

Johnson, Chalmers. 'The Developmental State: Odyssey of a Concept.' The Developmental State. Meredith Woo-Cumings (ed.). Ithaca: Cornell University Press, pp. 32-6o.

Jung, Jai Kwan. 2011. 'Popular Mobilization and Democratization: A Comparative Study of South Korea and Taiwan.' Korea Observer, 42 (3): 377-411.

Kang, In-Chul. 200o. 'Religion and the Democratization Movement.' Korea Journal, 40 (2): 225-247. 
Kim, Dong-Choon. 2006. 'Growth and Crisis of the Korean Citizens' Movement.' Korea Journal, 46 (2): 99-128.

Kim, Euiyoung. 2009b. 'The Limits of NGO-Government Relations in South Korea.' Asian Survey, 49 (5): 873-894.

Kim, Sunhyuk. 2009a. 'Civic Engagement and Democracy in South Korea.' Korea Observer, 40 (1): 1-26.

Koo, Hagen. 1993. 'Strong State and Contentious Society.' State and Society in Contemporary Korea. Hagen Koo (ed.). Ithaca: Cornell University Press, pp. 231-249.

Koo, Hagen. 2001. Korean Workers: The Culture and Politics of Class Formation. Ithaca: Cornell University Press.

Lee, Hyeon-Woo. 2009. 'Political Implications of Candle Light Protests in South Korea.' Korea Observer, 40 (3): 495-526.

Lee, Seung-Ook; Sook-Jin Kim; Joel Wainwright. 2010. 'Mad Cow Militancy: Neoliberal Hegemony and Social Resistance in South Korea.' Political Geography, $29(7): 359-369$.

Lee, Sook-Jong; Celeste Arrington. 2008. 'The Politics of NGOs and Democratic Governance in South Korea and Japan.' Pacific Focus, 23 (1): 75-96.

Lee, Yeonho; Taeyong Park. 2009. 'Civil Participation in the Making of a New Regulatory State in Korea: 1998-2008.' Korea Observer, 40 (3): 461-493.

Lewis, Roxanne E.; Michael G. Tyshenko. 2009. 'The Impact of Social Amplification and Attenuation of Risk and the Public Reaction to Mad Cow Disease in Canada.' Risk Analysis, 29 (5): 714-728.

Liu, Hwa-Jen. 2005. Leverage of the Weak: Labor and Environmental Movements in Taiwan and South Korea. Minneapolis: University of Minnesota Press.

Mann, Michael. 1988. States, War, and Capitalism: Studies in Political Sociology. Oxford: Basil Blackwell.

Mann, Michael. 1993. The Sources of Social Power: The Rise of Classes and NationStates, 1760-1914. Cambridge: Cambridge University Press.

Melucci, Alberto. 1989. Nomads of the Present. London: Hutchinson Radius.

Meyer, David S.; Sidney Tarrow. 1998a. 'A Movement Society: Contentious Politics for a New Century.' The Social Movement Society: Contentious Politics for a New Century. David S. Meyer; Sidney Tarrow (eds). Oxford: Rowman \& Littlefield, pp. 1-28.

Meyer, David S.; Sidney Tarrow. 1998b. The Social Movement Society: Contentious Politics for a New Century. Oxford: Rowman \& Littlefield.

Migdal, Joel S. 1988. Strong Societies and Weak States: State-Society Relations and State Capabilities in the Third World. Princeton: Princeton University Press.

Moore, Barrington. 1966. Social Origins of Dictatorship and Democracy: Lord and Peasant in the Making of the Modern World. Boston: Beacon Press.

Nam, Jeong-Lim. 2000. 'Gender Politics in the Korean Transition to Democracy.' Korean Studies, 24: 94-112. 
Neidhardt, Friedhelm; Dieter Rucht. 1993. 'Auf dem Weg in die "Bewegungsgesellschaft"? Über die Stabilisierbarkeit sozialer Bewegungen.' Soziale Welt, 44 (3): 305-326.

Oh, Jennifer S. 2012. 'Strong State and Strong Civil Society in Contemporary South Korea: Challenges to Democratic Governance.' Asian Survey, $5^{2}$ (3): 528-549.

Park, Mi. 2007. 'South Korean Trade Union Movement at the Crossroads: A Critique of “Social Movement” Unionism.' Critical Sociology, 33 (1-2): 311-344.

Piven, Francis Fox; Richard A. Cloward. 1977. Poor People's Movements: Why They Succeed, How They Fail. New York: Pantheon Books.

Setbon, Michel; Jocelyn Raude; Claude Fischler; Antoine Flahault. 2005. 'Risk Perception of the "Mad Cow Disease" in France: Determinants and Consequences.' Risk Analysis, 25 (4): 813-826.

Shin, Jin-Wook. 2015. 'Ideological Conflict in Civil Society and Korean Democracy in Trouble.' Civil Society on the Move. Eun-Jeung Lee; Hannes B. Mosler (eds). Frankfurt: Peter Lang, pp. 73-92.

Simmel, Georg. 1992. Georg Simmel Gesamtausgabe. Bd. 11: Soziologie. Untersuchungen über die Formen der Vergesellschaftung. Franfkurt: Suhrkamp.

Skocpol, Theda. 1979. States and Social Revolutions: A Comparative Analysis of France, Russia, and China. Cambridge: Cambridge University Press.

Taylor, Charles. 1990. 'Modes of Civil Society.' Public Culture, 3 (1): 95-118.

Tilly, Charles. 1990. Coercion, Capital, and European States, AD 990-199o. Oxford: Basil Blackwell.

Weiss, Linda. 1998. The Myth of the Powerless State. Ithaca: Cornell University Press. Yoon, Bang-Soon L. 2001. 'Democratization and Gender Politics in South Korea.' Gender, Globalization and Democratization. Rita Mae Kelly; Jane H. Bayes; Mary E. Hawkesworth; Brigitte Young (eds). Lanham: Rowman \& Littlefield, pp. 171-193. Wright, Erik Olin. 200o. 'Working-Class Power, Capitalist-Class Interests, and Class Compromise.' American Journal of Sociology, 105 (4): 957-1002.

\section{About the Author}

Jin-Wook SHIN is Professor of Sociology at the Chung-Ang University, South Korea. He received his $\mathrm{PhD}$ from the Free University Berlin. He was a visiting professor at the Free University of Berlin and a fellow of the Alexander von Humboldt Foundation in 2012. He also taught at the University of Graz, Austria, in 2018. His research interests are democratic theory, party politics, social movements, social inequalities and the welfare state. Besides a large number of research articles in Korean, English, and German, he has also published books on civil society, democracy and social inequalities, 
including Modernisierung und Zivilgesellschaft in Südkorea:Zur Gewalt und Heiligkeit in der modernen Politik (in German, Deutscher Universitätsverlag, 2005); From Symbol to Mobilization: The Cultural Dynamics of South Korean Democratization Movements (in Korean, co-author, Ihaksa, 2007); Citizen (in Korean, 2008); Multiple Inequalities: The Structure of Inequalities in South Korean Society (in Korean, co-author, Peipeo Lodeu 2016). 


\title{
11 Opening up the Welfare State to 'Outsiders'
}

\author{
Pro-Homeless Activism and Neoliberal Backlashes in Japan
}

Mahito Hayashi

\begin{abstract}
This chapter examines local/national trajectories of social movements for homeless people, arguing that 'pro-homeless' activism has fundamentally improved the Japanese welfare state. State-led high growth historically allocated resources favouring capitalist expansion, not people's welfare. This tendency hit the homeless the most. In turn, this has given pro-homeless activism significant potentials and capacities. Firstly, pro-homeless activism has dominantly taken local forms, improving welfare provision at welfare offices. Secondly, in the late 200os, activism won achievements at the national level, by reframing homelessness as a national problem. Thirdly, the wholesale inclusion of the homeless/poor has evoked their $r e$-marginalization. Today, neoliberal/neoconservative forces are advancing anti-poor politics to revoke movements' prior successes, paradoxically testifying to the power of pro-homeless activism in developing the welfare state.
\end{abstract}

Keywords: social movements, social exclusion, neoliberalism, welfareworkfare transitions, poverty

At the endpoint of the high-growth era and notorious 'bubble economy,' in the 1990s, Japan entered a new period of socio-economic instability. Over these decades, homelessness grew although the quantitative aspect could not be compared, for example, to the rise of homelessness in the United States in the 1980 s when HUD (the Department of Housing and Urban Development)

Chiavacci, David, Simona Grano, and Julia Obinger (eds), Civil Society and the State in Democratic East Asia: Between Entanglement and Contention in Post High Growth. Amsterdam, Amsterdam University Press 2020 DOI: 10.5117/ 9789463723930_CH11 
estimated the number of homeless street people at around 300,000 (Rossi 1989: 37-38). According to official counts organized by the Ministry of Health, Labour and Welfare (MHLW), homeless people living in Japanese public space was below 30,000 at its peak during the early 2000s (MHLW 2003). This number seems insignificant even after taking into account Japan's smaller national population. That estimation, however, seriously underrates the impact of homelessness in post-high-growth Japan. For one thing, homelessness in and after the 1990s radically challenged Japan's well-organized construction of urban public space as well as the nation's homogeneous self-portrait of domestic society as 'all-one-hundred-million middle class' (ichioku sō chūryū). For another, it sent a palpable sign to many that Japan's state-led development, which had once enjoyed an international reputation for equality, was now in crisis. Moreover, homelessness was the harbinger and herald of the 'generalized poverty' which Japan was to experience to the present day.

Yet, there is a completely different angle from which we can assess the impact of homelessness in Japan: that of the social movements for homelessness. These movements are what this chapter calls 'pro-homeless movements,' which grew during and after the 1990 s and played a fundamental role in changing local and national modes of citizenship. While the core programme of Japan's citizenship for the poor - Public Assistance - took its current form in the early 1950s, it was unable to effectively contribute to poverty alleviation for the most needy for a long time. The national programme rejected those who were most impoverished and in need of public support. When the rise of homelessness reminded citizens and political leaders of this weakness of the welfare state, pro-homeless activists and volunteers stood up and started redressing the exclusive nature of this citizenship. Owing to their extreme sensitivity to citizens' rights, to the 'fringe politics' of exclusion and inclusion, pro-homeless movements have played a special role in contemporary Japan - namely, improving the circumscribed welfare state by opening it up to its 'outsiders.' By tracing local and national trajectories of this 'opening up,' this chapter assesses how and to what extent the Japanese welfare state overcame its exclusive character between the 199os and $2010 \mathrm{~s}$.

I do not claim that this welfare state lacked any instances of improvement before the 199os. Positive developments took place, for example, in the 1950s, 1970s and 1990s, when new systems of provision materialized (Calder 1988; Peng 2005; Shinkawa 2005). By and large, however, even the periods of expansion improved only those measures that targeted 'worthy' - childraising, disadvantaged, and elderly - households; this could be understood as a ramification of Japan's productivist welfare regime (Kwon 2005). At 
any rate, it was in this context of exclusion that pro-homeless activists, supersensitive to the unnoticed and unresolved plight of the homeless, played key roles in changing the status quo, not only for those without a roof or home but for the entire nation. Overall, this chapter's analysis shows that social movements for the homeless became the 'game changers' of the welfare state in post-high-growth Japan. In what follows, I first look at the local pro-homeless movements that changed the local conditions of the citizenry beginning in the 1990s. I further argue that a new pro-homeless movement in the late 2000 s played a pivotal role in improving the Japanese welfare state nationwide. I reveal that the wholesale inclusion of various (previously excluded) impoverished populations in the welfare state provoked a backlash politics of neoliberalism and widespread popular discourses on 'welfare dependency.' I conclude that these neoliberal responses are now necessitating that radical activists reposition themselves in the new, unfolding political landscape of 'workfarist regulation' (Peck 2001).

While this chapter elaborates the central themes of this volume from a unique perspective, its discussions are pertinent especially to two chapters. Chapter 8 (Chiavacci) considers the influence of civil society actors to labour immigration policy in Japan. This chapter, focusing similarly on social actors working for the population marginal to mainstream society, explore national and local spaces in which these social actors can have the rule-changing influence on state actors. Chapter 9 (Ogawa) considers the contradictory ways in which Japanese non-profit organizations become, at once, a tool of neoliberalization and leverage for participatory democracy. This chapter resonates with this research interest as it locates Japanese social movements in the ongoing dynamism of neoliberalization.

\section{Local and National: Two Spaces of Activism}

In Japan, the historical pattern of the Japanese welfare state has conditioned homelessness and social movements for the homeless. The state has a progressive framework of citizenship for the poor (see the next section), yet, individuals who were without fixed addressed, able-bodied, unmarried, and male were largely rejected as they were considered employable individuals capable of supporting themselves in the labour market. They thus constituted the 'unworthy' poor categorically located outside of the Japanese welfare state, whose receipt of public support was considered to deteriorate their work ethic and promote the self-destruction of their 'able bodies.' Their survival process was located outside of Japan's 'welfare through work' (Miura 
2012), the enterprise-level system of welfare provision for core labourers. As a result, not a few Japanese citizens historically suffered low-wage problems and poor living conditions even in boom years (MHL 1962). They also formed a body of the 'working-poor' population whose existence was elusive (Eguchi 1979). The important thing is that the exclusion of these poverty-stricken labourers and citizens from the Japanese welfare state occurred at the local (rather than national) level because the state gave the welfare office a considerable degree of discretion over everyday decision-making with regard to the applicants.

The localization and denationalization that one finds in the operation of citizens' rights and programmes for the 'unworthy' poor were both threats and opportunities for the pro-homeless movements. It was problematic because the state's responsibility was obscured and because national-level standardization was difficult. At the same time, however, the localized system presented some opportunities within the municipality. Due the localized procedure of decision-making, movements could perhaps change the trajectory of municipal decisions by influencing them. Activists may have been able to change the attitude of rank-and-file workers and higher administrators in the municipality in such a way that the municipality responded more positively to the 'unworthy' poor by using citizens' rights and programmes for citizenship. The possibility of such local-level improvement was dependent on the construction of sound strategies by the movements. If deployed appropriately, by reflexively responding to the exclusive ethos of the gatekeepers, these tactics proved capable of advancing the inclusion of the homeless within the municipality concerned.

This might sound hypothetical. However, real improvements did transpire. Local conditions for homeless citizens really have been improved through the cumulative actions of pro-homeless activists vis-à-vis the welfare office and other sections in the municipality (e.g. Yamasaki et al. 2006). Nonetheless, this approach did encounter problems, such as non-standardization and uncertainty. Supporters and the homeless could hardly expect a more desirable, nationally standardized situation in which every needy individual would receive national benefits across Japan no matter where they lived and how they approached the welfare office. Hypothetically, one way exists to overcome the limits of the locality: nationalization. Activism might construct national spaces and strategies, in such a way as to make national (not local) organs attentive to the plight of the homeless. Such nationalization remained a hypothetical possibility for quite a long time, but a new pro-homeless movement came into being in the late 2000 s and effectively nationalized citizenship politics for the homeless and other poverty-stricken labourers 
and citizens. At the same time, this nationalization had an unexpected corollary as it also nationalized adversarial forces that disagreed with benevolent inclusion. Today, movements have to justify their progressive causes more reflexively at the national level vis-à-vis the ongoing backlash politics and the lay audience.

\section{What Is Good about the Japanese Welfare State? Benign Laws as a 'Hope'}

The ungenerous character of the Japanese welfare state is widely acknowledged (Esping-Andersen 1989, 1997; Estevez-Abe 2008). How could activists make this welfare state attentive to the 'unworthy' poor locally and nationally? Answering this question demands a closer look at the legal system. The best part of the Japanese welfare state resides in the way it benevolently legalizes 'livelihood rights' (seizon ken) as the sacred rights of all citizens, regardless of their prior contributions and social attributes. The constitution establishes the livelihood rights in a rigorous universal manner by declaring: 'All people shall have the right to maintain the minimum standards of wholesome and cultured living' (art. 25). To realize these livelihood rights, the Public Assistance Act of $195^{\circ}$ constructs the framework of Public Assistance, saying: "The minimum standard of living guaranteed by this Act shall be where a person is able to maintain a wholesome and cultured standard of living' (art. 3). Essential benefit programmes in Public Assistance - income, medical and housing benefit - are expected to serve as practical tools to maintain the livelihood rights of all citizens. Even more, the act has clauses that facilitate the flexible mobilization of Public Assistance, enumerating unique problems unhoused individuals can have (arts 4, 10, 38).

This highly benevolent legal conception of livelihood rights becomes a weapon for activists when they ask local/national authorities to include the homeless in the rights to national citizenship. Realistically speaking, there are obstacles. Most obstructing, court cases such as Asahi vs Horiki $(1967)$ have powerfully established that the benevolent clauses of livelihood rights merely set an 'effort target' - not a real goal - for the Japanese welfare state. 'Judgements like this one served as powerful excuses for the local authority to exclude the poor from Public Assistance even when they

1 In this court case, the Supreme Court declared that 'Article 25 of the Constitution declares [livelihood rights] only as the liability of the state and it is no intended to provide each Japanese citizen with rights in a concrete sense.' The irrationality of this judgement in light of the 
suffered homelessness, suggesting that the benefits would only promote their self-destruction and a weakened work ethic. Despite such conservative and patronizing interpretations, however, the benevolent livelihood clauses could be construed in a more inclusive and universal manner if one only reads them straightforwardly. This possibility has inspired local and national activists to allow the authorities to maintain the livelihood rights of the homeless. I do not say that the 'gatekeepers' of livelihood rights - local and national authorities - automatically opened up the welfare state upon request. To begin with, such instances of relaxation were rare. Whenever and wherever they took place, innovative, thoughtful and painstaking processes of activism lay behind the local and national authorities' acts of 'benevolent' inclusion. The following analysis takes instances from the Tokyo-Yokohama metropolitan region; the next section explains its key geographical and historical attributes.

\section{Field Setting}

The central area of the Tokyo-Yokohama region is the focus of this chapter. This geographical area is worth illuminating for two good reasons. First, it has major urban enclaves (yoseba) populated by precarious day labourers and the homeless, and these inner-city enclaves have nurtured pro-homeless movements within Japan's burgeoning cities. The enclaves of yoseba in the Tokyo-Yokohama area - San'ya (in Tokyo Metropolis) and Kotobuki (in Kanagawa Prefecture) - have accommodated homelessness-prone day labourers. Living in yoseba, day labourers found affordable hotels and casual labour markets opening on/off the streets. As such, yoseba was the space for day labourers, whose less-skilled workforce was vitally needed by Japan's unfolding industrialization, at docks, in construction sites, on manufacturing lines, etc. As day labourers suffered economically unstable conditions, they underwent episodic homelessness, triggering local homeless movements even before the 1990s (Aoki 1989; Hayashi 2014a). In and after the 1990s, many of them run into homelessness on a chronic basis. In this historical context, the inner-city areas of yoseba have strengthened their character as the strongholds of pro-homeless movements.

While the existence of yoseba, and its history of internalizing 'safe spaces' (Tilly 2000) for pro-homeless activism, offers the first rationale for my 
geographical selection in this chapter, the second justification comes from the rise of pro-homeless movements outside of the inner-city districts of yoseba. Tokyo Metropolis and Kanagawa Prefecture both came to host pro-homeless movements beyond the urban enclaves of yoseba (for the case of Tokyo, see Hasegawa 2006). In Tokyo Metropolis, several pro-homeless groups - such as Sinjuku Renrakukai (in Shinjuku Ward) and Nojiren (in Shibuya Ward) - started work during the 199os in Tokyo's major central business district, and these groups were followed by a further proliferation of new pro-homeless groups in the run-up to the 2010s. In Kanagawa Prefecture, social movements for the homeless also spread to the spaces outside of the traditional enclaves of yoseba in the 1990s and 2000s. The next two sections take up cases from the Tokyo-Yokohama region for these reasons.

\section{Opening up the Welfare State Locally: Social Movements in Kanagawa in the 1990s and $2000 \mathrm{~s}$}

\section{Pro-homeless Activism in Yokohama}

During the 1990s, homelessness grew in and outside of the inner-city districts called yoseba, which exist in every metropolitan region in Japan. In the small area, yoseba accumulates various functions needed for the life of day labourers - functions of the labour market, accommodation, dining, socialization, etc. - and it became the hotbed of homelessness that visited day labourers in the 1990s and 20oos. At the same time, yoseba became the hotbed of pro-homeless activism. Old and new participants stood up for the plights of homelessness-prone day labourers and promoted local waves of activism. As such, yoseba in metropolitan regions turned into the stronghold of social movements for the homeless (for the case of Tokyo Metropolis, see Hasegawa 2006). This chapter shall take a case of yoseba activism from the Kotobuki district, which is situated in the city of Yokohama.

In many cities, social movements for the homeless in these formative years concentrated on agitating against anti-homeless evictions, for one thing, and on providing food and medical services to the homeless, for another. While these issues gained importance in the Kotobuki district Yokohama's inner-city area of yoseba - the city's uniqueness was that the issues of livelihood rights and Public Assistance were recognized as hugely important by local activists from the beginning. While this focus on the 'social rights' of homeless people would later become widespread in other cities, Yohoama's pro-homeless activism and its offshoots in Kanagawa 
Prefecture were the forerunners of this movement strategy: opening up the welfare state to the homeless locally.

One reason why activists in Kotobuki were so able to pronounce the politics of homelessness in terms of social security can be found in the local history. In the 1970s, activism attempted by the Kotobuki Day Labourers Union repeatedly asked the municipality to maintain the livelihood rights of homelessness-prone labourers, causing the municipality to produce a local framework of provision (Nomoto 1977). When homelessness grew in the 199os, new and old activists stood up for the homeless by relying on this local history of activism back in the 1970s, thereby reactivating the old focus on citizenship issues in the new context.

In promoting the livelihood rights of the homeless, two courses of actions existed for local activists. On the one hand, they could push the municipality to offer a local framework of relief. That was a real possibility in the city of Yokohama because this particular city, as I have just mentioned, had a history of creating and using the local system of relief for homelessness-prone day labourers. Back in the 1970s, Yokohama's inner-city district hosted an indigenous form of day labourer activism, which pressed the local authorities regarding the rights of day labourers through negotiations as well as more physical measures. The municipality itself was led in the 1960s and 1970s by the progressive mayor Ichio Asukata. Despite having Socialist Party credentials, he failed to curtail the harsh methods of the police. However, he did involve the movements in local governing processes. In the light of the historical experience, activists in the 1990s expected a certain degree of continuity in the regulations to take place, making local policy somewhat more responsive to the needs of the homeless. On the other hand, the movements located in this local context could perhaps ask the municipality for something more than to rely on local relief: namely, the maintenance of the livelihood rights of homeless people by extending Public Assistance to them. If one reads the Constitution and the Public Assistance Act of 1950 literally, one can draw the conclusion that Public Assistance can (and should) be offered to the homeless. Practically speaking, however, asking the city to mobilize the Public Assistance programme for the homeless was an unusual idea since even the city of Yokohama had rejected that claim before the 1990s.

Located in this local history, movement participants in the Kotobuki district during the 1990s chose to pursue pro-homeless activism in both of these directions. Regarding the former direction - the reactivation of Yokohama's local relief system - the movement demanded the city implement the efficient use of hotel and food tickets. Around 1991, the municipality 


\section{Figure 11.1 Yokohama's local relief in the $1990 \mathrm{~s}$}

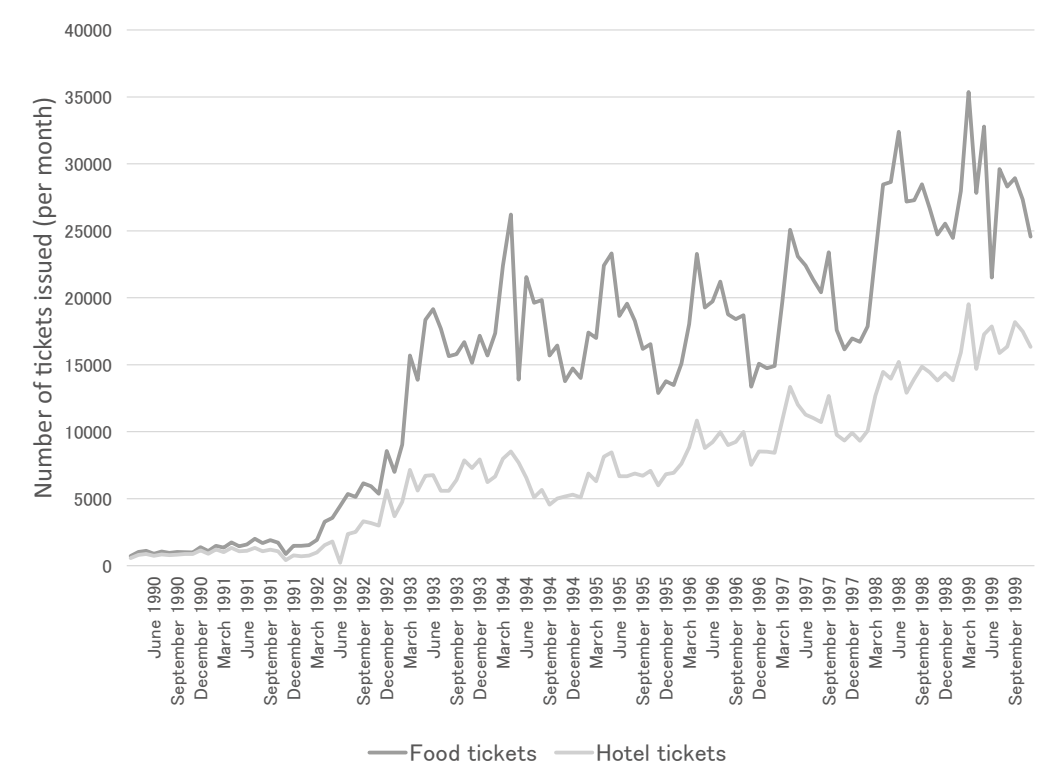

Source: Data in the Archives of Kotobuki Day Labourers' Union

had started mobilizing this local relief system to benefit the homeless. The problem was that the local relief system remained ineffective. The number of affordable hotels that could accommodate the homeless was limited, and the total number of hotel and food tickets issued by the municipality were also insufficient. The movement questioned the municipality about these problems. For that purpose, activists visited the welfare office on weekdays to monitor the municipality's operation of the local relief system. Activists also visited the welfare office to count the number of tickets being issued in order to ensure the city was allocating an adequate number. Further, the movement had discussions with municipal workers and demanded a better provision of hotel and food tickets. Figure 11.1 indicates the result: the numbers of hotel and food tickets issued per month skyrocketed in the 199os.

To tell the truth, the movement's request for local relief faced a dilemma as a pro-homeless strategy: the request for local relief could serve to reduce the access of homeless people to the national programme of Public Assistance and the higher living standards that this programme could achieve. In this context, the request for local relief could constitute an admission that homeless people could be dissociated from Public Assistance. Local relief could be a rationale for the city's not using it. Extending this national 
programme to the homeless demanded more time-consuming and costly work on the part of city officials. In order to solve this dilemma, in 1994, Kotobuki's homeless movement launched a new initiative, one designed to encourage the city of Yokohama to mobilize the national framework of Public Assistance for homelessness as well as to provide local relief. At the beginning, activists repeatedly held study meetings to understand the possibilities of this strategy, and they confirmed that the legal framework of Public Assistance had substantial capacity to help the homeless. In 1994, activists in the Kotobuki district formed a new body entitled the Group for Winning Livelihood Rights (Seizon Ken Wo Kachitoru Kai), a collective that dealt with the specific issue of Public Assistance.

At this point, I shall settle a question readers might have: Why was activism in Yokohama focused on welfare-providing issues and seemingly neglectful of its root causes, such as the labour market and wage relations, from which labourers' homelessness issued? In point of fact, homeless activism in Kanagawa Prefecture repeatedly asked the municipality, and even the national state, to ameliorate unemployment and homelessness by providing public work, so their original claim addressed the 'point of consumption' and the 'point of production' (see Hayashi 2014a). However, the latter part of their claim was rejected by the authorities. In the interests of space, I largely exclude this discussion from this chapter. For the same reason, I have also omitted my discussion of politics for public space and how activists opened up parks and streets for the homeless (see Hayashi 2013, 2018). It is sufficient for this chapter to say that the original construction of pro-homeless movements was multifaceted.

To come back to the Group for Winning Livelihood Rights, activists gathered in this coalition had meetings with municipal workers, in order to improve the issue of Public Assistance for the homeless. In particular, there were three big meetings between representatives of the movement and of the municipality in 1994. In summer 1994, one of these meetings mobilized 150 activists and homeless individuals against the health bureau of the city. On that occasion, the movement vocally demanded the non-discriminatory application of Public Assistance for any homeless individuals who wanted it. The municipality declined this inclusive idea, concerned that it would only deteriorate their work ethic and promote their self-destruction - a rationale that has been used historically when excluding the homeless.

Turning down the full inclusion, however, the municipality made a key change in the local operation of the Public Assistance programme. The city of Yokohama decided to help (what one would see as) the most vulnerable elements of the homeless community - that is, those over 65 years old, 
the sick and the injured - by using the framework of Public Assistance. This meant that the neediest sections of the homeless population were enabled to live, with the help of Public Assistance, in small individual hotel rooms in the Kotobuki district, eat decent food, receive proper medical treatments and buy other services. Such living conditions for the homeless would become possible only through the programme of Public Assistance. A core activist recalls how significant this change was (Interview Kondō 2006):

We let them [the city of Yokohama] say, 'The city accepts the application [of Public Assistance] even if applicants have no addressed.' That was decisive. And it has led to our style [of rescuing the homeless]. [...] So, our movement bore significant fruit.

In short, Kotobuki's pro-homeless activists managed to expand the scope of the welfare state at the local level. On the one hand, they improved the local relief system for the homeless. On the other hand, the same activists made some parts of the local homeless population eligible for the programme of Public Assistance. This two-fold improvement at the local level meant that the historical limitedness of the Japanese welfare state was partially - but significantly - overcome for the homeless in the city of Yokohama. As other cities in the 1990s were still rejecting the right of homeless people to access welfare programmes, it represents a significant success on the part of pro-homeless activism in Yokohama.

\section{Spreading Activism to New Cities}

In this new section, I shall show that a similar type of pro-homeless movement - that is, movements that were supersensitive to the citizenship conditions of homeless people - subsequently spread to new cities in Kanagawa Prefecture. On this subject, the first thing to be mentioned is the increase in movement groups working in new cities outside of Yokohama. In 2001, ten cities in Kanagawa Prefecture (out of 33) came to have pro-homeless groups while the number was two in 1993. This increase suggests a higher capacity of pro-homeless activism in this prefecture generally. All the new groups (except one) had direct connections with activists in Yokohama's Kotobuki district at the time of their emergence, and they were the offspring of Yokohama's pro-homeless activism. Spreading pro-homeless movements to the new cities could not happen automatically. It took place by putting into practice a combination of the following two strategies: 
1 Stretching 'old' resources. Faced with a general scarcity of resources, movements in new cities tried to mobilize resources held in the Kotobuki district. People in Kotobuki flew to new cities with food and blankets in order to support local homeless individuals there. This stretching strategy functioned typically for the nearby areas of Yokohama (such as Yokosuka and Kamakura).

2 Cultivating 'new' resources. Especially when activists succeeded in cooperating with local Christian churches - which are significant contributors to homeless movements in Japan - they enjoyed a development of new local resources. By 2001, activism in Fujisawa, Odawara, Chigasaki, Atsugi and Hiratsuka garnered significant support from local churches. In these cities, activists found new comrades, financial bases and various goods.

Through these activist scheme, essential resources and strategies of activism became available in new cities. On that basis, new groups engaged in the provision of food, blankets, clothes and information for the homeless. Even further, activist groups in new cities tried to reuse the political strategy attempted in the Kotobuki district: asking the municipality to unlock the welfare state locally. For this purpose, they sought to establish new channels of communication with policymakers and rank-and-file officials in the new cities.

Having discussions with the municipality was not a big problem. The real difficulty arose when the movements requested policy changes. As cities outside of Yokohama were smaller in size, their financial basis was more limited. Further, homelessness was often a new phenomenon in these cities and local authorities did not have much experience in helping the homeless. In this context, one focus of movement groups became the national programme of Public Assistance. When the new cities reported that they did not have a great deal of capacity to create a local relief programme for the homeless, the same cities could not find any good excuse to deny the homeless Public Assistance. In the case of Yokohama, the city's willingness and ability to create a local relief system was one reason not to allow all the homeless to rely on Public Assistance. Apparently, new cities could not use this excuse when excluding the homeless from Public Assistance.

With this in mind, activists held repeated discussions with local authorities to extend the citizenship programme of Public Assistance to the homeless. Let us take the instance of the city of Hiratsuka, lying in the southern area of Kanagawa Prefecture. In this city, activists formed a local movement group - the Hiratsuka Patrol - in 2001, initially, by stretching Kotobuki's resources and staff and, later, by constructing its own resource 
Figure 11.2 A meeting between Hiratsuka's activists and the then Mayor Ritsuko Ōkura (seen at the back)

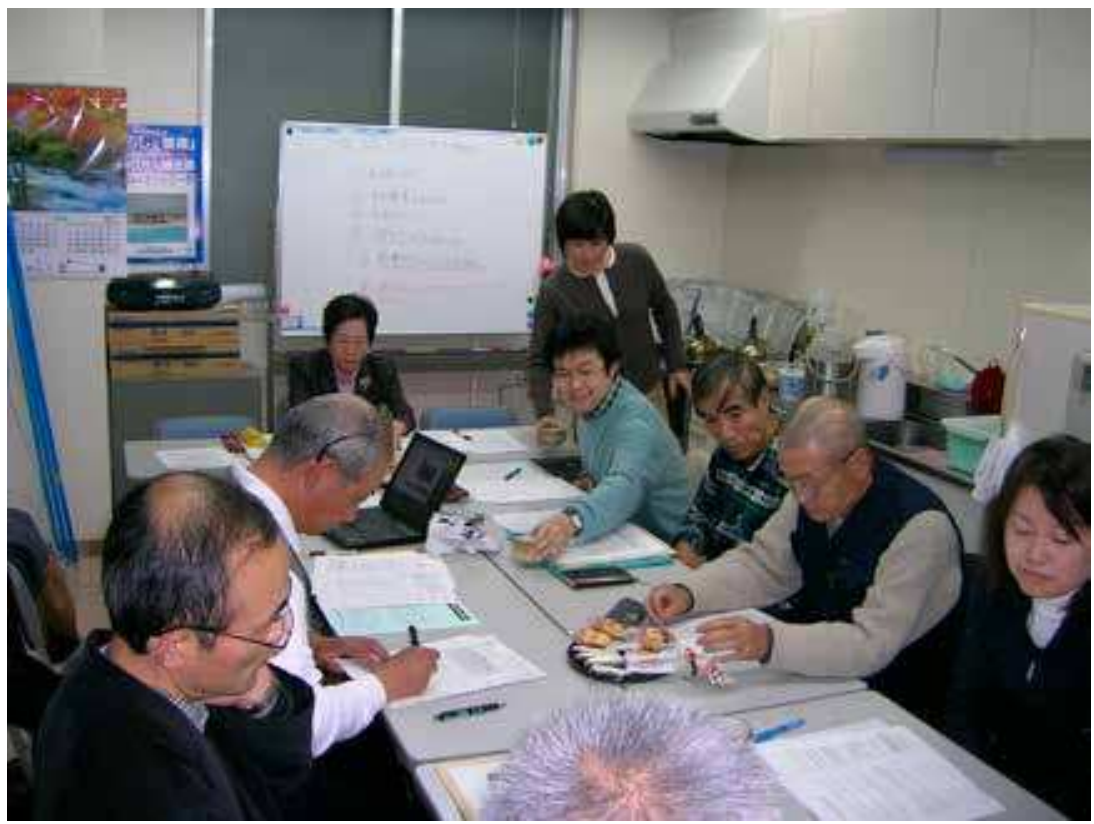

Source: Author's photograph

basis at the local church (the Hiratsuka Baptist church). As soon as they started homeless provision, they sought the possibility of getting the city to activate Public Assistance for the homeless. To this end, they had frequent meetings with local policymakers, in order to convince them that this municipality had a real capacity to help the homeless by means of Public Assistance.

Even though activists succeeded in convincing municipal workers of the validity of their legal interpretation, the problem existed that municipal workers had no practical knowledge about how to support the homeless by finding a room to rent and assisting them to reconstruct their life on that basis. It seemed very difficult for municipal workers to help each rough sleeper to the point where he/she became able to build a stable basis for life off the streets, primarily because supportive houses for the homeless did not exist at that time. Yet, the movement in Hiratsuka partially overcame this problem by finding several municipal workers who cherished the prohomeless spirit of activism. A core movement participant in Hiratsuka recollects the positive change that took place in the municipality (Interview Yura 2006): 
The thing was that a municipal worker in the leading position [at the welfare office] changed. Sasaki-san was replaced by Ōhara-san. And then he started working on the issues of homelessness himself. [...] He went to homeless people when they became interested in applying [for Public Assistance].

As this case of Hiratsuka shows, the mobilization of Public Assistance was actualized in the new cities through the efforts of the movements and movement-municipality relationships. Furthermore, movement groups sought discussions with hospitals, the police and supportive houses run by private agents. All in all, movements wanted to convince these private service providers that they could provide reliable and friendly support to maintain the citizenship rights of homeless people. The general outcome of these progressive attempts was the opening up of the local welfare state to the homeless.

It should be noted that new pro-homeless activism outside of Yokohama internalized structural problems. Smaller cities outside of Yokohama encountered more obstacles regarding welfare and service provision due to budgetary constraints, manpower shortages and inexperience. In the city of Hiratsuka, the provision of Public Assistance to the homeless became limited even after the intervention of the movement, as some extremely homeless-friendly workers at Hiratsuka's welfare office were transferred from the welfare office to different branches in the municipality. In Japan, the welfare office's decisions on the applications for Public Assistance largely depend on the character of its staff and administrators. In this context, this personnel change posed a problem to the movement. Activists thought that this change was to restrain - if not abandon - the provision of Public Assistance to the homeless. Despite having such limits at the local level, homeless movements working in the new cities succeeded in ameliorating the long-lived inadequacy of the Japanese welfare state for the homeless.

\section{Opening up the Welfare State Nationally: The Pro-homeless Movement in Tokyo in the Late 2000 S}

\section{New Contexts of the 2ooos}

We have seen that social movements for the homeless have improved the welfare state locally. However, problems remained because the local promotion of the citizenship rights of homeless people can, without the 
transformation of the Japanese welfare state per se, become uncertain at any time. In the late 2000 s, a new pro-homeless movement appeared in Japan and triggered national-level changes to the Japanese welfare state. This movement facilitated the national bureaucracy's promulgation of progressive administrative codes of Public Assistance for the homeless. This section unpacks how and under what conditions this movement achieved transformation on the national scale.

Let us look at some general facts. During this period, Japan saw increasing numbers of citizens other than the impoverished segment of day labourers face the risk of becoming homeless. This civic awareness notably rose in 2008 when the world financial crisis hit Japan. At this critical time, exportoriented firms suffered the loss of overseas demand, and they announced plans to stop using unskilled dispatched workers. Dispatched workers, called 'temp workers' in English, are referred to as 'haken' (the dispatched) in Japanese. Throughout the 2000s, the high availability of temp workers, itself a creation of prior neoliberal legal changes, greatly helped Japanese capitalism to reduce its wage costs and re-establish its global competitiveness. In the global financial crisis of the late 200os, the increased number of temp workers became superfluous, and firms cruelly rejected them from the shop floor.

Conditions of temp workers were not identical with the homeless. Nonetheless, from the beginning, their character - especially that of unskilled blue-collar workers working in the manufacturing industry - was not very far from homelessness-prone day labourers: they were low-waged and mobile workers suffering severe scarcity in social capital. Furthermore, temp workers are the first type of labourers to experience dismissals in downturns. In the crisis of the late 2000s, these unfavourable conditions worsened, and the homelessness of temp workers became a real threat. I find in this process a sea change regarding the form of homelessness in Japan. In the 1990s, homelessness became a major phenomenon, but it was primarily limited to disadvantaged day labourers. In and after 2007, the dismissal of temp workers and their near-homeless condition started alarming general citizens - homelessness now seemed to be engulfing the core of Japanese society.

\section{The Movement in Tokyo and Its National Impacts}

The empirical subject of this section is a successful case of pro-homeless activism that emerged in this national context of economic and societal crisis, which Japan entered around the late 20oos. Located within this context, 
a new movement used Japan's critical moment as a timely opportunity to nationalize pro-homeless causes and to advocate for the inclusion of homeless people in the welfare state. While the previous section's movement strategy was a local one that addressed citizenship at the level of the municipality in Kanagawa Prefecture, the new movement in this section tried to change (and succeeded in changing) the national understanding of citizenship entitlements. And, really, it became the hallmark of this nationalization movement. This national construction of activism learned much from the past successful/unsuccessful experiences of local movements; therefore, it should not be seen as a leap unrelated to past development. Rather, nationalizing attempts in the late 2000 s became possible through the cumulative impact of local pro-homeless activism. Hence, the key point: local movements were the prehistory of the nationalizing movement.

At the heart of this nationalization was an encampment event in Tokyo that took place during the winter of 2008/2009, an event called the Overwintering Village of Temp Workers (Toshikoshi Haken Mura). The concept was to attract temp workers who had been dismissed from their jobs (and thereby lost the basic means of survival) as a result of the global financial crisis to Tokyo's Hibiya Park. The location of the park is very close to nationally important buildings such as the Diet, the Supreme Court, the Imperial Palace, the headquarters of national ministries, etc. In Hibiya Park, the movement planned to pitch tents, maintain soup kitchens and open windows of consultation for employment and livelihood problems, all of which were intended to accommodate and support the dismissed temp workers for the period between late December and early January. From the outset, the leaders had the clear intention of drawing the public's attention to this event. The geography of Hibiya Park, which is close to the 'centre' of national politics, was consciously selected for that purpose. ${ }^{2}$

The idea of the public encampment first emerged in November 2008 when the mass media reported that approximately 400,000 temp workers were likely to be dismissed by March 2009 due to the impact of the global financial crisis ( $A S$ 2008). Concerning the poverty-prone character of temp workers, Tokyo's activists reached the conclusion that the dismissed temp workers would become homeless and thus needed special support. Because

2 Miura (2012) mentions this major social movement as a movement for non-regular workers and argues it had an impact as such. I further argue that it had a decisive impact on Japan's national discourses and legal frameworks because the leaders framed their claims as those for homelessness-prone and actually homeless workers. In other words, its strength was derived from its strategic identification with the 'outsiders' of the Japanese welfare state (see also Hayashi 2014b). 
the temp workers most affected by the crisis and dismissals were expected to be those mobile blue-collar workers working in factories and plants and living in their dormitories, the danger was imminent that the loss of employment would directly lead to the loss of housing - to homelessness. Union activists and legal specialists quickly arranged a plan to provide accommodation and other services for dismissed temp workers. At this point, they incorporated a key figure into the circle, Makoto Yuasa, in order to materialize the encampment plan.

After graduating from the University of Tokyo, Yuasa participated in a famous pro-homeless group (Nojiren) in Tokyo's Shibuya Ward and is considered to have much experience in pro-homeless events. The inclusion of Yuasa in the movement was initially to receive some special assistance in engineering the encampment event. However, the involvement of Yuasa meant more than this to the movement. By the late 200os, Yuasa was already an intellectual well known in leftist circles for his celebrated book Han hinkon (Anti-poverty, 2008). With ample knowledge of pro-homeless movements in the past, Yuasa soon began reconsidering the whole plan (Nakajima et al. 2018). When the event started, it was clear to everyone that this charismatic figure was leading it. What is more, he was seeing the transformation of the circumscribed Japanese welfare state as a real chance, finding in Hibiya Park the capacity to become a vortex of national-scale transformation (THMJI 2009: 16, 22).

On 29 December 2008, in front of volunteers and homeless individuals gathering in Hibiya Park, Yuasa - now a formal leader of the encampment event - made an opening speech for the tent village, which formally lasted until 5 January 2009. To understand the strong appeal that this event held for the broader audience, I need to reemphasize the conjuncture. First and foremost, the global financial crisis was engulfing the Japanese economy and frightening the Japanese. Dismissed temp workers had already been designated as the victims of this ongoing crisis by the media. The geography of Hibiya Park attracted the attention of citizens and political leaders and made them aware that the issue of temp workers was turning into the issue of homelessness under the ongoing crisis. On top of everything, the award-winning orator graduated from an elite university was now offering the 'legitimate' interpretation of the crisis.

The confluence of these various contexts in the middle of Tokyo helped the tent village event to enjoy a real resonance with a wider audience beyond the narrow circles of the left-wing public. TV shows repeatedly covered the event, running on the air heart-breaking personal experiences of being unemployed, impoverished and homeless. These stories heightened the 
public image of the unemployed workers as a homogeneous group of 'victims' (Jinbo 2009). Responding to this broad media coverage, as many as 1,692 volunteers gathered at Hibiya Park to help the homeless (Utsunomiya and Yuasa 2009). Moreover, well-known members of the national Diet - including Kan Naoto, who would later be appointed as Prime Minister - visited the tent village and expressed their solidarity with the general cause of the event as well as with the 505 homeless labourers gathered in the village (Utsunomiya and Yuasa 2009).

Of particular importance is the activists' relationships with the ministry. Yuasa and others embarked on innovative trials to exploit the channels of communication with the MHLW. The MHLW administers welfare policy and Public Assistance and - while movements in Kanagawa Prefecture tried to change the local authority - Tokyo's movement sought to change the national authority, in order to open up the Japanese welfare state to the homeless. Owing to the high level of support the movement received from the media and the public, and thanks to its cunning use of intellectual and symbolic resources, the venture succeeded.

First, the movement demanded that the MHLW let the homeless use its auditorium as a shelter, and the MHLW accepted this demand on 2 January 2009 (Utsunomiya and Yuasa 2009: 141). Second, also in response to activists, on 4January 2009 the MHLW opened four more temporary shelters to accommodate homeless individuals, whose increasing number was now overflowing Hibiya Park (THMJI 2009; Utsunomiya and Yuasa 2009). Third, in March 2009, the MHLW made a delayed response to the movement by calling for the local welfare office to positively consider the application of homeless people for Public Assistance (MHLW 2009b). Finally, in December 2009, the MHLW handed a stronger version of circulation to local welfare offices for the same purpose, thus further strengthening the access of homeless people to Public Assistance all over Japan (MHLW 2009a).

\section{The Rise and Fall of Citizenship: Neoliberal Backlashes in the 2010s}

\section{Neoliberal Backlashes against Universal Citizenship}

The upshot is that Tokyo's pro-homeless movement cunningly grasped the crisis-riven situation of the late 2000 s and turned this conjuncture into the opportune moment of transformation. It became possible through the mobilization of geographical, symbolic and intellectual resources to 
Figure 11.3 Households of Public Assistance, 1975-2014

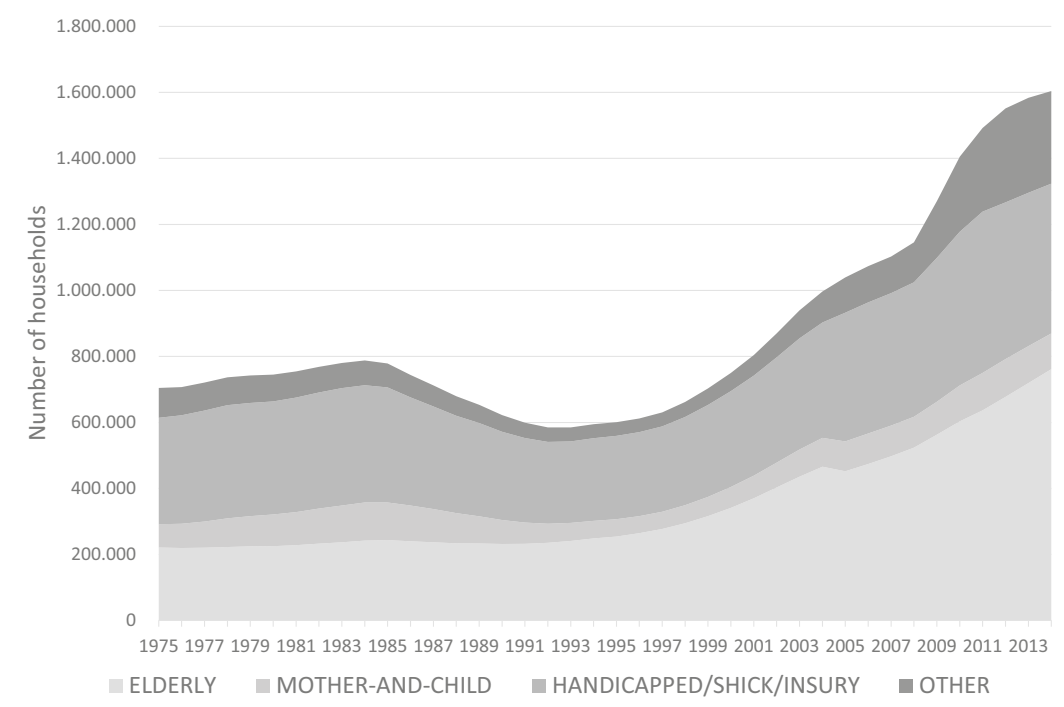

Source: National Institute of Population and Social Security Research (http://www.ipss.go.jp/sinfo/j/seiho/seihoH28/H28-3.xlsx, 3 February 2018)

nationalize a pro-homeless campaign. After the public encampment event in winter 2008/2009, and after the MHLW promulgated the new administrative guidance of Public Assistance in 2009, Japan saw a real increase in Public Assistance recipients among those populations who had previously been rejected. A new pro-homeless movement, which clamoured for the rights of the homeless, led the Japanese welfare state to incorporate its 'outsiders.'

Figure 11.3 suggests how quickly this inclusion happened as it shows the long-term trend of Public Assistance recipients for different household types. Readers can see that the category of 'other households' (sonota setai) quickly increased after 2008. This category refers to those who had previously been excluded from the Japanese welfare state: those without fixed address, the able-bodied and the unmarried male populations. For this very reason, government statistics refer to them as a vague group of the unworthy 'other.' By contrast, the 'elderly, 'mother and child,' and 'disadvantaged/ sick/injured' households were distinctly mentioned. This suggests that the state considered them to be the 'worthy' recipients. The fact that the other category grew after 2008 was the result of the MHLW's new legal interpretations, which pushed each municipality and local administrator to mobilize Public Assistance even for the homeless. As I have shown, that was the real political outcome of Tokyo's pro-homeless movement. 
In contemporary Japan, however, this quick incorporation of the 'unworthy' poor into the national welfare programme has been evoking serious concerns on the part of bureaucrats, politicians, intellectuals and citizens. An MHLW bureaucrat concerns the increasing rolls of 'other households,' saying: 'Among the households of the "elderly," "mother and child," "disadvantaged/ sick/injured," and "other" [...] we find an especially significant growth in "other households"' (CAO 2012). Politicians, intellectuals and the mass media shared this recognition and sometimes express sharp antipathy and animosity towards the poor on the rolls (e.g. Ikeda 2009; Takenaka et al. 2011; Katayama 2012; NHK News Crew 2012). The message was simple enough: there is now an increased population of 'welfare dependency' and we have to deal with it very carefully, in order not to further increase this population. Various conservative/neoliberal figures, who normally 'lived' in different camps, were lined up to persuade the nation of their underlying philosophy: let's re-exclude them once again. Thus, the nationalization of pro-poor politics also nationalized moments and forces that despised the inclusion of the poor.

While these antipathies represent one discursive reaction to the national inclusion of the 'unworthy' poor, more nuanced discursive constructs have also come into being. After the national acceptance of pro-poor causes by means of citizenship in the 2010s, wider debates have emerged about how Japan can address the increasingly omnipresent and omnipotent character of poverty in society. The pre-existing 'gap society' interpretations and arguments, which circulated in the mass media, publications, and internet spaces and constructed the self-images of 'poor us' until the 2000 (for an overview, see Chiavacci and Hommerich 2017), are now in the process of re-articulation, affecting the discourses of national politics in major ways (Chiavacci 2018).

These national concerns about the 'welfare dependency' problem can be ideological. Yet, the strong sensitivity to the 'unworthy' poor has structural roots in political economy. That is, Japan's massive national deficits delimit total welfare spending, and Japan's serious aging/depopulation trends demand the special allocation of budgets, to the exclusion of what one might conceive as the 'unworthy' poor. It is this resource-allocation problem - a structural 'root cause' - that now facilitates the formation of ideological constructs and neoliberal backlashes against the 'outsiders.' In this context, Japan until the late 2010s, had already advanced a series of reforms to reduce the rolls of Public Assistance and relocate its recipients into the labour market. At the core are efforts of bureaucrats and politicians to forge the Japanese version of a 'workfare state' (Peck 2001) and to replace the traditional welfare policy with a more market-driven 'workfare' 
policy. Because these neoliberal reforms have been advanced cunningly, it is becoming hard for pro-homeless and pro-poor activists to wage effective campaigns against them.

- In 2012, the Japanese government announced the final draft of a comprehensive tax and social welfare reform, which determined that Japan's public welfare is overloaded and called for radical reform by establishing the 'second layer of the safety-net' (i.e. more time-limited provisions of support) outside of the first layer of Public Assistance (CAS 2012: 7).

- Beginning in 2013, the Japanese state started radically slashing the benefit level of Public Assistance. Between 2013 and 2015, there was a reduction of approximately $6 \%$ in the benefit level. In 2017, a further reduction was suggested.

- In 2014, the Act for Promoting Social Welfare Reform was enforced, which targets the 'best balance of self-help, mutual help, and public help' (art. 2), and demands a reduction of Public Assistance by constructing a work-first policy (Additional Clause, art. 2).

- In 2015, the Act for the Self-Support of Needy Persons was enforced and created the space of workfare policy by founding the 'consultation assistance programme for the self-support of needy persons' (art. 1).

- In 2015, the Public Assistance Act of 1950 itself was revised to add to the Public Assistance programme a new incentive system for the recipients, designed to encourage their quick job search after being on the rolls.

In short, the neoliberal reform of the welfare state in the 2010 s has already produced the new space of workfare on the national scale. As a result, Public Assistance - Japan's core welfare programme - became tightly integrated with the national realm of workfare, thereby establishing the continuity of welfare-workfare systems and promoting the transfer of the needy to the labour market. The Public Assistance programme was systematically made remote especially for those who were considered as 'unworthy' recipients - such as able-bodied, unmarried and male populations - and the welfare office of the locality was redefined, for these populations, as the frontline of 'workfarist regulation' (Peck 2001). Furthermore, the Japanese state set ambitious targets for each municipality to achieve the curtailing of Public Assistance recipients by relocating them to the new workfare system and the labour market (MHLW 2018).

While these neoliberal reforms, which are still ongoing, were the state's response to the general increase of welfare budgets and national deficits 
in Japan, the previous inclusion of the 'outsiders' in the welfare state was not unrelated. In drawing up these reforms, the central concern of policymakers was that the number of recipients belonging to the 'workable age group' had increased and that it represented a critical situation that departed from traditions of the past when Public Assistance was for the elderly, injured/sick and disadvantaged populations (MHLW 2013: 4). When Japan embarked on the neoliberal reforms, policymakers targeted especially those who were previously considered as the 'outsiders' of the welfare state.

\section{Rediscovering the Pro-homeless Cause}

In the upbeat phase of Public Assistance increase beginning in the late 200os, which was consolidated through Tokyo's tent village movement and resulting politics, pro-homeless activists felt their relationship with local authorities was improving, as municipalities became ever more willing to accept the application of homeless people to the national citizenship programme. At the same time, in this phase, it became clear to everyone that the number of homeless who 'lived' on the streets had significantly decreased due to public welfare provision and also because the authorities strengthened anti-homeless policing at the street level. The rationale was that the remaining homeless individuals on the streets were eager 'outsiders' of Japanese society who intentionally preferred street-based life and that, therefore, these most 'unworthy' poor could be evicted even from the streets.

Given this new context, the unintended consequence of the improved welfare state, the movements' strategy began to diverge. First, the majority of pro-homeless activists redefined their role as the supporters of ex-homeless individuals now housed by welfare measures. Movements that adopted this strategy heightened the degree of collaboration with authorities and sometimes ran dormitories for ex-homeless individuals on Public Assistance. Second, a few activists pursued a different strategy. That is, they stuck to street homelessness in order to problematize the ongoing exclusion of the homeless from the welfare state and society. Activists adopting this strategy could sometimes not be clearly distinguished from the former group. In the case of Kanagawa Prefecture, the same activists, who radically opposed the authorities' anti-homeless policing, closely collaborated with municipal workers when they accommodated ex-homeless individuals in their dormitory houses. Despite this complexity, there were undoubtedly some activists who were still firmly committed to the assistance of homeless individuals remaining (and being 'trapped') on the streets. 
What about activism in the most contemporary phase of neoliberal backlashes? The Japanese landscape of pro-homeless movements in this latest period is 'fixed.' However, what can be said is that the mounting pressure for welfare-state retrenchment for the sake of a workfare policy - pressure exerted by conservative politicians, bureaucrats, intellectuals and citizens - is presenting formidable challenges to activists working for homeless and ex-homeless individuals. For one thing, the much deteriorated rate of Public Assistance in the current period is already inspiring fear among ex-homeless individuals housed in dormitory houses run by movements, thereby causing uneasiness among activists. The manager of one such dormitory for ex-homeless individuals, run by a movement organization in Kanagawa Prefecture, told me that the lowered amount of Public Assistance has directly worsened the level of services they can provide for ex-homeless residents in the dormitory house, changing homeless movement relationships for the worse (Interview Matsumoto 2018).

For another, activists say that the deteriorated conditions of the Japanese welfare state at the current time, as well as the intensification of antihomeless policing in the streets, should revitalize the meaning of prohomeless movements. They dare to make this hypothetical comparison: if today's public space were subject to the same (lower) level of intensity regarding anti-homeless policing as it was ten years ago, not a few homeless individuals would choose to stay in parks and streets rather than to leave them and rely on Public Assistance. The reasons are that the rate of assistance has already declined and that it is set to further deteriorate over the next few years, and that parks and streets were more livable' for the homeless before the 2010s. In this regard, one activist vocally claims (Interview Takazawa 2018):

There are some homeless people who can do better by living in the streets than by leaving them. [...] Unfortunately, citizens do not understand this way of living a life. Citizens harshly think that such homeless people are criminals. They castigate the homeless on that ground. [...] The job of our [pro-homeless] movements is to change [the views of] such society.

This statement, made by a veteran activist in Yokohama, suggests that a potential new avenue for pro-homeless movements is now emerging amidst the neoliberal backlashes. That is, the ongoing reduction in welfare spending and the resultant degradation of livelihood rights, which have powerfully destroyed the legal basis of the welfare state, could be combated by movements that support the homeless and homelessness-prone labourers living' in public space. 


\section{Conclusion}

Due to their sensitivity to citizenship problems, social movements for the homeless have played significant roles in improving Japan's welfare state, especially after the early 199os. It was a time when the nation reached the endpoint of post-war development, whose good growth capacity had masked the malfunctioning of the welfare state. By clamouring for the opening up of public-welfare measures to the 'outsiders' of the welfare state, activists have tried to produce better safety net conditions, nationally and locally, for the homeless and other impoverished populations. To this end, the institutions of consumer rights and public provision in the welfare state, which had long dismissed the homeless, have become the targets of activism. The livelihood rights enshrined in the constitution, and the Public Assistance programme established by the Public Assistance Act of 1950, had been implemented in a highly restricted way regarding homeless people even though they have strong potential to ameliorate homelessness. Pro-homeless activists have found in the gap - a cleavage between citizenship clauses and their real operation - a chance to improve the circumscribed welfare state of Japan.

Before the late 200os, activists tried to persuade local authorities to construct a local mode of welfare provision for the homeless. These trials were based on their critical interpretations of the law, which emphasized the 'worthiness' of homeless individuals. The inner-city area of metropolises populated by day labourers - segregated districts called 'yoseba' - became a hive for such pro-homeless activism. In the case of the city of Yokohama, the municipality responded to the activists by mobilizing Public Assistance - the core programme of the Japanese welfare state - for elderly and sick/injured homeless persons. While this decision was progressive in itself, the city also revitalized its local relief system for the local homeless population. As similar types of movement-regulation dynamics spread to other cities in Kanagawa Prefecture, by the 200os, this area became a major hotbed for local welfare states attentive to the plight of the homeless, creating new conditions of citizenship in the prefecture.

In the late 2000s, an entirely new form of pro-homeless movement came into being in Tokyo, which ambitiously sought to change the Japanese welfare state at the national level. The (potential) number of precarious homeless labourers quickly increased during the winter of 2008/2009 as a result of the global financial crisis. In response, the movement set up a 'village' of tents, soup kitchens and consultation windows in the middle of Tokyo's central business district, just in front of politically important buildings of 
the Japanese state. As this cunning choice of geography was combined with the strategic use of symbolic and intellectual resources, which were largely 'personified' by orator Makoto Yuasa, the movement succeeded in attracting much public attention and persuading the MHLW, the national gatekeeper of Public Assistance, to open up the core programme of citizenship to the homeless at the national level. While this facilitated the inclusion of the homeless into the Japanese welfare state, in the 2010s, Japan ran into yet another new phase of neoliberal backlashes and workfare-state building, leading to the deterioration of citizenship for the poor. In this context, prohomeless activism is gaining new importance in combating neoliberalism and promoting a better welfare state at the national and local levels.

\section{References}

Aoki, Hideo. 1989. Yoseba Rōdōsha no Sei to Shi [Lives and deaths of Yoseba labourers]. Tōkyō: Akashi shoten.

AS. 2008. 'Shinsotsu Naitei Torikeshi 331 Nin: Hiseiki Sanman Nin Shisshoku mo' [Informal job appointments of 331 newly graduated students cancelled: Thirty thousand irregular workers to be unemployed]. Asahi Shinbun, 28 November. http://www.asahi.com/special/o8016/TKY200811280032.html (15 June 2018).

Calder, Kent. 1988. Crisis and Compensation: Public Policy and Political Stability in Japan, 1949-1986. Princeton: Princeton University Press.

CAO. 2012. 'Teigengata Seisaku Shiwake' Teigen o Uketa Kakuhucho no Torikumi Gaiyo [Ministries' outlines of response to the 'policy sorting-out conference']. Cabinet Office. Tōkyō: CAO.

CAS. 2012. Shakaihosho Zei Ittaikaikaku Seian [Final draft of comprehensive tax and social welfare reform], Cabinet Secretariat. https://www.cas.go.jp/jp/seisaku/ syakaihosyou/kentohonbu/pdf/23063okettei.pdf (2 February 2018).

Chiavacci, David. 2018. 'Inequality and the 2017 Election: Decreasing Dominance of Abenomics and Regional Revitalization.' Japan Decide 2017: The Japanese General Election. Robert J. Pekkanen; Steven R. Reed; Ethan Scheiner; Daniel M. Smith (eds). London: Palgrave Macmillan, pp. 219-242.

Chiavacci, David; Carola Hommerich (eds). 2017. Social Inequality in Post-Growth Japan: Transformation during Economic and Demographic Stagnation. New York: Routledge

Eguchi, Ēichi. 1979. Gendai no 'Teishotokusha Sō, Jō’ [The 'low income' strata of the contemporary era, vol. 1]. Tōkyō: Miraisha.

Esping-Andersen, Gøsta. 1989. Three Worlds of Welfare Capitalism. New York: Polity Press. 
Esping-Andersen, Gøsta. 1997. 'Hybrid or Unique? The Japanese Welfare State between Europe and America.' Journal of European Social Policy, 7 (3): 179-189.

Estevez-Abe, Margarita. 2008. Welfare and Capitalism in Postwar Japan. Cambridge: Cambridge University Press.

Hasegawa, Miki. 2006. We Are Not Garbage! Movement in Tokyo, 1994-2002. New York: Routledge.

Hayashi, Mahito. 2013. 'Times and Spaces of Homeless Regulation in Japan, 1950s200os: Historical and Contemporary Analysis.' International Journal of Urban and Regional Research, 37 (4): 1188-1212.

Hayashi, Mahito. 2014a. Hōmuresu to Toshikukan: Shūdatsu to Ika, Shakaiundō, Shihon to Kokka [The homeless and urban space: Deprivation by othering, social movements, and the capital-state nexus]. Tōkyō: Akashi Shoten.

Hayashi, Mahito. 2014b. 'Rescaled “Rebel Cities", Nationalization, and the Bourgeois Utopia: Dialectics between Urban Social Movements and Regulation for Japan's Homeless.' Antipode, 47 (2): 418-441.

Hayashi, Mahito. 2018. 'Public Space Excludes Homeless Workers in Japan: Regulating the "Recyclers" for Hegemonic Habitat.' Social Theory and Dynamics, 2 (1): 3-17.

Ikeda, Nobuo. 2009. Kibo o Suteru Yuki [The courage to abandon hopefulness]. Tōkyō: Daiamondo.

Jinbo, Taro. 2009. 'Media Hihyō 15' [Media Critic 15]. Sekai, 788: 126-133.

Katayama, Satsuki. 2012. Shojiki Mono Ni Yaruki wo Nakusaseru? [Discouraging the honest?]. Tōkyō: Okura.

Kwon, Haku-Ju (ed.). 2005. Transforming the Developmental Welfare State in East Asia. London: Palgrave Macmillan.

MHL. 1962. Kōsei Kakusho [White paper on welfare]. Ministry of Health and Labour. Tōkyō: MHL.

MHLW. 2003. Hōmuresu noJittai ni Kansuru Zenkoku Chōsa Hōkoku Sho [Research report on the actual conditions of homelessness]. Tōkyō: Ministry of Health, Labour and Welfare.

MHLW. 20oga. Shitsugyō Nado niyori Seikatsu ni Konkyū Suru Katagata heno Shien no Ryüijikō ni Tsuite [On the matter of advancing assistants to those who lost employment and housing]. Tōkyō: Ministry of Health, Labour and Welfare.

MHLW. 20ogb. Syoku ya Sumai o Usinatta Kata he no Shien no Tettei ni Tsuite [For the enforcement of assistants to those who lost employment and housing]. Tōkyō: Ministry of Health, Labour and Welfare.

MHLW. 2012. 'Seikatsu Sien Senryaku' Chukan Matome [Interim report for the life support strategy']. Tōkyō: Ministry of Health, Labour and Welfare.

MHLW. 2013. Shakai Hoshō Shingikai Sēkatsu Konkyūsha no Sēkatsu Shien no Arikata ni Kansuru Tokubetsu Bukai Hōkokusho [Report on the livelihood support of 
needy person by the special committee of social security advisory council]. Ministry of Health, Labour and Welfare.

MHLW. 2015. Shakai Hoshō Shingikai Seikatsu Konkyūsha no Seikatsu Shien no Arikata ni Kansuru Tokubetsu Bukai Hōkokusho [Report on the livelihood support of needy person, the Special Committee of Social Security Advisory Council]. Ministry of Health, Labour and Welfare, http://www.mhlw.go.jp/stf/ shingi/2r9852000002tpzu-att/2r9852000002tq1b.pdf (2 February 2018).

MHLW. 2018. Seikatsu Hogo Hyukyūsha ni Taisuru Shūrō Shiensaku ni Tsuite [On the policy of employment support for Public Assistance recipients], Ministry of Health, Labour and Welfare. http://www5.cao.go.jp/keizai-shimon/kaigi/ special/reform/wg1/291018/sankou1-11.pdf (2 February 2018).

Miura, Mari. 2012. Welfare through Work: Conservative Ideas, Partisan Dynamics and Social Protection in Japan. Ithaca: Cornel University Press.

Nakajima, Yumiko, Sekine, Shūichirō and Yamada, Shingo. 2018. Hiseiki Rōdōsha no Undō [Movements of non-regular workers]. Rōdō Jōhō, 968: 26-33.

NHK News Crew. 2012. Seikatsuhogo Sanchouen no Shougeki [The shocking facts in the three-trillion-yen Public Assistance]. Tōkyō: Takarajimasha.

Nomoto, Ssankichi. 1977. Kotobuki Seikatsukan Nōto [Notes on Kotobuki Seikatsukan]. Tōkyō: Tabata Shoten.

Peck, Jamie. 2001. Workfare States. New York: Guilford.

Peng, Itoh. 2005. 'The New Politics of the Welfare State in a Developmental Context: Explaining the 1990s Social Care Expansion in Japan.' Transforming the Developmental Welfare State in East Asia. Huck-Ju Kwon (ed.). London: Palgrave Macmillan, pp. 73-97.

Rossi, Peter. 1989. Down and Out in America. Chicago: University of Chicago Press. Shinkawa, Mitsutoshi. 2005. Nihongata Fukushi Regìmu no Hatten to Hen'yō [The development and change of the Japanese welfare regime]. Tōkyō: Mineruba Shobō.

Takenaka, Heizō; Ikeda, Nobuo; Suzuki, Waturu; Doi, Takerō. 2011. Nihon Keizai Yomei San'nen [The Japanese economy will perish in three years]. Tōkyō: PHP. THMJI. 2009. Haken-Mura:Kuni o Ugokashita Muikakan [Haken Mura: The six days that moved the state]. Toshikoshi Haken Mura Jikko I'inkai. Tōkyō: Mainichi Shinbunsha.

Tilly, Charles. 2000. 'Spaces of Contention.' Mobilization: An International Journal, $5(2): 135^{-159}$.

Utsunomiya, Kenji; Makoto Yuasa (eds). 2009. Haken Mura [Village of precarious workers]. Tōkyō: Iwanam Shoten.

Yamasaki, Katsuaki; Chikashi Okuda; Tadasi Inatsuki; Osamu Fujimura; Nagao Morimatsu. 2006. Hōmuresu Jiritsu Shien: NPO, Shimin, Gyōsēkyōdō ni yoru 
'Hōmu' no Kaihuku [The promotion of the self-help life of homeless people: The restoration of 'home' by NPO, Citizens and their collaboration with the municipality]. Tōkyō: Akashi Shoten.

Yuasa, Makoto. 2008. Han Hinkon [Anti-poverty]. Tōkyō: Iwanami Shoten.

Yuasa, Makoto. 2009. Haken Mura ha Nani o Toikake te Irunoka? [What does Haken Mura question?]. Sekai, 788: 138-156.

\section{Interviews}

Interview Kondō 2006. Noboru Kondō, member of the Kotobuki Day Labourers' Union, 18 June 2006.

Interview Matsumoto 2018. Kazushi Matsumoto, manager of Poruto Shōnan Chigasaki, 20 February 2018.

Interview Takazawa 2018. Yukio Takazawa, member of the Kotobuki Supporters' Club, 21 February 2018.

Interview Yura 2006. Tetsuo Yura, member of the Kotobuki Day Labourers' Union and the Hiratsuka Patrol, 11 February 2006.

\section{About the Author}

Mahito Hayashi is Assossiate Professor at the Kinjo Gakuin University, Japan. His research interests include regulation theory, social problems and social movements. His articles have appeared in major journals including Antipode, International Journal of Urban and Regional Research, and Environment and Planning A. He is now working on a book project, entitled Rescaling Urban Poverty: Homelessness, State Restructuring and City Politics in Japan, under contract with the Royal Geographical Society's book series at Wiley. 


\title{
12 Legal Mobilization and the Transformation of State-Society Relations in South Korea in the Realm of Disability Policy
}

\author{
Celeste L. Arrington
}

\begin{abstract}
Since the 1990s, South Koreans have gained better access to the courts as a channel for pursuing social and policy change. In particular, Koreans with disabilities began using the courts to challenge discrimination, enforce their rights, and influence policymaking. Through qualitative comparative analysis of recent legal mobilization by Koreans with disabilities, this chapter investigates factors that influence when and why people mobilize the law. Drawing on sociolegal and social movement theories, it shows that explanations focused on evolving legal opportunity structures encompassing procedural rules, statutes, and legal interpretations - can only partly explain changing patterns in legal mobilization. Explanations should also consider the 'support structures' for legal mobilization: lawyers, advocacy organizations, and funding.
\end{abstract}

Keywords: legal mobilization, Korea, disabilities, reform, social movements

Societal groups have many options when seeking to influence policy decisions. In between elections, they can contact bureaucrats, lobby elected officials, join or support an interest group, raise public awareness via the media or public events, publish reports, protest, or file lawsuits. Mobilizing the law by turning to the courts has long been considered a form of political participation, albeit a challenging one (e.g. Zemans 1983). The complex rules, procedures, and costs of litigation can be daunting. Judicial processes

Chiavacci, David, Simona Grano, and Julia Obinger (eds), Civil Society and the State in Democratic East Asia: Between Entanglement and Contention in Post High Growth. Amsterdam, Amsterdam University Press 2020 DOI: $10.5117 / 9789463723930 \_C H 12$ 
are arguably more structured than other forms of political participation. Changes in these rules and procedures can render legal mobilization more or less attractive to those seeking to sway state actions. Yet for marginalized groups, legal activism may be the only path forward when they fail to capture the establishment's attention.

Since the 1990s, South Koreans have gained better access to the courts as a forum for advocacy and grievance articulation. Democratization in 1987 entailed a decline in state interference in judicial processes, and the 1988 establishment of the Korean Constitutional Court became a new channel for claims making (Ginsburg 2003). Institutional and cultural hurdles to legal mobilization continued to fall in the democratic era. Legal reforms increased the size of the private bar, created a system of legal aid and improved the efficiency and predictability of judicial processes (Choi and Rokumoto 2007; Ginsburg 2004). Domestic civil society demand for better access to justice and foreign business pressures for neoliberal deregulation after the Asian Financial Crisis of 1997 propelled these changes (Kim 2011b). New legislation also created justiciable rights and shifted the burden of proof for cases related to product liability and pollution. Greater access to justice and pent-up claims, however, fuelled a dramatic rise in per capital litigation rates. Newer institutions, such as the National Human Rights Commission of Korea (NHRCK), opened non-judicial channels for rights claiming in the new millennium. Impact litigation and other forms of legal activism became important tactics for civic groups in Korea, and they diversified with the emergence of public interest lawyering after 2004 (e.g. Hong 2011; Goedde 2013). Legal mobilization has also served to bolster other forms of political activism, including protest and lobbying.

This chapter traces how particularly marginalized individuals - those with disabilities - are increasingly leveraging the law and making rights claims. Historically, Koreans with disabilities were excluded from society and kept at home or sometimes in residential institutions (Kim 2005). As in many societies, the Korean government first assisted the physically disabled, who were often veterans, and only later those with mental or intellectual disabilities. As economic growth accelerated in the 1980 s and social welfare policies were introduced, state assistance for people with disabilities gradually improved. But policies adopted a welfare-based paternalistic understanding of disability, not one that recognized people with disabilities as rights-bearing individuals who should be included in society. Hence, Koreans with disabilities mobilized and drew inspiration from international disability rights activism starting in the 1980 s. Emboldened by broader pro-democracy mobilization at the time, they protested the state's superficial 
reforms ahead of the 1988 Seoul Olympics and Paralympics. Thereafter, they overcame marginalization to seek other reforms and increasingly use the courts to challenge discrimination, enforce their rights, augment other activism tactics, and influence political agendas and policymaking. The chapter asks: What explains the rise of legal activism among Koreans with disabilities? What do these changes reveal about access to justice more generally?

Liberalizing political opportunity structures contributed to the changing relationship between Korea's disability communities and the establishment in the past three decades. Political institutions liberalized with democratization and spurred judicial reforms. Scholars often emphasize the institutional structures which frame state-society relations and change relatively slowly (e.g. Checkel 1999; Lee 2012; Centeno et al. 2017). I argue that institutional explanations are important but can only partly account for the increased use of legal tactics by persons with disabilities. Scholars recently coined the useful term 'legal opportunity structure' to describe the relatively stable but not static features of legal and judicial systems that encourage or discourage people from mobilizing the law (Andersen 2006; Wilson and Rodriguez Cordero 2006; Vanhala 2012, 2018a). In this concept, they include rules governing access to the courts and the costs of litigation, existing laws and judicial precedents, and sometimes the presence of resources and allies for the litigation process. While scholars have long noted how structural factors like rules on standing (i.e. who has the right to bring suit) or cost shifting affect litigation rates, Hilson (2002) and Andersen (2006) drew on social movement studies' notion of opportunity structures to highlight how some factors that affect groups' propensity to litigate are more contingent than structural. The concept of opportunity structures adds an awareness of the perceptual elements of opportunity to the traditional structural accounts. Opportunities need to be recognized and seized. Relatively few studies of legal opportunity structures, however, have analysed how they change (but see Evans Case and Givens 2010; Vanhala 2012, 2018b).

The chapter traces how the legal opportunity structure for disabilityrelated claims in Korea has improved in the past two decades. New domestic statutes and Korea's ratification of the Convention on the Rights of Persons with Disabilities (CRPD) supplied justiciable rights; changes in rules and judicial rulings related to the burden of proof and statute of limitations have lowered impediments to litigation; new institutions like the NHRCK have facilitated non-judicial rights claiming, sometimes combined with litigation; and courts are making accommodations for persons with disabilities. Drawing on sociolegal and social movement theories, however, I suggest that 
a fuller explanation of disability-related claiming must also consider the 'support structures' for legal mobilization: lawyers, advocacy organizations, and funding (Epp 1998). I highlight, therefore, how an infrastructure for legal mobilization has become institutionalized in Korea, enabling claimants to better recognize, utilize, and incrementally pry open legal opportunities.

This research demonstrates the importance of analysing interactions between structure and agency in shaping state-society relations. It provides evidence for the growing awareness that societal actors are hardly passive within structural constraints but can incrementally reshape opportunity structures through strategic litigation and policy innovations (Andersen 2006). Courts in Korea are considered some of the most conservative institutions, so a liberalizing legal opportunity structure indicates that democratic consolidation is reaching the judiciary. By analysing a country with historically low levels of judicial intervention in policymaking and high marginalization of persons with disabilities, this chapter also reveals how legal mobilization is reconfiguring the ways in which disabled persons' organizations engage with the establishment. The shift towards a rightsbased understanding of disabilities, which is associated with legal tactics and rights claiming, spurred Koreans with disabilities to demand and achieve a voice in domestic policymaking and thereby realize the CRPD's principle of participation and the global disability activism slogan 'Nothing about us, without us.' Their access to the courts and resources for gaining access to the courts have also improved.

The chapter begins by introducing the issue of disability rights in Korea to explain the theoretical leverage this case gives us for understanding changing state-society relations in one of East Asia's established democracies. It then examines relevant changes to rules governing access to the courts, adjudication procedures and judicial remedies, focusing on how these changes affect the incentive structures for persons with disabilities. It also investigates how claims in court relate to other claiming, such as through the NHRCK. Examining changes in the legal opportunity structure elucidates how relatively obscure or technical aspects of the law can have significant political consequences, especially for patterns of state-society relations.

\section{Case Selection and Background}

As a relatively new democracy and an East Asian case with low rates of litigation historically, Korea represents an ideal case for investigating changes in legal opportunity structures. Korea has become something of a juggernaut 
in terms of the growing role of law and courts in politics generally since its democratization. The Korean Constitutional Court, which started hearing complaints in 1988, saw its caseload rise by nearly five-fold between 1996 and 2016. ${ }^{1}$ In addition, in the past two decades, the number of new civil lawsuits rose by $150 \%$, and the number of administrative lawsuits rose by $230 \% .^{2}$ These figures include a variety of private and public causes, only a fraction of which are related to disabilities.

Korean citizens' turn towards the courts constitutes an accelerated version of changes in governance that are happening in democracies worldwide. The trend has been called the judicialization or legalization of politics (e.g. Barnes and Burke 2015; Hirschl 2011; Vallinder 1994). Citizens are demanding and achieving greater transparency and accountability from their governments, often through the courts (Cain et al. 2003; Cichowski 2006). Korean courts have played important roles in political conflicts, including those related to presidential impeachment, state liability for authoritarian-era abuses, and public corruption. Most analyses of the judicialization of politics in Korea focus on such high-visibility cases and the Constitutional Court (Kim 2008; Kim and Park 2012). However, as Ramseyer (1985:605-606) noted with regard to Japan, private litigation can serve the public interest when it deters rights abuses or catches state misconduct. Private litigation may also have public benefits in that it enhances enforcement and state agencies' regulatory goals, albeit to a lesser extent in Korea than in the United States (Farhang 2010; Kagan 2001). It can reveal information that informs policy debates and adds impetus for policy change. Disputes related to disabilities are increasingly the subject of such legal mobilization, as citizens frame their demands in terms of rights and seek policy change.

Disability policy is an especially fruitful issue area in which to study legal mobilization's role in state-society relations because it advanced rapidly in the past two decades and illustrates the confluence of international factors and domestic forces like democratization. Though adapted by domestic activists, internationally circulating ideas about disability rights and legal tactics for promoting them gained traction in Korea, only to flourish in the past decade. Beginning with the UN Decade of Disabled Persons (19831992), rights-based self-advocacy gradually replaced the traditional Korean model of single-disability and service-oriented associations and networks of families of disabled persons that cooperated with the government. Youth

1 Data from the Korean Constitutional Court (KCC) website, http://www.ccourt.go.kr (20 February 2018).

2 Calculated from data available in the Sabeop Yeongam (Judicial yearbook), various years. 
with various disabilities leveraged the 1988 Paralympics in Seoul to protest for reforms, including the introduction of employment quotas and welfare benefits for the disabled. As a result, the Law to Promote Employment among Persons with Disabilities and revisions to the Disability Welfare Law came into force in 1990. The state's welfare support for people with disabilities, which was allocated through a much criticized medically based rating system, and disability accommodations incrementally grew in the $1990 \mathrm{os}$ with the introduction of modest social welfare programmes for all (Yang 2017). Social welfare reform policies were consolidated under Korea's first progressive president, Kim Dae-jung, in the wake of the financial crisis of 1997 (Wong 2004), but families and increasingly NGOs were still expected to help care for people with disabilities.

Some disability activists continued to favour direct action even after democratization. For example, many members of the Solidarity for the Right to Move (Idonggwon Yeondae) that formed in the early zooos to protest for accessible public transportation after the much publicized death of a wheelchair user in the Seoul metro in 2001, had been active in the prodemocracy movement and spearheaded the sit-ins and hunger strikes around the 1988 Paralympics. They achieved the first legal guarantee of a right to mobility in article 3 of the 2005 Transportation Convenience Law, even after the Constitutional Court had denied any government obligation to provide low-floor buses. ${ }^{3}$ They also cooperated with the newer self-advocacy groups that had established the Korea Federation of Organizations of the Disabled (Jangchongryeon) in the mid-199os. Around the same time, more traditional disability groups that include caregivers and researchers had formed the Korea Differently Abled Federation (Jangchong) as civil society blossomed in newly democratic Korea and state-NGO partnerships came into vogue. As umbrella organizations, Jangchongryeon and Jangchong did not cooperate but helped realize policy changes like the 1994 Special Education Law and the 1997 Convenience Promotion Law to facilitate greater participation by people with disabilities in society. Further lobbying for these reforms came from the Research Institute for Disability Rights in Korea (Jangae U Gwonik Munje Yeonguso, RIDRIK), which lawyers and researchers had founded in 1987 and which gained direct access to lawmakers after its first director was elected to the National Assembly in the 199os. RIDRIK's 35 or so volunteer lawyers led the few early disability-related lawsuits and established a hotline for legal counselling. In short, disability-related civic groups flourished in 
the 199os, but litigation remained costly and time-consuming. While civil society organizations increasingly used litigation to pursue policy change in other issue areas in the late 199os (see Shin, in this volume), disability-related litigation was limited by the lack of statutory basis for discrimination claims. ${ }^{4}$

\section{Towards a Korean Disability Discrimination Act}

Disability activists overcame internal divisions to realize the historic Act on the Prohibition of Discrimination against Disabled Persons, Remedy against Infringement of their Rights, etc. (hereafter the Korean Disability Discrimination Act, or KDDA) in 2007.5 The movement for the KDDA began in 2001 when two groups separately published proposals for legislation banning disability-based discrimination. One was Open Network (Yeollin Network), which a few lawyers, scholars and activists had founded in 1999 as an online community to study foreign laws and promote disability rights (Interview AA 2016). The other organization was RIDRIK. Its draft drew heavily on data about common forms of disability discrimination, which RIDRIK had been collecting from its counselling activities for over a decade. As in other countries, the 1990 Americans with Disabilities Act (ADA) and foreign disability discrimination acts were influential models. One Korean activist explained: 'We felt frustrated because, despite the many reforms of the 199os, the rights hotline we opened [at RIDRIK] in 2000 revealed that horrible things were still happening to persons with disabilities. So we organized presentations about the ADA and the British and German anti-discrimination laws to catch up with these other countries' (Interview RIDRIK 2017). Encouraged by Open Network and others, Jangchong and Jangchongryeon set aside their differences as more than 75 disability groups united to launch the Disability Discrimination Act Solidarity of Korea (Jangchuryeon, hereafter the Solidarity) in 2003 (Arrington and Moon 2020).

Contemporaneously to the KDDA movement, disability rights were spreading globally during negotiations to create the Convention on the Rights of People with Disabilities (CRPD). Korea signed and ratified the CRPD at the same time as it enacted the KDDA, and Koreans were active in the CRPD negotiations. Korean women with disabilities, for instance, co-authored article 6 of the CRPD while helping to draft the KDDA (Kim 2014). Domestically, Korean activists and their government also embraced

4 The Korean Special Education Law (rev. 1994) and Law to Promote Employment among Persons with Disabilities (rev. 2001) included anti-discrimination clauses but provided no specifics or enforcement mechanisms.

5 Jangaein Chabyeol Geumjimit Gwonri Gujedeunge gwanhan Beomnul (Law no. 8341, 2007). 
the principle of participation that was articulated in article 4 of the CRPD. President Roh Moo-hyun's 'participatory administration' (2003-2008) launched a joint government-civil society task force in mid-2006 to draft a KDDA under the auspices of the Presidential Committee on Social Inclusion (PCSI 2007). The Solidarity selected representatives from all factions of Korea's disabilities community for the task force, which included officials from all relevant ministries and the NHRCK (as an observer). For expediency, the task force also referenced the draft KDDA bill submitted by a politician from the small far-left Democratic Labour Party in September 2005, which was ' $90 \%$ the same as the Solidarity draft' (Interview LE 2017).

To craft legislation with a reasonable budget and a high chance of passing in the National Assembly, officials on the government-civil society task force reportedly focused on moderating the Solidarity's demands for an independent dispute resolution body capable of issuing binding orders (Interview PCSI 2016). Originally, the Roh administration envisioned enacting general anti-discrimination legislation and tasked the NHRCK with designing it. Roh's progressive predecessor President Kim Dae-jung had created the NHRCK in 2001 after battling conservatives and the Ministries of Justice and Health and Welfare, which saw the new national human rights institution as encroaching on their domains (Koo 2011: 79). Creating a workload for the fledgling institution might bolster its legitimacy and improve its chances of surviving the widely anticipated return of conservatives to the Blue House in the presidential election in December 2007. But disability activists demanded disability-specific legislation and fought against what they considered toothless remedies through the NHRCK with a two-month sit-in at the NHRCK in 2006. Indeed, the NHRCK route would contain challenges to the state, since the NHRCK lacked the injunctive powers and manpower courts had. Ultimately, conservative Christian opposition to LGBTQ rights stymied discussions on general anti-discrimination legislation within the NHRCK, and the NHRCK switched to recommending disability-specific anti-discrimination legislation.

In subsequent deliberations in the government-civil society task force and in the National Assembly, officials continued to advocate the NHRCK rather than an independent disputing mechanism that might overlap with the NHRCK functions. The NHRCK route was seen by many lawmakers as faster and easier; complaints could be filed in person at its central office or one of the four branch offices, as well as online, by fax, or by third parties. ${ }^{6}$ Disability activists ultimately acquiesced to this route because 'time was running out with the relatively more receptive Roh administration' (Interview AE 2017). 
In a concession to disability activists, however, the government added clauses to the KDDA permitting courts to hear discrimination cases and order injunctions in cases of non-compliance with the NHRCK's non-binding recommendations (arts 43-46). Furthermore, the KDDA banned four types of discrimination - direct, indirect, refusing reasonable accommodations, and interfering with aides to disabled persons (art. 4). Litigation, as well as complaints to the NHRCK, in the decade since the KDDA was enacted have helped clarify the law's scope.

Thus, the KDDA, the CRPD, and other reforms significantly advanced disability rights in Korean society in the past two decades and helped open legal opportunities. Because the advances occurred not just through the courts, the case of disability policy permits us to explore judicial rightsclaiming mechanisms in their broader sociopolitical context. Activists were initially disappointed that state actors channelled discrimination complaints to the NHRCK, but they have discovered ways of leveraging this institution. During the first eight months after the KDDA went into force in 2008 , for example, the proportion of discrimination complaints received by the NHRCK that were related to disability leapt from $14 \%$ to $61 \%$ (NHRCK 2016a: 137). Disability activists frequently file NHRCK complaints simultaneously to lawsuits because doing so 'can increase publicity' and the 'NHRCK officers are very knowledgeable and helpful' (Interview LKLL 2015). Beginning with the 2004 National Assembly elections, Korean political parties also started nominating candidates with disabilities to proportional representation lists, resulting in the election of some from both conservative and progressive parties. Jang Hyang-sook from President Roh's Uri party was in a wheelchair, and Jung Hwa-won from the conservative Grand National Party was visually impaired.

More open political and legal opportunity structures were not unqualified victories for people with disabilities, however. In its first review of Korea's compliance with the CRPD, for instance, the UN Committee on the Rights of Persons with Disabilities (2014:2) noted how few complaints had elicited NHRCK recommendations and how the NHRCK lacks injunctive powers for remedying complaints. Local government-funded Disability Human Rights Centres are gradually being established to offer advice in discrimination cases and alleviate such backlog. Additionally, the NHRCK established a standing committee on disability discrimination remedies and two disability rights divisions within its investigation bureau, which have conducted on-site inspections of residential facilities. It also recently created a watch team of 178 people - two-thirds of whom have disabilities - to check for disability discrimination (NHRCK 2016b: 38). Meanwhile, disability activists 
have capitalized on growing opportunities and resources for recognizing and creating legal opportunities to use the courts to monitor and enhance implementation of the KDDA and other policy reforms.

\section{Methods}

The findings reported in this chapter are based on interpretive analysis of semi-structured interviews that I conducted in Korean with 20 individuals who directly engaged with the legal opportunity structure - lawyers, judges, plaintiffs, and activists - and of various documents, including judicial rulings, litigation strategy memos, legal scholarship, and movement newsletters or websites. Rather than attempting to comprehensively cover all institutional changes, I highlight changes in features generally emphasized by the legal opportunity structure literature and by my informants. I adopt the law-in-action perspective used in the legal mobilization literature (McCann 2004), acknowledging the contingency of judicial interpretations and rule application and emphasizing the value of analysing how litigants perceive and strategically use such structural factors.

I do not claim that legal opportunity structures are the only factors affecting rights claiming by people with disabilities. There are many factors that affect citizens' decisions about when and how to assert their rights. For instance, perceived 'political disadvantage' may drive groups to the courts, as opposed to conventional democratic channels (Cortner 1968; Javeline and Baird 2007; Zackin 2008). Learning from international models or the socialization that occurs in the context of cooperation in international forums can likewise stimulate claimants to use the courts more (e.g. Checkel 2001; Dobbin, Simmons, and Garrett 2007). The presence of lawyers in a movement or the structure and network linkages of an organization may also push towards judicial remedies (Scheppele and Walker 1991; Vanhala 2018a). I argue, however, that any explanation of patterns of legal mobilization needs to consider the ways in which seemingly technical or obscure rules and procedures interact with lawyers and the infrastructures they utilize for litigation.

\section{The Evolving Legal Opportunity Structure for Disability Rights}

As rights claiming through the courts became more common worldwide, sociolegal scholars developed the concept of legal opportunity structures to explain why some civil society groups adopt legal tactics while others do 
not. This framework offers a useful lens for identifying and analysing key changes in the incentives that Koreans with disabilities face when deciding how to assert their rights. The emerging consensus is that the core parts of the legal opportunity structure are courts' procedural rules related to access, litigation's costs and rewards, and the existing body of laws and rulings (Vanhala 2018a: $384-385$ ). The legal opportunity structure framework built on the concept of political opportunity structures in social movements scholarship. Like that concept, legal opportunity structure developed fuzzy conceptual boundaries to the extent that it also was 'in danger of becoming a sponge that soaks up every aspect of the social movement environment' (Gamson and Meyer 1996: 275). Political and legal opportunity structures are related concepts but distinguishing them helps avoid conceptual bloat and is important because they affect movements' strategies and issue framing in different ways.

Like the concept of political opportunity structures, legal opportunity structure includes structural and contingent components but focuses on institutions and actors specific to the law. Tarrow (1994: 85) defined the structure of political opportunity as 'consistent - but not necessarily formal or permanent - dimensions of the political environment that provide incentives for people to undertake collective action by affecting their expectations for success or failure.' Most political opportunity structure scholarship focuses on how movements' choices are shaped by the accessibility of political institutions, presence of elite allies, and the instability in elite alignments. The concept emphasizes how subtle institutional changes, shifts in state capacity, and changing levels of elite receptivity to claims might become resources external to the group. Some legal opportunity structure scholars include judicial receptivity, the presence of allies for litigation, and even resources for litigation in their conceptualizations of the legal opportunity structure (Andersen 2006; Epp 1998; Evans Case and Givens 2010; Lejeune 2017).

Rather than stretching the concept by including such factors, I define the legal opportunity structure in line with the emerging consensus: the legal stock and rules related to access to the courts, adjudication procedure, and judicial remedies. First, the legal stock encompasses existing statutes and judicial precedents that constrain how people can frame their claims, how persuasive those claims are, and how disputes are adjudicated (Andersen 2006). Although in civil law systems like Korea's, judicial precedents are not binding, courts still do often reference prior rulings. Thus, prior rulings are 'de facto binding' in Korea (Kwon 2007: 137). Second, procedural rules are numerous, but several are significant for rights claimants considering 
litigation: standing rules, fee-shifting rules, the statute of limitations, and the burden of proof. Standing rules determine who can bring cases to court. Prior studies have shown how liberalized rules on standing facilitated NGO litigation in Europe (Alter and Vargas 2000; Cichowski and Stone Sweet 2003), but Korean courts have resisted suits by interest groups except at the Constitutional Court. Statutes of limitations affect when claims can be brought, relative to when the alleged injury or rights violation occurred. The burden of proof and standards of evidence may be shifted through judicial precedent or legislation aimed at increasing access to judicial remedies. And rules on who bears the costs of litigation affect the potential risks and rewards of legal mobilization.

This section discusses noteworthy changes to the legal opportunity structure related to disability rights in Korea. It identifies key changes by comparing features pinpointed in the legal opportunity structure literature with what lawyers and disability activists emphasized. I highlight changes that have lowered barriers to entry, improved the adjudication process for claimants with disabilities, and set important precedents, as well as facilitated claims making through the NHRCK. The section after that explores the development of an infrastructure of lawyers with organizational and financial resources for taking advantage of or even contributing to such legal opportunities.

\section{Noteworthy Changes}

Litigation related to disabilities in Korea began to grow in the 2000 s and especially after the $2007 \mathrm{KDDA}$, following decades of petitions to the government and a few attempts at litigation. In 1967 , for instance, families in Busan collected citizens' signatures on petitions after several schools denied their children admittance due to their disabilities. The petitions catalysed policy reforms, and a historic but isolated lawsuit was won in 1982 by a student with disabilities after he was denied admittance to a prestigious university (Hong 2016:389). But protests and petitioning remained more common than litigation until the 199os. Individual lawsuits were occasionally effective. In 1994, for instance, a man successfully challenged a local government's decision not to hire him due to his disability. ${ }^{7}$ Residents' resistance to a school for people with disabilities being built in their neighbourhood was also deemed illegal in a 1996 ruling. ${ }^{8}$ Then, in 2003 , Lee Hee-won filed the first disability discrimination complaint at the newly established NHRCK 
after he was dismissed from a public service job due to his disability. He simultaneously filed a lawsuit, which he won in February 2004. RIDRIK supported many such early cases, while also lobbying for the legislative reforms discussed above.

Nonetheless, the KDDA's passage notably opened the legal opportunity structure. Article 38 of the KDDA expanded standing to allow organizations that know about discrimination to file NHRCK claims on behalf of people with disabilities (KDLA 2017:328). Litigation and NHRCK complaints thereafter sought to clarify who has standing to bring claims based on the KDDA. For instance, a 2014 petition to the NHRCK, supported by fourteen civic groups, successfully expanded the definition of disabilities to include HIV/AIDS after some sufferers of the disease were rejected by hospitals (KDLA 2017: 24). NHRCK decisions also clarified that the KDDA applies when disabled individuals are denied insurance due to disability or have their life choices limited in residential facilities. ${ }^{9}$

In addition, broader reforms (most notably in 2002) to the Korean Civil Procedure Act (KCPA) and rulings in cases not related to disabilities had ripple effects for disability-related litigation and made the adjudication process more amenable to people with disabilities (Kwon 2007). In 2010, for example, Korea introduced an electronic litigation system, which has made it easier for people with mobility impairments to file lawsuits..$^{10}$ Complaints may now be filed over the internet, rather than just in person. The new law's declared purpose was to 'enhance the swiftness and transparency [of civil procedure] thereby contributing to realizing people's rights.' With its reduced filling fees compared with paper-based filing, it became popular. The new system also expanded the range of material admissible in court to include images, video, and sounds (Baik 2015: 223-224). The increased number of cases, however, raised longstanding concerns about courts being overburdened, and thus perhaps also slowing down disability-related claims. Filing complaints at the NHRCK remains faster and easier, which is partly why lawmakers made it the primary remedy mechanism in the KDDA.

The relatively short duration of the statute of limitations in Korea was long seen as impeding claims making. Tort claims must be filed within three years of when the victim becomes aware of the tortious act and within ten years of when the tortious act was committed (KCPA art. 766). A landmark Supreme Court ruling in 2011, however, waived the statute of limitations

9 NHRCK 2014 jinjeong 001300 decision, 2015 jinjeong o610400 decision.

10 Act on the Use of Electronic Documents in Civil Litigation etc. (Minsa Sosongdeungesoeui Jeonjamunseo Iyongdeunge gwanhan Beonmul) (Law no. 10183, 24 March 2010). 
regarding compensation claims by bereaved families of victims of the police killing of thousands affiliated with the National Guidance League (Bodo Yeonmaeng) in Ulsan in 1950 (Kim 2011a). More than 500 leprosy survivors who suffered forced vasectomies and abortions through the 1980 s cited this interpretation of a limitless claim period in cases of state crimes when they filed six collective lawsuits for compensation in 2011 (Arrington 2014). The Supreme Court ruled in the leprosy plaintiffs' favour in 2017 (YN 2017). Anecdotal evidence indicates that such looser interpretations have not been uniformly applied. However, partially successful litigation by persons with mental disabilities who were enslaved in salt farms decades ago cited the leprosy ruling to 'persuade the judges to waive the statute of limitations' (Interview LF 2017). Additionally, disability lawyers argue that the one-year statute of limitations for filing discrimination claims at the NHRCK should be loosened because people with disabilities may take longer to become aware of discrimination they encounter (KDLA 2017: 330).

For litigation regarding sensitive or stigmatizing issues like disabilities, Korean courts have introduced some innovations to protect the parties' privacy (Arrington 2019). Since anyone with a complaint's number can look up plaintiffs' names and other details online, Korean attorneys often closely guard case numbers and ask reporters to conceal their clients' names. A researcher at RIDRIK noted that legal professionals only gradually realized the risks of 'secondary victimization' for plaintiffs in cases related to disabilities in the early 2000 s and began 'monitoring media interviews and developing procedures for getting plaintiffs' approval before using their stories in advocacy related to the lawsuits, such as press conferences or demonstrations' (Interview RIDRIK 2017). Some of the privacy innovations began in cases involving people with disabilities. For instance, an activist reported: 'The prosecutor in the recent Dogani case [involving sexual abuse of disabled minors] used witnesses' real names only once, as the judges required. After that he called them "witness" in court to minimize their exposure. I think he became aware of privacy concerns and stigma through his wife's work as a lawyer with sexual violence victims [which was the first area to adopt privacy protections]' (Interview AC 2013). Disability rights advocates also observe that some judges are 'more aware of the issue of secondary victimization' from the court process (Interview AA 2017). The Supreme Court began redacting names and addresses from rulings made available online starting in 2013 (Won 2016: 82-83). The introduction of such measures lowers the disincentives to litigation for people with disabilities.

Enhancing procedural justice and courts' openness has long been a reform goal because, in the past, Korean courts' adjudication procedures posed 
numerous hurdles to claimants. The judicial process was like 'dripping water,' with oral hearings happening only every few months (Baik 2015: 229). Judges had to revisit the facts of the case each time, and the sporadic pace clashed with the frequent rotation of judges. Korean judges historically weighted documents more than witnesses and oral arguments (Kwon 2007:132). The courts' reliance on paper documents was seen as impeding citizens' ability to understand and participate in adjudication process, particularly for people with disabilities. The Korean Civil Procedure Act overhaul in 2002 aimed at increasing procedural efficiency, and the Supreme Court began recommending more dynamic argumentation (Kwon 2007: 142).

While not necessarily always accessible for parties with disabilities, increasingly active discussions in oral arguments signalled greater flexibility in courtroom procedures and opened up opportunities for people with disabilities to participate in various ways. In the intercity bus lawsuits, for example, judges agreed to ride the bus to personally observe the challenges people with disabilities face (Interview RIDRIK 2017). One judge explained that many judges are 'wanting to hear more from the plaintiffs and from all parties to the lawsuits in the past ten years to increase public trust in the courts. Whereas I used to call one witness, now I call two or three' (Interview JA 2015). He said he explains things more carefully and clearly now in oral hearings. The move towards electronic records also enabled judges to use PowerPoint in the courtroom and facilitate oral debates. Furthermore, disability rights lawyers have fought to enhance accommodations for people with disabilities in the courtroom, including sign language interpreters, captioning, and simpler presentation of points (Interview LKLL 2015). The Korean Supreme Court published - with significant input from activists and lawyers - a set of Guidelines for Judicial Assistance for Persons with Disabilities in 2013, but its implementation has been uneven according to the UN Committee on the Rights of Persons with Disabilities (2014: 2).

Additionally, provisions to shift the burden of proof away from plaintiffs enhanced the prospects for private rights enforcement in Korea. For instance, Korea's Supreme Court has ruled in several cases to relax the KCPA's high bar for tort liability. Article $75^{\circ}$ requires proof of (1) intention or negligence, (2) an unlawful act, (3) plaintiffs' losses or injuries, and (4) a (proximate) causal relationship between the unlawful act and the injuries. Negligence or intention and causation are usually hardest to prove. Hence, article 47 of the KDDA shifts the burden of proof to the alleged discriminator. And in 2014, judges recognized partial liability for the first time in determining damages awarded due to the rail company's failure to provide reasonable 
accommodations in a lawsuit brought by a person with visual impairment, who was injured after falling onto the tracks. ${ }^{11}$

Yet, the challenge of overcoming courts' propensity to issue narrow rulings remains in Korea. For instance, in the first lawsuit filed in 2011 by five wheelchair users over inaccessible intercity buses, the court ruled in 2013 that the KDDA prohibited limits, exclusions, or rejections of usage based on disability but did not require equipment for equal usage by people with disabilities on all forms of transportation. ${ }^{12}$ In addition, the Constitutional Court ruled in 2014 that the Election Law did not require campaign leaflets to be printed in Braille, as the plaintiff demanded, because persons with visual impairments could get the information from other sources, such as TV or the internet. ${ }^{13}$

More generally, the judicial impact of the KDDA and its enforcement decree took time to be felt. The first ruling to clearly articulate the judicial remedies available under the law was in July 2014 (Hong 2016: 408). It found that Seohae University had discriminated when dismissing the plaintiff, who had become disabled after a traffic accident in $2010 .{ }^{14} \mathrm{~A}$ Seoul court also ruled in 2014 that the amusement park Everland had violated the KDDA with its official policy of barring unaccompanied people with mental disabilities from rides (RIDRIK 2016: 12-17). Due to the remaining challenges of litigation, some disability activists opt more often for protest. For example, the Solidarity's successor organization, Solidarity against Disability Discrimination (SADD, or Jeonchangyeon), has protested to promote independent living and de-institutionalization based on the Korean Constitution's rights to self-determination (art. 10) and personal liberty (art. 12). Nonetheless, disability-related litigation has increased, and courts' accommodations for people with disabilities and their rights are changing prosecutors and police behaviour as well. ${ }^{15}$

\section{Growing Infrastructure for Legal Mobilization}

What is driving these changes? While judges' behaviour and policy reforms are part of the explanation, we must not neglect the demand side. An increasingly 
institutionalized infrastructure for legal mobilization related to disabilities in Korea has spurred some of the changes in legal opportunities and has equipped disability activists to recognize and utilize these changes. Epp's (1998) comparative research demonstrated that groups seeking to use the courts to push for sociopolitical change depend on 'support structures' comprising advocacy organizations, funding, and especially rights-advocacy lawyers. Lawyers supply not just legal expertise. Even if legal victories prove elusive, lawyers can also help recruit plaintiffs, frame causes, devise movement strategy, build alliances with other civil society organizations and pressure state officials (inter alia McCann 2004; Jones 2006; Marshall 2006; Shdaimah 2006). More critical assessments argue that lawyers can deter grassroots mobilizing, narrow the scope of a cause, or redirect a movement (e.g. Burstein 1991; Handler 1978; Levitsky 2006; McCarthy and Zald 1977). While they are not necessary to legal mobilization, lawyers with the capacity to mobilize financial and organizational resources facilitate strategic litigation (Arrington and Moon 2020).

In the wake of Korea's democratization, numerous civil society organizations formed, often with significant input from activist lawyers. Many of these activist lawyers were also members of Minbyeon (Lawyers for a Democratic Society, also Romanized as 'Minbyun'), which was launched in 1988 and today includes more than 900 members (about $7 \%$ of all lawyers). In the 1990s, lawyers and the NGOs they worked with used combinations of lobbying, protest, media campaigns, and strategic litigation to sway public opinion, advance civil and political rights, and unravel leftover authoritarian laws (see Shin, in this volume). The largest NGOs - People's Solidarity for Participatory Democracy (PSPD, or Chamyeoyeondae), Citizens' Council for Economic Justice (Gyeongsilyeon), and Korean Federation for Environmental Movements (Hwanggyeonyeonhap) - all used litigation in their political activism. For instance, PSPD had a Public Interest Law Centre already when it was founded in $1994 .{ }^{16}$ Yet PSPD litigation peaked in 1999 and declined after the progressive administration of President Roh Moo-hyun appointed many lawyers and PSPD activists to positions in government (Hong 2011). By the early 200os, a key PSPD figure had moved on to cultivate what he called gongik byeonhosa (public interest lawyer), which was imported from English to denote a broader and less politicized range of causes than the work of human rights lawyers who had represented political dissidents in the 1980 os (Goedde 2013). Disability rights was one such cause.

Since the early 2000s, more and more legal professionals have been engaged in reform litigation by marginalized groups, including people with disabilities. 
For instance, the Korean Bar Association added a separate chapter about disability rights in its human rights report in 2001 (KBA 2001). Minbyeon also established a minorities subcommittee and began offering small grants as seed money for reform litigation (Interview LB 2015; Interview LK 2015; Interview LL 2015). The progressive Christian Lawyer Fellowship formed a disabilities subcommittee, and one of its members became the lead author of the KDDA in the Solidarity. In addition, the revised Lawyers' Act of 2000 required all lawyers to perform at least 30 hours of pro bono work per year. Consequently, large law firms like Bae, Kim \& Lee (Taepyeongyang) founded public interest working groups, often with a disability law team. These lawyers became core nodes in an increasingly institutionalized 'infrastructure' for disability-related litigation (see also Morton and Knopff 2000: 25).

Since 2004, new organizational forms emerged in Korea to institutionalize these networks: public interest law firms and public interest foundations within large law firms. Lawyers in these firms and their networks have played crucial roles in disability-related cases, brokering reform coalitions, improving legal education and in opening legal opportunities by pushing judges to innovate or adopt looser interpretations of various rules. They have also used the courts in innovative ways to advance various reforms. Gonggam was Korea's first public interest law firm, established in 2004 by one of the founders of Minbyeon and PSPD, the lawyer Park Won-soon, who became Seoul's mayor. ${ }^{17}$ Gonggam was a pioneer, has the broadest focus among Korea's public interest law firms, and does most in terms of legal education and support for NGOs (Goedde 2013: 141-143). Its ten attorneys' original practice areas were disability rights, violence against women, and migrant worker rights, but now include sexual minorities, the poor and workers. Gonggam helped found several other public interest law firms. For instance, Hope and Law (Heuimangbeop, also called Korean Lawyers for Public Interest and Human Rights) was founded in 2011 and has nine attorneys who belong to Minbyeon, work closely with Gonggam, and focus on disability rights and sexual minorities. ${ }^{18}$

Public interest law foundations, meanwhile, were pioneered by the large law firm Taepyeongyang when it established Dongcheon as a non-profit in 2009. ${ }^{19}$ Dongcheon employs three attorneys and several interns and fellows and works closely with Taepyeongyang's Pro Bono Committee. Disability rights is a core practice area and advances its mission to serve the 'socially 
disadvantaged and minorities' and foster 'public interest organizations, activists, and pro bono lawyers while engaging in research on public interest law, pro bono legal counselling, and legal and policy reforms' (Dongcheon 2016). In addition to representing clients, Dongcheon awards grants to public interest organizations and scholarships, hosts symposia on public interest law, and recently established a legal centre for NPOs. In 2016, it gave its Public Interest Law and Human Rights award to the successor organization of the Solidarity. More recently, the law firm Jipyong established Duru as its public interest law foundation in 2014. ${ }^{20}$ Its nine attorneys work on a similar range of issues as Dongcheon, as well as cases related to freedom of expression and labour (Jipyong 2016). Jipyong provides matching grants to NGOs and to the public interest law firms described above. Duru lawyers also drafted the revised article 48 of the KDDA to specify court remedies for cases of disability discrimination.

Public interest law firms and foundations provide important resources for legal mobilization beyond legal representation. Their institutionalization in the past decade means that the resources for legal mobilization are more visible and accessible for potential claimants. They are sources of funding, key nodes in networks of legal professionals, and centres for research. In 2011, lawyers who had helped the Solidarity achieve anti-discrimination legislation also founded the Korea Disability Law Association (KDLA) with prosecutors, judges and scholars to create a network for identifying test cases for litigation, advising on disability cases, researching foreign examples and policy advocacy. These groups serve as mobilizing structures for reform litigation. For example, KDLA members and several large law firms' disability rights teams are cooperating on litigation over the inaccessibility of intercity buses (Interview LI 2017). Such networks have also been writing manuals, which are useful for elucidating legal opportunities. The KDLA published a manual through the Supreme Court Administration for lawyers and judges in 2013 (Interview LGLH 2015). Thus, Korea's infrastructure for more effectively recognizing and using, as well as sometimes even creating, legal opportunities, including disabilities-specific ones, has developed significantly.

\section{Conclusion}

This chapter traced the liberalization of structures of legal opportunity for people with disabilities in Korea. It showed how Koreans with disabilities 
have gained access to an increasingly institutionalized infrastructure for supporting legal mobilization in the past decade. I highlighted the emergence of public interest law firms and foundations, as well as networks of legal professionals with disability law expertise, because they serve as mobilizing structures for legal activism and conduits of knowhow that enable claimants to better recognize, utilize and sometimes pry open legal and political opportunities. While the state succeeded in containing litigation by channelling most discrimination complaints through the NHRCK, activists (including those unrelated to disabilities) have found creative ways of leveraging synergies between the NHRCK and courtrooms. Moreover, litigation is not the only tactic disability activists use today in Korea. Protests continue in conjunction with litigation over accessible intercity buses. Moreover, after a 1,842-day sit-in at a major metro station in Seoul by people with disabilities, President Moon Jae-in - who was elected after his predecessor's impeachment in 2017 and is a left-leaning former human rights lawyer - pledged to further improve disability rights by abolishing the medically-based rating system for disability welfare benefits (Ho 2018). Critics of this proposal fear ballooning deficits (e.g. $\mathrm{KH}$ 2017).

Despite the institutional changes to facilitate legal mobilization and the rise of public interest lawyering, societal resistance to people with disabilities persists. In 2017, for instance, residents in western Seoul protested construction of a special education school, even though a court had ruled in 1996 that the detriment to neighbours of such schools was outweighed by the detriment of denying education to disabled students (Bak 2017, and see note 15 above). As recently as 2016, a plurality of Koreans surveyed (42.2\%) responded that the human rights of people with disabilities were still not respected (SSK Human Rights Forum-Hyundai Research 2016). The NHRCK is also hardly an unqualified ally. Of the 1,638 disability-related discrimination complaints the NHRCK handled in 2016, it rejected 1,194 cases and dismissed 383 (NHRCK 2016b, 65). Just 19 cases received NHRCK recommendations, and another 32 were settled or resolved through conciliation. Moreover, while Korea has experienced a liberalizing structure of legal opportunities for disability rights in the past 20 years, this trend could reverse. Continued political activism by people with disabilities will help forestall backsliding and continue the trend of increasing participation by people with disabilities in crafting and implementing policy.

More broadly, this study contributes to our understanding of what role courts play in state-society relations and policy processes. Scholars have observed the judicialization or legalization of politics in various policy fields and investigated the spread of US-style 'adversarial legalism' (Kagan 2007). 
Due to the outsized global impact of the ADA, which encouraged disabilityrelated litigation in the United States (Burke 2004), it makes sense to ask if the spread of disability rights in Korea similarly signals the 'Americanization' of its legal framework (Kelemen 2008). This chapter suggests not. Korean activists' demands for judicial remedies were diluted in negotiations for the KDDA, wherein state actors pitched the NHRCK route as an easier and more flexible dispute resolution mechanism. The Solidarity's original demands of punitive damages and class action possibilities (both of which Korea largely lacks) were also rejected. In exchange, however, lawmakers permitted cases of non-compliance with NHRCK recommendations to be taken to court. With support from an increasingly institutionalized infrastructure for legal mobilization, litigation - albeit often in conjunction with NHRCK claims - has become a more and more viable mechanism for enforcing disability rights and influencing policy implementation. As one Korean researcher noted, 'creative claims, including harassment, are now being pursued in court' (Interview RIDRIK 2017). On balance, the relatively accessible NHRCK, the possibility that courts can halt ongoing discrimination and remedy past discrimination via the KDDA, and a growing support structure for disability rights claiming has improved the outlook for Koreans with disabilities. This research indicates, however, that a full understanding of changing state-society relations requires analysing both changes in structural constraints and how social groups and professionals, including within the state, may interact to stretch or creatively use such constraints.

\section{References}

Alter, Karen J.; Jeannette Vargas. 2000. 'Explaining Variation in the Use of European Litigation Strategies European Community Law and British Gender Equality Policy.' Comparative Political Studies, 33 (4): 452-482.

Andersen, Ellen Ann. 2006. Out of the Closets and into the Courts: Legal Opportunity Structure and Gay Rights Litigation. Ann Arbor: University of Michigan Press. Arrington, Celeste L. 2019. 'Hiding in Plain Sight: Pseudonymity and Participation in Legal Mobilization.' Comparative Political Studies, $5^{2}$ (2): 310-341.

Arrington, Celeste L. 2014. 'Leprosy, Legal Mobilization, and the Public Sphere in Japan and South Korea.' Law \& Society Review, 48 (3): 563-593.

Arrington, Celeste L. and Yong-il Moon. 2020. 'Cause Lawyering and Movement Tactics: Disability Rights Movements in South Korea and Japan.' Law \& Policy $42(1): 5^{-30}$. 
Baik, Kang-Jin. 2015. 'Civil Disputes in Korea and the New Role of the Court.' The Functional Transformation of Courts: Taiwan and Korea in Comparison. Jiunn-rong Yeh (ed.). Göttingen: Vandenhoeck \& Ruprecht, pp. 215-238.

Bak, Se-hwan. 2017. 'Disabled Students in South Korea Struggle to Find Right School.' Korea Herald, 17 September.

Barnes, Jeb; Thomas F. Burke. 2015. How Policy Shapes Politics: Rights, Courts, Litigation, and the Struggle over Injury Compensation. Oxford: Oxford University Press.

Burke, Thomas F. 2004. Lawyers, Lawsuits, and Legal Rights. Berkeley: University of California Press.

Burstein, Paul. 1991. 'Legal Mobilization as a Social Movement Tactic: The Struggle for Equal Employment Opportunity.' American Journal of Sociology, 96 (5): 1201-1225.

Cain, Bruce E.; Dalton, Russell J.; Scarrow, Susan E. (eds). 2003. Democracy Transformed? Expanding Political Opportunities in Advanced Industrial Democracies. Oxford: Oxford University Press.

Centeno, Miguel A., Atul Kohli, and Deborah J. Yashar. 2017. States in the Developing World. Cambridge: Cambridge University Press.

Checkel, Jeffrey T. 1999. 'Norms, Institutions, and National Identity in Contemporary Europe.' International Studies Quarterly, 43 (1): 83-114.

Checkel, Jeffrey T. 2001. 'Why Comply? Social Learning and European Identity Change.' International Organization, 55 (3): 553-588.

Choi, Dai-Kwon; Rokumoto, Kahei (eds). 2007. Korea and Japan:Judicial System Transformation in the Globalizing World. Seoul: Seoul National University Press.

Cichowski, Rachel A. 20o6. 'Introduction: Courts, Democracy, and Governance.' Comparative Political Studies, 39 (1): 3-21.

Cichowski, Rachel A.; Alex Stone Sweet. 2003. 'Participation, Representative Democracy and the Courts.' Democracy Transformed? Expanding Political Opportunities in Advanced Industrial Democracies. Bruce Cain, Russell J. Dalton, Susan E. Scarrow (eds). Oxford: Oxford University Press, pp. 192-220.

Cortner, Richard C. 1968. 'Strategies and Tactics of Litigants in Constitutional Cases.' Journal of Public Law, 17: 287-307.

Dobbin, Frank; Beth Simmons; Geoffrey Garrett. 2007. 'The Global Diffusion of Public Policies: Social Construction, Coercion, Competition, or Learning?' Annual Review of Sociology, 33: 449-472.

Dongcheon. 2016. 2016 BKL-Dongcheon LSR Report. Seoul: BKL-Dongcheon. http:// bkl.or.kr/bbs/board.php?bo_table=E21\&wr_id=7 (12 December 2019).

Epp, Charles R. 1998. The Rights Revolution: Lawyers, Activists, and Supreme Courts in Comparative Perspective. Chicago: University of Chicago Press. 
Evans Case, Rhonda; Terri E. Givens. 2010. 'Re-Engineering Legal Opportunity Structures in the European Union? The Starting Line Group and the Politics of the Racial Equality Directive.'JCMS:Journal of Common Market Studies, 48 (2): 221-241. Farhang, Sean. 2010. The Litigation State: Public Regulation and Private Lawsuits in the US. Princeton: Princeton University Press.

Gamson, William A.; David S. Meyer. 1996. 'Framing Political Opportunity.' Comparative Perspectives on Social Movements: Political Opportunities, Mobilizing Structures, and Cultural Framings. Doug McAdam; John D. McCarthy; Meyer N. Zald (eds). Cambridge: Cambridge University Press, pp. 275-29o.

Ginsburg, Tom. 2003. Judicial Review in New Democracies: Constitutional Courts in Asian Cases. Cambridge: Cambridge University Press.

Ginsburg, Tom (ed.). 2004. Legal Reform in Korea. New York: Routledge.

Goedde, Patricia. 2013. 'The Making of Public Interest Law in South Korea via the Institutional Discourses of Minbyeon, PSPD, and Gonggam.' Law and Society in Korea. Hyunah Yang (ed.). Cheltenham: Edward Elgar Publishing, pp. 131-149.

Handler, Joel F. 1978. Social Movements and the Legal System: Theory of Law Reform and Social Change. New York: Academic Press.

Hilson, Chris. 2002. 'New Social Movements: The Role of Legal Opportunity.' Journal of European Public Policy, 9 (2).

Hirschl, Ran. 2011. 'The Judicialization of Politics.' The Oxford Handbook of Political Science, Robert E. Goodin (ed.). London: Oxford University Press.

Ho, Kyeong Jang. 2018. 'Let Everyone Shine: South Korea to Abolish Decades-Long Disability Rating System.' Korea Exposé, 16 March. https://www.koreaexpose. com/paralympics-disability-rating-system-south-korea/ (11 December 2019).

Hong, Joon Seok. 2011. 'From the Streets to the Courts: PSPD's Legal Strategy and the Institutionalization of Social Movements.' South Korean Social Movements. Gi-Wook Shin; Paul Y. Chang (eds). London: Routledge, pp. 96-116.

Hong, Seok-pyo. 2016. 'Hanguk Jangaein Gongiksosongeui Yeoksawa Gwaje [The history and problems of Korean disability-related public interest litigation].' Jangaeinbeop Yeongu. Seong-taek Im; Ye-won Kim; Jae Won Kim (eds). Seoul: Kyungin Munhwasa, pp. 385-439.

Javeline, Debra; Vanessa Baird. 2007. 'Who Sues Government? Evidence from the Moscow Theater Hostage Case.' Comparative Political Studies, 40 (7): 858-885. Jipyong. 2016. Jipyong Annual Report: Social Responsibility and Sustainability. Seoul: Jipyong.http://www.jipyong.com/newsletter_alert/171108/JIPYONG_social_responsibility_and_sustainability_2016_en.pdf (11 December 2019).

Jones, Lynn. 2006. 'The Haves Come out Ahead: How Cause Lawyers Frame the Legal System for Movements.' Cause Lawyers and Social Movements. Austin Sarat; Stuart A. Scheingold (eds). Stanford: Stanford University Press, pp. 182-196. 
Kagan, Robert A. 2001. Adversarial Legalism: The American Way of Law. Cambridge, MA: Harvard University Press.

Kagan, Robert A. 2007. 'Globalization and Legal Change: The "Americanization" of European Law?' Regulation \& Governance, 1 (2): 99-120.

KBA. 2001. Ingwon Bogoseo [Human rights report]. Seoul: Korean Bar Association. https://www.koreanbar.or.kr/pages/board/view.asp?teamcode=\&category=\& page $=3 \&$ seq $=5118 \&$ types $=9 \&$ searchtype $=$ contents $\&$ searchstr $=\% E C \% 9 D \% B 8$ \%ЕА\%В6\%8C\%ЕВ\%B3\%B4\%ЕA\%B3\%Ao\%EC\%84\%9C (11 December 2019).

KDLA. 2017. Jangaein Chabyeol Geumjibeop Haeseolseo [Manual on the KDLA]. Korea Disability Law Association. Seoul: Nanam.

Kelemen, R. Daniel. 2008. 'The Americanisation of European Law? Adversarial Legalism à la Européenne.' European Political Science, 7 (1): 32-42.

KH. 2017. 'Super Welfare Budget.' Korea Herald, 31 August. http://www.koreaherald. com/view.php?ud=20170831000440 (11 December 2019).

Kim, Eunjung. 2005. 'History of Disability: Korea.' Encyclopedia of Disability. Sharon L. Snyder; David T. Mitchell; Gary L. Albrecht (eds). Thousand Oaks: Sage, pp. 858-864.

Kim, Jongcheol. 2008. 'Government Reform, Judicialization, and the Development of Public Law in the Republic of Korea.' Administrative Law and Governance in Asia: Comparative Perspectives. Tom Ginsburg; Albert Chen (eds). London: Routledge, pp. 129-154.

Kim, Jongcheol; Jonghyun Park. 2012. 'Causes and Conditions of Sustainable Judicialization of Politics in Korea.' The Judicialization of Politics in Asia. Björn Dressel (ed.). Oxon: Routledge, pp. 37-55.

Kim, Mi Yeon. 2014. 'Women with Disabilities: The Convention through the Prism of Gender.' Human Rights and Disability Advocacy. Maya Sabatello; Marianne Schulze (eds). Philadelphia: University of Pennsylvania Press, pp. 113-13o.

Kim, Rahn. 2011a. 'Compensation Claim Period Limitless for Inhumane State Crimes.' Korea Times, 8 September.

Kim, Seong-hyun. 2011b. 'The Democratization and Internationalization of the Korean Legal Field.' Lawyers and the Rule of Law in an Era of Globalization. Yves Dezalay; Bryant G. Garth (eds). New York: Routledge, pp. 217-238.

Koo, Jeong-Woo. 2011. 'Origins of the National Human Rights Commission of Korea.' South Korean Social Movements. Gi-Wook Shin; Paul Y. Chang (eds). London: Routledge, pp. 77-95.

Kwon, Youngjoon. 2007. 'Litigating in Korea: A General Overview of the Korean Civil Procedure.' Journal of Korean Law, 7: 109-144.

Lee, Cheol-Sung. 2012. 'Associational Networks and Welfare States in Argentina, Brazil, South Korea, and Taiwan.' World Politics, 64 (3): 507-554. 
Lejeune, Aude. 2017. 'Legal Mobilization within the Bureaucracy: Disability Rights and the Implementation of Antidiscrimination Law in Sweden.' Law \& Policy, 39 (3): 237-258.

Levitsky, Sandra R. 2006. 'To Lead with Law: Reassessing the Influence of Legal Advocacy Organizations in Social Movements.' Cause Lawyers and Social Movements. Austin Sarat; Stuart A. Scheingold (eds). Stanford: Stanford Law and Politics, pp. 145-163.

Marshall, Anna-Maria. 2006. 'Social Movement Strategies and the Participatory Potential of Litigation.' Cause Lawyers and Social Movements. Austin Sarat; Stuart A. Scheingold (eds). Stanford: Stanford University Press, pp. 164-181.

McCann, Michael. 2004. 'Law and Social Movements.' The Blackwell Companion to Law and Society. Austin Sarat (ed.). London: Blackwell, pp. 506-522.

McCarthy, John D.; Meyer N. Zald. 1977. 'Resource Mobilization and Social Movements: A Partial Theory.' American Journal of Sociology, 82 (6): 1212-1241.

Morton, F.L.; Rainer Knopff. 2000. The Charter Revolution and the Court Party. Toronto: University of Toronto Press.

NHRCK. 2016a.Jangaein Chabyeol Geumjibeop Eehang Jego Mit Jangaein Ingwon Jeungjineul Wihan Toronhoe [Public hearing for the enhancement of KDDA and the improvement of the rights of people with disabilities]. National Human Rights Commission of Korea. Seoul: Hanhak Munhwa.

NHRCK. 2016b. NHRCK Annual Report 2016. Seoul: National Human Rights Commission of Korea. https://www.humanrights.go.kr/site/program/board/basicboard/ view ?menuid $=002003003001 \&$ pagesize $=10 \&$ boardtypeid $=7017 \&$ boardid $=7602641$ (11 December 2019).

PCSI. 2007.Jangaein Chabyeol Geumjibeop Chujin Kyeonggwa Deung [Advancing etc. the Disability Discrimination Prohibition Act]. Seoul: Presidential Committee on Social Inclusion.

Ramseyer, J. Mark. 1985. 'The Costs of the Consensual Myth: Antitrust Enforcement and Institutional Barriers to Litigation in Japan.' Yale Law Journal, 94 (3): 604-645.

RIDRIK. 2016. Didimdol Geollimdol Pangyeol [Stepping stone rulings]. Seoul: Research Institute for Disability Rights in Korea.

Scheppele, Kim Lane; Jack Walker. 1991. 'The Litigation Strategies of Interest Groups.' Mobilizing Interest Groups in America. Jack Walker (ed.). Ann Arbor: University of Michigan Press, pp. 335-372.

Shdaimah, Corey S. 2006. 'Intersecting Identities: Cause Lawyers as Legal Professionals and Social Movement Actors.' Cause Lawyers and Social Movements: Austin Sarat; Stuart A. Scheingold (eds). Stanford: Stanford Law and Politics, pp. 220-248.

SSK Human Rights Forum-Hyundai Research. 2016. National Human Rights Survey. 
Tarrow, Sidney. 1994. Power in Movement: Social Movements, Collective Action and Politics. Cambridge: Cambridge University Press.

UN Committee on the Rights of Persons with Disabilities. 2014. 'Concluding Observations on the Initial Report of the Republic of Korea.' CRPD/C/KOR/ CO/1. UN Convention on the Rights of Persons with Disabilities.

Vallinder, Torbjörn. 1994. 'The Judicialization of Politics - A World-Wide Phenomenon: Introduction.' International Political Science Review, 15 (2): 91-99.

Vanhala, Lisa. 2012. 'Legal Opportunity Structures and the Paradox of Legal Mobilization by the Environmental Movement in the UK.' Law \& Society Review, $46(3): 523-55^{6}$.

Vanhala, Lisa. 2018a. 'Is Legal Mobilization for the Birds? Legal Opportunity Structures and Environmental Nongovernmental Organizations in the United Kingdom, France, Finland, and Italy.' Comparative Political Studies, 51 (3):380-412. Vanhala, Lisa. 2018b. 'Shaping the Structure of Legal Opportunities: Environmental NGOs Bringing International Environmental Procedural Rights Back Home.' Law \& Policy, 40 (1): 110-127.

Wilson, Bruce M.; Juan Carlos Rodriguez Cordero. 2006. 'Legal Opportunity Structures and Social Movements: The Effects of Institutional Change on Costa Rican Politics.' Comparative Political Studies, 39 (3): 325-351.

Won, Hoshin. 2016. 'Measures to Realize Sustainable and Efficient Justice from the Perspective of Information and Communications Technology Focusing on the Korean Court Special Articles: SNU-JPRI-Berkeley.' Journal of Korean Law, 16: 67-92.

Wong, Joseph. 2004. Healthy Democracies: Welfare Politics in Taiwan and South Korea. Ithaca: Cornell University Press.

Yang, Jae-jin. 2017. The Political Economy of the Small Welfare State in South Korea. New York: Cambridge University Press.

YN. 2017. 'Top Court Orders Gov't to Compensate Lepers for Abuse.' Yonhap News, 15 February.

Zackin, Emily. 2008. 'Popular Constitutionalism's Hard When You're Not Very Popular: Why the ACLU Turned to Courts.' Law \& Society Review, 42 (2): 367-396.

Zemans, Frances Kahn. 1983. 'Legal Mobilization: The Neglected Role of the Law in the Political System.' American Political Science Review, 77 (3): 690-703.

\section{Interviews}

Interview AA 2016. Activist A, 17 August 2016.

Interview AA 2017. Activist A, 14 September 2017.

Interview AC 2013. Activist C, 22 July 2013.

Interview AE 2017. Activist E, 15 September 2017. 
Interview JA 2015. Judge A, 29 May 2015.

Interview LB 2015. Lawyer B, 27 May 2015.

Interview LE 2017. Lawyer E, 12 September 2017.

Interview LF 2017. Lawyer F, 12 September 2017.

Interview LGLH 2015. Lawyer G and Lawyer H, 27 May 2015.

Interview LI 2017. Lawyer I, 11 September 2017.

Interview LK 2015. Lawyer K, 27 May 2015.

Interview LKLL 2015. Lawyer K and Lawyer L, 28 May 2015.

Interview LL 2015. Lawyer L, 27 May 2015.

Interview PCSI 2016. Former official of Presidential Committee on Social Inclusion (PCSI), 3 August 2016.

Interview RIDRIK 2017. Representative of Research Institute for Disability Rights in Korea (RIDRIK), 14 September 2017.

\section{About the Author}

Celeste Arrington is Korea Foundation Assistant Professor of Political Science and International Affairs at George Washington University, United States. She received her PhD from the University of California, Berkeley, and specializes in comparative politics, with a regional focus on the Koreas and Japan. Her research interests include civil society, social movements, democratic governance, law and society, policymaking processes, the media and politics, and qualitative methods. Besides a number of peer-reviewed articles and chapters, she is the author of Accidental Activists: Victim Movements and Government Accountability in Japan and South Korea (Cornell University Press, 2016), which was selected to be part of the Studies of the Weatherhead East Asian Institute publication series at Columbia University. 



\section{Index}

Abe, Shinzō $\quad$ 17, 122, 137, 192

Abenomics 221

Abortion 16, 21, 141, 143, 147, 150, 152, 310

Legal regulation on abortion 147,153

Opposition to abortion $142,146-147$, $155^{-1} 5^{6}, 15^{8}, 160$

Pro abortion 147

Activism 23, 38, 54

Anti-progressive activism $\quad 54,85$

Civic activism 18, 21-22, 24

Environmental activism $14,19,35-39,41$, 49-50, 53, 59-64, 66, 69-70, 72-74, 86, 88, 90, 93-95, 142, 144, 168, 177-178, 251, 313

Pro-homeless activism $\quad 23,269-272$, 274-279, 281-287, 289-292

Progressive activism $10,16-20,25,37,54$, $85-86,93,142,144,153,15^{6}, 15^{8}, 160,249$ $252-253,261,273,282$

Religion-based activism $\quad 141,143,145,151$, 153,160

Ageing $15-16,25,192,270,287$

Proportion of elderly people $\quad 15-16$

Anti-nuclear movements see social

movements

Anti-racism law 20, 117, 119

April Revolution $1960 \quad 242$

Arima, Akito $\quad 96,98,100,102,104,106-107$

Asian Developmental Bank 75,77

Asian financial crisis 1997 12, 248, 26o, 298, 302

Asō, Tarō 17

Australia 222

Authoritarianism 12, 37-38, 62, 145, 240-243, $247,250,253,256-257,262-263,301,313$

Bangkok 67

Beck, Ulrich 260

Beijing $36,62,64,66-67,70,78-79,128$

Beijing Olympics and Paraolympics 2008 62, 128

Blair, Tony $\quad 223$

Bubble economy see economic growth

Buddhism 120, 144, 147, 149, 154

Cabinet Office (CAO) 202, 205, 231

Candlelight protests $\quad 239-240,253-260$

Chan, Shun-kuei $\quad 35,42-44,49,57$

Chen, Chi-chung 35-36

Chen, Man-li $\quad 35-36,42,47-48,57$

Chen, Shui-bian $\quad 17,39,147-148$

China $9,14,20,24,30,34,36,5^{2-53}, 55,58-60$, $62-63,66,70,77-78,123-124,127-129,132-134$, $149,159,168,176$

Chiu, Hsien-chih $\quad 172,174$

Chosen Soren 131
Christianity $20,141,144-146,156-160,244,280$, 304,314

Catholicism 21, 141, 146-148, 156, 16o, 243-244

Protestantism 21, 141, 144-148, 160, 243

Chun, Doo-hwan $\quad 245^{-246}$

Civil society $\quad 9-10,14,16-18,20,22,24-25,33-34$, $36-38,43,47,52,54,59,85-87,92,98,100-102$, 104-108, 141-142, 152, 158, 16o, 171, 176, 187, 190191, 194-195, 219-226, 229, 231-233, 239-248, 250, 252-253, 259-264, 271, 298, 302-304, 306, 313 Civil society organization (CSO) 168, 190, 195, 205, 208-209, 220

Climate change $18,62,67$

Clinton, Bill 223

Cold War 11, 86, 123, 132-133, 137, 241

Confucianism 61

Conservatism 20, 135, 141, 143-145, 259

Contentious politics $142,239-240,242,253$, 259,261

Co-production 108, 219, 224-226, 231-232

Countermovements $10,16,25,37,85,87$, $141-142,144,151^{-1} 5^{2}, 15^{6}$

Cross-Strait Service Trade Agreement 9,36 , $168,172-173,176$

Day labourer $\quad 274-277,283,292$

Democratic Party of Japan (DPJ) 102-105, 107-108, 124-125, 129, 208

Democratic People's Republic of Korea (DPRK) see North Korea

Democratic Progressive Party (DPP) 18, 21, 33-41, 43-49, 51-54, 146-150, 153-156, 167-168, $170,173-183$

Democratization $12,21,142-143,149,167-168$, 239-241, 243-245, 247-250, 254, 259, 261, 298, 301-302, 313

Developmental state $10,18-19,24,34,59-60$, $63,86-87,108,263$

Developmental citizenship 11

Developmentalism 10-12, 18, 34

Disabilities $\quad 23,297-317$

Diversity $10,16,21,25,48,131,167-169,192-193$, $196,231,25^{\circ}$

East Asia $34,59-65,72-73,80-81,123-126,129$, $133-135,137,155,248,300$

Economic growth $11-14,18,20,22,34,59,86$, 191, 298

Bubble economy $\quad 12,189,217,269$

Economic recession $36,89,192$

High growth $10-11,14-15,23,269$

Post high growth $10,12,80,270-271$

Shared growth $11-13,18,34$

Edano, Yukio 102-104 
Education $16,21,72,94-95,101,108,141-143$, $146-147,150-153,155,158,160,226-229,231$, $243,250,256-257,314,316$

Gender equity education see gender

Lifelong learning 22, 219-222, 224, 226-230, 233

Elite $11,22,61,80,87,97-98,107,120-121,137$, 191, 194-195, 199, 208-209, 238, 240, 242-243 $245,260-261,285,307$

Entertainer 203-207, 210

Environment $19,35,37,44,46-47,59-60,63$, $66,71,95,99,249$

Environmental governance 33,36

Environmental issues $18,41,70-72,95$, 177,179

Environmental policy $19,59,61,63-64$, 68,250

Environmental policymaking $\quad 73-74$

Environmental pollution $14,18,39,42-43$, $45-48,51,53-54,59-63,71,76,79,89,298$

Environmental protection movements see social movements

Environmental Impact Assessment Act (EIA Act) $33,35,39,44,46,49-54$

Environmental Protection Administration (EPA) $44,46-47,50-51,53$

Establishment $10-11,14-15,18,20-21,24-25,117$, 120-123, 125, 127, 129-137, 155, 173, 189-191, 193, $195,200,298,300$

Ethnic minorities $119,121,125$

European Union (EU) 203

Fan, Yun $\quad$ 180-181

Feminism 146-147, 149-154, 159, 176

Foreign trainee system see immigration policy

Foucault, Michel 225

France 16

Fukuda, Yasuo 17

Fukushima nuclear disaster $9,14,18-19,63$, $85,87,102,106,108,170,195$

Gender 21, 87, 123, 135, 141-142, 147, 159, 260

Gender equality $85,205,250$

Gender equity education $16,21,141,143$, $146,15^{0-153}, 155,15^{8}, 160$

Gender movements see social movements

Genetic Health Act $\quad 146$

Germany 16, 121-122

Globalization $\quad 9,11$

Government-organized non-governmental organizations (GONGOs) 65, 223

Green Party Taiwan (GPT) 25, 53, 167-170, 175, 177-183

Guest worker programme see immigration policy

Habermas, Jürgen 143

Haiphong 76

Hashimoto, Ryūtarō $\quad 17$
Hata, Tsutomu 17

Hate crimes $\quad 20,117$

Hate speech $119,132,135,137$

Hate Speech Elimination Law 119,132

Hatoyama, Kunio 192

Hatoyama, Yukio 17

High growth see economic growth

Hirschman, Albert $\quad 259$

Homelessness $\quad 269-271,274-276,278,280$, 282-285, 290-292

Hong Kong 145, 177

Hong Kong Umbrella Movement 154

Hosokawa, Morihiro 17

Hsiao, Bi-khim 148

Huang, Kuo-chang $\quad 172,174$

Hub see networks

Human trafficking $\quad 21,144,187,203,205-208,210$

Identity $15,148,155,159,187,243^{-244}, 25^{\circ}$

Gender identity $\quad 150-151,159$

Identity politics 18,20

Japanese identity $189,200,207,210$

National identity $15,20,53,169,176,179,209$

Middle-class identity 34

Religious identity 157

Taiwanese identity 175

Immigrant advocacy groups (IAGs) 21, 187, 190-191, 194-196, 198-205, 207-210

Immigration policy $\quad 21,136,187,189-184,196$, 198-200, 202, 205, 209-210, 271

Foreign trainee system $193,207-208$

Guest worker programme 192-193, 207

Immigration policymaking 191, 202, 209-210

Irregular immigrants $\quad 200-202,209,248$

Inaba, Hidezō 9o-91

Indonesia 74

Institute for Global Environmental Strategies (IGES) 67-69, 75-76

International Labour Organization (ILO) 203 205

International Monetary Fund (IMF) 222

International Organization for Migration (IOM) 205

Irregular immigrants see immigration policy Ishihara, Shintarō 202

Italy 16

Japan 9-17, 19-23, 25, 59-63, 67-70, 73-74, 85-94, 96-100, 103-104, 106-107, 117-125, 127-129, 131-137, 187-210, 219-228, 231-233, 241, 269-275, 280, 282-293, 301

Japanese government 11, 67, 127, 203, 206, 208, 224, 289

Japanese civil society $\quad 22,86,194,219-221$, 233

Japanese social movements $\quad 220,271$

Japanese society $122,127,220,225,232$, 283,290 
Japan Atomic Energy Commission (JAEC) 9o, 100-101, 103, 107

Japan Atomic Energy Relations Association (JAERO) 89-90, 92, 94-95, 98, 107-108

Japan Atom Industrial Forum (JAIF) 88-89, $92,94,97,100$

Japan Communist Party (JCP) 91

Japan Productivity Center (JPC) 89-92, 95, 100, 103-104, 108

Japan Socialist Party (JSP) 91

Johnson, Chalmers $\quad 86,90,191$

Kaifu, Toshiki 17

Kan, Naoto $\quad 17,102,105,286$

Kanagawa $67,274-275,278-280,284,286$, 290-292

Kansai $\quad 67,88,135$

Ke, Chien-ming $\quad 175,181$

Kim, Dae-jung $17,248,252,302,304$

Kim, Young-sam 17, 248, $25^{2}$

Kitakyushu $67,74-76$

Koizumi, Junichirō 17, 124, 222

Kōmeitō 105

Korea see North Korea; South Korea

Koreans in Japan see Zainichi Koreans

Korean War 241-242, 244

Kuomintang (KMT) 9, 18, 21, 34, 36, 38-40, 48, 51-53, 144-147, 149-150, 153-157, 159, 167-169, $173,175,177-180,182-183,242$

Kyoto 70, 119

Kyoto Protocol 62,70

Labour movements see social movements

Lai, William 44, 47-49

Lee, Myung-bak 17, 256, 259

Lee, Teng-hui 17

Legal mobilization $\quad 23,297-298,300-301,306$, $308,312-313,315-317$

Legislative channels for popular participation 33

LGBT (lesbian, gay, bisexual, and transgender) $147-155,157-159,177,179$

Liberal Democratic Party (LDP) 9, 61, 88, 92, 96, 101-102, 105-106, 108, 119-121, 124, 130, 134-137, 190, 192, 199, 206, 208

Lifelong learning see education

Lim, Freddy 174

Lin, Fei-fan 172

Ma, Ying-jeou $\quad 17,19,33-34,36,38-40,142$, 147-148, 16o, 177

Martial law $12,34,37,141$

Migration 122, 127, 129-130, 188

Ministry of Economic Affairs (MOEA) $\quad 47,51$

Ministry of Economy Trade and Industry (METI) 90, 94, 97, 101-103, 106-108, 123, 231, 249, 252, 288, 290, 298-299, 315-316

Ministry of Education (MEXT) 9, 97, 101, $107-108,151,153,239$
Ministry of Foreign Affairs (MOFA) 199

Ministry of Health, Labour and Welfare (MHLW) 199, 270, 286-288, 293

Ministry of Interior (MOI) $\quad 16$

Ministry of Justice (MOJ) $\quad 127,153,188,191-192$, 199-202

Ministry of the Environment (MOE) 95, 105

Miyazawa, Kiichi 17

Modernity 143,161

Modernization 12, 34, 86, 142, 242

Moon, Jae-in 17,316

Mori, Yoshiro 17

Murayama, Tomiichi 17

Nagase, Jinen 192

Nakasone, Yasuhiro 222

Nationalism 117, 119-121

Nativism $\quad 20,117,119-120,127,129,132,135$

Neoliberalism 18, 22, 25, 219, 221-222, 224, 231-233, 256, 269, 271, 293

Neoliberal reform $13,22,24,222-223$, 255-256, 289-290, 298

Neoliberal state $18,22,219,222-228,230$

Networks $\quad 69,72-74,76,78,80,87,92-94,145$, 19o, 195, 199, 209, 226, 239, 245, 259, 261, 301, 314-316

Event-focused networks $69-70$

Horizontal networks $64,69,80$

Hub 19, 64-67, 72, 80, 90

Hub-and-spoke networks $\quad 64-65,80$

Issue-focused networks 71

Submerged networks $\quad 25^{8-259}$

Vertical Network $64,71,80$

New Delhi 67

New Power Party (NPP) 40, 44-45, 48, 53, $149-150,155,167-177,180-183$

New public governance 219, 223, 225, 233

New public management (NPM) 219, 223, 233

NIMBY (Not In My Back Yard) 6o, 71

Nippan Kaigi 120

Nippon Keidanren 190-191, 193-194, 196, 199, 209

Noda, Yoshihiko 17, 104

Nojiren $\quad 275,285$

Non-profit organization (NPO) 19, 22, 95-98, 100-101, 106-108, 130, 195, 219-221, 223-227, 230-232

NPO Law $1998 \quad 22,195,219,224,227,231$

North Korea 123-124, 127-128, 130-131, 206

Nuclear energy/power $19,37,39-40,42$, 44-46, 51, 53-54, 85-86, 88-107, 142, 178-179, 195

Nuclear accidents see Fukushima nuclear disaster

Nuclear free homeland 44

Nuclear Regulation Authority (NRA) 105, 107 
Obuchi, Keizō 17

Oil price shock $1973 \quad 89$

Opportunity structures 299-300

Legal opportunity structures $\quad 23,297$, 299-300, 305-307

Political opportunity structures (POS) 33, $38,194,307$

Park, Geun-hye $\quad$ 9, 17, 25, 256-257

People's Republic China (PRC) see China

Political Opportunity Structures (POS) see opportunity structures

Political parties $\quad 24,122,132-133,156,185,192,199$, 247, 250-252, 254-255, 258, 261, 263-264, 305

Movement parties $\quad 21,167-171,177,180-183$

Small parties $\quad 21,167-170,173,182-183$

Political protest see protest

Populism 25

Post high growth see economic growth

Poverty 13, 269-270, 272, 284, 288

Pro-nuclear movements see social movements

Protest $22,24,36,93,119,122,134,136-137,142-$ $143,147,156,159,176-177,194-195,239-247$, 252, 254-261, 297-298, 302, 312

Protest cycle 195

Protest movements see social movements

Racism 132

Radical right $\quad 25,117,120-123,125,129,131-133,137$

Reagan, Ronald $\quad 222-223$

Religion 245

Folk religion 144

Republic of China (ROC) see Taiwan

Republic of Korea (ROK) see South Korea

Roh, Moo-hyun 17, 248, 252, 255, 304, 313

Roh, Tae-woo $17,245-246,248$

Sakurai, Makoto $\quad 119-120,122,128,131,133$

Same-sex marriage $16,21,141,143,146-15^{\circ}$, $15^{2-155,159-161}$

Seoul $64,255^{-25} 6,258-259,314$

Seoul Olympics and Paraolympics $1988 \quad 299,302$

Seoul Spring $1980 \quad 245$

Shared growth see economic growth

Shinjuku Renrakukai $\quad 275$

Shinto 120

Simmel, Georg $\quad 241$

Singapore 145

Social change 220

Social class $\quad 11,52,135$

General middle-class society $\quad 13,270$

Lower class 248

Middle class $11-13,34,144,244,247-248$, 270

Working class 249

Social cleavages $\quad 21,141,242,264$

Social Democratic Party (SDP) 21, 53, 167-170, $174,180-181,183$
Social equality $34,52,243-244,263,270$

Gender equality see gender

Marriage equality $150,153-154,175,180$

Social exclusion $\quad 25,269$

Social Impact Assessment (SIA) 50

Social inclusion $11,18,20,22,52,225$

Social inequality 13,260

Rising social inequality $\quad 24-25,34$

Social movements $9,19,22-23,25,33,35$,

37-41, 47, 53, 85, 121-122, 129, 132, 141-144,

152, 156, 16o, 167, 169, 171, 180, 191, 194-195,

239-241, 246, 248-249, 251-254, 256-264,

269-271, 275, 282, 292, 297, 307

Anti-nuclear movements $18-19,30,45,54$, $58,63,86-88,90,93,119,179,195$

Environmental protection movements 14 , 168

Gender movements $\quad 143,151,154,157,160$

Labour movements 90, 93, 107, 243, 248-249, 261

Nativist movements $\quad 20,117,119-123,125$, 127-137

Pro-nuclear movements $37,44-45,53$, 87-88, 91-92, 94-95, 98-108, 195

Protest movements $9,241,243,245,260$, $289,298,302$

Social welfare $47,50,220,223-224,249$

South Korea $9-17,19-20,22-23,25,59-63$,

123-124, 127-136, 145, 209, 239-251, 253-264,

297-298

South Korean civil society $\quad 245^{-246}, 25^{\circ}$, 259-26o, 262

South Korean social movements $\quad 22$, 239-241, 249, 256, 260, 262

South Korean society 245

Strong state $10,13,21,33-34,40,59-60,86,187$, 190-191, 194, 226, 242, 259, 262

Sunflower Movement $9-10,38,149,157,159$, $168,172-174,176,180,183,254$

Taipei $33,36,41,44-45,64,148,174,178-180$

Taiwan 9-21, 23, 33-39, 42-48, 50-52, 59-62, 71, 141-161, 167-179, 182-183, 242, 244, 254

Taiwanese Air Pollution Control Act $\quad 45$, 48

Taiwanese civil society $\quad 16,20,5^{2}, 141-142$

Taiwanese government $\quad 150-151$

Taiwanese party system $\quad 21,167-169,171$, 182-183

Takeshita, Noboru $\quad 17$

Thatcher, Margaret $\quad$ 222-223

Tohoku 63

Tokyo 22, 61, 64, 67, 70, 99-100, 117, 119, 122, 133, 136, 198, 202, 204, 206, 219, 227, 230, 274-275, 282-287, 290, 292

Tokyo Electric Power Company (TEPCO) 89, 94-96, 103, 105-106

Tokyo Olympics and Paraolympics $2020 \quad 62$, 230 
Tsai Ing-wen $17,19,33,36,38-39,41-42,48$, $174-175,179,181$

Tsai, Pei-hui Frida $\quad 35,42,57$

Tsui, Su-hsin $\quad 41-42,44-45,48,57,178$

Tsunami $63,102,105$

United Kingdom (UK) 22, 170, 222-223

United Nations (UN) 69, 203

UN Committee on the Rights of Persons with Disabilities 305, 311

UN Decade of Disabled Persons 301

UN Framework Convention on Climate Change 62

UN Security Council 206

United States (US) 11, 14, 16, 22, 35, 51, 73, 78, $88,120,127,134,137,142,144-146,157,203$, 205-208, 210, 222, 254-256, 269, 301, 316-317

Uno, Sōsuke 17

Upward mobility $11,5^{2}$

Urban Planning Act $\quad 51$

Vietnam 76

Violence 20, 117, 121-122, 157, 205, 241-247,

$257-260,310,314$
Weber, Max 241

Neo-Weberian state 233

Welfare state $11,22-23,228,269-276,279-280$, 282-287, 289-293

Welfare-workfare systems $\quad 289$

World Bank 11, 13, 75, 222

World War II 10, 127, 137, 226

World-wide economic crisis 2007/2008 9, 13, $189,192,283-285,292$

Wu, Kuen-Yuh $\quad 35,57$

Xenophobia $\quad 117,131-132$

Xi, Jinping 36,177

Yokohama 274-276, 278-28o, 282, 291-292

Yuasa, Makoto $\quad 285^{-2} 86,293$

Zainichi Koreans $\quad$ 117, 119, 125-131, 133, 135

Zaitokukai (Zainichi Tokken o yurusanai Shimin no Kai) 117-119, 122, 125-133, 136

Zhang, Yu-yin 44-46, 57 
